\title{
Atomic-Scale Design of Iron Fischer-Tropsch Catalysts: \\ A Combined Computational Chemistry, Experimental, and Microkinetic Modeling Approach
}

\author{
Final Technical Report \\ 9/30/2003 - 9/29/2008
}

Award Number: DE-FC26-03NT41966

\author{
Professor Manos Mavrikakis, \\ Professor James A. Dumesic, \\ Rahul P. Nabar \\ Department of Chemical and Biological Engineering \\ University of Wisconsin - Madison \\ Madison, WI 53706 \\ Professor Calvin H. Bartholomew, \\ Dr. Hu Zou, \\ Uchenna Paul \\ Department of Chemical Engineering \\ Brigham Young University \\ Provo, UT 84602
}




\section{Disclaimer}

This report was prepared as an account of work sponsored by an agency of the United States Government. Neither the United States Government nor any agency thereof, nor any of their employees, makes any warranty, express or implied, or assumes any legal liability or responsibility for the accuracy, completeness, or usefulness of any information, apparatus, product, or process disclosed, or represents that its use would not infringe privately owned rights. Reference herein to any specific commercial product, process, or service by trade name, trademark, manufacturer, or otherwise does not necessarily constitute or imply its endorsement, recommendation, or favoring by the United States Government or any agency thereof. The views

and opinions of authors expressed herein do not necessarily state or reflect those of the United States Government or any agency thereof. 


\begin{abstract}
This work focuses on (1) searching/summarizing published Fischer-Tropsch synthesis (FTS) mechanistic and kinetic studies of FTS reactions on iron catalysts; (2) preparation and characterization of unsupported iron catalysts with/without potassium/platinum promoters; (3) measurement of $\mathrm{H}_{2}$ and $\mathrm{CO}$ adsorption/dissociation kinetics on iron catalysts using transient methods; (3) analysis of the transient rate data to calculate kinetic parameters of early elementary steps in FTS; (4) construction of a microkinetic model of FTS on iron, and (5) validation of the model from collection of steady-state rate data for FTS on iron catalysts.

Three unsupported iron catalysts and three alumina-supported iron catalysts were prepared by non-aqueous-evaporative deposition (NED) or aqueous impregnation (AI) and characterized by chemisorption, BET, temperature-programmed reduction (TPR), extent-of-reduction, XRD, and TEM methods. These catalysts, covering a wide range of dispersions and metal loadings, are well-reduced and relatively thermally stable up to $500-600^{\circ} \mathrm{C}$ in $\mathrm{H}_{2}$ and thus ideal for kinetic and mechanistic studies. Kinetic parameters for $\mathrm{CO}$ adsorption, $\mathrm{CO}$ dissociation, and surface carbon hydrogenation on these catalysts were determined from temperature-programmed desorption (TPD) of $\mathrm{CO}$ and temperature programmed surface hydrogenation (TPSR), temperatureprogrammed hydrogenation (TPH), and isothermal, transient hydrogenation (ITH). A microkinetic model was constructed for the early steps in FTS on polycrystalline iron from the kinetic parameters of elementary steps determined experimentally in this work and from literature values. Steady-state rate data were collected in a Berty reactor and used for validation of the microkinetic model. These rate data were fitted to "smart" Langmuir-Hinshelwood rate expressions derived from a sequence of elementary steps and using a combination of fitted steady-state parameters and parameters specified from the transient measurements. The results provide a platform for further development of microkinetic models of FTS on Fe and a basis for more precise modeling of FTS activity of Fe catalysts.

Calculations using periodic, self-consistent Density Functional Theory (DFT) methods were performed on various realistic models of industrial, Fe-based FTS catalysts. Close-packed, most stable $\mathrm{Fe}(110)$ facet was analyzed and subsequently carbide formation was found to be facile leading to the choice of the $\mathrm{Fe}_{\mathrm{C}}(110)$ model representing a Fe facet with a sub-surface $\mathrm{C}$ atom. The Pt adatom $\left(\mathrm{Fe}^{\mathrm{Pt}}(110)\right)$ was found to be the most stable model for our studies into Pt promotion and finally the role of steps was elucidated by recourse to the defected $\mathrm{Fe}(211)$ facet. Binding Energies(BEs), preferred adsorption sites and geometries for all FTS relevant stable species and intermediates were evaluated on each model catalyst facet. A mechanistic model (comprising of 32 elementary steps involving 19 species) was constructed and each elementary step therein was fully characterized with respect to its thermochemistry and kinetics. Kinetic calculations involved evaluation of the Minimum Energy Pathways (MEPs) and activation energies (barriers) for each step. Vibrational frequencies were evaluated for the preferred adsorption configuration of each species with the aim of evaluating entropy-changes, pre exponential factors and serving as a useful connection with experimental surface science techniques. Comparative analysis among these four facets revealed important trends in their relative behavior and roles in FTS catalysis. Overall the First Principles Calculations afforded us a new insight into FTS catalysis on Fe and modified-Fe catalysts.
\end{abstract}




\section{Table of Contents}

Abstract ..........................................................................................................................................

Table of Contents............................................................................................................... iv

List of Tables....................................................................................................................................

List of Figures ...................................................................................................................................... vii

I. Background and Objectives ................................................................................................... 1

A. Background..................................................................................................................................... 1

B. Work Statement.................................................................................................................. 2

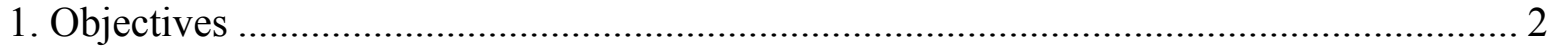

2. Scope

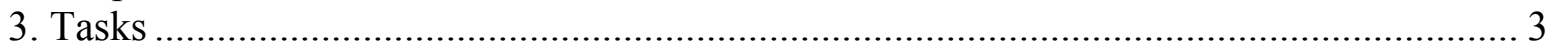

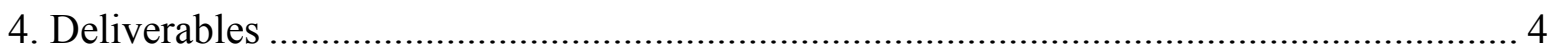

II. Executive Summary ............................................................................................................................ 5

III. Experimental Procedures.................................................................................................................. 7

A. Preparation of Alumina Binder and Supported Fe Catalysts................................................. 7

1. Preparation of $1 \mathrm{wt} \% \mathrm{Al}_{2} \mathrm{O}_{3} / 99 \mathrm{wt} \% \mathrm{Fe}$ Catalyst .................................................... 7

2. Preparation of $\mathrm{Al}_{2} \mathrm{O}_{3}$-Promoted Iron Catalysts with $1 \mathrm{wt} \% \mathrm{~K}$, or $1 \mathrm{wt} \%$ Pt Promoters ..... 7

3. Preparation of stabilized $\gamma$-Al2O3 ............................................................................ 8

4. Preparation of $10 \mathrm{wt} \% \mathrm{Fe} / \mathrm{Al}_{2} \mathrm{O}_{3}$ Catalysts ..................................................................... 8

5. Preparation of $20 \mathrm{wt} \% \mathrm{Fe} / \mathrm{LaOAl}_{2} \mathrm{O}_{3}$ Catalysts (two-step non-aqueous evaporative

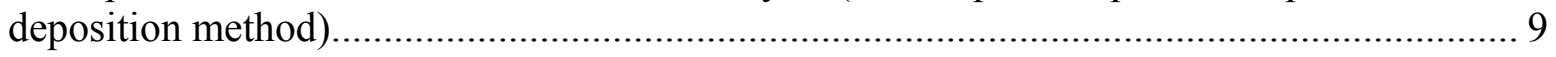

B. Characterization of Fe Catalysts ............................................................................................... 10

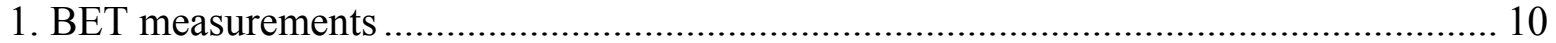

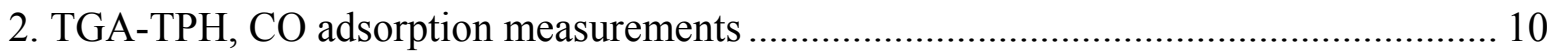

3. $\mathrm{H}_{2}$ Chemisorption Measurements ……………....................................................... 10

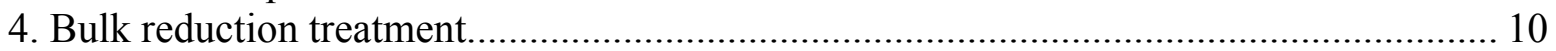

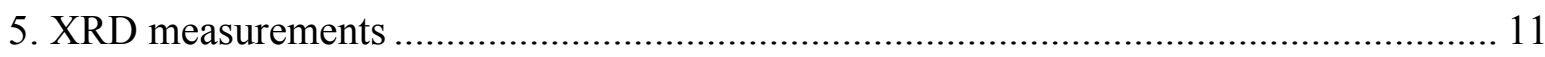

6. TPH measurements on supported iron catalysts by TGA ................................................ 11

7. CO adsorption and TPD measurements on unsupported iron catalysts by Mass-

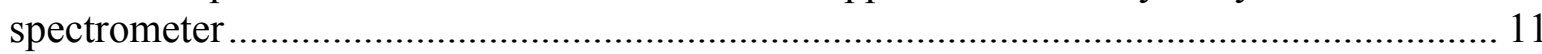

8. ITH and TPH measurements by Mass-spectrometry ....................................................... 11

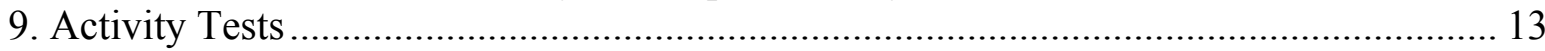

IV. Results and Discussion................................................................................................................ 15

A. Chemical and Physical Properties of Unsupported and Supported Fe Catalysts Prepared by Aqueous and Non-aqueous Methods ................................................................... 15

B. TGA-TPR Measurements....................................................................................................... 16

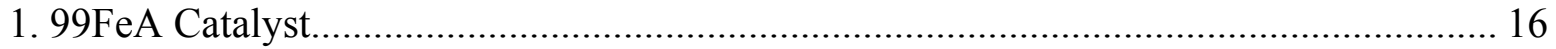

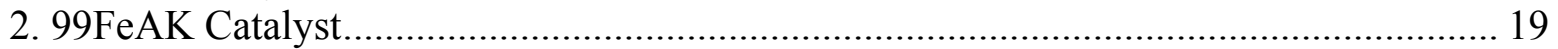

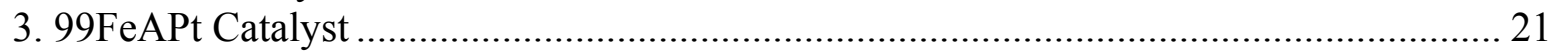

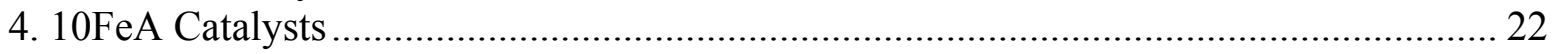

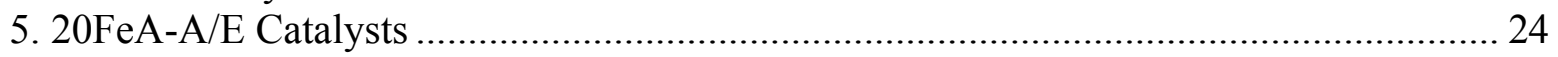

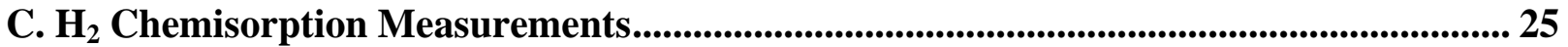

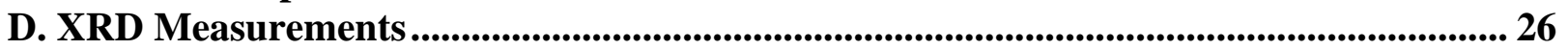

E. TEM Measurements and EDX ............................................................................................ 29

F. CO-Temperature-Programmed Desorption (TPD), Hydrogenation (TPH) and Modeling ................................................................................................................................................. 32 


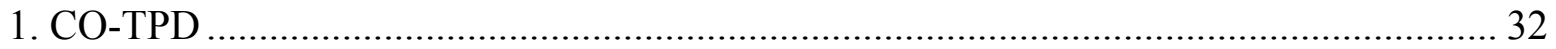

2. CO-TPD microkinetic model................................................................................... 40

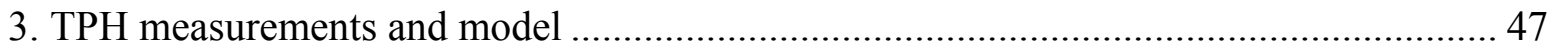

G. Activity tests ................................................................................................................................ 63

H. Sequential Design for Determining Kinetic Constants for FT Reaction Rate Model.... 65

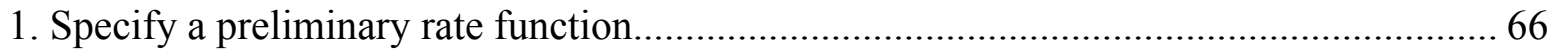

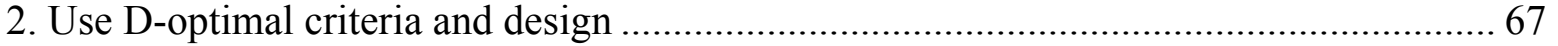

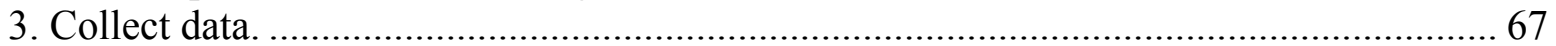

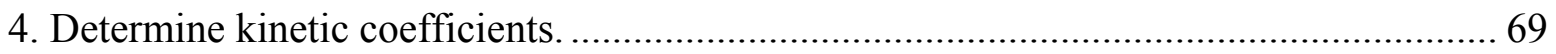

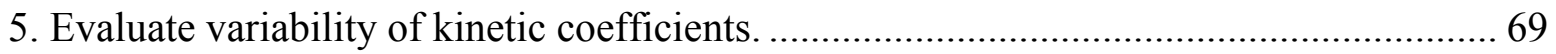

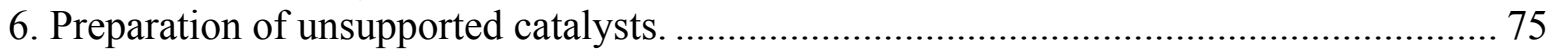

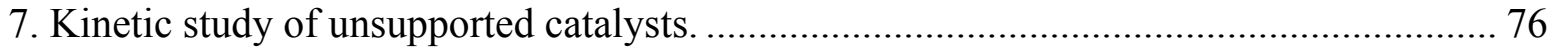

V. Results and Discussion based on First Principles Calculations.................................................. 85

A. Overview and model description. ............................................................................................... 85

B. Thermodynamic Studies ................................................................................................................ 89

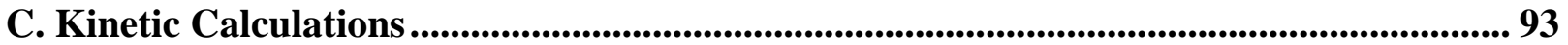

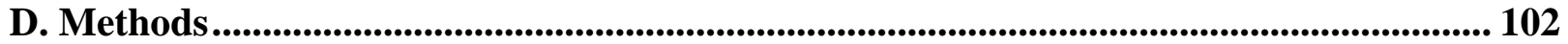

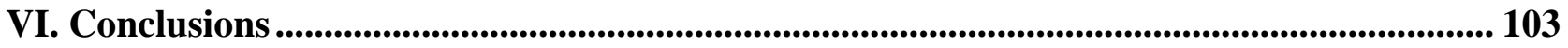

VII. References ................................................................................................................................................ 107 


\section{List of Tables}

Table 1 Catalyst codes, compositions, and physical properties ........................................................15

Table $2 \mathrm{H}_{2}$ Chemisorption Uptakes, EOR, and Dispersion of 10 and $20 \% \mathrm{Fe} / \mathrm{Al}_{2} \mathrm{O}_{3}$ Catalysts.............26

Table 3 Comparison of iron crystallite diameters determined by XRD, TEM, and $\mathrm{H}_{2}$

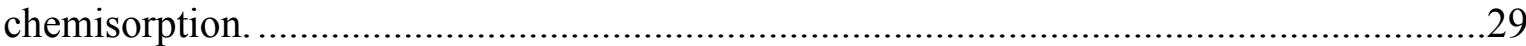

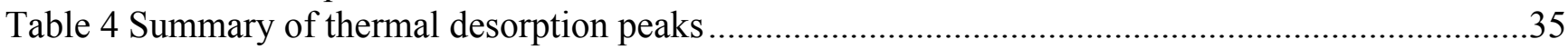

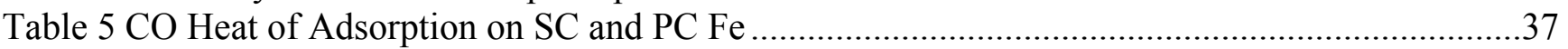

Table 6 Estimated kinetic parameters and their $95 \%$ confidence intervals for each elementary step. 45

Table 7 Peak temperature assignments for TPH of carbonaceous species on 99FeA series

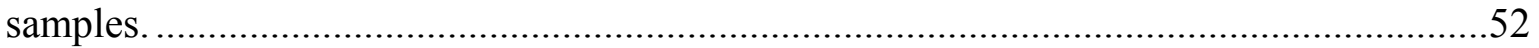

Table 8 Results of Temperature-Programmed Surface Reaction (TPH) of $\mathrm{H}_{2}$ with carbonaceous species on supported catalysts ...................................................................................57

Table 9 Fractional compositions for various carbon phases on supported catalysts ..............................57

Table 10 Monolayer carbon equivalents of peak areas on supported catalysts.......................................57

Table 11 Experimental Run Number and Reactor Outlet Conditions at $220^{\circ} \mathrm{C}$..................................71

Table 12 Regressed values of pre-exponential factors, activation energy and heat of adsorption...........74

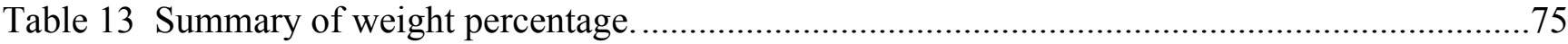

Table 14 Summary of run conditions and results ................................................................................79

Table 15 Values of regressed constants and confidence intervals as a function of run number..............80

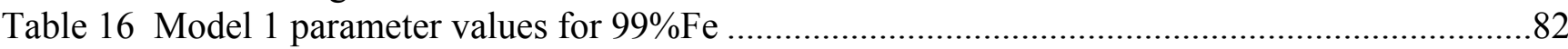

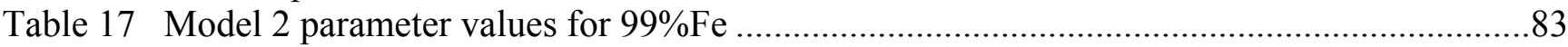

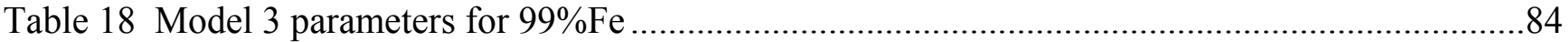




\section{List of Figures}

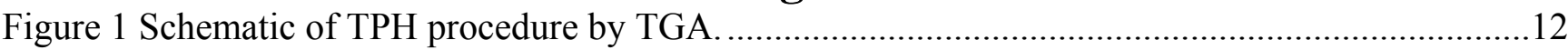

Figure 2 Schematic of CO adsorption/desorption procedure with mass-spectrometry..........................12

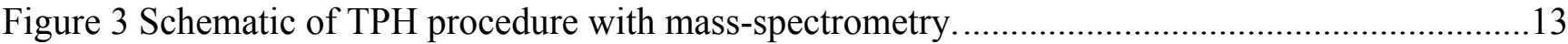

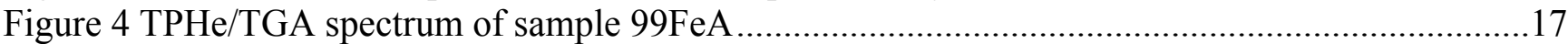

Figure 5 TGA-TPR spectrum for $\mathrm{H}_{2}$ reduction of sample 99FeA after calcination...............................18

Figure 6 TGA-TPR spectrum for CO reduction of sample 99FeA before calcination. ..........................19

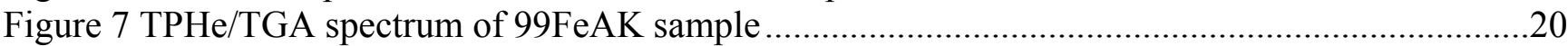

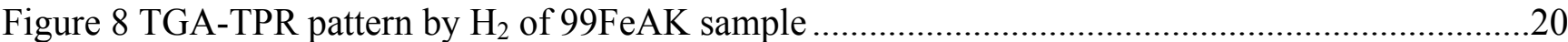

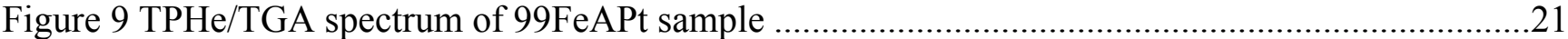

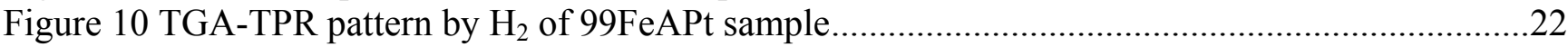

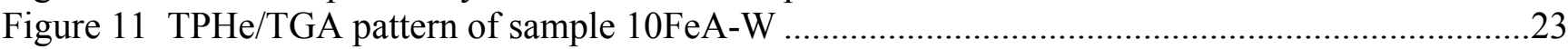

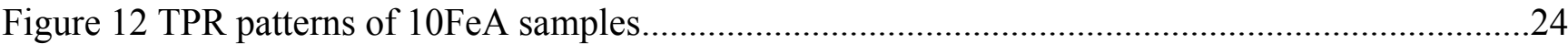

Figure 13 TGA-TPR patterns by $\mathrm{H}_{2}$ of 20FeA-A/E sample after calcination........................................25

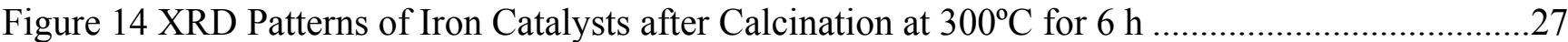

Figure 15 XRD Patterns of Iron Catalysts after Reduction at $500^{\circ} \mathrm{C}$ for $12 \mathrm{~h} \mathrm{f...................................28}$

Figure 16 XRD Patterns of Iron Catalysts in $40 \sim 50^{\circ}$ after Reduction at $500^{\circ} \mathrm{C}$ for $12 \mathrm{~h} \ldots \ldots \ldots \ldots \ldots \ldots \ldots \ldots . . . . . . . . .28$

Figure 17 TEM Images of $10 \mathrm{FeA}-\mathrm{A} / \mathrm{E}$ (left) and $10 \mathrm{FeA}-\mathrm{W}$ (right) after Reduction at $500^{\circ} \mathrm{C}$ for 12 h 29

Figure $18 \mathrm{TEM}$ Images of $20 \mathrm{FeA}-\mathrm{A} / \mathrm{E}$ (left) and $99 \mathrm{FeA}$ (right) after Reduction at $500^{\circ} \mathrm{C}$ for $12 \mathrm{~h} . \ldots \ldots . . .30$

Figure 19 TEM image (left) and its associated energy dispersion (right) of elemental oxygen, iron and alumina for $10 \mathrm{FeA}-\mathrm{W}$ sample........................................................................... 31

Figure 20 TEM image (left) and its associated energy dispersion (right) of elemental oxygen, iron and alumina for 10FeA-A/E sample. .......................................................................31

Figure 21 TEM image (left) and its associated energy dispersion (right) of elements oxygen, iron

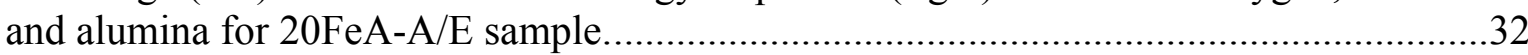

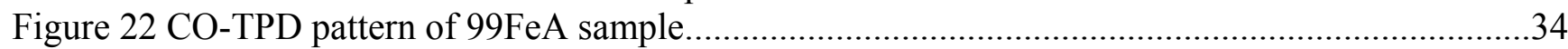

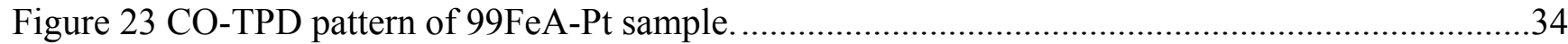

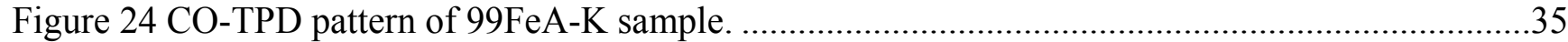

Figure 25 CO-TPD patterns at Different Adsorption Temperatures on 99FeA. .....................................36

Figure 26 Enthalpy of adsorption of $\mathrm{CO}$ on unsupported iron catalysts as a function of coverage.........37

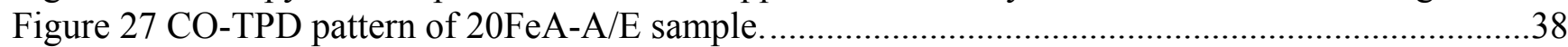

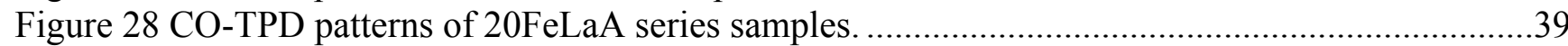

Figure 29 Normalized $\mathrm{CO}$ mole fraction during CO TPD. $\mathrm{yCO}_{\max }=4.20 \mathrm{E}-03 \ldots \ldots \ldots \ldots \ldots \ldots \ldots \ldots \ldots \ldots \ldots \ldots . . . .43$

Figure 30 Normalized $\mathrm{CO}_{2}$ mole fraction during CO TPD. $\mathrm{yCO}_{2 \max }=2.19 \mathrm{E}-03 \ldots \ldots \ldots \ldots \ldots \ldots \ldots \ldots \ldots \ldots \ldots . . . .43$

Figure 31 Comparison of observed normalized $\mathrm{CO}$ mole fraction during TPD and mole fraction profile predicted by model. ...........................................................................................43

Figure 32 Comparison of observed normalized $\mathrm{CO}_{2}$ mole fraction during $\mathrm{CO}$ TPD and mole fraction profile predicted by model.

Figure 33 Fractional coverages of $\mathrm{CO}, \mathrm{C}$, and $\mathrm{O}$ as a function of temperature on both $\alpha_{1}$ and $\alpha_{2}$ sites. 46

Figure 34 Isothermal hydrogenation spectrum of carbonaceous species of 99FeA sample at $200^{\circ} \mathrm{C}$

Figure 35 (A) TPH spectra of 99FeA series samples; (B) Enlarged section of temperature period between 200 and $600^{\circ} \mathrm{C}$.........................................................................................

Figure $36 \mathrm{TPH}$ spectra showing individual peak contributions from the carbon species on $99 \mathrm{FeA}$......51 
Figure $37 \mathrm{TPH}$ spectra showing individual peak contributions from the carbon species on 99FeA-Pt.

Figure $38 \mathrm{TPH}$ spectra showing individual peak contributions from the carbon species on 99FeA-K. 52

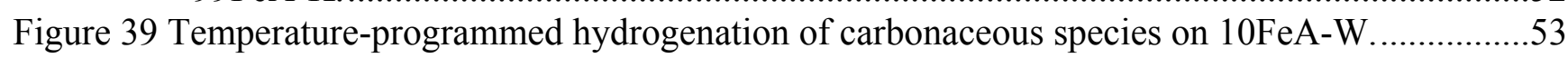

Figure 40 TPH-TGA of carbonaceous species on 10FeA-A/E . ...................................................54

Figure 41 Temperature-programmed hydrogenation of carbonaceous species on $20 \mathrm{FeA}-\mathrm{A} / \mathrm{E}$............54

Figure $42 \mathrm{TPH}$ spectra showing individual peak contributions from various carbon species for

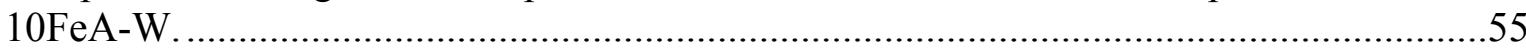

Figure 43 TPH spectra showing individual peak contributions from various carbon species for

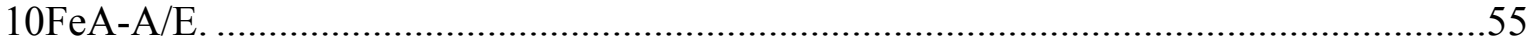

Figure 44 TPH spectrum obtained by TGA showing individual peak contributions from various

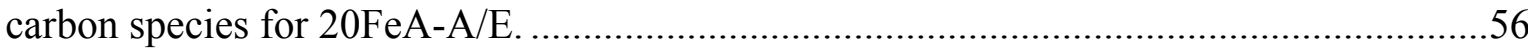

Figure 45 TPH spectrum obtained by TPSR/MS showing individual peak contributions from the various carbon species of $20 \mathrm{FeA}-\mathrm{A} / \mathrm{E}$ sample. .......................................................56

Figure 46 Isothermal hydrogenation spectra of 99FeA samples after pretreatment in syngas. .............58

Figure 47 Simulated (model 1) and experimental methane concentration vs. reaction time for the isothermal hydrogenation of carbonaceous species on $99 \mathrm{FeA}$ samples after pretreatment in syngas at $175^{\circ} \mathrm{C}$....

Figure 48 Simulated (model 2) and experimental methane concentration vs. reaction time for the isothermal hydrogenation of carbonaceous species on 99FeA samples after pretreatment in syngas at $175^{\circ} \mathrm{C}$.

Figure 49 Simulated (Model 3) and experimental methane concentration vs. reaction time for isothermal hydrogenation of carbonaceous species on $99 \mathrm{FeA}$ samples after pretreatment in syngas at $175^{\circ} \mathrm{C}$.

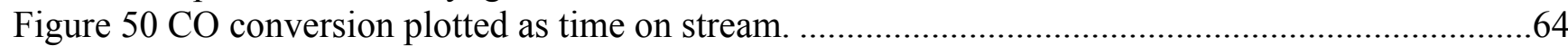

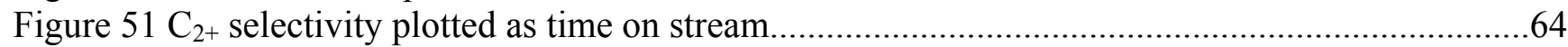

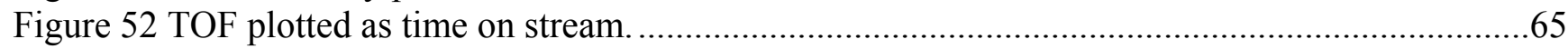

Figure 53 General Approach to D-Optimal Experimental Design................................................68

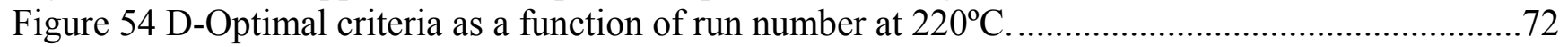

Figure 55 Regressed kinetic constants as a function of run number at $220^{\circ} \mathrm{C}$. .................................72

Figure 56 Joint $95 \%$ likelihood confidence regions for $\mathrm{k}$, and $\mathrm{K}$ at $220^{\circ} \mathrm{C}$ at different run lengths.......73

Figure 57 Experimental rates versus model predicted rates for sequentially designed experiments

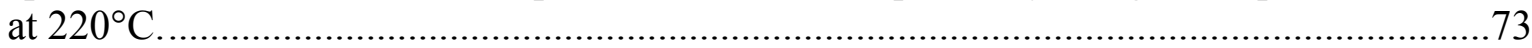

Figure 58 Temperature-programmed reduction spectrum for 99FeAl-monolith catalyst....................76

Figure 59 Rate of $\mathrm{CO}$ versus time for Run \#3 $\left(P_{C O}=3.263 \mathrm{~atm}\right.$ and $\left.P_{H 2}=2.351 \mathrm{~atm}\right) \ldots \ldots \ldots \ldots \ldots \ldots \ldots . . . \ldots 7$

Figure 60 Conversion of CO versus time for run $\# 3\left(P_{C O}=3.263 \mathrm{~atm}\right.$ and $\left.P_{H 2}=2.351 \mathrm{~atm}\right) \ldots \ldots \ldots \ldots . .78$

Figure $61 \mathrm{Graph}$ of regressed kinetic constants as a function of number of experimental runs. ............80

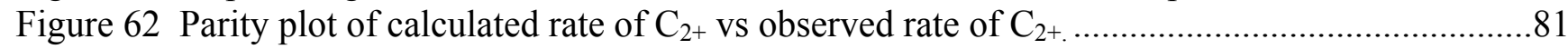

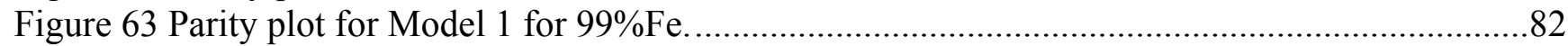

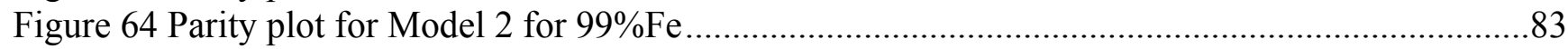

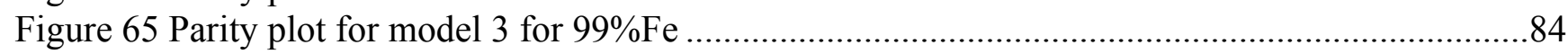

Figure 66 Model systems for FTS mechanistic studies on Fe catalysts. ......................................86

Figure 67 Functional Classification of elementary steps included in the mechanistic model for FTS on Fe catalysts. 
Figure 68 Reaction Network for the major elementary steps included in our models for FTS on $\mathrm{Fe}(110), \mathrm{Fe}(211), \mathrm{Fe}^{\mathrm{Pt}}$ and $\mathrm{Fe}_{\mathrm{C}}$

Figure 69 Binding Energies of $\mathrm{C}_{1}$ intermediates and some miscellaneous small molecules on $\mathrm{Fe}(110), \mathrm{Fe}(211), \mathrm{Fe}^{\mathrm{Pt}}$ and $\mathrm{Fe}_{\mathrm{C}}$. 91

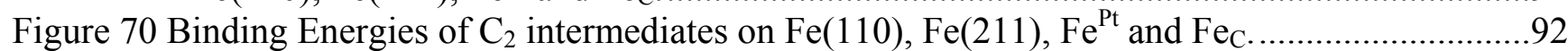

Figure 71 Potential Energy Surface (PES) for early FTS steps on $\mathrm{Fe}(110), \mathrm{Fe}(211), \mathrm{Fe}^{\mathrm{Pt}}$ and $\mathrm{Fe}_{\mathrm{C}} \ldots . . . .93$

Figure 72 Activation energies for early FTS steps (including CO dissociation) on $\mathrm{Fe}(110)$, $\mathrm{Fe}(211), \mathrm{Fe}^{\mathrm{Pt}}$ and $\mathrm{Fe}_{\mathrm{C}}$ .96

Figure 73Activation Energies for the C-C Coupling Steps on $\mathrm{Fe}(110), \mathrm{Fe}(211), \mathrm{Fe}^{\mathrm{Pt}}$ and $\mathrm{Fe}_{\mathrm{C}} \ldots \ldots \ldots \ldots . . . .96$

Figure 74 Activation energies for the $\mathrm{C}_{2}$ hydrogenation steps on $\mathrm{Fe}(110), \mathrm{Fe}(211), \mathrm{Fe}^{\mathrm{Pt}}$ and $\mathrm{Fe}_{\mathrm{C}} \ldots \ldots . . .97$

Figure 75 Comparative analysis of the thermodynamics of $\mathrm{C}-\mathrm{C}$ coupling reactions on $\mathrm{Fe}(110)$, $\mathrm{Fe}_{\mathrm{C}}, \mathrm{Fe}^{\mathrm{Pt}}$ and $\mathrm{Fe}(211)$ facets. .98

Figure 76 Potential Energy Surface(PES) for direct water formation on $\mathrm{Fe}(110), \mathrm{Fe}(211), \mathrm{Fe}_{\mathrm{C}}$ and $\mathrm{Fe}^{\mathrm{Pt}}$.

Figure 77 Timeline of first-principles calculations completed over the course of the project. 101 


\section{Background and Objectives}

\section{A. Background}

Fischer-Tropsch Synthesis (FTS) has been used commercially for more than 70 years in the conversion of syngas $\left(\mathrm{H}_{2} / \mathrm{CO}\right)$, derived from primarily coal but more recently from natural gas, into liquid hydrocarbons [1,2]. Its application to production of liquid fuels from natural gas (GTL) is expanding into a large world-wide industry, while its application to conversion of syngas from renewable biomass is being researched. Gasoline and diesel fuels produced from FT synthesis are premium products of low aromaticity and zero sulfur content. Although FTS is in some respects a "mature technology", substantial improvements have been realized during the past three decades in catalyst, reactor, and process technologies as a result of intensive research. Moreover, improvements could yet be realized in catalyst and reactor design through a deeper fundamental understanding of the reaction mechanism and catalyst activity-structure relationships. Combined application of modern surface science and computational chemistry tools is a powerful methodology for realizing deeper understanding required for improving catalyst design.

Almost 80 years ago, Fischer and Tropsch postulated that $\mathrm{CO}$ hydrogenation takes place on bulk carbides of $\mathrm{Co}$ and Fe. Over the decades a consensus has emerged that FTS is a polymerization process involving addition of a $\mathrm{CH}_{\mathrm{x}}(\mathrm{x}=0-2)$ monomer to a growing hydrocarbon chain. The formation of the surface $\mathrm{CH}_{\mathrm{x}}$ is proposed to occur via adsorption of $\mathrm{CO}$ on a metal site and dissociation of $\mathrm{CO}$ to a surface carbon atom, i.e. a surface carbide $\left(\mathrm{C}_{(\mathrm{ad})}\right)$, followed by stepwise addition of $\mathrm{H}$ atoms to produce methylidyne $\left(\mathrm{CH}_{(\mathrm{ad})}\right)$, methylene $\left(\mathrm{CH}_{2(\mathrm{ad})}\right)$ methyl $\left(\mathrm{CH}_{3(\mathrm{ad})}\right)$ species. However, there is little quantitative information regarding the potential energies of these intermediates or the kinetic parameters for these and the subsequent elementary steps producing hydrocarbons. Moreover, there is little consensus regarding the mechanisms of C-C coupling, i.e. which of the $\mathrm{CH}_{\mathrm{x}}$ species are involved in this important step for either Co or Fe catalysts.

Both $\mathrm{Co}$ and $\mathrm{Fe}$ catalysts have been used commercially for FTS. Fe catalysts were used for 55 years at Sasol for conversion of coal to fuels and chemicals because of their low cost and ability to process coal syngas having low $\mathrm{H}_{2} / \mathrm{CO}$ ratios as a result of their high activities for the water gas shift reaction. For the same reason Fe catalysts are favored for production of fuels from biomass. Since Co catalysts are more productive and stable than Fe catalysts, they are 
presently favored in GTL processes; nevertheless, the low cost and low methane selectivity of Fe catalysts make them an attractive option, especially if more productive, stable, supported $\mathrm{Fe}$ catalysts can be developed. A microkinetic model for Fe FTS could enable the needed improvements in design. There are no previously reported microkinetic studies of FTS on Fe.

This microkinetic sub-model developed in this study is intended to enable prediction of catalyst activity and hydrocarbon selectivities over a range of temperatures, pressures, and $\mathrm{H} 2 / \mathrm{CO}$ ratio and as a function of promoter type, and of surface carbon coverage. It addresses the molecular principles that govern rates of the kinetically-relevant or early steps in FTS, e.g. adsorption of $\mathrm{CO}$ and $\mathrm{H}_{2}$, dissociation of $\mathrm{CO}$, and hydrogenation of surface carbon. This report describes the progress made during the four year duration of this DOE-sponsored project for advanced design of supported iron Fischer-Tropsch catalysts through development of a microkinetics model for FTS based on theoretical computations and mechanistic experiments. The BYU catalysis research team assisted the computations team at U. Wisconsin through study and search of literature addressing FTS kinetics and mechanisms, experimental mechanistic studies of elementary reactions, and the development of rate data for alumina supported iron FTS catalysts.

\section{B. Work Statement}

\section{Objectives}

The principal objective of this work was to develop and validate a detailed microkinetic submodel describing the rates of the important early elementary steps that occur during FTS on the surface of an iron catalyst and which incorporates to a limited extent effects of potassium oxide and Pt promoters and of surface and subsurface carbon species on reaction rate.

\section{Scope}

This microkinetics submodel will enable prediction of catalyst activity and hydrocarbon selectivities over a range of temperatures, pressures, and $\mathrm{H}_{2} / \mathrm{CO}$ ratio and as a function of promoter type, and of surface carbon coverage. It will address the molecular principles that govern the relative rates of chain growth versus termination on iron FT catalysts, thereby providing a basis for maximizing desirable products (e.g. olefins, diesel liquids and waxes) while minimizing formation of undesirable products such as methane, LPG, and alcohols. 


\section{Tasks}

To accomplish the above objectives, the proposed research has been divided into the following specific tasks to be accomplished over a period of 36 months:

Task 1: Search literature and incorporate available kinetic parameters into a microkinetics model for FT surface reactions on iron; determine consistency of available data and needs for obtaining additional parameters - this will be an ongoing task. (BYU and UW)

Task 2: Measure kinetic parameters for key elementary steps including $\mathrm{CO}$ and $\mathrm{H}_{2}$ adsorptions/desorptions, $\mathrm{CO}$ dissociation, $\mathrm{C}$ hydrogenation, olefin adsorption on unpromoted $\mathrm{Fe}$ catalysts and Fe catalysts promoted with $\mathrm{K}_{2} \mathrm{O}$ and/or Pt. Catalysts will be prepared using coprecipitation and non-aqueous, evaporative deposition methods and will be characterized by $\mathrm{H}_{2}$ and $\mathrm{CO}$ adsorptions, XRD, TPR, TEM, and BET methods. Studies of elementary steps will be conducted at high pressure conditions using TPD and temperature-programmed reaction spectroscopies combined with isotopic tracer studies. (BYU)

Task 3: Use DFT Calculations to determine reaction thermochemistry and kinetics for key elementary steps in Tasks 1 and 2, including propagation and termination steps and steps involving reactive intermediates such as hydrogenation of $\mathrm{CH} 2$. Investigate effects of surface/subsurface $\mathrm{O}$ and $\mathrm{C}$, at various concentrations, on the reactivity of $\mathrm{Fe}$ surfaces. Determine effects of promoter type and concentration, coverage of surface/subsurface carbon species, and surface defects on the kinetic/thermodynamic parameters for key steps. (UW)

Task 4: Obtain a statistical set of rate and selectivity data on $\mathrm{Fe} / \mathrm{K}_{2} \mathrm{O} / \mathrm{Pt} / \mathrm{Al}_{2} \mathrm{O}_{3}$ catalysts over a relevant range of reaction temperatures, reactant compositions, and $\mathrm{H}_{2} / \mathrm{CO}$ ratios at commercially relevant pressures and use these data to validate the microkinetics model. Data will be obtained using a Berty CSTR reactor system. (BYU and UW)

Task 5: Build collaborative relationships with other research groups and companies and develop proposals for funding the continuation of the proposed work and its incorporation into a comprehensive catalyst particle/reactor/process model. (BYU and UW) 


\section{Deliverables}

1) The first stage in the development of a microkinetics sub-model that enables prediction of catalyst activity over a range of temperatures, pressures, $\mathrm{H}_{2} / \mathrm{CO}$ ratio, and as a function of promoter type, and of surface carbon coverage.

2) First-Principles DFT calculations of binding energies, reaction barriers, and preexponential factor estimates for key elementary steps in the FTS mechanism.

3) Experimental values of kinetic parameters for key elementary steps including $\mathrm{CO}$ and $\mathrm{H}_{2}$ adsorptions / desorptions, $\mathrm{CO}$ dissociation, $\mathrm{C}$ hydrogenation, and olefin adsorption on unpromoted and promoted $\mathrm{Fe} / \mathrm{K}_{2} \mathrm{O} / \mathrm{Pt}$ using TPD and temperature-programmed reaction spectroscopies.

4) A statistical set of rate and selectivity data on $\mathrm{Fe} / \mathrm{K}_{2} \mathrm{O} / \mathrm{Pt}$ catalysts over a relevant range of reaction temperatures, reactant compositions, and $\mathrm{H}_{2} / \mathrm{CO}$ ratios that can be used to validate mechanistic models. 


\section{Executive Summary}

The principal objective of this research is to develop and validate a microkinetics submodel which describes the rates of the important early elementary steps that occur on the surface of an iron catalyst during FTS. The model will incorporate in part the effects of potassium oxide, a Pt promoter, and surface carbon species on the important elementary steps.

To accomplish these objectives, a series of experiments were conducted including (1) searching/summarizing published FTS mechanistic and kinetic studies of FTS reactions on iron catalysts; (2) preparation and characterization of unsupported iron catalysts with/without $\mathrm{K}$ and Pt promoters; (3) the application of TPR, TPD, TPH, and ITH to measurement of kinetic parameters for $\mathrm{H}_{2}$ and $\mathrm{CO}$ adsorption/dissociation and hydrogenation of surface carbonaceous species on iron catalyst surface sites; (4), $\mathrm{H}_{2}$ chemisorption, HRTEM and BET surface area measurements coupled with activity and stability tests of the supported catalysts in a fixed bed reactor under industrially-relevant process conditions; and (5) FTS kinetics study on Berty CSTR reactor system over unsupported/supported iron catalysts to provide data for validation of the microkinetic model.

Methods for preparation of alumina-supported iron catalysts suitable for kinetic and mechanistic studies in FTS process were investigated. Three unsupported iron catalysts and three alumina-supported iron catalysts were prepared by non-aqueous, evaporative deposition (NED), aqueous impregnation (AI), and co-precipitation methods. These catalysts, covering a wide range of dispersions and metal loadings, are well-reduced and relatively thermally stable up to 500$600^{\circ} \mathrm{C}$ in $\mathrm{H}_{2}$, thus ideal for kinetic and mechanistic studies.

Several kinds of experiments were undertaken in the characterization of the catalysts, including Thermogravimetric Analysis-Temperature Programmed Reduction (TGA-TPR), BET surface area measurements, $\mathrm{H}_{2}$ and $\mathrm{CO}$ chemisorptions, X-ray Diffraction (XRD) analysis, and Transmission Electron Microscopy (TEM).

A $10 \mathrm{wt} \% \mathrm{Fe} /$ alumina catalyst prepared by the NED method and reduced at $500^{\circ} \mathrm{C}$ for $12 \mathrm{~h}$ has a BET surface area of $138 \mathrm{~m}^{2} / \mathrm{g}$ and an average pore diameter of $9.5 \mathrm{~nm}$. TGA-TPR experiments revealed that $10 \% \mathrm{Fe} / \mathrm{Al}_{2} \mathrm{O}_{3}$ prepared by the NED method are more easily reduced, i.e., have a higher extent of reduction than $10 \mathrm{wt} \% \mathrm{Fe} / \mathrm{Al}_{2} \mathrm{O}_{3}$ prepared by the AI method. Furthermore, iron crystallite diameters estimated from $\mathrm{H}_{2}$ chemisorption, XRD, and TEM measurements provide evidence that iron metal dispersions of $\mathrm{Fe} / \mathrm{Al}_{2} \mathrm{O}_{3}$ catalysts prepared by the NED method are higher. The FT activity tests in a fixed bed reactor on supported iron catalysts indicate that at iron crystallite size less than about $5 \mathrm{~nm}$, supported iron catalysts have lower FT activity.

Kinetic parameters for $\mathrm{CO}$ adsorption, $\mathrm{CO}$ dissociation, and surface carbon hydrogenation on these catalysts were determined from temperature-programmed desorption (TPD) of CO and temperature program-med surface hydrogenation (TPSR) and isothermal, transient hydrogenation (ITH). CO-TPD experiments were conducted on unsupported and supported iron catalysts. Two types of $\mathrm{CO}$ desorption, molecularly adsorbed $\mathrm{CO}$ and dissociated $\mathrm{CO}$, were observed. A model based on plausible $\mathrm{CO}$ desorption mechanism reveals that $\mathrm{CO}$ adsorbs on at least two different active sites of different binding energy on unsupported catalysts. Similarly, from ITH experiments, it was found that carbon atoms of different binding energy occur on the iron surface following reaction under mild reaction conditions. A microkinetic model was 
constructed for the early steps in FTS on polycrystalline iron from the kinetic parameters of elementary steps determined experimentally in this work and from literature values.

Kinetic data were obtained at different temperatures and various feed compositions of $\mathrm{CO}$, $\mathrm{H}_{2}$ and $\mathrm{He}$ on a Berty reactor using sequential design of experiments for both unsupported $\mathrm{Fe}$ and supported $\mathrm{Fe}$ catalysts. Langmuir-Hinshelwood type rate expressions were derived for the disappearance of $\mathrm{CO}$; the formation of $\mathrm{C}_{2+}$ hydrocarbons and $\mathrm{CO}_{2}$ by assuming various rate determining steps. Multi-response non-linear regression analysis was used to fit the measured rates to the model. These results will be used to validate the microkinetic model and provide a platform for further development of microkinetic models of FTS on Fe and a basis for more precise modeling of FTS activity of Fe catalysts.

On the theoretical side our work over the four years focused on conducting a detailed study for FTS on a variety of Fe based catalyst models. The most-stable, close-packed Fe(110) facet was the fundamental surface that was analyzed and this was followed by other suitable models that explored the effects of sub-surface carbon $\left(\mathrm{Fe}_{\mathrm{C}}(110)\right.$ facet) and promotion by $\mathrm{Pt}$ adatoms $\left(\mathrm{Fe}^{\mathrm{Pt}}(110)\right.$ facet). Finally the defected $\mathrm{Fe}(211)$ facet was also considered in order to evaluate the role of steps on FTS catalysis. All models were chosen based on the criteria of computational viability and a desire to obtain good representation of the actual experimental situation. Using state-of-the-art Density Functional Theory (DFT) methods our FTS reaction-model (comprising of 32 elementary steps involving 19 species) was fully characterized with respect to its thermochemistry which involved evaluation of the Binding Energies (BEs), preferred adsorption sites and geometries of all the component stable species and intermediates. Subsequently, detailed kinetic studies were performed using the Climbing Image Nudged Elastic Band (CINEB) method, a state-of-the-art iterative method to evaluate the Minimum Energy Pathways (MEPs), Transition State (TS) structures and activation energies for each elementary step. An evaluation of the vibrational frequencies for each species in its preferred adsorption configurations was also performed which provides a useful connection with experimental vibrational frequency work (e.g.: IRAS, HREELS, etc) while allowing us to compute entropychanges and pre-exponential factors for each elementary reaction step. CO dissociation was found to be a consistently difficult (high barrier step) and other interesting trends (described in detail later) were also discovered by a comparative analysis of the elementary steps on the four different model surfaces. Significant success has thus been achieved in characterizing FTS on these model surfaces and an extensive database of BEs, activation barriers, vibrational frequencies, entropies and pre-exponential factors has been established. Overall the reaction networks for the model-systems are quite complex; a detailed microkinetic model is expected to shed more light into the fundamental mechanisms of FTS on Fe-based catalysts, for a wide range of experimental conditions. 


\section{Experimental Procedures}

\section{A. Preparation of Alumina Binder and Supported Fe Catalysts}

\section{Preparation of 1 wt $\% \mathrm{Al}_{2} \mathrm{O}_{3} / 99 w t \%$ Fe Catalyst}

1. $\mathrm{Fe}\left(\mathrm{NO}_{3}\right)_{3} \cdot 9 \mathrm{H}_{2} \mathrm{O}(\mathrm{AR})$ and $\mathrm{Al}\left(\mathrm{NO}_{3}\right)_{3} \cdot 9 \mathrm{H}_{2} \mathrm{O}(\mathrm{AR})$ were mixed to the desired ratio and dissolved to obtain an aqueous solution with total cation concentrations of $1 \mathrm{M}$.

2. $\mathrm{NH}_{4} \mathrm{OH}(\mathrm{AR})$ was dissolved in demineralized water to form another aqueous solution with the appropriate amount calculated according to the relation $\left[\mathrm{NH}_{4} \mathrm{OH}\right]=3.2$ $\left[\mathrm{M}^{3+}\right]$.

3. The $\mathrm{NH}_{4} \mathrm{OH}$ solution was added drop wise to the solution of $\mathrm{Fe}\left(\mathrm{NO}_{3}\right)_{3}$ and $\mathrm{Al}\left(\mathrm{NO}_{3}\right)_{3}$ solution at $70^{\circ} \mathrm{C}$ while stirring over an interval of $2 \mathrm{~h}$.

4. A brown precipitate was formed. The $\mathrm{pH}$ of the slurry was controlled to 8-9.

5. After precipitation, the slurry was stirred for another $30 \mathrm{~min}$ at $70^{\circ} \mathrm{C}$.

6. The precipitate was filtered, washed with demineralized water three times.

7. The wet catalyst paste was dried at $110^{\circ} \mathrm{C}$ for $12 \mathrm{~h}$ in an oven.

8. The sample was designated as 99FeA.

2. Preparation of $\mathrm{Al}_{2} \mathrm{O}_{3}$-Promoted Iron Catalysts with $1 \mathrm{wt} \% \mathrm{~K}$, or $1 \mathrm{wt} \%$ Pt Promoters

1. Dissolved suitable amount of $\mathrm{K}_{2} \mathrm{CO}_{3}$ or $\mathrm{H}_{2} \mathrm{PtCl}_{4}$ salt in desired amount of water to form a solution.

2. Measured the desired amount of dried $1 \mathrm{wt} \% \mathrm{Al}_{2} \mathrm{O}_{3} / 99 \mathrm{wt} \%$ Fe catalyst.

3. Slowly drop wise introduced the K or Pt solution to the catalyst powder.

4. Stirred the slurry for another $15 \mathrm{~min}$.

5. Put the catalyst paste aside at room temperature for $12 \mathrm{~h}$.

6. Dried the catalyst at $110^{\circ} \mathrm{C}$ in oven for $12 \mathrm{~h}$.

7. These two samples are designated as $99 \mathrm{FeAK}$ and $99 \mathrm{FeAPt}$. 


\section{Preparation of stabilized $\gamma$-Al2O3}

1. Add $20 \mathrm{~g}$ of alumina (Catapal A, Sasol) to $750 \mathrm{ml}$ doubly-distilled, high grade water to form suspension.

2. Adjust the $\mathrm{pH}$ of the suspension to 5 by addition of concentrated nitric acid.

3. Dissolve $5.196 \mathrm{~g}$ of $\mathrm{La}(\mathrm{NO} 3) 3 \cdot 6 \mathrm{H} 2 \mathrm{O}$ in $18 \mathrm{ml}$ demineralized water.

4. Dissolve an equimolar amount (3.507 g) of EDTA in $90 \mathrm{ml}$ demineralized water and increase the $\mathrm{pH}$ to 5 by addition of concentrated ammonia.

5. Slowly add the $\mathrm{La}(\mathrm{NO} 3) 3 \cdot 6 \mathrm{H} 2 \mathrm{O}$ solution to the EDTA solution and maintain the $\mathrm{pH}$ of the solution at 5 .

6. Add [La(EDTA)]- solution to the alumina suspension and stir vigorously, while maintaining a constant $\mathrm{pH}$ of 5 by the addition of dilute nitric acid.

7. After 2 hours, filter suspension, and wash with demineralized water.

8. Store filtrate in covered contained and repeat steps $2-8$.

9. Combine filtrates and dry in drying oven, on a flat evaporating dish (with a cover glass) using the following temperature profile:

a. Hold at $60^{\circ} \mathrm{C}$ for 24 hours and stir every $30 \mathrm{~min}$ for 6 hours.

b. Hold at $80^{\circ} \mathrm{C}$ for 12 hours

c. Hold at $120^{\circ} \mathrm{C}$ for 12 hours

10. Calcine support at $5^{\circ} \mathrm{C} / \mathrm{min}$ to $700^{\circ} \mathrm{C}$ according to profile determined by TPO; hold at $700^{\circ} \mathrm{C}$ for 8 hours.

\section{Preparation of $10 \mathrm{wt} \% \mathrm{Fe} / \mathrm{Al}_{2} \mathrm{O}_{3}$ Catalysts}

$\underline{10 \mathrm{wt} \% \mathrm{Fe} / \mathrm{Al}_{2} \underline{\mathrm{O}}_{3} \text { Catalyst with Aqueous Solution (incipient wetness impregnation method) }}$

1. A pre-measured amount of iron nitrate was dissolved in certain amount of demineralized water.

2. The solution was added to the alumina support while stirring vigorously.

3. Set catalyst aside at RT for $10 \mathrm{~h}$. 
4. Place the sample in a covered evaporating dish in oven to dry at $110^{\circ} \mathrm{C}$ overnight.

5. Place samples in a desiccator.

6. Catalyst code: $10 \mathrm{FeA}-\mathrm{W}$.

$10 \mathrm{wt} \% \mathrm{Fe} / \mathrm{Al}_{2} \underline{\mathrm{O}}_{3}$ Catalyst with Acetone/Ethanol Solution (non-aqueous evaporative deposition $\underline{\text { method) }}$

1. $\mathrm{Fe}\left(\mathrm{NO}_{3}\right)_{3} \cdot 9 \mathrm{H}_{2} \mathrm{O}$ was added to a flask, which was immersed into a water bath at a temperature of $52^{\circ} \mathrm{C}$ and connected to a vacuum pump.

2. The melted $\mathrm{Fe}\left(\mathrm{NO}_{3}\right)_{3} \cdot 9 \mathrm{H}_{2} \mathrm{O}$ salt was evacuated for $24 \mathrm{~h}$.

3. While the iron nitrate was still liquid, $10 \mathrm{ml}$ ethanol and $10 \mathrm{ml}$ acetone were added to dissolve it.

4. Alumina powder previously calcined at $650^{\circ} \mathrm{C}$ for $6 \mathrm{~h}$, was added to the solution and the sample was stirred well by shaking.

5. The sample was put aside at RT until the ethanol/acetone had evaporated.

6. The sample was then dried at $110^{\circ} \mathrm{C}$ overnight and placed in a desiccator.

7. Catalyst code: $10 \mathrm{FeA}-\mathrm{A} / \mathrm{E}$.

\section{Preparation of $20 \mathrm{wt} \% \mathrm{Fe} / \mathrm{LaOAl}_{2} \mathrm{O}_{3}$ Catalysts (two-step non-aqueous evaporative deposition} method)

1. $\mathrm{Fe}\left(\mathrm{NO}_{3}\right)_{3} \cdot 9 \mathrm{H}_{2} \mathrm{O}$ was treated and dissolved in acetone/ethanol as in Procedure $4 \mathrm{~b}$.

2. La-alumina powder was added to the solution and the sample was stirred by shaking.

3. Ar gas was bubbled through the solution until the ethanol/acetone had evaporated.

4. The sample was dried at $60^{\circ} \mathrm{C}$ overnight, further dried at $110^{\circ} \mathrm{C}$ for another $12 \mathrm{~h}$, and calcined at $300^{\circ} \mathrm{C}$ for $6 \mathrm{~h}$ with a temperature ramp of $1^{\circ} \mathrm{C} / \mathrm{min}$.

5. The second impregnation treatment was repeated to reach an iron loading of $20 \mathrm{wt} \%$.

6. Catalyst code: $20 \mathrm{FeA}-\mathrm{A} / \mathrm{E}$. 


\section{B. Characterization of Fe Catalysts}

\section{BET measurements}

BET surface area, pore volume, pore size, and average pore size distribution of supports and catalysts were obtained from full-range $\mathrm{N}_{2}$ sorption isotherms using an adsorption surface area Tristar analyzer (Micromeritics).

\section{TGA-TPH, CO adsorption measurements}

Reducibility behavior measured by temperature-programmed reduction (TPR) and CO adsorption uptakes were determined by TGA (Perkin Elmer TGA7 Thermogravimetric Analyzer). TPR runs were conducted in $10 \% \mathrm{H}_{2} / \mathrm{He}$ at a ramping rate of $5^{\circ} \mathrm{C} / \mathrm{min}$ from RT to $850^{\circ} \mathrm{C}$. TPR curves were obtained by differentiating TGA weight loss curves. CO adsorption measurements were conducted following reduction (the experimental procedure will be explained in the Results and Discussion section).

\section{3. $\mathrm{H}_{2}$ Chemisorption Measurements}

$\mathrm{H}_{2}$ chemisorption measurements were conducted in flow chemisorption system with TCD detector. Unreduced and pre-reduced (in bulk) samples were reduced at $300^{\circ} \mathrm{C}$ for $16 \mathrm{~h}$ and $6 \mathrm{~h}$, respectively. Previously unreduced samples were calcined at $200^{\circ} \mathrm{C}$ in argon for $3 \mathrm{~h}$ before reduction. After $\mathrm{H}_{2}$ reduction, each sample was purged in $\mathrm{Ar}$ for $30 \mathrm{~min}$ at $300^{\circ} \mathrm{C}$ then cooled to $100^{\circ} \mathrm{C}$; pure $\mathrm{H}_{2}$ was introduced to the sample (at $100^{\circ} \mathrm{C}$ ) and the sample was soaked for $45 \mathrm{~min}$. The sample was then cooled in $\mathrm{H}_{2}$ with a dry ice/acetone bath to $-84^{\circ} \mathrm{C}$ and purged in $\mathrm{Ar}$ for 30 min to remove physically adsorbed $\mathrm{H}_{2}$; it was then heated to $500^{\circ} \mathrm{C}$ at $15^{\circ} \mathrm{C} / \mathrm{min}$ with a hold for 3 $\mathrm{h}$ at $500^{\circ} \mathrm{C}$. The $\mathrm{H}_{2}$ uptake in this process was determined from the TCD detector area.

\section{Bulk reduction treatment}

Catalyst samples were pre-reduced in a quartz or stainless-steel reactor placed in a temperature-programmed 3-zone furnace. Fe catalysts were calcined in air at $300^{\circ} \mathrm{C}$ for $6 \mathrm{~h}$ at a heating ramp of $1^{\circ} \mathrm{C} / \mathrm{min}$, and then purged in He for $30 \mathrm{~min}$. After purging, $10 \% \mathrm{H}_{2}$ in $\mathrm{He}$ was introduced and temperature was increased from $300^{\circ} \mathrm{C}$ to $500^{\circ} \mathrm{C}$ at a heating ramp of $1{ }^{\circ} \mathrm{C} / \mathrm{min}$ with a hold for $12 \mathrm{~h}$ at $500^{\circ} \mathrm{C}$. 


\section{XRD measurements}

Phases present in the catalysts and estimates of crystallite diameters were determined by Xray diffraction (XRD) using the Scintag XDS2000 diffractometer equipped with a $\mathrm{Cu}$ target and graphite monochromator.

\section{TPH measurements on supported iron catalysts by TGA}

\section{$\underline{\mathrm{H}}_{2}$ reduction:}

About 30 40 mg samples were put on a TGA pan and treated in $10 \% \mathrm{H}_{2} / \mathrm{He}\left(20 \mathrm{sccm} \mathrm{H}_{2}\right.$ in $180 \mathrm{sccm} \mathrm{He}$ ), ramped at $1^{\circ} \mathrm{C} / \mathrm{min}$ to $400^{\circ} \mathrm{C}$, held for $12 \mathrm{~h}$, and then cooled to $380^{\circ} \mathrm{C}$ in pure $\mathrm{He}$ and held for $30 \mathrm{~min}$ (see Figure 1).

\section{CO hydrogenation:}

Samples were cooled down to $200^{\circ} \mathrm{C}$ in pure $\mathrm{He}$ with ramping rate of $40^{\circ} \mathrm{C} / \mathrm{min}$, and then reacted in $\mathrm{CO} / \mathrm{H}_{2} / \mathrm{He}(1: 4: 16)$ at $200^{\circ} \mathrm{C}$ for $5 \mathrm{~min}$, then purged in He for another $5 \mathrm{~min}$. Samples were cooled to room temperature quickly (see Figure 1).

\section{$\underline{\mathrm{TPH}}$.}

Following these pretreatments, samples were exposed to $10 \% \mathrm{H}_{2} / \mathrm{He}$ while ramping to $800^{\circ} \mathrm{C}$ at $5^{\circ} \mathrm{C} / \mathrm{min}$ (see Figure 1).

\section{CO adsorption and TPD measurements on unsupported iron catalysts by Mass-spectrometer}

About $300 \mathrm{mg}$ of catalyst was reduced at $450^{\circ} \mathrm{C}$ for $12 \mathrm{~h}$ at $1^{\circ} \mathrm{C} / \mathrm{min}$, and then purged in $\mathrm{He}$ at $430^{\circ} \mathrm{C}$ for $30 \mathrm{~min}$. After cooling to RT, CO was introduced to the catalyst for $12 \mathrm{~h}$. The sample was then cooled in $\mathrm{CO}$ with a dry ice/acetone bath to $-84^{\circ} \mathrm{C}$ and purged in $\mathrm{He}$ for $30 \mathrm{~min}$ to remove physically adsorbed $\mathrm{CO}$; it was then heated to $750^{\circ} \mathrm{C}$ at $15^{\circ} \mathrm{C} / \mathrm{min}$. The $\mathrm{CO}$ in this process was determined by mass spectrometry. The procedure is shown schematically in Figure 2.

\section{ITH and TPH measurements by Mass-spectrometry}

Two sets of $\mathrm{C}$ hydrogenation rate versus time were conducted on Fe samples (see Figure 3):

Isothermal hydrogenation of carbonaceous adsorbed species:

The sample was pretreated in $\mathrm{H}_{2}$ at $450^{\circ} \mathrm{C}$ and 1 atm for $12 \mathrm{~h}$. After decreasing the reaction temperature to $200^{\circ} \mathrm{C}$ in helium, 


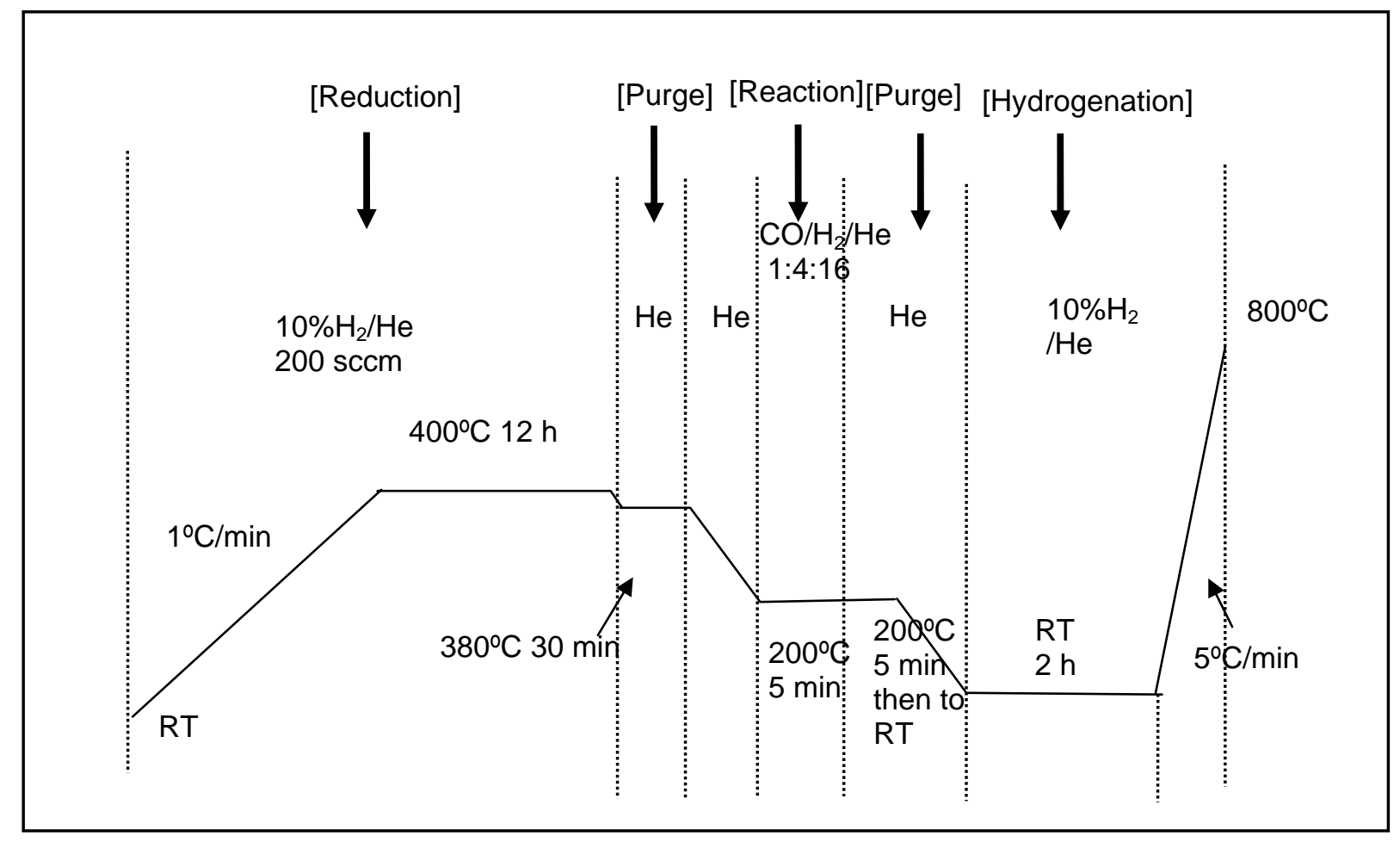

Figure 1 Schematic of TPH procedure by TGA.

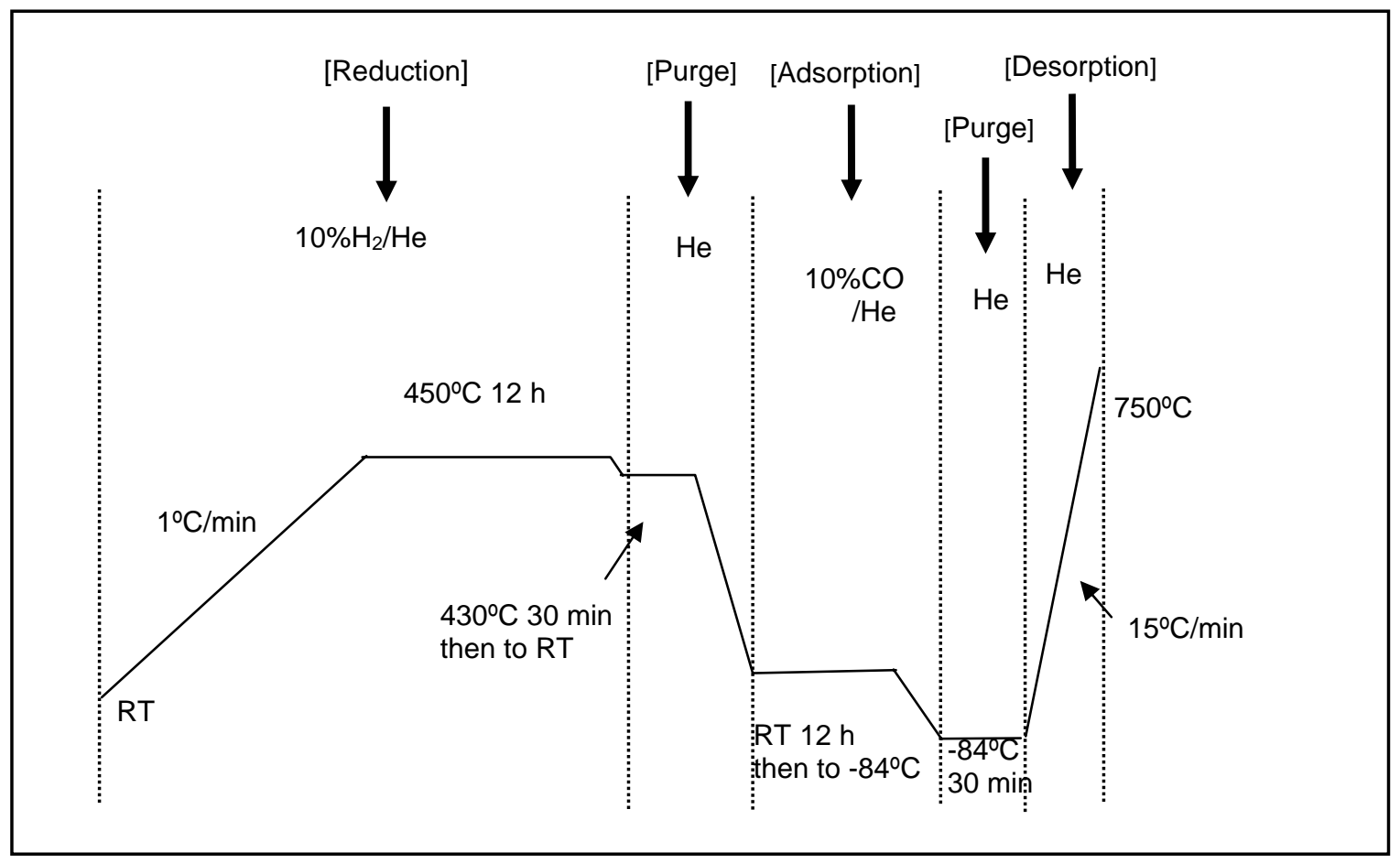

Figure 2 Schematic of $\mathrm{CO}$ adsorption/desorption procedure with mass-spectrometry. 


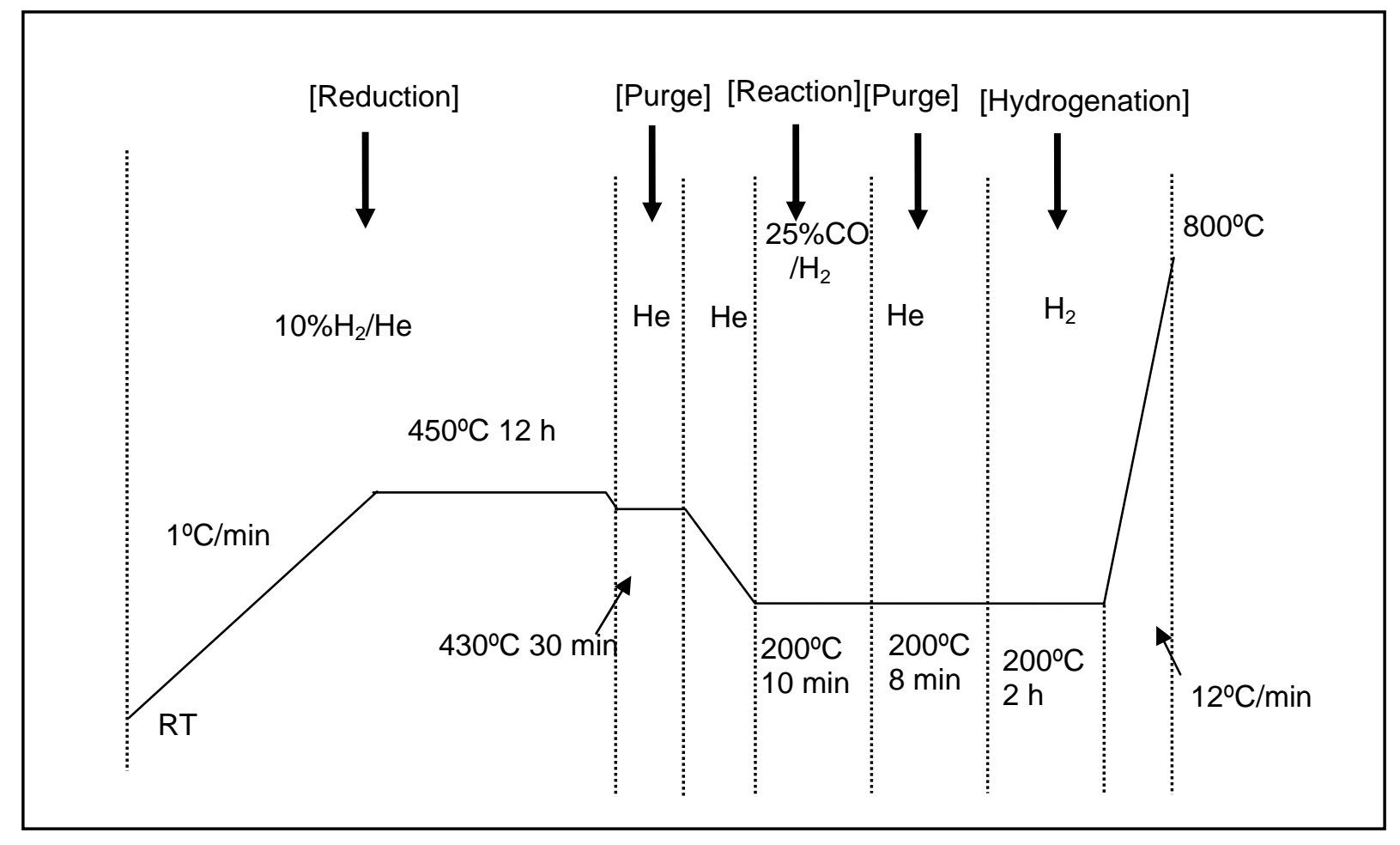

Figure 3 Schematic of TPH procedure with mass-spectrometry.

the reactant mixture of $25 \% \mathrm{CO} / \mathrm{H}_{2}$ was then admitted for $10 \mathrm{~min}$, followed by a purge in helium for $8 \mathrm{~min}$. $\mathrm{H}_{2}$ was then introduced immediately onto the catalyst and methane evolved was detected by a quadrupole mass-spectrometer.

\section{TPH:}

After isothermal hydrogenation for $2 \mathrm{~h}$, the temperature was increased from $200^{\circ} \mathrm{C}$ to $800^{\circ} \mathrm{C}$ at $12^{\circ} \mathrm{C} / \mathrm{min}$ in $\mathrm{H}_{2}$ to obtain a $\mathrm{TPH}$ spectrum.

\section{Activity Tests}

Activity tests were carried out in a $1 \mathrm{~cm}$ I.D. fixed-bed reactor with a three-zone furnace with a separate controller for each zone. One gram of catalyst (100-150 mesh) was diluted with $2 \mathrm{~g}$ of quartz chips (70 mesh) to minimize the axial temperature gradient. The temperature inside the catalyst bed was measured by a thermocouple inserted into the catalyst bed.

Feed gas was purified using deoxygenation and zeolite traps and metered with calibrated mass flow controllers. A calibration mixture of 92\% CO and 8\% Ar was employed to provide an internal standard for accurate measurement of $\mathrm{CO}$ concentration. The reactor pressure was 
regulated by a Mighty Mite backpressure regulator. Heavier waxy products were collected in a hot trap while lighter liquid products were collected at ambient pressure in a cold trap at ice temperature. The exit gas was then analyzed for $\mathrm{H}_{2}, \mathrm{CO}, \mathrm{CO}_{2}, \mathrm{CH}_{4}$ and Ar using an $\mathrm{HP} 5890$ gas chromatograph.

The iron catalyst was pretreated in-situ as follows at atmospheric pressure before each activity test. Reactor temperature was increased at $1{ }^{\circ} \mathrm{C} / \mathrm{min}$ to $200^{\circ} \mathrm{C}$ and held at $200^{\circ} \mathrm{C}$ for $3 \mathrm{~h}$. A helium flow of $200 \mathrm{sccm}$ was used to decompose the iron nitrates. The temperature was then increased at $1^{\circ} \mathrm{C} / \mathrm{min}$ to $300^{\circ} \mathrm{C}$ and held for $12 \mathrm{~h} \mathrm{in} \mathrm{H}_{2}$ flowing at $200 \mathrm{sccm}$. The reactor was then pressurized to 310 psi with a gas mixture containing syngas and an argon tracer at a flow of 65 sccm. The reactor temperature was then adjusted to the desired value and the FT reaction was begun.

Calculations of $\mathrm{CO}$ conversion and consumption rates and of $\mathrm{CH}_{4}$ and $\mathrm{CO}_{2}$ selectivities were made using the following equations:

(1) CO conversion (fractional conversion):

$$
X_{\mathrm{CO}}=\frac{(\mathrm{CO} / \mathrm{Ar})_{\text {product }}}{(\mathrm{CO} / \mathrm{Ar})_{\text {feed }}}
$$

(2) $\mathrm{CH}_{4}$ selectivity (mole \%)

$$
S_{\mathrm{CH}_{4}}=\frac{100 \times\left(\mathrm{CH}_{4} / \mathrm{Ar}\right)_{\text {product }}}{(\mathrm{CO} / \mathrm{Ar})_{\text {feed }} \times \mathrm{X}_{\mathrm{CO}}-\mathrm{S}_{\mathrm{CO}_{2}} \times \mathrm{X}_{\mathrm{CO}}}
$$

(3) $\mathrm{CO}_{2}$ selectivity (mole \%)

$$
S_{\mathrm{CO}_{2}}=\frac{100 \times\left(\mathrm{CO}_{2} / \mathrm{Ar}\right)_{\text {product }}}{(\mathrm{CO} / \mathrm{Ar})_{\text {feed }} \times \mathrm{X}_{\mathrm{CO}}}
$$

(4) $\mathrm{C}_{2+}$ selectivity (mole \%)

$$
S_{\mathrm{C}_{2+}}=1-\mathrm{S}_{\mathrm{CH}_{4}}
$$




\section{Results and Discussion}

\section{A. Chemical and Physical Properties of Unsupported and Supported Fe Catalysts Prepared by Aqueous and Non-aqueous Methods}

Chemical compositions, pretreatment conditions, BET surface areas and average pore diameters of unsupported and alumina-supported catalysts, prepared by aqueous and nonaqueous evaporation methods, are summarized in Table 1.

Table 1 Catalyst codes, compositions, and physical properties

\begin{tabular}{|c|c|c|c|c|c|}
\hline $\begin{array}{l}\text { Catalyst } \\
\text { codes }\end{array}$ & Compositions & $\begin{array}{c}\text { Treatment/ } \\
\text { Temperature } \\
\left({ }^{\circ} \mathrm{C}\right)\end{array}$ & $\begin{array}{l}\text { Time } \\
\text { (h) }\end{array}$ & $\begin{array}{c}\mathrm{S}_{\mathrm{BET}} \\
\left(\mathrm{m}^{2} / \mathrm{g}\right)\end{array}$ & $\begin{array}{c}\text { Ave. Pore } \\
\text { Diameter } \\
(\mathrm{nm})\end{array}$ \\
\hline \multirow{3}{*}{$99 \mathrm{FeA}$} & \multirow{3}{*}{$\begin{array}{c}99 w \mathrm{wt}^{\%} \mathrm{Fe}-1 \\
\mathrm{wt} \% \mathrm{Al}_{2} \mathrm{O}_{3}\end{array}$} & drying / 110 & 12 & & \\
\hline & & calcination / 300 & 6 & 59 & 10.4 \\
\hline & & reduction/500 & 12 & 12 & 52.1 \\
\hline \multirow{3}{*}{ 99FeAK } & \multirow{3}{*}{$\begin{array}{c}98 \mathrm{wt} \% \mathrm{Fe}-1 \\
\mathrm{wt} \% \mathrm{Al}_{2} \mathrm{O}_{3}-1 \\
\text { wt } \% \mathrm{~K}\end{array}$} & drying / 110 & 12 & & \\
\hline & & calcination / 300 & 6 & 56 & \\
\hline & & reduction/500 & 12 & 14 & \\
\hline \multirow{3}{*}{ 99FeAPt } & \multirow{3}{*}{$\begin{array}{c}98 \mathrm{wt} \% \mathrm{Fe}-1 \\
\mathrm{wt} \% \mathrm{Al}_{2} \mathrm{O}_{3}-1 \\
\text { wt } \% \mathrm{Pt}\end{array}$} & drying / 110 & 12 & & \\
\hline & & calcination / 300 & 6 & 51 & \\
\hline & & reduction/500 & 12 & 10 & \\
\hline \multirow{3}{*}{$10 \mathrm{FeA}-\mathrm{W}$} & \multirow{3}{*}{$\begin{array}{c}10 \mathrm{wt} \% \mathrm{Fe}-90 \\
\mathrm{wt} \% \mathrm{Al}_{2} \mathrm{O}_{3}\end{array}$} & drying / 110 & 12 & & \\
\hline & & calcination / 300 & 6 & 182 & 8.0 \\
\hline & & reduction/500 & 12 & 164 & 7.9 \\
\hline \multirow{3}{*}{$10 \mathrm{FeA}-\mathrm{A} / \mathrm{E}$} & \multirow{3}{*}{$\begin{array}{c}10 \mathrm{wt} \% \mathrm{Fe}-90 \\
\mathrm{wt} \% \mathrm{Al}_{2} \mathrm{O}_{3}\end{array}$} & drying / 110 & 12 & & \\
\hline & & calcination / 300 & 6 & 166 & 9.1 \\
\hline & & reduction/500 & 12 & 138 & 9.5 \\
\hline \multirow{3}{*}{$20 \mathrm{FeA}-\mathrm{A} / \mathrm{E}$} & \multirow{3}{*}{$\begin{array}{c}20 \mathrm{wt} \% \mathrm{Fe}-80 \\
\mathrm{wt} \% \mathrm{Al}-\mathrm{La}\end{array}$} & drying / 60 110 & 24 & & \\
\hline & & calcination / 300 & 6 & 156 & 7.7 \\
\hline & & reduction/500 & 12 & 112 & 8.1 \\
\hline
\end{tabular}

BET surface areas of calcined and reduced samples of $99 \mathrm{FeA}$ are $59 \mathrm{~m}^{2} / \mathrm{g}$ and $12 \mathrm{~m}^{2} / \mathrm{g}$ respectively. Addition of $\mathrm{K}$ or Pt promoter doesn't affect the surface area of unsupported samples materially. Given very similar surface areas, the unsupported Fe samples are useful polycrystalline materials for study of effects of promoter on $\mathrm{CO}$ adsorption/desorption properties. BET surface areas of calcined and reduced samples of $10 \mathrm{FeA}-\mathrm{W}$ prepared by aqueous impregnation are $182 \mathrm{~m}^{2} / \mathrm{g}$ and $164 \mathrm{~m}^{2} / \mathrm{g}$ respectively (see Table 1). Both values are larger than 
surface areas of $10 \mathrm{FeA}-\mathrm{A} / \mathrm{E}$ and $20 \mathrm{FeA}-\mathrm{A} / \mathrm{E}$ samples prepared by evaporative deposition in acetone/ethanol. This observation is logical given that the alumina supports for $10 \mathrm{Fe} A-\mathrm{A} / \mathrm{E}$ and 20FeA-A/E samples were pre-calcined before their use in preparation of the iron catalysts; moreover the 20FeA-A/E sample is supported on a La-stabilized $\mathrm{Al}_{2} \mathrm{O}_{3}$, pre-calcined at high temperature. The surface areas and average pore diameters of $10 \mathrm{Fe} A-\mathrm{A} / \mathrm{E}$ and $20 \mathrm{Fe} \mathrm{A}-\mathrm{A} / \mathrm{E}$ samples are nevertheless suitable for FTS. Since these supports were pre-stabilized, it is unlikely that the significant decreases in BET surface area during reduction are due to breakdown of the support; rather they are likely due to blockage of smaller pores by large metal crystallites formed during reduction.

\section{B. TGA-TPR Measurements}

\section{99FeA Catalyst}

\section{TPHe measurement.}

The TPHe-TGA decomposition pattern of dried samples in helium is shown in Figure 4. The differentiated curve is characterized by overlapping peaks around $80-120^{\circ} \mathrm{C}, 150-300^{\circ} \mathrm{C}$, and $320-400^{\circ} \mathrm{C}$. The peak at $80-100^{\circ} \mathrm{C}$ is easily assigned to removal of physically adsorbed water. Other peaks starting at $150-300^{\circ} \mathrm{C}$ are probably due to decomposition of iron hydroxide, $\mathrm{Fe}(\mathrm{OH})_{3}$, to $\alpha-\mathrm{FeO}(\mathrm{OH})$ and $\mathrm{Fe}_{2} \mathrm{O}_{3}$. The third peak between $320-400^{\circ} \mathrm{C}$ is probably due to decomposition of remained $\alpha-\mathrm{FeO}(\mathrm{OH})$ to $\mathrm{Fe}_{2} \mathrm{O}_{3}[3]$.

\section{TGA-TPR measurement by $\mathrm{H}_{2}$.}

The TGA-TPR pattern for direct reduction of dried samples in hydrogen (no calcination) is shown in Figure 5. As in the TPHe, the peaks around 100 and $400^{\circ} \mathrm{C}$ are attributed to water removal and decomposition of iron hydroxides. However, the peaks at about 267 and $286^{\circ} \mathrm{C}$ may be due to the reduction of $\mathrm{Fe}_{2} \mathrm{O}_{3}$ to $\mathrm{Fe}_{3} \mathrm{O}_{4}[4,5]$. In fact, some $\mathrm{Fe}_{2} \mathrm{O}_{3}$ is visible during the precipitation process [5]:

$$
3 \mathrm{Fe}_{2} \mathrm{O}_{3}+\mathrm{H}_{2} \rightarrow 2 \mathrm{Fe}_{3} \mathrm{O}_{4}+\mathrm{H}_{2} \mathrm{O}
$$

The peak with a maximum at $503^{\circ} \mathrm{C}$ is due to a second reduction step from $\mathrm{Fe}_{3} \mathrm{O}_{4}$ to the metallic iron [5]:

$$
\mathrm{Fe}_{3} \mathrm{O}_{4}+4 \mathrm{H}_{2} \rightarrow 3 \mathrm{Fe}+4 \mathrm{H}_{2} \mathrm{O}
$$

Weight losses associated with the peak at $286^{\circ} \mathrm{C}$ and the peak at $503^{\circ} \mathrm{C}$ in Figure 5 are approximately $2.4 \%$ and $20.9 \%$, respectively. The later value is about 8 times larger than the 
former one consistent with the theoretical weight loss of oxygen calculated from the reduction reactions in the previous two paragraphs.

\section{TGA-TPR measurement during reduction in $\mathrm{CO}$.}

The TGA-TPR pattern for direct reduction of the dried 99FeA sample in CO (no calcination) is shown in Figure 6. The profile is different from that for $\mathrm{H}_{2}$ reduction. The peaks with maxima at 364,468 , and $605^{\circ} \mathrm{C}$ are probably due to the reduction of (a) $\mathrm{Fe}_{3} \mathrm{O}_{4}$ to $\mathrm{FeO}$ (Eqn. 3); (b) of $\mathrm{FeO}$ to $\mathrm{Fe}$ (Eqn. 4) and of $\mathrm{Fe}$ to Haag carbide (Eqn. 5); and (c) of $\mathrm{FeO}$ interacting strongly with $\mathrm{Al}_{2} \mathrm{O}_{3}$ to $\mathrm{Fe}$ (also Eqn. 4) and $\mathrm{Fe}$ to Haag carbide (also Eqn. 5) [6]. The negative peak at $679^{\circ} \mathrm{C}$ (mass increase) is probably due to deposition of carbon. These results need to be followed up with $\mathrm{XRD}$ of samples treated in $\mathrm{CO}$ at different temperatures.

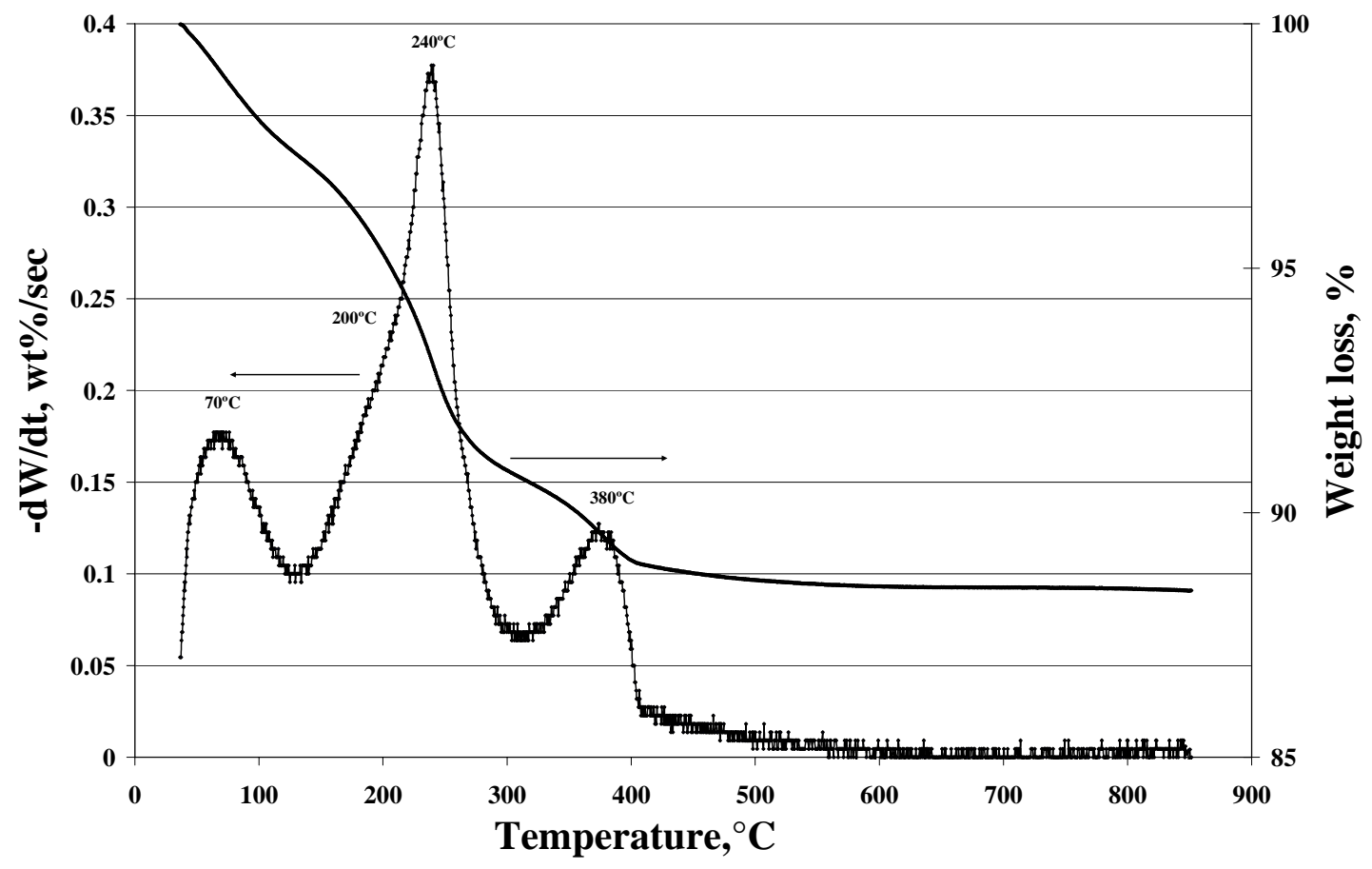

Figure 4 TPHe/TGA spectrum of sample 99FeA 


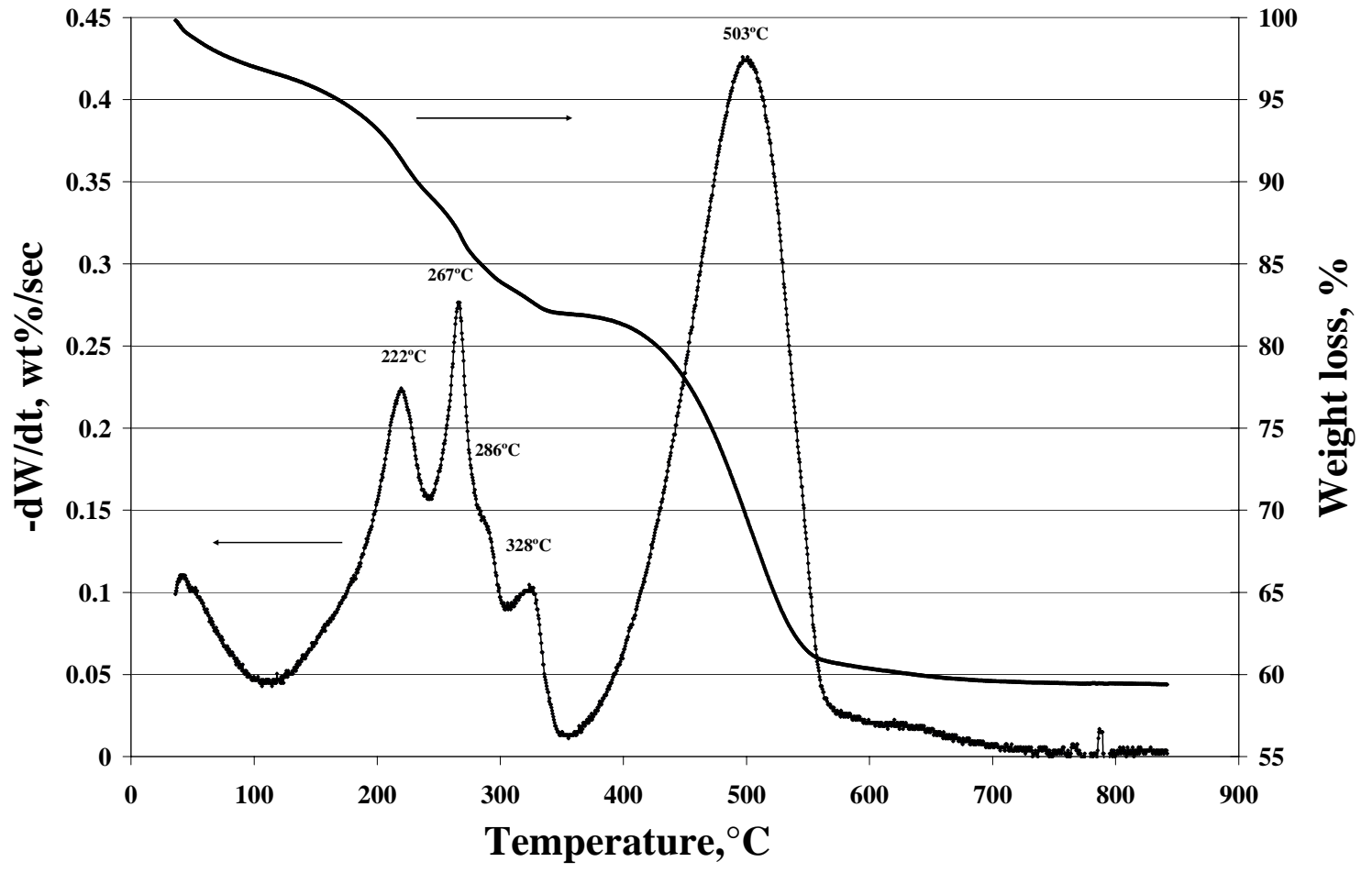

Figure 5 TGA-TPR spectrum for $\mathrm{H}_{2}$ reduction of sample $99 \mathrm{FeA}$ after calcination.

$$
\begin{aligned}
& 2 \mathrm{Fe}_{3} \mathrm{O}_{4}+2 \mathrm{CO} \rightarrow 6 \mathrm{FeO}+2 \mathrm{CO}_{2} \\
& \mathrm{FeO}+\mathrm{CO} \rightarrow \mathrm{Fe}+\mathrm{CO}_{2} \\
& 15 \mathrm{Fe}+12 \mathrm{CO} \rightarrow 3 \mathrm{Fe}_{5} \mathrm{C}_{2}+6 \mathrm{CO}_{2}
\end{aligned}
$$




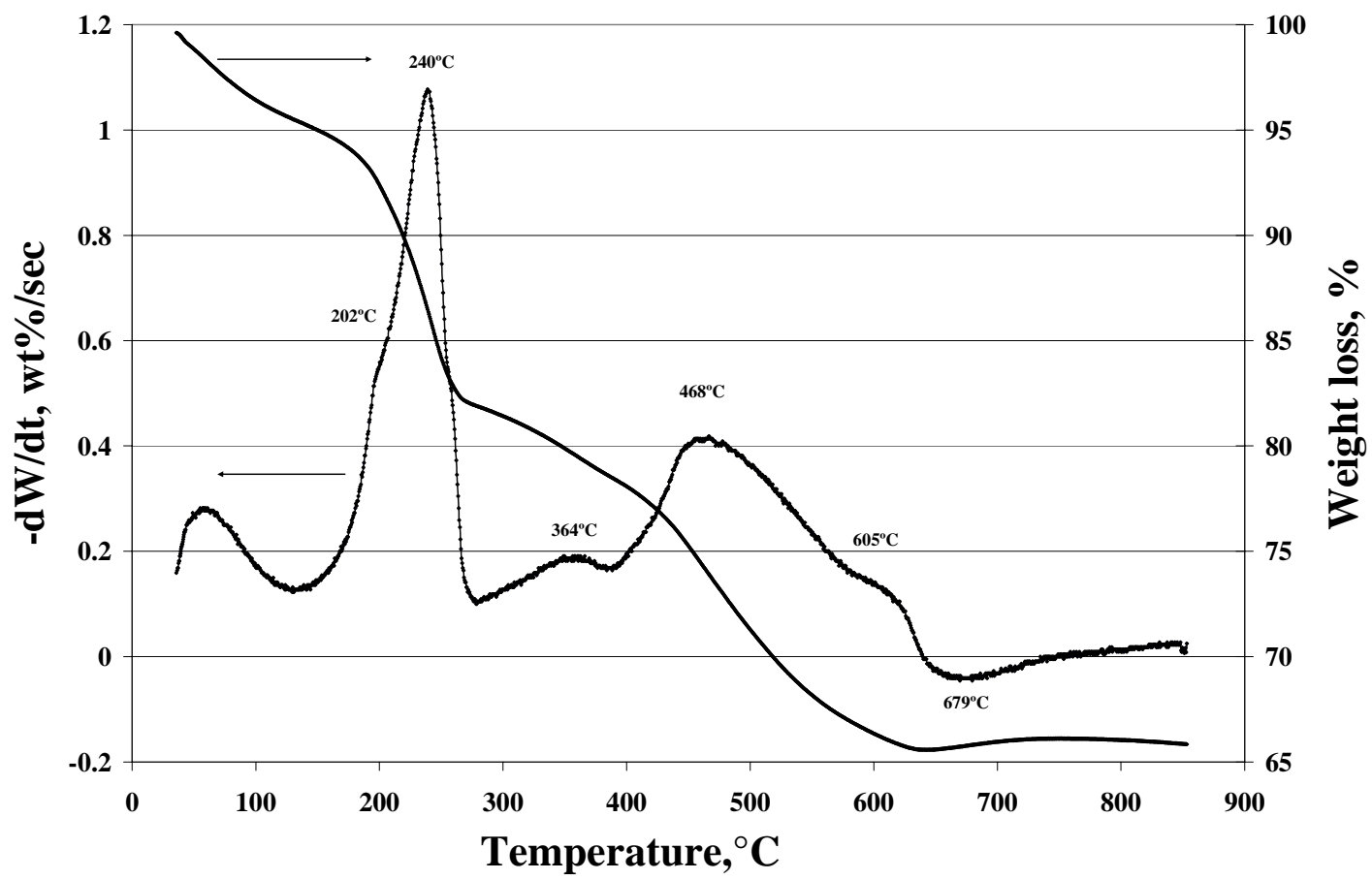

Figure 6 TGA-TPR spectrum for CO reduction of sample 99FeA before calcination.

\section{99 FeAK Catalyst}

\section{TPHe measurement.}

The TPHe pattern of dried 99FeAK sample in helium is shown in Figure 7. Two main peaks appear at $237^{\circ} \mathrm{C}$ and $359^{\circ} \mathrm{C}$, similar to the peaks attributed to decomposition of iron hydroxide, $\mathrm{Fe}(\mathrm{OH})_{3}$, to $\alpha-\mathrm{FeO}(\mathrm{OH})$ and $\alpha-\mathrm{FeO}(\mathrm{OH})$ to $\mathrm{Fe}_{2} \mathrm{O}_{3}[3]$ in the TPR profile of sample $99 \mathrm{FeA}$ in Figure 4.

\section{TGA-TPR measurements by $\mathrm{H}_{2}$.}

The TGA-TPR pattern of a pre-dried 99FeAK sample in hydrogen is shown in Figure 8. The profile is similar to that of sample 99FeA (Figure 5) with the exception of a new peak appearing at high temperature $\left(809^{\circ} \mathrm{C}\right)$, which is probably due to reduction of potassium ferrite. The reduction peak for $\mathrm{Fe}_{3} \mathrm{O}_{4}$ is shifted to higher temperature $\left(554^{\circ} \mathrm{C}\right.$ relative to $\left.503^{\circ} \mathrm{C}\right)$ with a small shoulder peak at $606^{\circ} \mathrm{C}$, probably due to the reduction of $\mathrm{FeO}$ to $\mathrm{Fe}$. The $+51^{\circ} \mathrm{C}$ shift indicates that reduction of potassium-promoted iron is more difficult than for the unpromoted catalyst. 


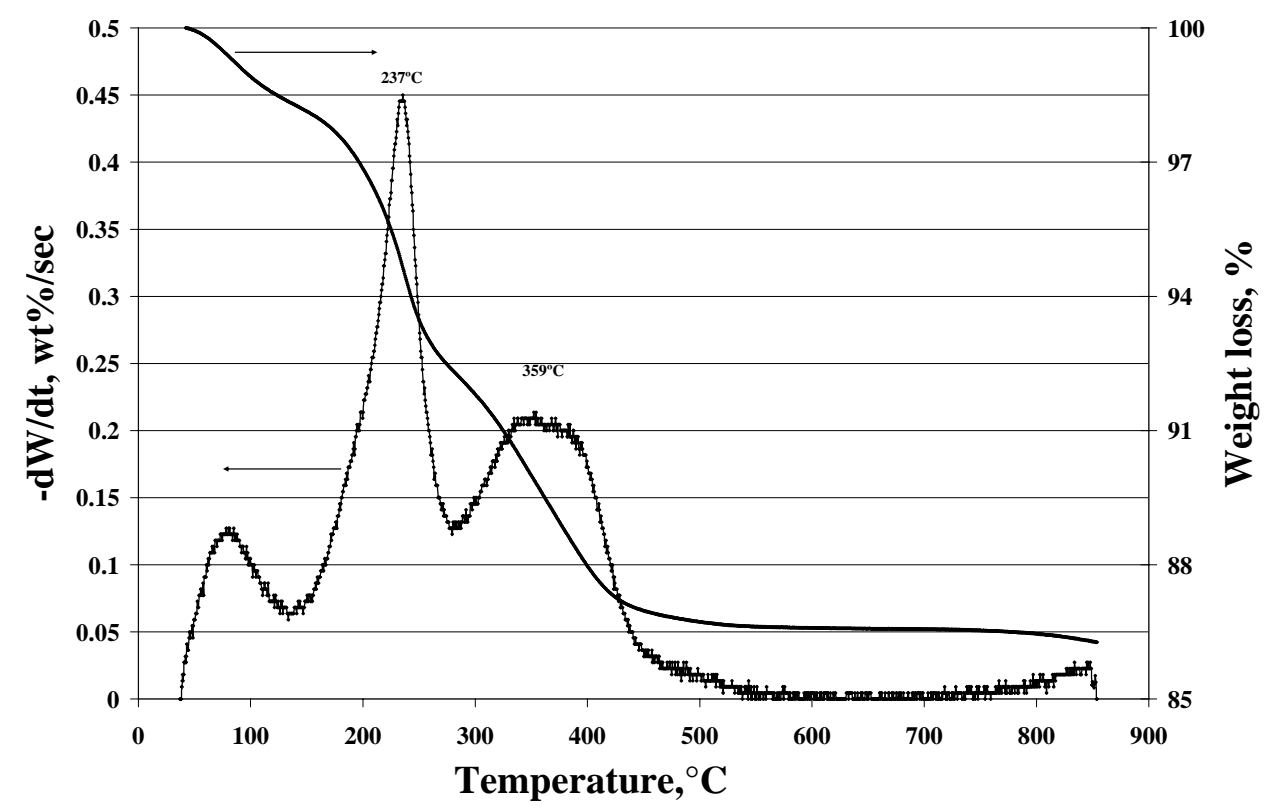

Figure 7 TPHe/TGA spectrum of 99FeAK sample

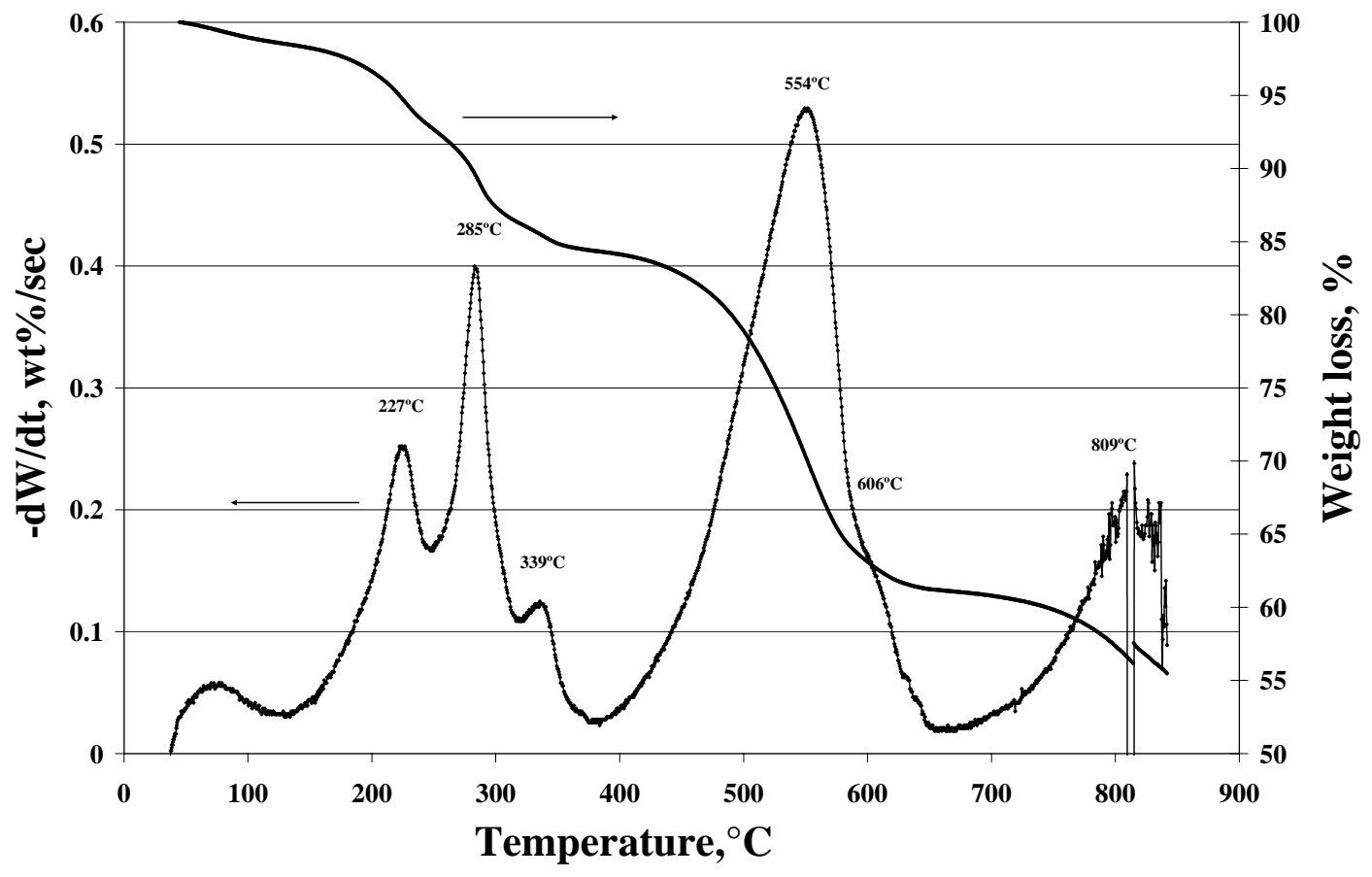

Figure 8 TGA-TPR pattern by $\mathrm{H}_{2}$ of $99 \mathrm{FeAK}$ sample 


\section{99FeAPt Catalyst}

\section{TPHe measurement.}

The TPHe/TGA pattern of dried 99FeAPt sample in He is shown in Figure 9. An obvious difference of this TGA pattern with those of both 99FeA and 99FeAK samples is two additional small peaks at around $423^{\circ} \mathrm{C}$ and $619^{\circ} \mathrm{C}$, which are possibly due to the Pt-catalyzed reduction of $\mathrm{FeO}_{\mathrm{x}}$ and $/ \mathrm{orAl}_{2} \mathrm{O}_{3}$ to $\mathrm{PtAl}_{\mathrm{x}}$ or PtFe.

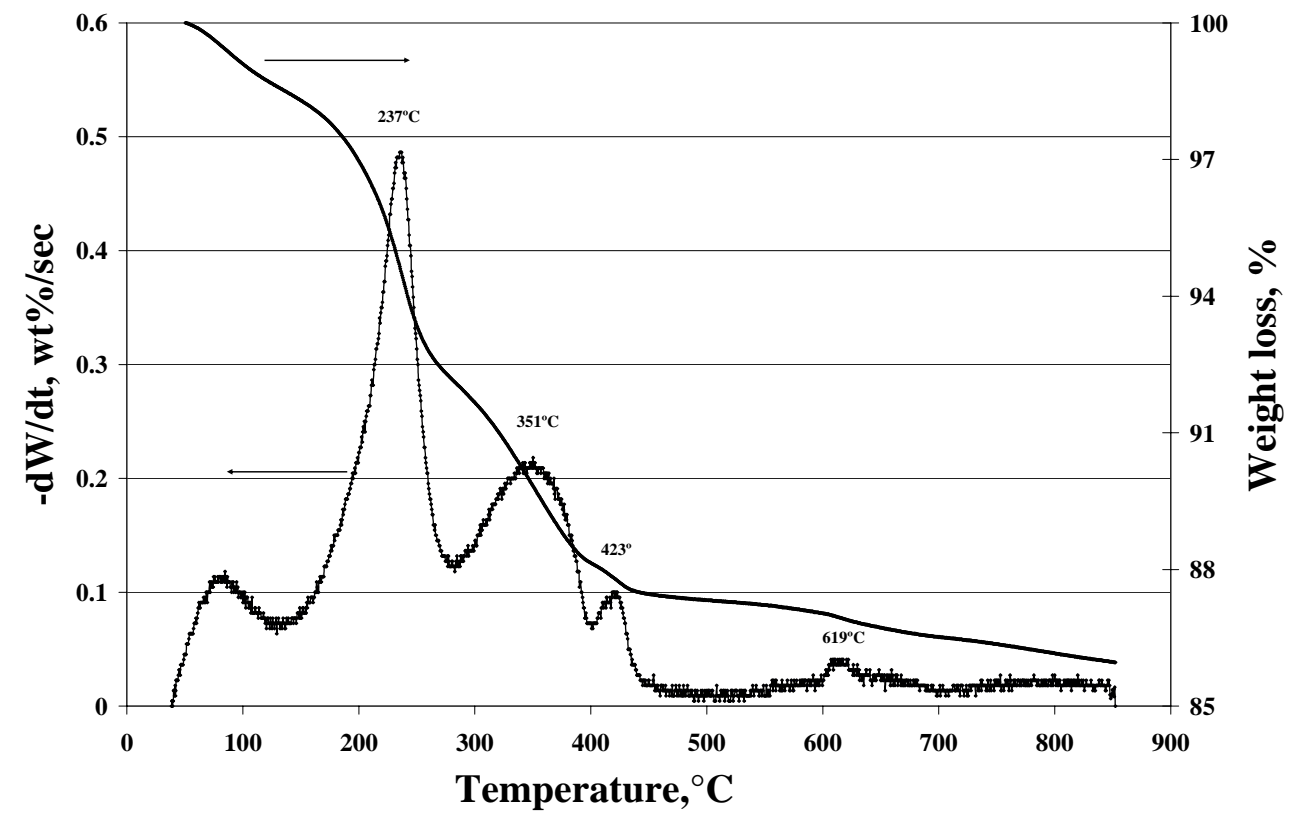

Figure 9 TPHe/TGA spectrum of 99FeAPt sample

TGA-TPR measurements by $\mathrm{H}_{2}$.

The TGA-TPR pattern of dried 99FeAPt sample in hydrogen is shown in Figure 10. The most important differences with the corresponding spectrum for 99FeA (Figure 5) are shifts of the peaks at $146,237,283$, and $294^{\circ} \mathrm{C}$ to lower temperatures compared to unpromoted Fe. This is consistent with the expectation that Pt would assist the reduction of Fe. 


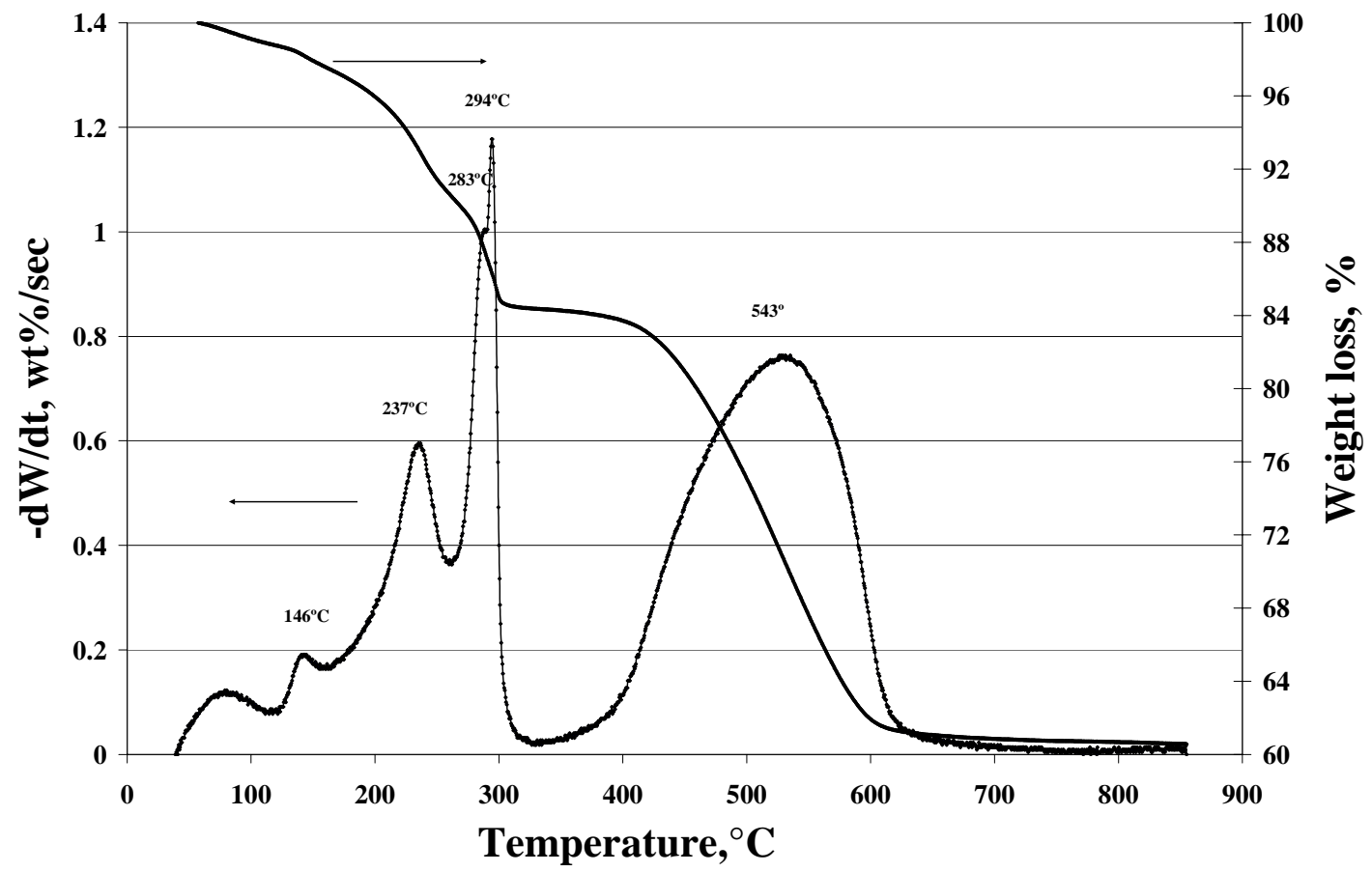

Figure 10 TGA-TPR pattern by $\mathrm{H}_{2}$ of $99 \mathrm{FeAPt}$ sample

\section{10FeA Catalysts}

TGA-TPR measurements with $\mathrm{He}$ and $\mathrm{H}_{2}=$

The decomposition of $10 \% \mathrm{Fe} / \mathrm{Al}_{2} \mathrm{O}_{3}(10 \mathrm{FeA})$ catalysts in $\mathrm{He}$ is much simpler than that of $99 \mathrm{FeA}$ samples because the iron precursor in the $10 \mathrm{FeA}$ samples is iron nitrate. TGA For example the He decomposition pattern of the $10 \mathrm{FeA}-\mathrm{W}$ catalyst (Figure 11) consists of two low temperature peaks at 213 and $258^{\circ} \mathrm{C}$ attributed to decomposition of iron nitrate.

Figure 12 shows the TPR patterns of three $10 \mathrm{FeA}$ catalyst prepared by different methods, after drying at $110^{\circ} \mathrm{C}$ for $12 \mathrm{~h}$. Three large peaks at $155^{\circ} \mathrm{C}, 225^{\circ} \mathrm{C}$, and $305^{\circ} \mathrm{C}$ are observed for the dried $10 \mathrm{FeA}-\mathrm{W}$ sample. The peak at $155^{\circ} \mathrm{C}$ is attributed on the basis of the TPHe results to the decomposition of iron nitrate. Generally, the reduction reaction proceeds in a stepwise manner: $\alpha-\mathrm{Fe}_{2} \mathrm{O}_{3}$ (hematite) $\rightarrow \mathrm{Fe}_{3} \mathrm{O}_{4}$ (magnetite) $\rightarrow \mathrm{FeO}$ (wustite) $\rightarrow \alpha-\mathrm{Fe}$ (iron). The peak of the TPR profile at $225^{\circ} \mathrm{C}$ is the largest and represents a very complicated reduction stage. It consists of the process of reduction from $\alpha-\mathrm{Fe}_{2} \mathrm{O}_{3}$ to $\mathrm{Fe}_{3} \mathrm{O}_{4}$, then to $\mathrm{FeO}$. The peak at $305^{\circ} \mathrm{C}$ is assigned to the reduction of $\mathrm{FeO}$ to $\mathrm{Fe}$. The small broad peak from $400^{\circ} \mathrm{C}$ to $500^{\circ} \mathrm{C}$ is assigned to the reduction of iron oxide which has a strong action with alumina support to Fe. For the other two samples, FeA-A (acetone) and 10FeA-A/E (acetone/ethanol), three peaks are seen in their TPR patterns. 
The first one around $215^{\circ} \mathrm{C}$ is attributed not only to the combination of decomposition of Feacetone-polymers but also to the reduction process of $\alpha-\mathrm{Fe}_{2} \mathrm{O}_{3}$ to $\mathrm{Fe}_{3} \mathrm{O}_{4}$, and $\mathrm{Fe}_{3} \mathrm{O}_{4}$ to $\mathrm{FeO}$. The peaks at $300^{\circ} \mathrm{C}$ for $\mathrm{FeA}-\mathrm{A} / \mathrm{E}$ and at $340^{\circ} \mathrm{C}$ for $10 \mathrm{FeA}-\mathrm{A}$ are attributed to the reduction of $\mathrm{FeO}$ to Fe. The last peak around $450^{\circ} \mathrm{C}$ is assigned to the reduction of $\mathrm{Fe}$ oxide compounds formed with alumina support to $\mathrm{Fe}$.

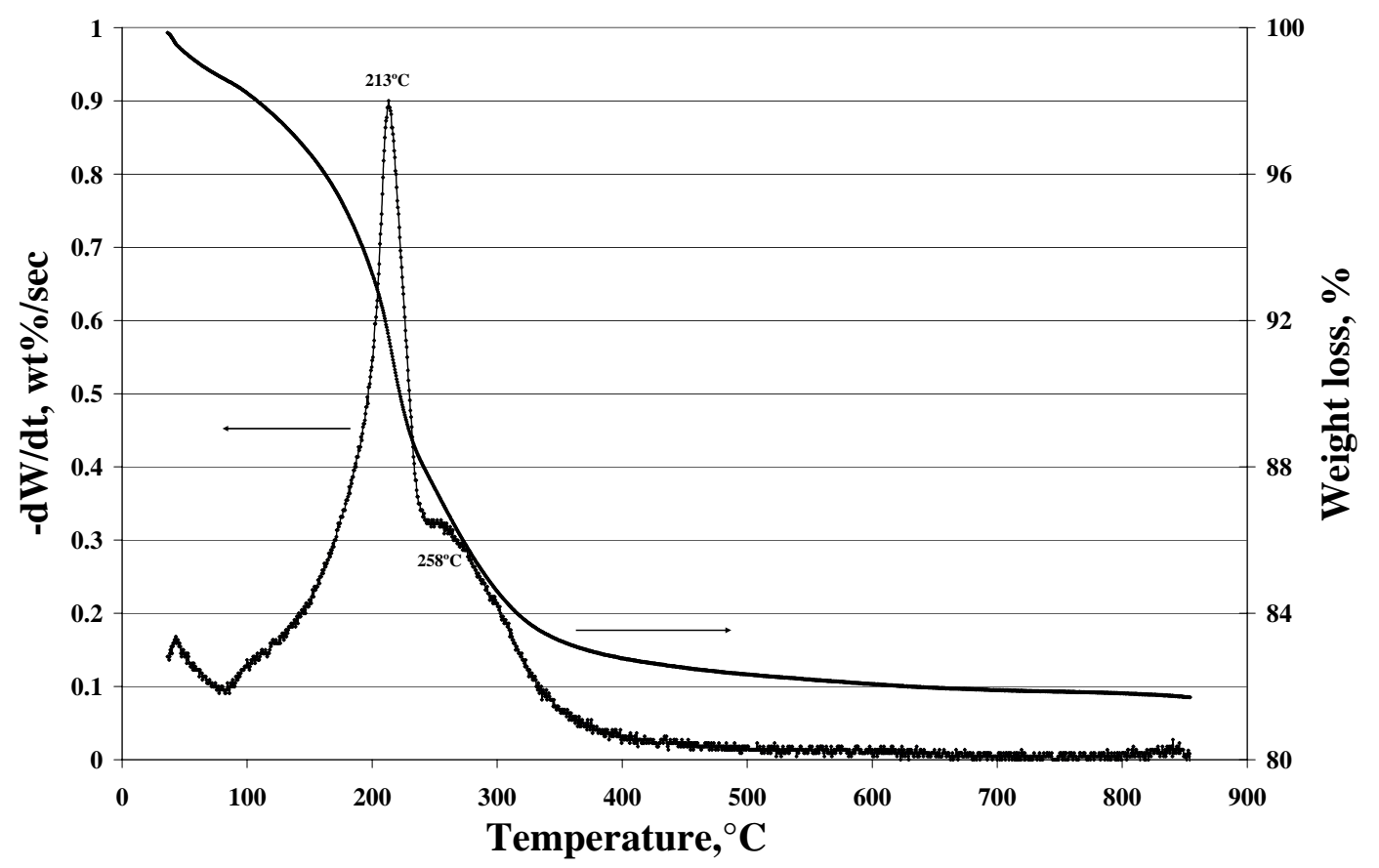

Figure 11 TPHe/TGA pattern of sample 10FeA-W 


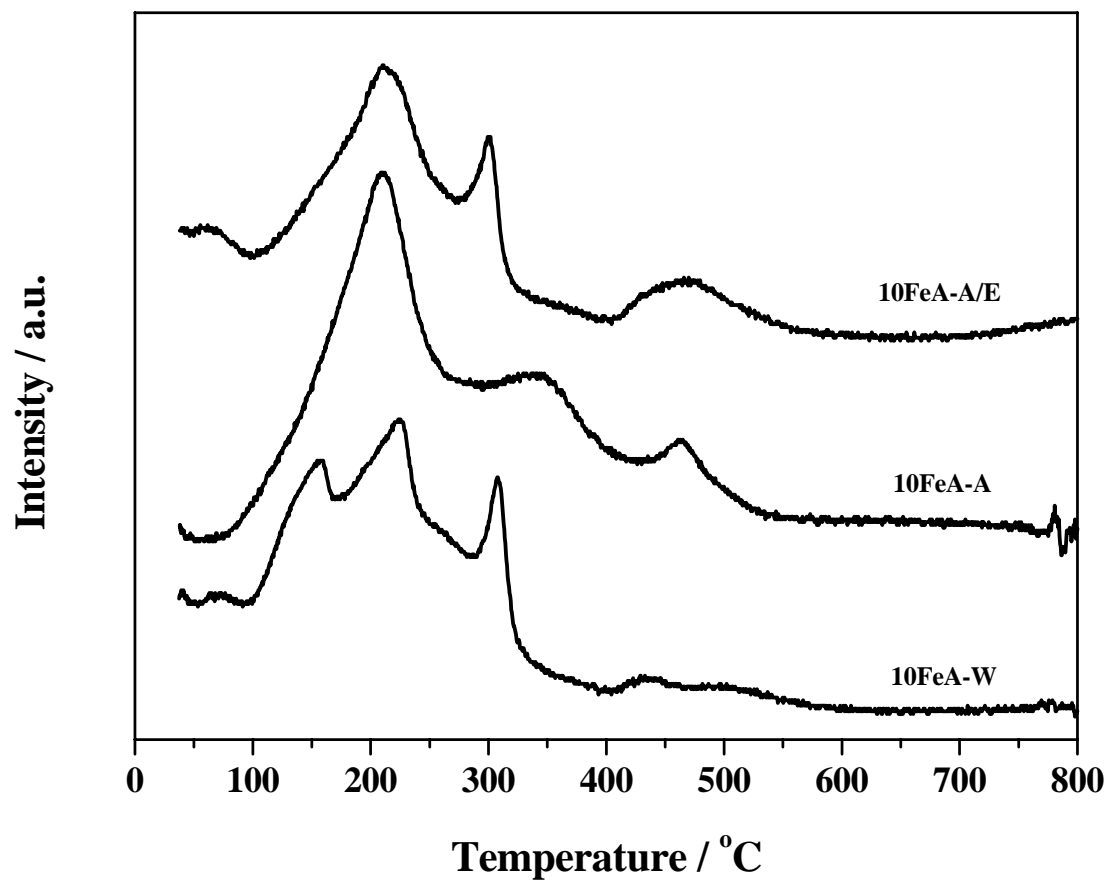

Figure 12 TPR patterns of 10FeA samples

\section{20FeA-A/E Catalysts}

$\underline{\mathrm{H}_{2}} \underline{\underline{T P R}}$.

The $\mathrm{H}_{2}$-TPR profiles of the $20 \mathrm{FeA}-\mathrm{A} / \mathrm{E}$ catalyst calcined in air at $300^{\circ} \mathrm{C}$ for $6 \mathrm{~h}$ are shown in Figure 13. The overlapping peaks of the TPR curve at $286^{\circ} \mathrm{C}$ are attributed to the phase transformations of $\mathrm{Fe}_{2} \mathrm{O}_{3}$ to $\mathrm{Fe}_{3} \mathrm{O}_{4}$ and $\mathrm{Fe}_{3} \mathrm{O}_{4}$ to $\mathrm{FeO}$. There is a shoulder peak followed the peak of $283^{\circ} \mathrm{C}$ due to the reduction from $\mathrm{FeO}$ to $\mathrm{Fe} .\left(283^{\circ} \mathrm{C}\right)$. The peak at $500^{\circ} \mathrm{C}$ is due to the reduction of $\mathrm{Fe}_{3} \mathrm{O}_{4}-\mathrm{Al}_{2} \mathrm{O}_{3}$ to $\mathrm{Fe}$. The catalyst can be largely reduced below about $370{ }^{\circ} \mathrm{C}$. 


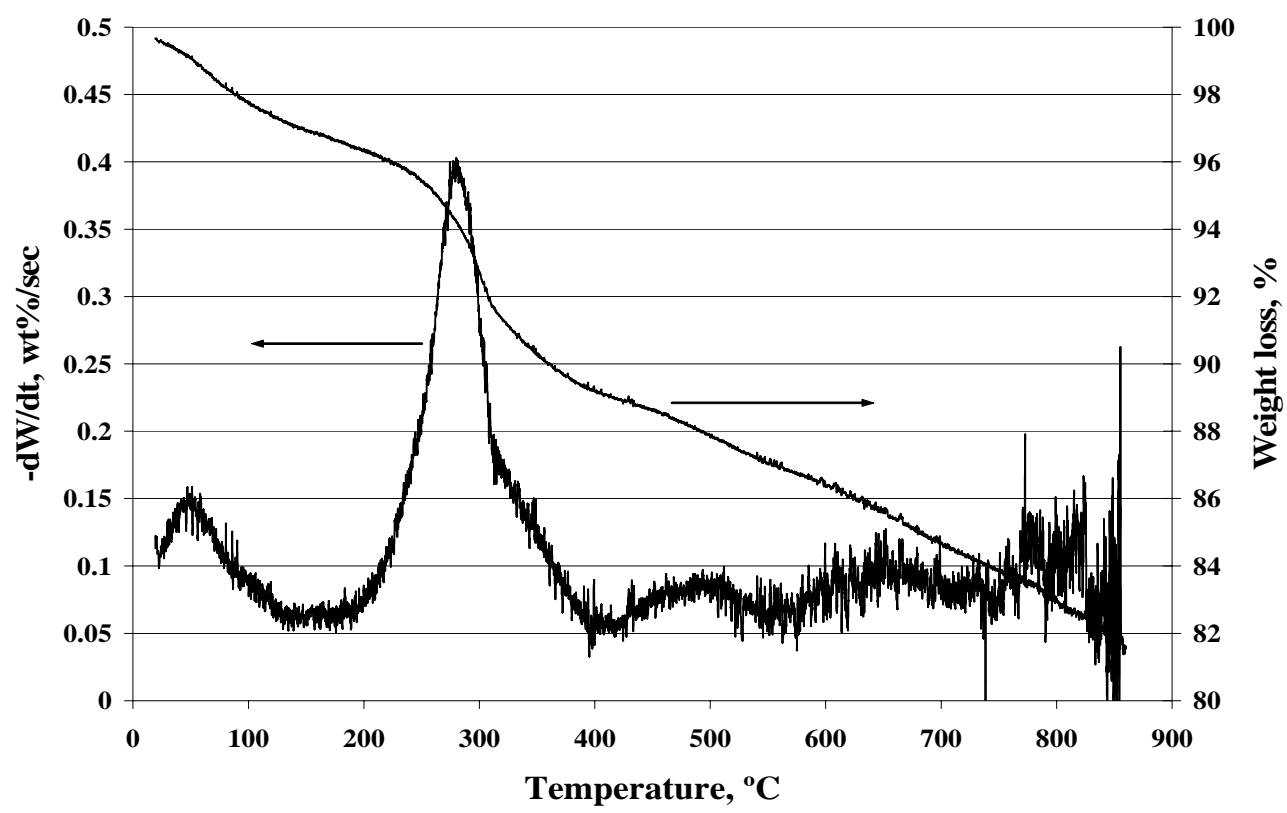

Figure 13 TGA-TPR patterns by $\mathrm{H}_{2}$ of $20 \mathrm{FeA}-\mathrm{A} / \mathrm{E}$ sample after calcination.

\section{C. $\mathrm{H}_{2}$ Chemisorption Measurements}

$\mathrm{H}_{2}$ chemisorption uptakes of the supported iron samples are listed in Table 2. The average $\mathrm{H}_{2}$ chemisorption uptakes for the $20 \mathrm{FeA}-\mathrm{A} / \mathrm{E}, 10 \mathrm{FeA}-\mathrm{A} / \mathrm{E}$, and $10 \mathrm{FeA}-\mathrm{W}$ catalysts are 455,253 , and $43 \mu \mathrm{mol} / \mathrm{g}$. Extents of reduction are 45, 60 and 49\%, Fe dispersions catalysts are 37, 48 and 9.8\%. The $37 \%$ and $48 \%$ dispersions are unusually high, and the average crystallite diameter remarkably low for the $10 \%$ and $20 \% \mathrm{Fe} /$ alumina catalyst prepared in acetone/ethanol. The dispersion for the catalyst prepared in aqueous environment is just right. However, the crystallite diameters for the $10 \mathrm{FeA}-\mathrm{A} / \mathrm{E}$ catalyst of $2.6 \mathrm{~nm}$ and the $20 \mathrm{FeA}-\mathrm{A} / \mathrm{E}$ catalyst of $3.3 \mathrm{~nm}$ are too small to be stable during FTS at high conversions where water partial pressures are likely to be high enough to oxidize these crystallites of high surface energy. To further detect the crystallite diameter, XRD and TEM techniques were used and the results are given in following sections. 
Table $2 \mathrm{H}_{2}$ Chemisorption Uptakes, EOR, and Dispersion of 10 and $20 \% \mathrm{Fe} / \mathrm{Al}_{2} \mathrm{O}_{3}$ Catalysts.

\begin{tabular}{|c|c|c|c|c|}
\hline Catalysts & $\begin{array}{c}\mathrm{H}_{2} \text { uptake }^{\mathrm{a}} \\
(\mu \mathrm{mol} / \mathrm{g} \text { catalyst })\end{array}$ & EOR,\% & \%D $^{\mathrm{b}}$ & $\mathrm{d}(\mathrm{nm})^{\mathrm{c}}$ \\
\hline $10 \mathrm{FeA}-\mathrm{W}$ & 43 & 49 & 9.8 & 12.6 \\
\hline $10 \mathrm{FeA}-\mathrm{A} / \mathrm{E}$ & 253 & 60 & 47.5 & 2.6 \\
\hline $20 \mathrm{FeA}-\mathrm{A} / \mathrm{E}$ & $455^{\mathrm{d}}$ & 45 & 37.4 & 3.3 \\
\hline
\end{tabular}

a. Catalysts calcined at $200^{\circ} \mathrm{C}$ in argon for $3 \mathrm{~h}$ followed by $\mathrm{H}_{2}$ reduction at $1{ }^{\circ} \mathrm{C} / \mathrm{min}$ from $200^{\circ} \mathrm{C}$ (after pretreatment) to $300^{\circ} \mathrm{C}$ with a hold for $16 \mathrm{~h}$ at $300^{\circ} \mathrm{C}$, and then was run $\mathrm{H}_{2}$ uptake.

b. $\% \mathrm{D}=\mathrm{C}_{2} \mathrm{X} /(100 \mathrm{fw}): \mathrm{C}_{2}$ is a constant, $\mathrm{Fe}=1.12 ; \mathrm{X}$ is the chemisorptive uptake; $\mathrm{f}$ is the fraction of active element present in the metallic state; and $\mathrm{w}$ is the weight fraction of the catalytic element present as either metal or oxide.

c. $\mathrm{d}=\mathrm{C}_{1} /(\% \mathrm{D}): \mathrm{C}_{1}$ is a constant for a given catalytic phase, $\mathrm{Fe}=123$.

d. This catalyst was bulk reduced by $\mathrm{H}_{2}$ at $500^{\circ} \mathrm{C}$ for $12 \mathrm{~h}$ before measurement of $\mathrm{H}_{2}$ uptake.

\section{XRD Measurements}

XRD measurements were conduced on all iron catalysts for both calcined and reduced samples. The XRD spectra in Figure 14 are the diffraction patterns of the catalyst samples taken after calcination in air at $300^{\circ} \mathrm{C}$ for $6 \mathrm{~h}$. The peaks at $33^{\circ}, 35.7^{\circ}, 41^{\circ}, 49.6^{\circ}, 54.2^{\circ}, 62.5^{\circ}$, and $64.2^{\circ}$ in the diffraction pattern of $99 \mathrm{FeA}$ sample, shown in Figure 14 curve D, are attributed to $\alpha$ $\mathrm{Fe}_{2} \mathrm{O}_{3}$ phase. It indicates that $\alpha-\mathrm{Fe}_{2} \mathrm{O}_{3}$ phase is formed after calcination at $300^{\circ} \mathrm{C}$, in agreement with the conclusion drawn from TPHe-TGA experiments. The diffraction patterns of three supported iron catalysts are similar with the diffraction pattern of pure alumina support, not shown in the figure, indicating there is not iron based phase formed on the surface of those samples. However, TPHe-TGA measurements reveal decomposition of iron compounds to iron oxide is finished before $300^{\circ} \mathrm{C}$. Thus, the possibility is that the portion of iron oxide on supported iron catalysts is too small to be detected by XRD technique.

The XRD patterns of the catalyst samples after reduction in $\mathrm{H}_{2} / \mathrm{He}$ at $500^{\circ} \mathrm{C}$ for $12 \mathrm{~h}$ are shown in Figure 15. Two iron phases can be detected in the XRD patterns of 99FeA sample based on the characteristic diffraction peaks. The peaks at $44.5^{\circ}$ and $65.5^{\circ}$ are attributed to $\alpha$-Fe phase and the other peaks are assigned to the magnetite $\mathrm{Fe}_{3} \mathrm{O}_{4}$ phase. For supported iron catalysts, $\alpha$-Fe phase also can be found in the XRD patterns at $44.5^{\circ}$. The XRD curves between $40^{\circ}$ and $50^{\circ}$ of alumina-supported iron catalysts were enlarged in Figure 16. Iron crystallite sizes of all supported iron catalysts were calculated by Scherrer equation: 


$$
\mathrm{D}=0.9 \lambda /(\beta \cos \theta)
$$

where D - Crystallite size, $\lambda$ - X-ray wavelength, $\beta$ - Full width at half maximum (FWHM) of the peak, and $\theta$ - Angle at FWHM.

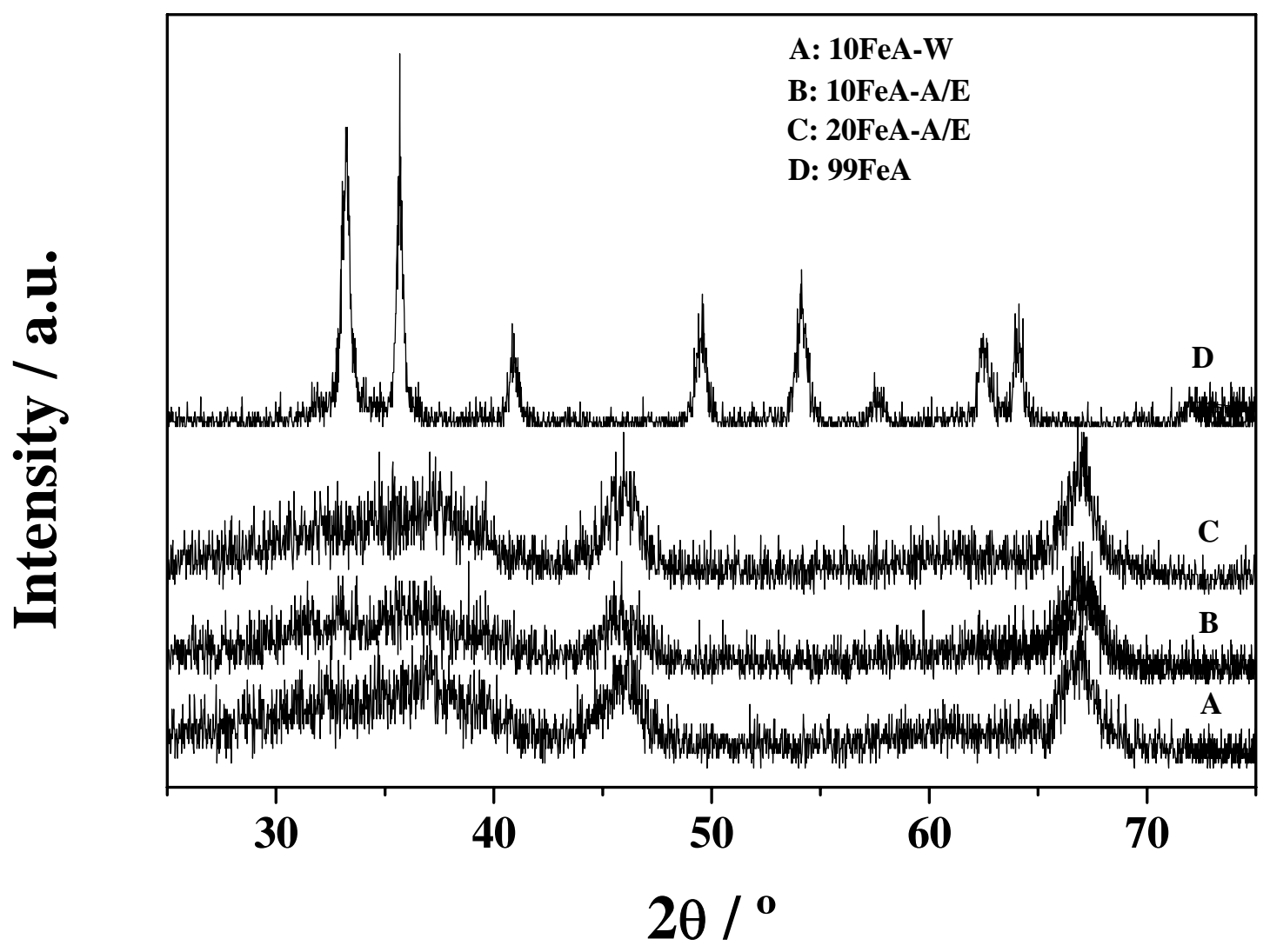

Figure 14 XRD Patterns of Iron Catalysts after Calcination at $300^{\circ} \mathrm{C}$ for $6 \mathrm{~h}$ 


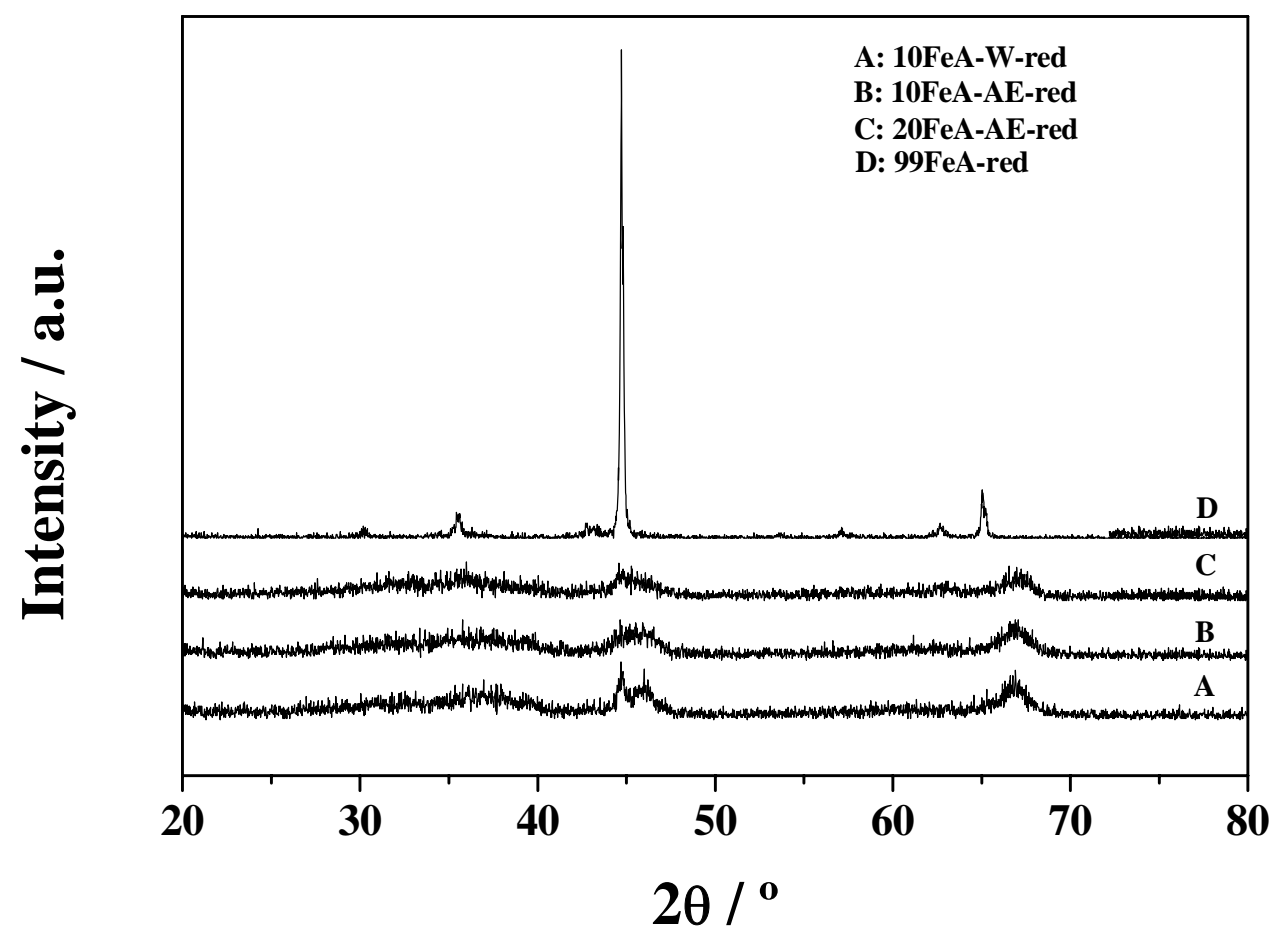

Figure 15 XRD Patterns of Iron Catalysts after Reduction at $500^{\circ} \mathrm{C}$ for $12 \mathrm{~h}$

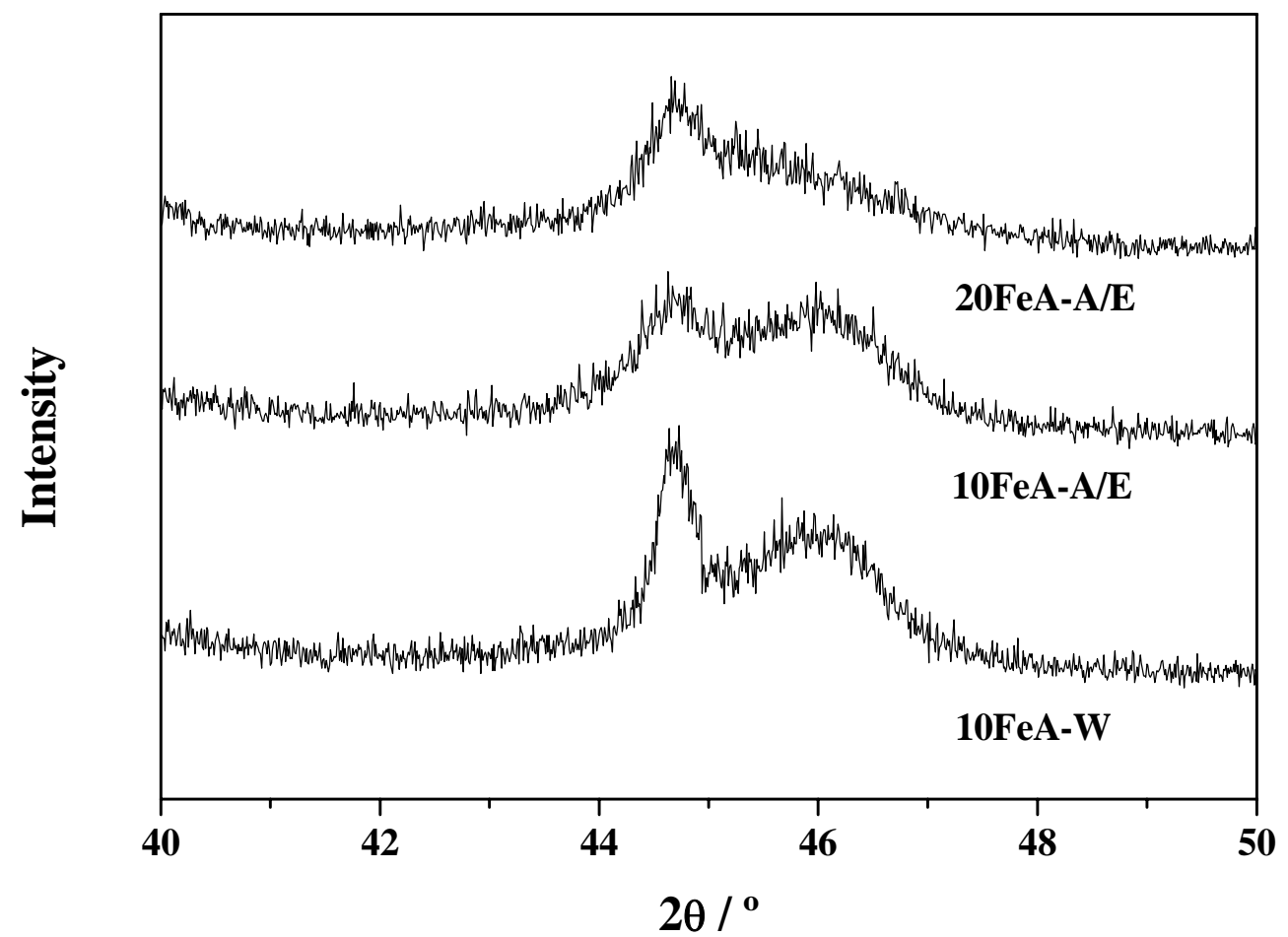

Figure 16 XRD Patterns of Iron Catalysts in $40 \sim 50^{\circ}$ after Reduction at $500^{\circ} \mathrm{C}$ for $12 \mathrm{~h}$ 
Iron crystallite diameters estimated by $\mathrm{XRD}, \mathrm{H}_{2}$ chemisorption and TEM measurements are compared in Table 3.

Table 3 Comparison of iron crystallite diameters determined by XRD, TEM, and $\mathrm{H}_{2}$ chemisorption.

\begin{tabular}{cccc}
\hline Samples & XRD $(\mathrm{nm})$ & $\mathrm{H}_{2}$ Chemisorption $(\mathrm{nm})$ & TEM $(\mathrm{nm})$ \\
\hline 10FeA-W & 20.1 & 12.6 & 20 \\
10FeA-A/E & 6.0 & 6.2 & $5 \sim 10$ \\
20FeLaA-A/E & 10.1 & 4.2 & $\sim 10$ \\
\hline
\end{tabular}

\section{E. TEM Measurements and EDX}

HRTEM was utilized to study the surface morphology of iron catalyst samples. The surface morphology includes iron metal particle sizes and surface phases. The TEM images of 10FeAA/E catalyst (left) and 10FeA-W (right) are shown in Figure 17 and of 20FeA-A/E (left) and 99FeA (right) in Figure 18. The black spots on images are $\alpha-\mathrm{Fe}$; this was confirmed by the ring images at corner of figures. The iron metal sizes estimated from images are listed in Table 3.
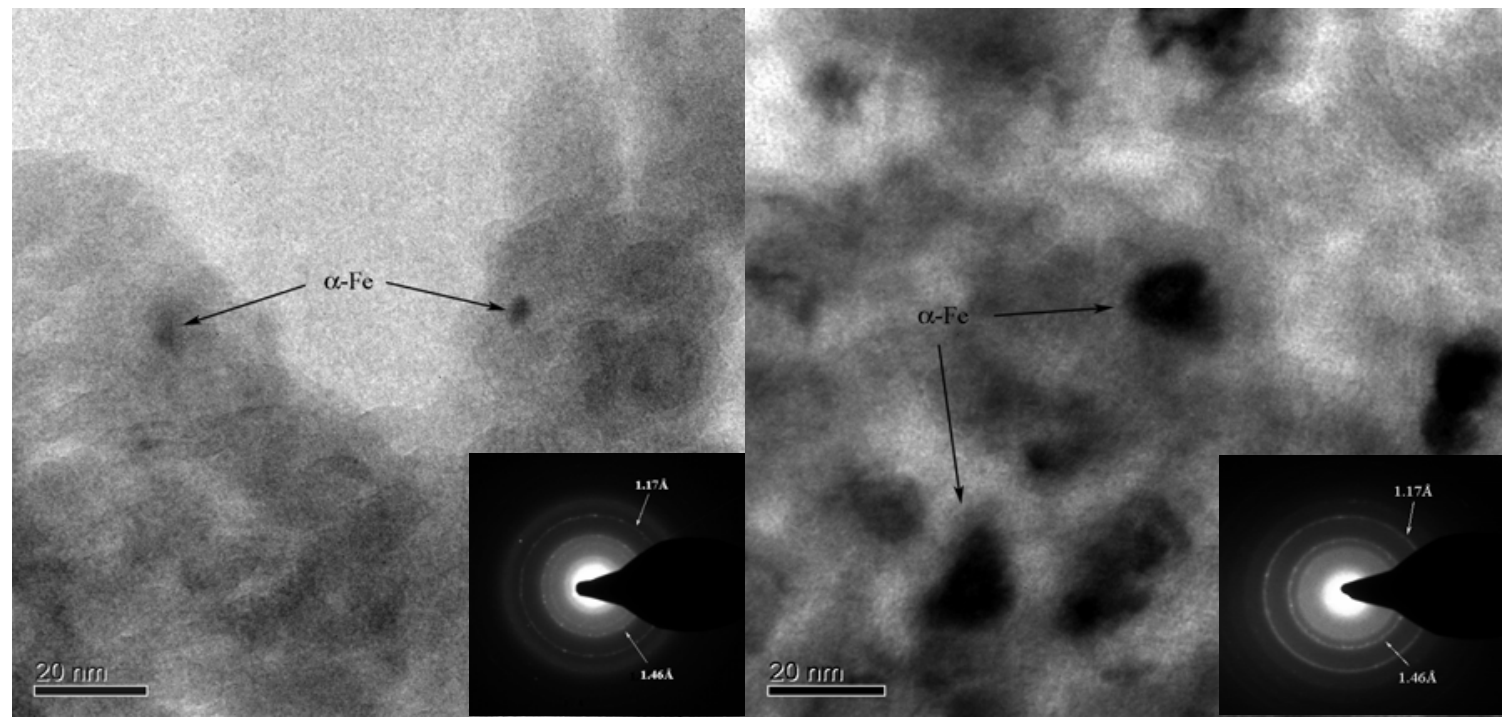

Figure 17 TEM Images of 10FeA-A/E (left) and 10FeA-W (right) after Reduction at $500^{\circ} \mathrm{C}$ for $12 \mathrm{~h}$ 

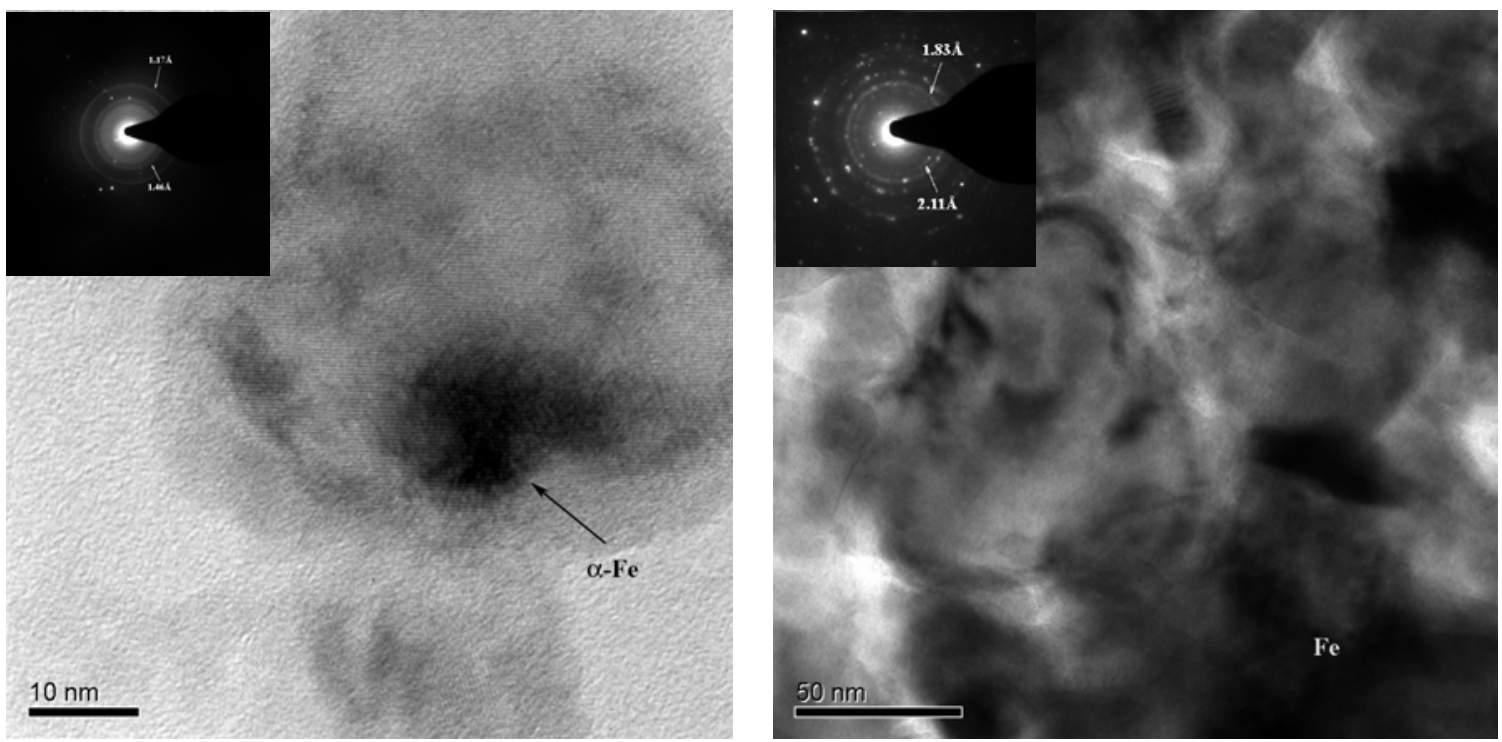

Figure 18 TEM Images of 20FeA-A/E (left) and 99FeA (right) after Reduction at $500^{\circ} \mathrm{C}$ for $12 \mathrm{~h}$

Energy Dispersion X-ray (EDX) analysis of alumina-supported iron catalysts reduced at $500^{\circ} \mathrm{C}$ was conducted using a Tecnai F20 Analytical STEM. The resolution of the equipment for particle size identification was effectively about 5-10 $\mathrm{nm}$.

Figure 19, Figure 20 and Figure 21 are TEM images and their associated elemental energy dispersion profiles of oxygen, iron, and aluminum for $10 \mathrm{FeA}-\mathrm{W}, 10 \mathrm{FeA}-\mathrm{A} / \mathrm{E}$, and $20 \mathrm{FeA}-\mathrm{A} / \mathrm{E}$ catalysts, respectively. The bright areas in TEM images are attributed to iron crystallites, grey areas to catalyst support, and dark areas to the background (grid and/or holes). In the TEM image for $10 \mathrm{FeA}-\mathrm{W}$ (Figure 19 left) elemental energy dispersion analysis was conducted along a line intersecting three prominent bright spots; the element energy dispersions of $\mathrm{Al}, \mathrm{O}$, and $\mathrm{Fe}$ along the line are plotted in Figure 19 (right). The observation of three intense peaks in the Fe dispersion curve, distinct of those for $\mathrm{Al}$ and $\mathrm{O}$ curves, indicates that the bright spots are due to Fe crystallites of about $20 \mathrm{~nm}$ in diameter; that their curves track each other closely indicates that $\mathrm{Al}$ and $\mathrm{O}$ are associated with each other, i.e., in $\mathrm{Al}_{2} \mathrm{O}_{3}$ ). However, the elemental energy dispersion curves of $\mathrm{Fe}$ for the $10 \mathrm{FeA}-\mathrm{A} / \mathrm{E}$ catalyst is essentially flat and of low intensity; this is likely due to a predominance in these samples of small iron crystallites having dimensions of the same order or smaller than the instrumental resolution. The Fe dispersion curve for and 20FeAA/E, containing 3-4 small, overlapping peaks of low intensity suggests that some fraction of the Fe crystallites may be about $5-10 \mathrm{~nm}$ in diameter, while others might be smaller. The EDX 
results for these catalysts suggesting $20 \mathrm{~nm}$ diameter particles in the $10 \mathrm{Fe} \mathrm{A}-\mathrm{W}$ catalyst (prepared by aqueous impregna-tion) and $5-10 \mathrm{~nm}$ or smaller diameter crystallites in the two catalyst $(10 \mathrm{FeA}-\mathrm{A} / \mathrm{E}$, and $20 \mathrm{FeA}-\mathrm{A} / \mathrm{E})$ prepared by nonaqueous impregnation is very consistent with estimates of particle diameter from $\mathrm{H}_{2}$ chemisorption, TEM, and XRD measurements (see Table 3).
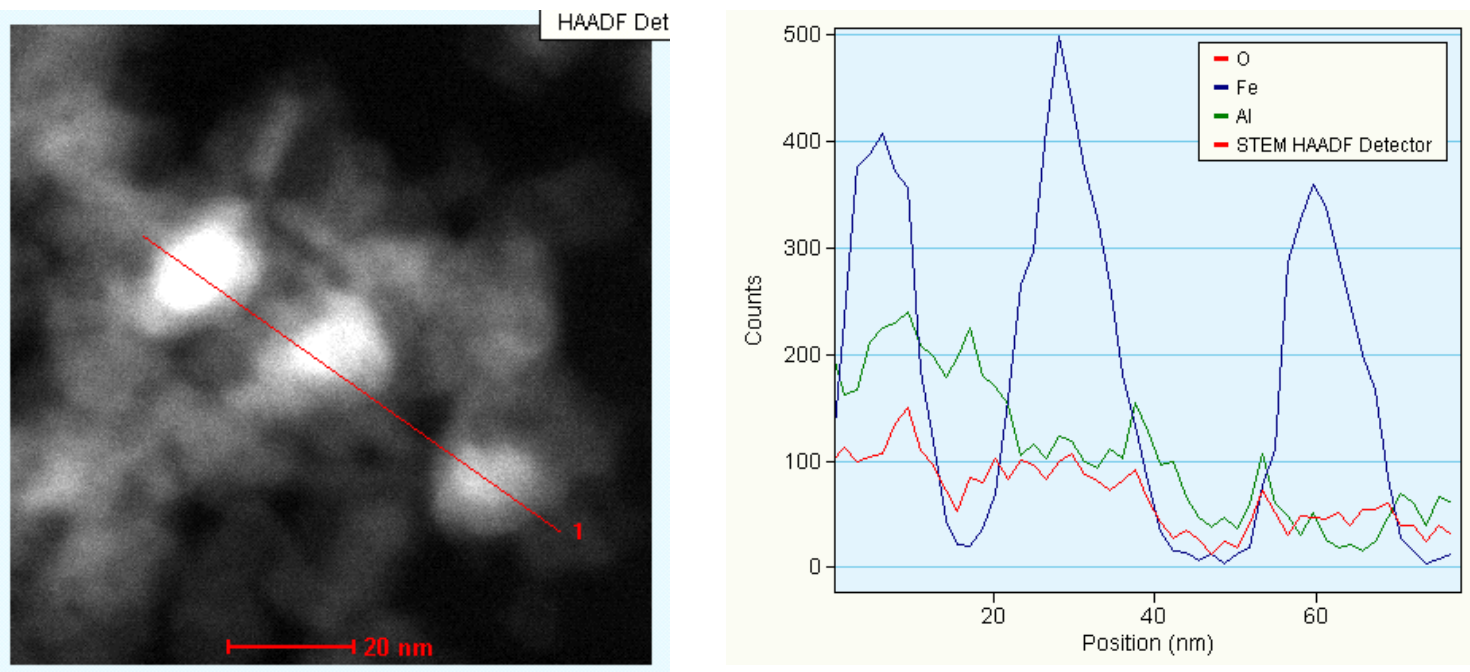

Figure 19 TEM image (left) and its associated energy dispersion (right) of elemental oxygen, iron and alumina for 10FeA-W sample.
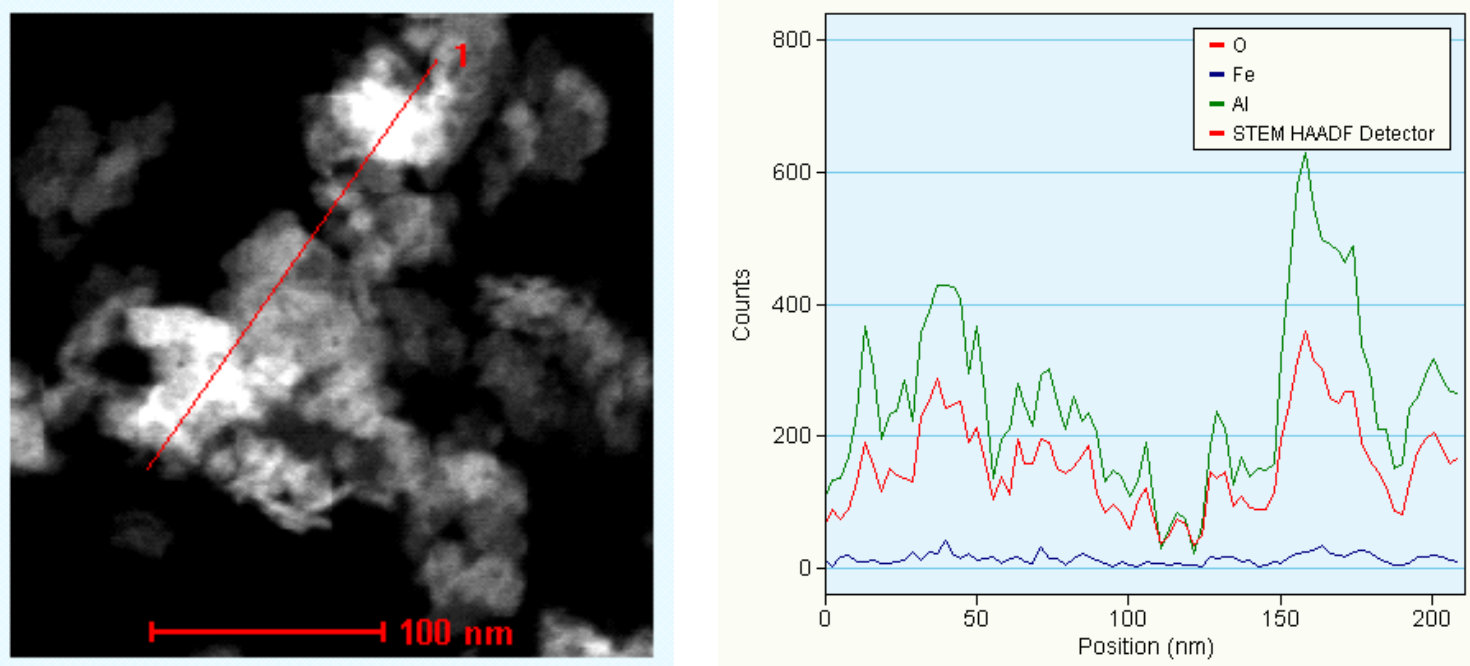

Figure 20 TEM image (left) and its associated energy dispersion (right) of elemental oxygen, iron and alumina for $10 \mathrm{FeA}-\mathrm{A} / \mathrm{E}$ sample.

Crystallite diameters determined by XRD, TEM, and $\mathrm{H}_{2}$ chemisorption are summarized in Table 3. Crystallite sizes calculated from XRD and TEM are very similar and for two of the samples larger than those estimated from $\mathrm{H}_{2}$ chemisorption. Smaller estimates from $\mathrm{H}_{2}$ 
adsorption are expected, since iron clusters of $d<3 \mathrm{~nm}$ of which there could be many, cannot be detected by XRD but can nevertheless adsorb $\mathrm{H}_{2}$, while TEM averages are based on distributions which weight more heavily the largest crystallites. The order of crystallite size for these three alumina-supported iron catalysts is $10 \mathrm{FeA}-\mathrm{W}>20 \mathrm{FeA}-\mathrm{A} / \mathrm{E}>10 \mathrm{FeA}-\mathrm{A} / \mathrm{E}$. These data establish
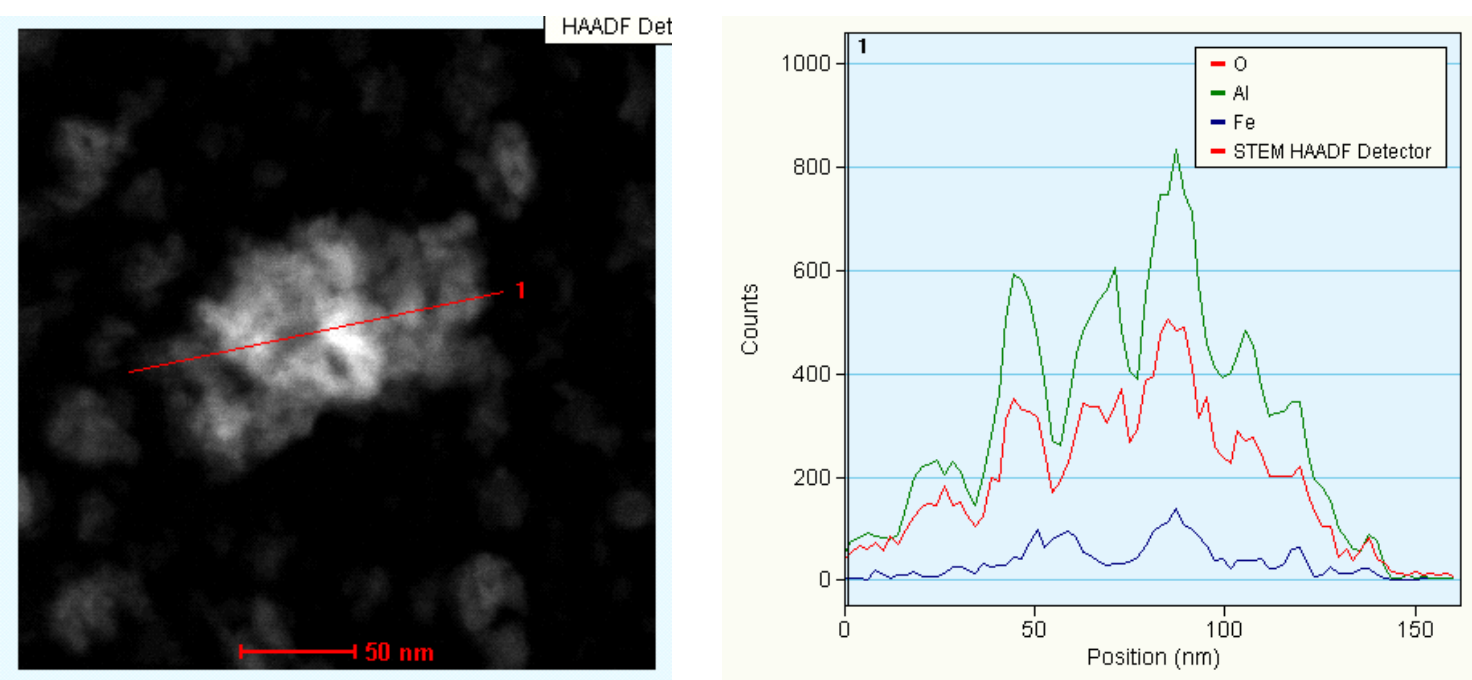

Figure 21 TEM image (left) and its associated energy dispersion (right) of elements oxygen, iron and alumina for $20 \mathrm{FeA}-\mathrm{A} / \mathrm{E}$ sample.

that the nonaqueous evaporative deposition method produces supported iron catalysts of higher metal dispersion than the aqueous impregnation.

\section{F. CO-Temperature-Programmed Desorption (TPD), Hydrogenation (TPH) and Modeling}

1. CO-TPD

During thermal desorption of CO from a stepped Fe (111) surface at low exposures, two desorption maxima (peaks) are observed at $\sim 380 \mathrm{~K}(\alpha-\mathrm{CO})$ and at $\sim 700 \mathrm{~K}$ (assumed to be a broad $\beta$-peak). [7, 8] At higher exposures, the $\alpha$-peak is accompanied by a shoulder at the lower temperature side. The $\alpha-\mathrm{CO}$ from the iron surfaces can be ascribed to molecularly-adsorbed $\mathrm{CO}$ of the linear type and the $\beta-\mathrm{CO}$ from the iron surfaces is assigned to dissociated $\mathrm{CO}$. Other researchers observed these two thermal desorption peaks at different temperatures. For example, U. Seip et. al. [9] reported peaks at $420 \mathrm{~K}$ and $820 \mathrm{~K}$, respectively, and C. E. Bartosch et. al. [10] observed peaks at $400 \mathrm{~K}$ and $750 \mathrm{~K}$. Thermal desorption spectroscopy of CO from $\mathrm{Fe}(110)$ was studied by K. Ueda et. al; [11] two peaks at $293 \mathrm{~K}$ and $723 \mathrm{~K}$ were observed. 
Figure 22, Figure 23 and Figure 24 show the CO-TPD patterns of 99FeA, 99FeA-Pt, and 99FeA-K samples, respectively. Table 4 summarizes peak temperatures and their assignments. Desorption peaks below $298 \mathrm{~K}$ for all three reduced samples are probably due to weakly physically and molecularly-adsorbed CO. Two other typical desorption peaks observed for 99FeA and 99FeA-Pt CO-TPD at 353-383 K and 629-715 K are associated with molecularlychemisorbed $\mathrm{CO}$ and dissociated $\mathrm{CO}$ respectively, similar to those observed for the Fe single crystal surfaces, although the peak temperatures for dissociative adsorption are generally lower for the $99 \%$ Fe relative to single crystal surfaces. However, two additional peaks for the $99 \mathrm{Fe} A-$ $\mathrm{K}$ sample are observed at higher temperatures than for $99 \mathrm{FeA}$, i.e. $182^{\circ} \mathrm{C}(455 \mathrm{~K})$ and $571^{\circ} \mathrm{C}$ (844 K), suggesting that CO adsorbs on 99FeA-K sample more strongly than 99FeA sample. These peaks are attributed to Fe-K-CO interfacial sites.

It is worth noting that $\mathrm{CO}$ adsorption on unsupported $\mathrm{Fe}$, FePt, and $\mathrm{FeK}$ catalysts was carried out at mainly room temperature (see Experimental section). $\mathrm{CO}$ dissociation takes place at this mild condition and the fraction of dissociatively-adsorbed $\mathrm{CO}$ is roughly 0.5 estimated by the peak areas. This suggests that this step is facile in FTS process which takes place at much higher temperatures; hence $\mathrm{CO}$ dissociation is unlikely to be a slow or rate-determining step at typical FT reaction temperatures.

Figure 25 shows CO-TPD patterns following adsorption at three different temperatures (25, 50 , and $100^{\circ} \mathrm{C}$ ) on the $99 \mathrm{FeA}$ catalyst. CO-TPD experiments were stopped at $450^{\circ} \mathrm{C}$. The amounts of adsorbed $\mathrm{CO}$ of both types decrease with increasing adsorption temperature. Less CO adsorbed at higher temperatures indicates that $\mathrm{CO}$ adsorption is increasingly reversible with increasing adsorption temperature, a phenomenon typical of chemisorption on metals. 


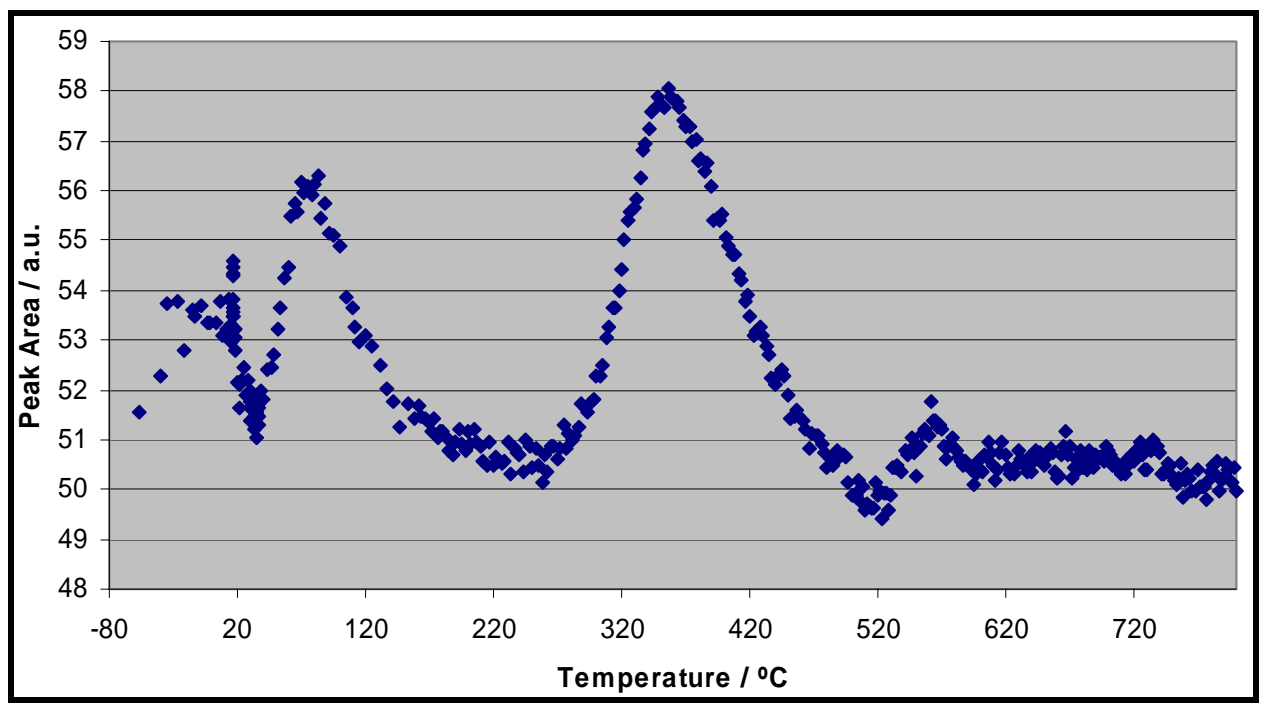

Figure 22 CO-TPD pattern of 99FeA sample.

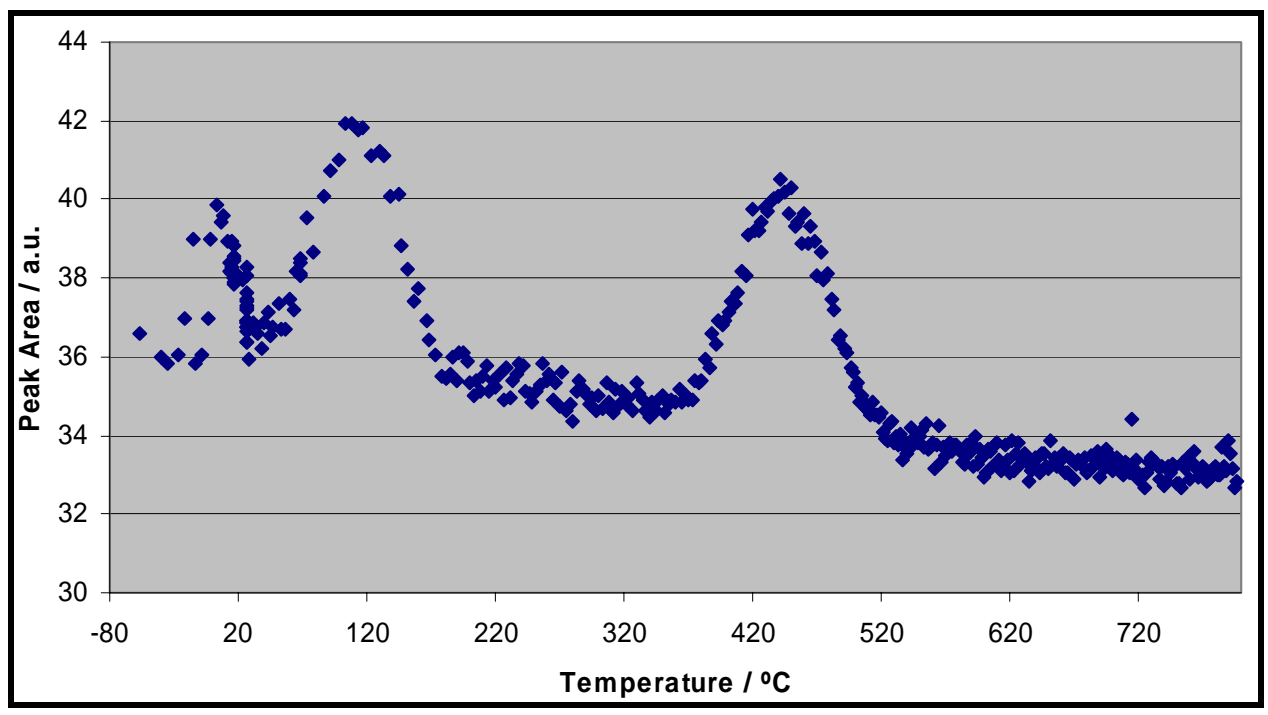

Figure 23 CO-TPD pattern of 99FeA-Pt sample. 


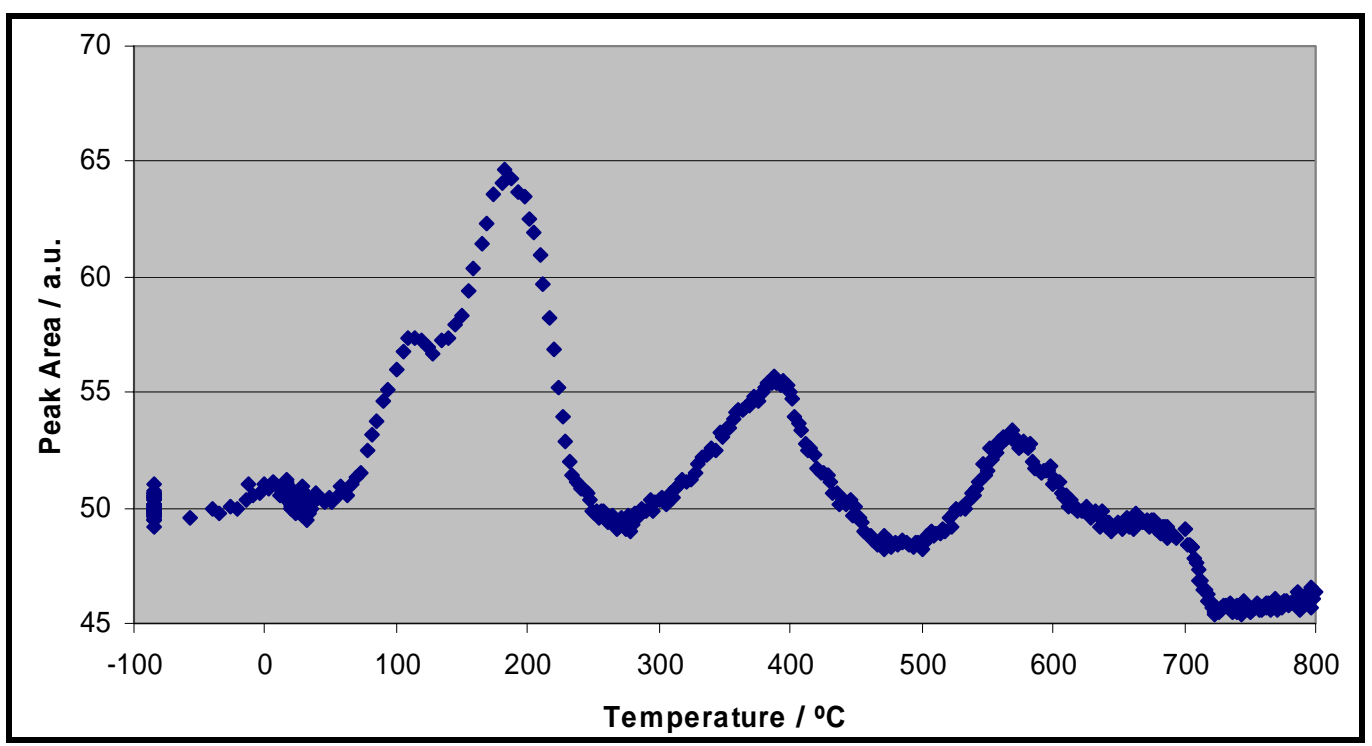

Figure 24 CO-TPD pattern of 99FeA-K sample.

Table 4 Summary of thermal desorption peaks

\begin{tabular}{|c|c|c|}
\hline Samples & Peak temperatures, ${ }^{\circ} \mathrm{C}(\mathrm{K})$ & Assignment \\
\hline \multirow{3}{*}{$99 \mathrm{FeA}$} & $15(288)$ & Weak physically molecularly-adsorbed CO \\
\hline & $80(353)$ & Molecular chemisorbed linear CO \\
\hline & $356(629)$ & Dissociated CO \\
\hline \multirow{3}{*}{$99 \mathrm{FeA}-\mathrm{Pt}$} & $10(283)$ & Weak physically molecularly-adsorbed CO \\
\hline & $110(383)$ & Molecular chemisorbed linear $\mathrm{CO}$ \\
\hline & $442(715)$ & Dissociated CO \\
\hline \multirow{5}{*}{ 99FeA-K } & $6(279)$ & Weak physically molecularly-adsorbed CO \\
\hline & $114(387)$ & Molecular chemisorbed linear $\mathrm{CO}$ \\
\hline & $182(455)$ & $\begin{array}{l}\text { Molecularly-adsorbed CO of the linear type } \\
\text { on Fe-K sites }\end{array}$ \\
\hline & $395(668)$ & Dissociated CO on iron sites \\
\hline & $571(844)$ & $\mathrm{K}_{x}(\mathrm{CO})_{y}$ species \\
\hline
\end{tabular}




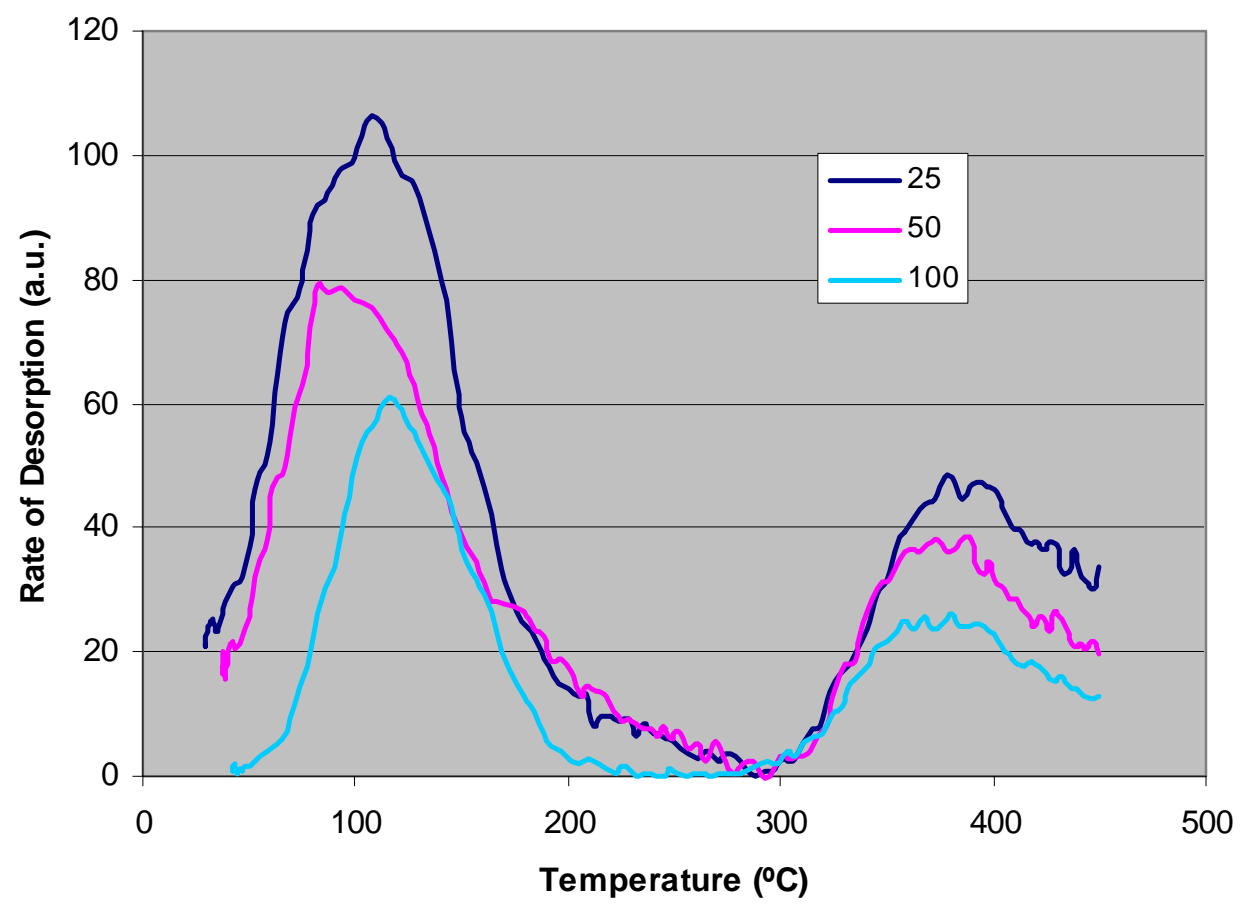

Figure 25 CO-TPD patterns at Different Adsorption Temperatures on 99FeA.

Determination of the heat of adsorption for $\mathrm{CO}$ on the unsupported iron catalysts involved using the CO-TPD spectra as a function of varying initial coverage. Data analysis is based on an Arrhenius form of the rate constant for adsorption. A linear form involves plotting $\ln \left(\theta_{n} /\left(1-\theta_{n}\right)\right)$ versus $1 / T_{a}$. Figure 26 shows the plot of heat of adsorption of $\mathrm{CO}$ versus coverage. 


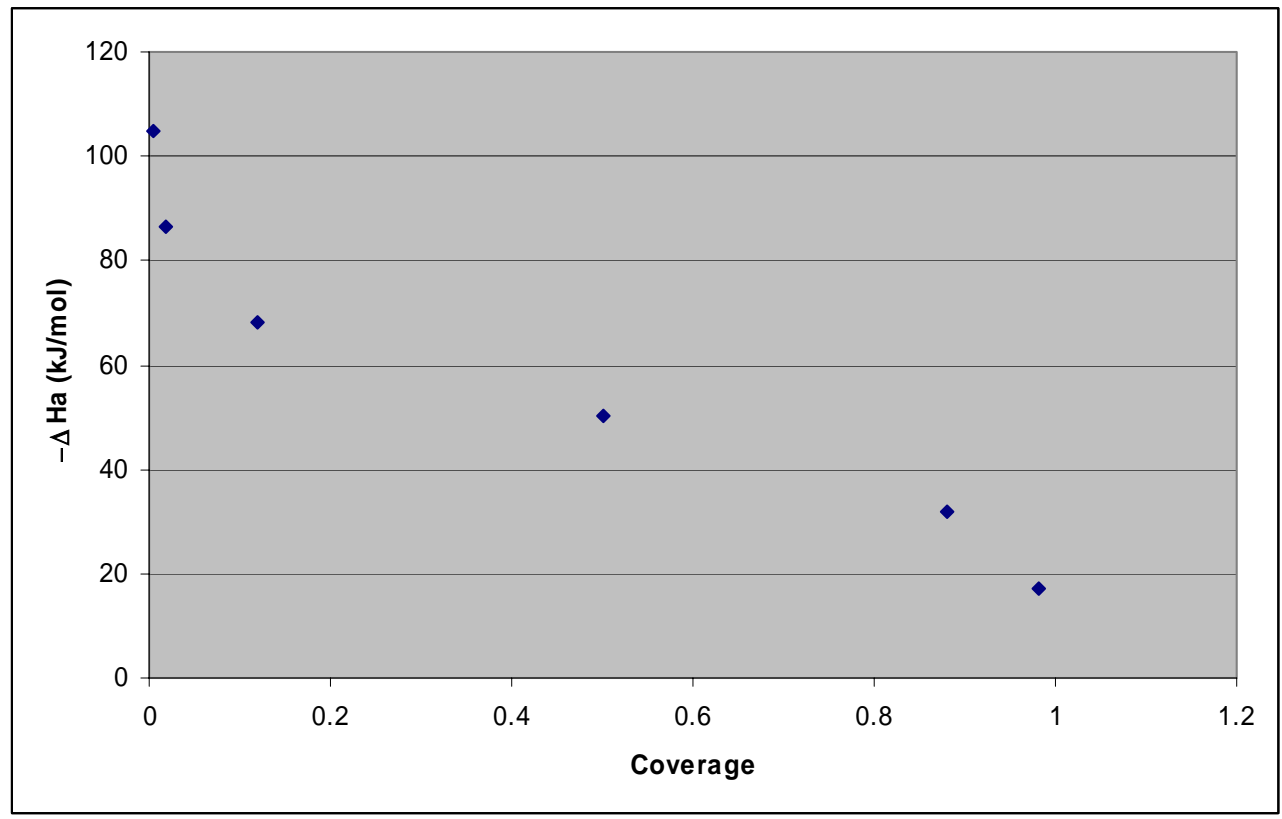

Figure 26 Enthalpy of adsorption of $\mathrm{CO}$ on unsupported iron catalysts as a function of coverage.

Table 5 compares the $\mathrm{CO}$ heat of adsorption on iron in this work with other studies.

Table 5 CO Heat of Adsorption on SC and PC Fe

\begin{tabular}{lcc}
\hline & $\begin{array}{c}\text { Heat of Adsorption } \\
(\mathrm{kJ} / \mathrm{mol})\end{array}$ & Reference \\
\hline $\mathrm{SC} \mathrm{Fe}$, Calculated & $140 \sim 200$ & 12 \\
\hline $\mathrm{Fe}(100)$, Experimental & $100 \pm 5$ & 13 \\
$\mathrm{PC} \mathrm{Fe}$, Experimental & 100 & This work \\
\hline
\end{tabular}

$\mathrm{CO}$ adsorption on and desorption from alumina-supported samples were conducted by TGA. A catalyst sample $40-50 \mathrm{mg}$ was charged to the TGA pan. The sample was first reduced in $10 \%$ $\mathrm{H}_{2} / \mathrm{He}$ as follows: $1^{\circ} \mathrm{C} / \mathrm{min}$ from room temperature to $120^{\circ} \mathrm{C}$, hold at $120^{\circ} \mathrm{C}$ for $1 \mathrm{~h}, 1^{\circ} \mathrm{C} / \mathrm{min}$ to $400^{\circ} \mathrm{C}$, and hold at $400^{\circ} \mathrm{C}$ for $12 \mathrm{~h}$. After reduction, $\mathrm{H}_{2}$ flow was discontinued, while He flow was continued for $30 \mathrm{~min}$ at $400^{\circ} \mathrm{C}$ to desorb $\mathrm{H}_{2}$. The sample was cooled to room temperature in flowing $\mathrm{N}_{2}$. $\mathrm{CO}$ was introduced to the sample at room temperature by flowing $10 \% \mathrm{CO} / \mathrm{He}$ for 1 h. Finally, $\mathrm{CO}$ was desorbed in pure He while temperature was increased linearly.

Figure 27 shows the CO-TPD spectrum for a 20FeA-A/E sample. Consistent with unsupported iron samples, two $\mathrm{CO}$ desorption peaks assigned to molecularly-adsorbed and 
dissociated $\mathrm{CO}$ can be seen in Figure 27. However, the peak for recombination of the predissociated $\mathrm{CO}$ is significantly shifted to lower temperature $\left(280^{\circ} \mathrm{C}\right)$. This indicates that the $\mathrm{C}-\mathrm{Fe}$ bond is weaker than that formed on $99 \mathrm{FeA}$ series samples.

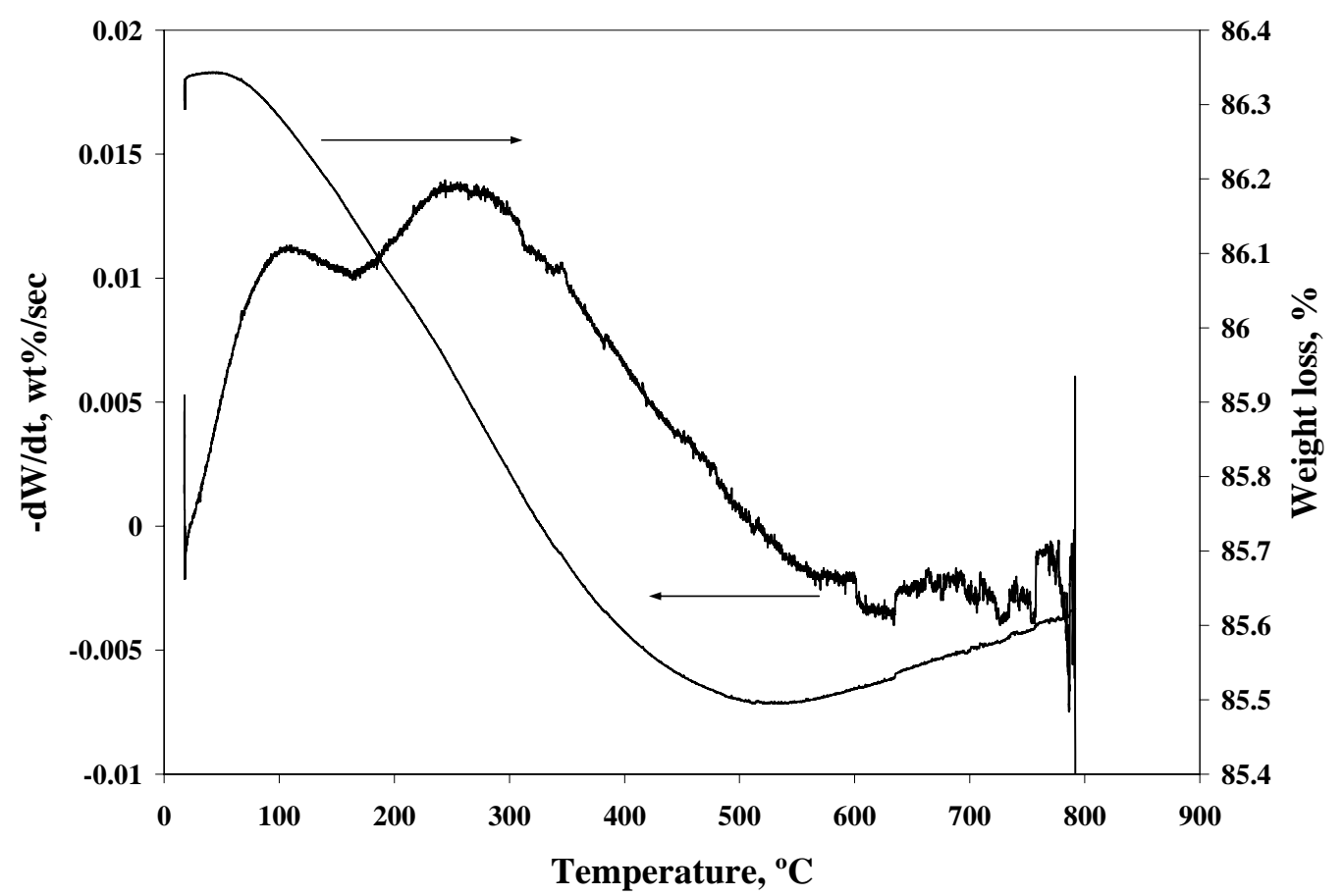

Figure 27 CO-TPD pattern of 20FeA-A/E sample.

In situ CO adsorption and TPD measurements were carried out on a series of La-alumina supported iron catalysts, denoted as $20 \mathrm{FeLaA}\left(20 \mathrm{wt} \% \mathrm{Fe} / 6 \mathrm{wt} \% \mathrm{La}_{2} \mathrm{O}_{3} / \mathrm{Al}_{2} \mathrm{O}_{3}\right), 20 \mathrm{FeKLaA}(20$ wt $\% \mathrm{Fe} / 1 \mathrm{wt} \% \mathrm{~K} / 6 \mathrm{wt} \% \mathrm{La}_{2} \mathrm{O}_{3} / \mathrm{Al}_{2} \mathrm{O}_{3}$ ), and $20 \mathrm{FePtLaA}(20 \mathrm{wt} \% \mathrm{Fe} / 1 \mathrm{wt} \% \mathrm{Pt} / 6 \mathrm{wt} \%$ $\mathrm{La}_{2} \mathrm{O}_{3} / \mathrm{Al}_{2} \mathrm{O}_{3}$ ) using our TPD/TPR system with mass spectrometric analysis. Figure 28 shows the CO-TPD patterns of these three catalysts following adsorption at $25^{\circ} \mathrm{C}$, cooling to $-83^{\circ} \mathrm{C}$, and ramping temperature linearly to $730^{\circ} \mathrm{C}$. Two $\mathrm{CO}$ desorption peaks are observed at -9 and $83^{\circ} \mathrm{C}$ for the $20 \mathrm{FeLaA}$ catalyst, and at -15 and $75^{\circ} \mathrm{C}$ for the $20 \mathrm{FePtLaA}$ catalyst. The first peak for both samples is due to weak molecular $\mathrm{CO}$ desorption (indicating physically adsorbed $\mathrm{CO}$ ), while the second peak is due desorption of chemisorbed $\mathrm{CO}$ molecules. The absence of a peak at higher temperatures (e.g. around $250-400^{\circ} \mathrm{C}$ ) indicates that $\mathrm{CO}$ dissociation does not occur on the 20FeLaA and 20FePtLaA catalysts after $\mathrm{CO}$ adsorption at room temperature. $\mathrm{CO}$ desorption from the $20 \mathrm{FeKLaA}$ catalyst is more complicated than for $20 \mathrm{FeLaA}$ and $20 \mathrm{FePtLaA}$ samples. 


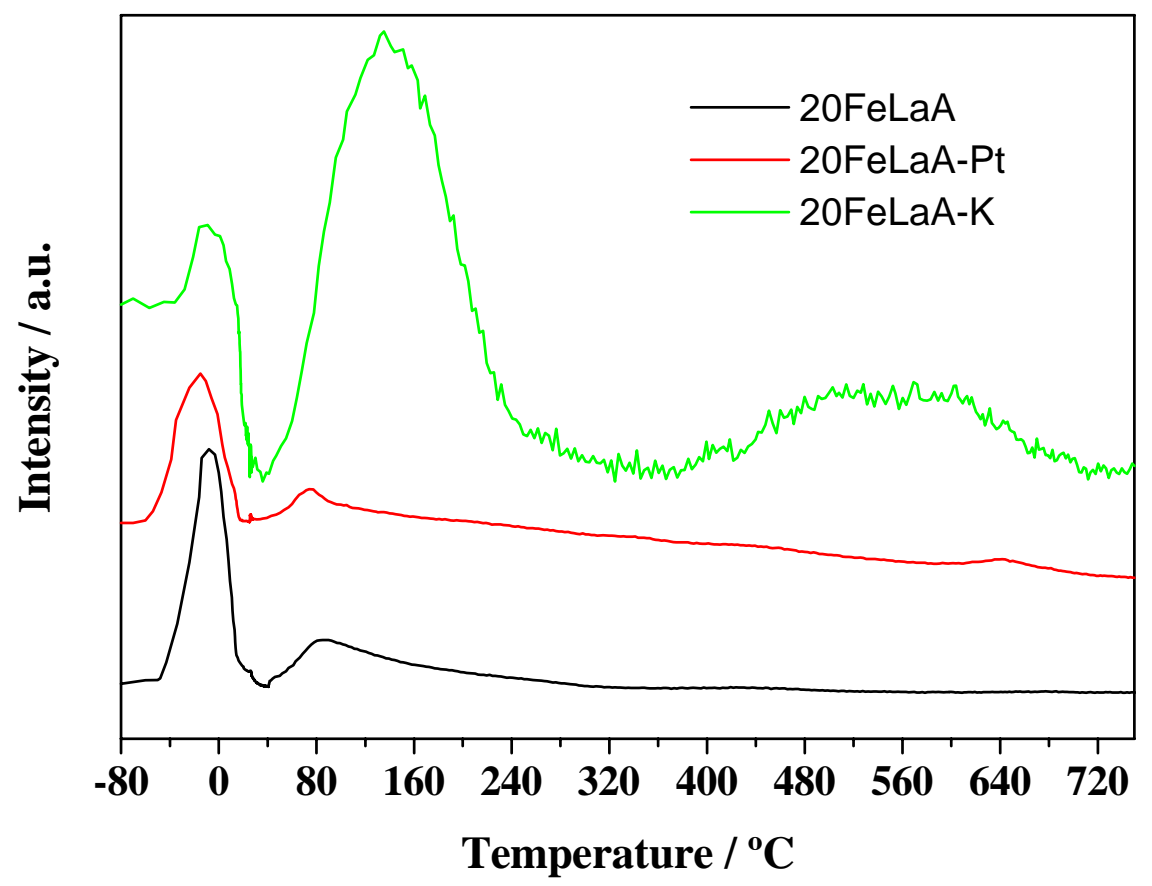

Figure 28 CO-TPD patterns of 20FeLaA series samples.

The first CO-TPD peak for $20 \mathrm{FeLaA}-\mathrm{K}$ located at $-10^{\circ} \mathrm{C}$ is probably due to desorption of physisorbed, molecular $\mathrm{CO}$. The second peak with a maximum at $138^{\circ} \mathrm{C}$ (significantly more intense and shifted to higher temperature relative to the 20FeLaA and 20FeLaA-Pt samples) is attributed to desorption of chemisorbed, molecular $\mathrm{CO}$. The broad peak at $554^{\circ} \mathrm{C}$ may be attributed to an overlap of peaks due to (1) recombination of adsorbed $\mathrm{C}$ and $\mathrm{O}$ atoms located on metal sites which desorb at lower temperatures and (2) recombination of adsorbed $\mathrm{C}$ and $\mathrm{O}$ atoms located on sites near to surface $\mathrm{K}$ which desorb at higher temperatures, since they are more strongly bound. The observation of the high-temperature desorption and its assignment to recombination of predissociated $\mathrm{CO}$ are consistent with observations from previous literature that surface $\mathrm{K}$ increases the $\mathrm{Fe}-\mathrm{C}$ bond strength, thus enhancing $\mathrm{CO}$ dissociation. Thus, the supported 20FeKLaA catalyst behaves similarly to the unsupported 99FeKA catalyst in dissociating $\mathrm{CO}$ at low temperature. However, the inability of the supported 20FeLaA catalyst to dissociate $\mathrm{CO}$ after adsorption at $\mathrm{RT}$ is qualitatively and quantitatively different than for unsupported 99FeA. TPD measurements following adsorption at progressively higher temperatures would be important, since at higher temperatures, $\mathrm{CO}$ dissociation is more likely to occur on the $\mathrm{La}-\mathrm{Al}_{2} \mathrm{O}_{3}$-supported catalysts. 


\section{CO-TPD microkinetic model}

At room temperature and pressure, $\mathrm{CO}$ adsorbs molecularly on iron. However, during TPD, adsorbed $\mathrm{CO}$ desorbs as both $\mathrm{CO}$ and $\mathrm{CO}_{2}$. Previous studies teach that during TPD of $\mathrm{CO}$ from porous Fe catalysts: (1) adsorbed $\mathrm{CO}$ is in equilibrium with gas phase $\mathrm{CO}$ and hence at relatively low temperatures (300-400 K) a significant fraction of adsorbed molecular $\mathrm{CO}$ desorbs as gas phase $\mathrm{CO}$; (2) above a temperature of about $400-450 \mathrm{~K}$ a fraction of the adsorbed $\mathrm{CO}$ dissociates to $\mathrm{C}$ and $\mathrm{O}$ atoms; (3) at significantly higher temperatures $(500-600 \mathrm{~K})$ a fraction of the dissociated $\mathrm{O}$ combines with adsorbed $\mathrm{CO}$ to form $\mathrm{CO}_{2}$ and (4) at even higher temperatures (700-900 K) $\mathrm{C}$ and $\mathrm{O}$ atoms recombine to molecular $\mathrm{CO}$ which desorbs as gaseous $\mathrm{CO}$. A sequence of elementary steps describing the above processes is as follows:

$$
\begin{aligned}
& \mathrm{CO}^{*} \leftrightarrow \mathrm{CO}_{(\mathrm{g})}+* \\
& \mathrm{CO}^{*}+* \leftrightarrow \mathrm{C}^{*}+\mathrm{O}^{*} \\
& \mathrm{CO}^{*}+\mathrm{O}^{*} \leftrightarrow \mathrm{CO}_{2}^{* *} \\
& \mathrm{CO}_{2}^{* *} \leftrightarrow \mathrm{CO}_{2(\mathrm{~g})}+2^{*}
\end{aligned}
$$

Assuming a plug-flow reactor (PFR) model, and neglecting mass transfer resistance, the unsteady state mass balance for a gas-phase species A is given in Eqn. below: The assumption that pore diffusional mass transfer resistance is negligible is sustained by the facts that the catalyst in this study is an unsupported powder and hence catalyst pores are large and the diffusion path is small; film mass transfer is negligible since the concentration of $\mathrm{CO}$ in the carrier gas is much greater than that of the desorbed species.

$$
\frac{\partial C_{A}}{\partial t}=\frac{u(t)}{L} \frac{\partial C_{A}}{\partial Z}+r_{A}\left(C_{A}\right)
$$

Where $C_{A}=$ Concentration of species $A\left(\mathrm{~mol} / \mathrm{m}^{3}\right), u(t)=$ superficial gas velocity through the reactor as a function of time $(\mathrm{m} / \mathrm{s}), \mathrm{L} \quad=$ Length of reactor bed $(\mathrm{m}), r_{A}\left(C_{A}\right)=$ rate of formation or disappearance of $A\left(\mathrm{~mol} / \mathrm{m}^{3} \mathrm{~s}\right), t=$ time (s), and $z=$ dimensionless distance along the reactor.

If the rate of reaction is expressed in turnover frequency units and we equate $\frac{u(t)}{L}=\tau$, i.e. space time (s), Equation 11 can be written as: 
$\frac{\partial C_{A}}{\partial t}=-\frac{1}{\tau} \frac{\partial C_{A}}{\partial z}+\frac{M_{L} \cdot D \cdot \rho_{b}}{\varepsilon_{b} \cdot M_{W}} \cdot R_{A}\left(C_{A}, \theta_{A}\right)$

Where $M_{L}=$ fraction of the active metal loading of the catalyst,

$D=$ fraction of the active metal on the surface of the catalyst (dispersion),

$\rho_{b}=$ catalyst bed density $\left(\mathrm{kg} / \mathrm{m}^{3}\right)$,

$\varepsilon_{b}=$ bed void fraction,

$M_{W}=$ molecular weight of the active catalyst phase $(\mathrm{kg} / \mathrm{mol})$,

and

$$
\begin{aligned}
& R_{A}\left(C_{A}, \theta_{A}\right)=\text { rate of formation or disappearance of } A(1 / \mathrm{s}) . \\
& \frac{d \theta_{C O}}{d T}=\frac{(-R 1-R 2-R 3)}{\beta} \\
& \frac{d \theta_{C}}{d T}=\frac{R 2}{\beta} \\
& \frac{d \theta_{O}}{d T}=\frac{(R 2-R 3)}{\beta} \\
& \frac{d \theta_{C O_{2}}}{d T}=\frac{(R 3-R 4)}{\beta} \\
& \text { and } \tau=\tau^{o} \cdot\left(\frac{T^{o}}{T}\right)
\end{aligned}
$$

Where $A_{1 f}, A_{1 r}, \ldots, A_{4 r}$ are the pre-exponential factors for reactions 1 through 4 with units (1/s) for surface reaction and $(1 /(\mathrm{Pa} s))$ for gas-phase reaction. $E_{1 f}, E_{1 r}, \ldots, E_{4 r}$ are the activation energies for Reactions 1 through 4 with units $(\mathrm{J} / \mathrm{mol}) . \tau^{\mathrm{o}}$ is the space time at $\mathrm{T}=\mathrm{T}^{\mathrm{o}}$. $\theta_{\mathrm{xx}}$ represent the fractional coverage of each surface species while $\theta_{\mathrm{V}}$ represents the fraction of vacant sites. The solution of Equations 7-17 gives the TPD profile.

The objective of the data analysis procedure described here was to estimate the kinetic parameters (activation energies and pre-exponential factors) of the sequence of elementary reaction steps that occur during CO TPD on Fe catalyst. To do this, the numerical method of lines was employed to solve Equations 7-17 by discretizing the space variable into a uniform grid size of 10 using forward difference, and subsequently integrating the resulting system of first order ODE's with DVODE (developed by Livermore National Labs)[14], while the kinetic 
parameters were estimated by multi-response regression using DODR pack (an orthogonal regression routine) [15] by minimizing Equation 18.

$$
\underbrace{\min }_{\phi} \sum_{i=1}^{n} w_{\varepsilon_{i}}\left(y_{i}-f\left(x_{i}, \phi\right)\right)^{2}
$$

where $y_{i}$ is the observed or experimental response and $f\left(x_{i}, \phi_{i}\right)$ is the model response. $\phi$ is the parameter(s) to be estimated while $w_{\varepsilon_{i}}$ is the weighted errors in the observed response variable.

The data analysis procedure can thus be summarized as follows:

1. Make an initial guess of the kinetic parameters

2. With the guessed parameters, use DVODE to integrate the discretized forms of Equations 7-17.

3. Check whether Equation 18 is minimized. If yes, then the values of guessed kinetic parameters have been successfully estimated. Otherwise, use DODR to make new guesses for the parameters and repeat Steps 2 and 3 until Equation 18 is satisfied.

Figure 29 and Figure 30 show normalized mole fraction profiles of $\mathrm{CO}$ and $\mathrm{CO}_{2}$ obtained during the above TPD experiment. Examination of the observed profiles suggests perhaps the existence of more than one uniform energetic site. This may be due to varying proportion of edge or corner sites or due to interaction between $\mathrm{Al}_{2} \mathrm{O}_{3}$ and $\mathrm{Fe}$.

So to analyze the above data, we chose a two-site model ( $\alpha 1$ and $\alpha 2$ sites), however, we did not weight the errors in the response variables.

Figure 31 and Figure 32 show the graphs of observed normalized mole fraction profiles of $\mathrm{CO}$ and $\mathrm{CO}_{2}$ in comparison with that predicted by the model. Table 6 lists the estimated kinetic parameters and their confidence intervals. 


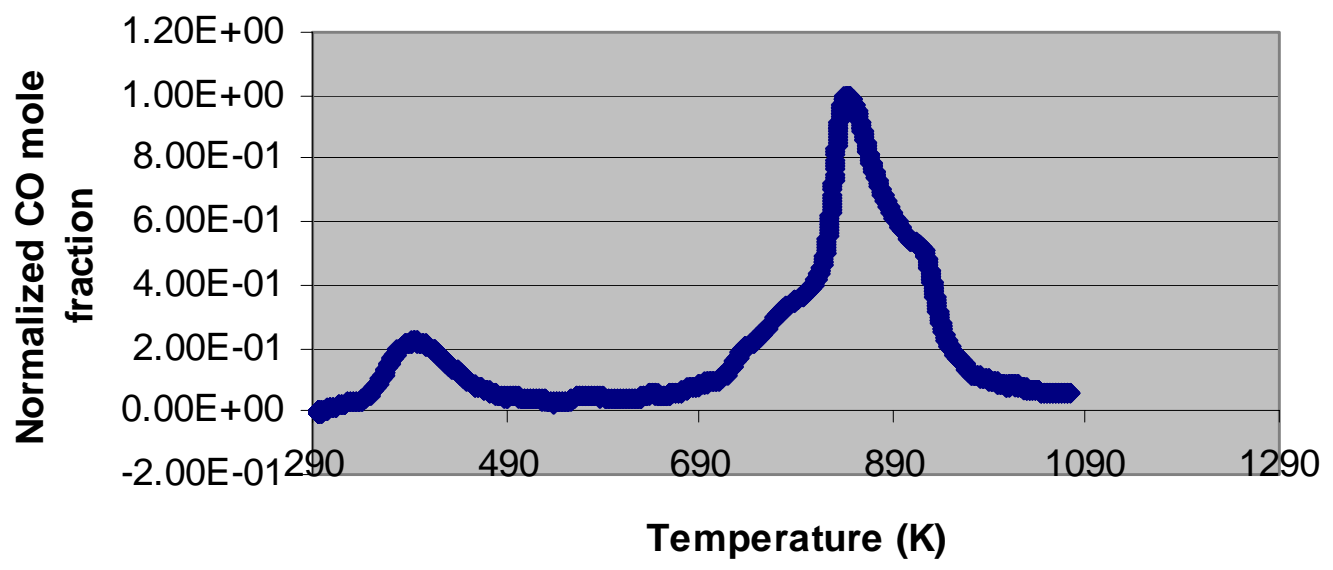

Figure 29 Normalized $\mathrm{CO}$ mole fraction during $\mathrm{CO}$ TPD. $\mathrm{yCO}_{\max }=4.20 \mathrm{E}-03$

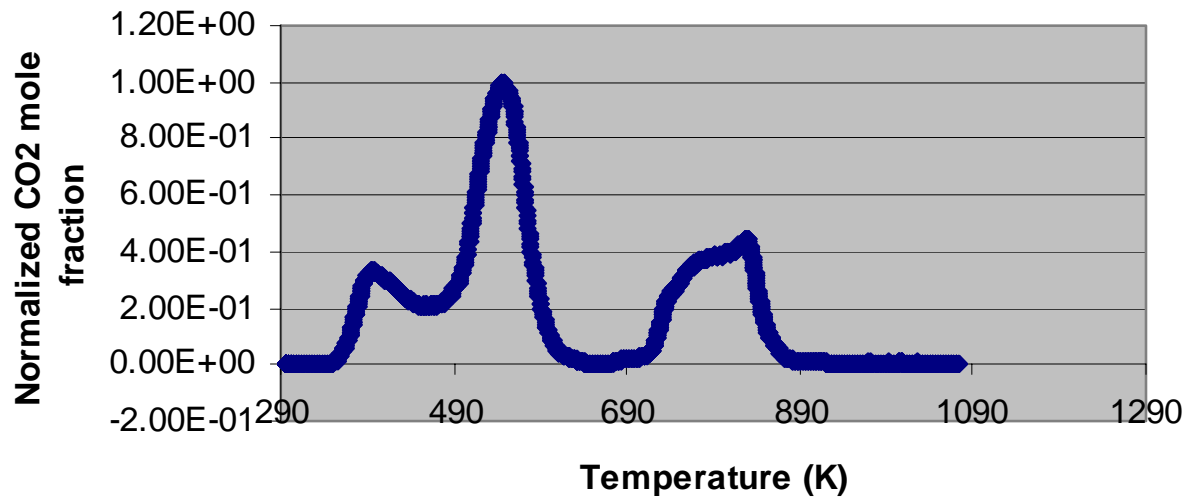

Figure 30 Normalized $\mathrm{CO}_{2}$ mole fraction during $\mathrm{CO}$ TPD. $\mathrm{yCO}_{2 \max }=2.19 \mathrm{E}-03$

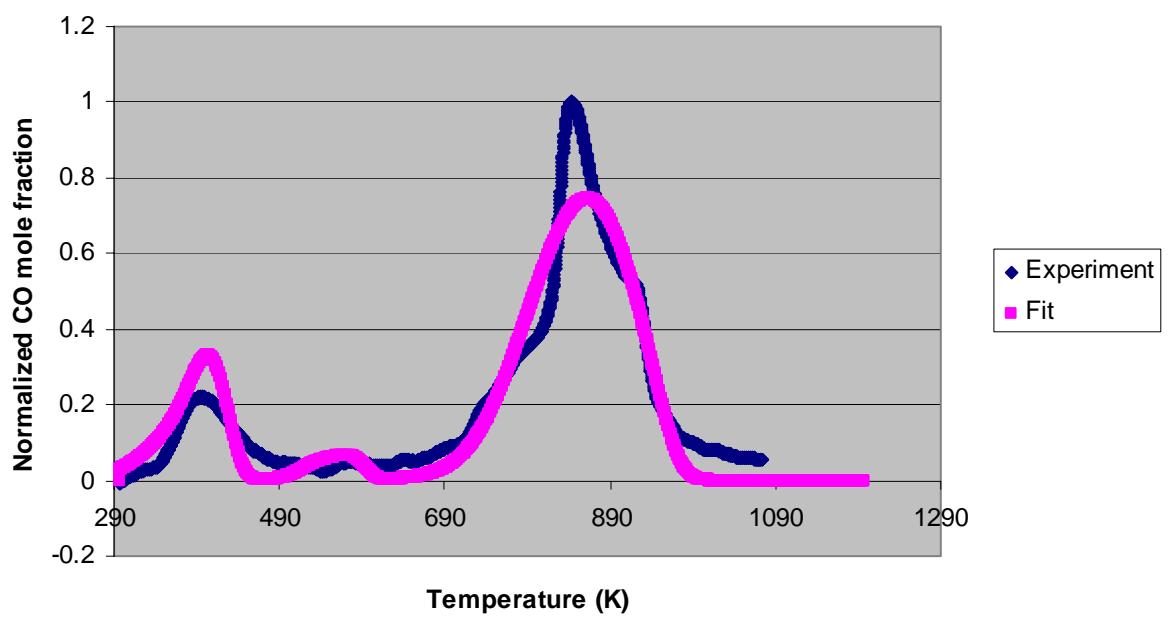

Figure 31 Comparison of observed normalized CO mole fraction during TPD and mole fraction profile predicted by model. 


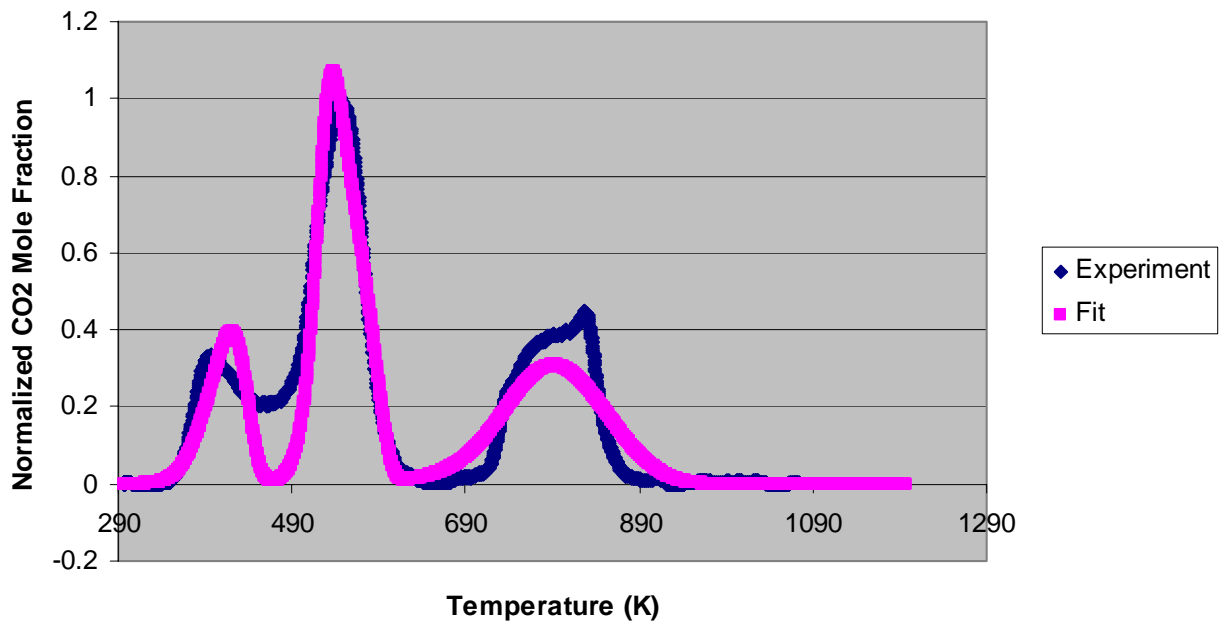

Figure 32 Comparison of observed normalized $\mathrm{CO}_{2}$ mole fraction during $\mathrm{CO}$ TPD and mole fraction profile predicted by model. 
Table 6 Estimated kinetic parameters and their 95\% confidence intervals for each elementary step.

\begin{tabular}{|c|c|c|c|c|c|}
\hline Reaction & $A_{f}^{*}$ & $A_{r}^{*}$ & $E_{f}(J / m o l)$ & $E_{r}(J / m o l)$ & Remarks \\
\hline$C O^{*} \leftrightarrow C O_{(g)}+*$ & $\begin{array}{c}1.53 \mathrm{E}+12 \\
(1.52 \mathrm{E}+12 \mathrm{TO} 1.54 \mathrm{E}+12)\end{array}$ & $\begin{array}{c}\text { 8.20E-01 } \\
\text { (8.13E-01 TO } 8.26 E-01)\end{array}$ & $\begin{array}{c}5.00 \mathrm{E}+04 \\
(4.96 \mathrm{E}+04 \mathrm{TO} 5.04 \mathrm{E}+04)\end{array}$ & $0.00 \mathrm{E}+00$ & \\
\hline$C O^{*}+{ }^{*} \leftrightarrow C^{*}+O^{*}$ & $\begin{array}{c}1.84 \mathrm{E}+13 \\
(1.83 \mathrm{E}+13 \mathrm{TO} 1.85 \mathrm{E}+13)\end{array}$ & $\begin{array}{c}5.81 \mathrm{E}+13 \\
(5.72 \mathrm{E}+13 \mathrm{TO} 5.89 \mathrm{E}+13)\end{array}$ & $\begin{array}{c}8.94 \mathrm{E}+04 \\
(8.90 \mathrm{E}+04 \mathrm{TO} 8.99 \mathrm{E}+04)\end{array}$ & $\begin{array}{c}1.90 \mathrm{E}+05 \\
(1.89 \mathrm{E}+05 \text { TO } 1.91 \mathrm{E}+05)\end{array}$ & \\
\hline$C O^{*}+O^{*} \leftrightarrow C O_{2}^{* *}$ & $\begin{array}{c}2.75 \mathrm{E}+09 \\
(2.73 \mathrm{E}+09 \text { TO } 2.76 \mathrm{E}+09)\end{array}$ & $\begin{array}{c}1.04 \mathrm{E}+13 \\
(1.04 \mathrm{E}+13 \mathrm{TO} 1.05 \mathrm{E}+13)\end{array}$ & $\begin{array}{c}3.82 \mathrm{E}+04 \\
(3.79 \mathrm{E}+04 \mathrm{TO} 3.85 \mathrm{E}+04)\end{array}$ & $\begin{array}{c}3.17 E+04 \\
(3.15 E+04 \text { TO } 3.19 E+04)\end{array}$ & \\
\hline$C O_{2}^{* *} \leftrightarrow C O_{2_{(g)}}+2^{*}$ & $\begin{array}{c}1.03 \mathrm{E}+13 \\
(1.03 \mathrm{E}+13 \mathrm{TO} 1.04 \mathrm{E}+13)\end{array}$ & $\begin{array}{c}1.73 \mathrm{E}-01 \\
(1.72 \mathrm{E}-01 \mathrm{TO} 1.74 \mathrm{E}-01) \\
\end{array}$ & $\begin{array}{c}9.02 \mathrm{E}+03 \\
(8.96 \mathrm{E}+03 \mathrm{TO} 9.08 \mathrm{E}+03) \\
\end{array}$ & $0.00 \mathrm{E}+00$ & $\alpha 1$ site \\
\hline$C O^{*} \leftrightarrow C O_{(g)}+*$ & $\begin{array}{c}1.19 \mathrm{E}+06 \\
(1.18 \mathrm{E}+06 \mathrm{TO} 1.20 \mathrm{E}+06)\end{array}$ & $\begin{array}{c}5.20 \mathrm{E}-01 \\
(5.16 \mathrm{E}-01 \mathrm{TO} 5.24 \mathrm{E}-01)\end{array}$ & $\begin{array}{c}3.61 \mathrm{E}+04 \\
(3.58 \mathrm{E}+04 \mathrm{TO} 3.63 \mathrm{E}+04)\end{array}$ & $0.00 E+00$ & \\
\hline$C O^{*}+* \leftrightarrow C^{*}+O^{*}$ & $\begin{array}{c}1.26 \mathrm{E}+06 \\
(1.25 \mathrm{E}+06 \mathrm{TO} 1.26 \mathrm{E}+06)\end{array}$ & $\begin{array}{c}6.57 \mathrm{E}+13 \\
(6.49 \mathrm{E}+13 \mathrm{TO} 6.65 \mathrm{E}+13)\end{array}$ & $\begin{array}{c}5.46 \mathrm{E}+04 \\
(5.43 \mathrm{E}+04 \mathrm{TO} 5.49 \mathrm{E}+04)\end{array}$ & $\begin{array}{c}1.60 \mathrm{E}+05 \\
(1.59 \mathrm{E}+05 \mathrm{TO} 1.61 \mathrm{E}+05)\end{array}$ & \\
\hline$C \mathrm{O}^{*}+\mathrm{O}^{*} \leftrightarrow C \mathrm{O}_{2}^{* *}$ & $\begin{array}{c}2.50 \mathrm{E}+12 \\
(2.47 \mathrm{E}+12 \mathrm{TO} 2.52 \mathrm{E}+12)\end{array}$ & $\begin{array}{c}1.38 \mathrm{E}+13 \\
(1.37 \mathrm{E}+13 \mathrm{TO} 1.39 \mathrm{E}+13)\end{array}$ & $\begin{array}{c}1.23 \mathrm{E}+05 \\
(1.23 \mathrm{E}+05 \mathrm{TO} 1.24 \mathrm{E}+05)\end{array}$ & $\begin{array}{c}1.19 \mathrm{E}+05 \\
(1.19 \mathrm{E}+05 \mathrm{TO} 1.20 \mathrm{E}+05)\end{array}$ & \\
\hline$C O_{2}^{* *} \leftrightarrow C O_{2_{(g)}}+2^{*}$ & $\begin{array}{c}2.85 E+04 \\
(2.83 E+04 \text { TO } 2.87 E+04)\end{array}$ & $\begin{array}{c}3.59 \mathrm{E}-01 \\
\text { (3.57E-01 TO 3.62E-01) }\end{array}$ & $\begin{array}{c}3.53 E+03 \\
(3.49 E+03 \text { TO } 3.56 E+03)\end{array}$ & $0.00 \mathrm{E}+00$ & $\alpha 2$ site \\
\hline
\end{tabular}

$*$ Unit $=[1 / \mathrm{s}]$ for surface reaction and $\left[(\mathrm{Pa} \mathrm{s})^{-1}\right]$ for gas phase reaction $\mathrm{CO}$ adsorption was at room temperature and pressure. TPD was at atmospheric pressure. The confidence intervals are given in parenthesis. Initial CO coverage for $\alpha 1$ and $\alpha 2$ sites was estimated to be 0.81 and 0.09 respectively. The dispersion of the catalyst was estimated to be $0.505 \%$ 
Figure 33 shows the fractional coverages of various surface species as a function of temperature.

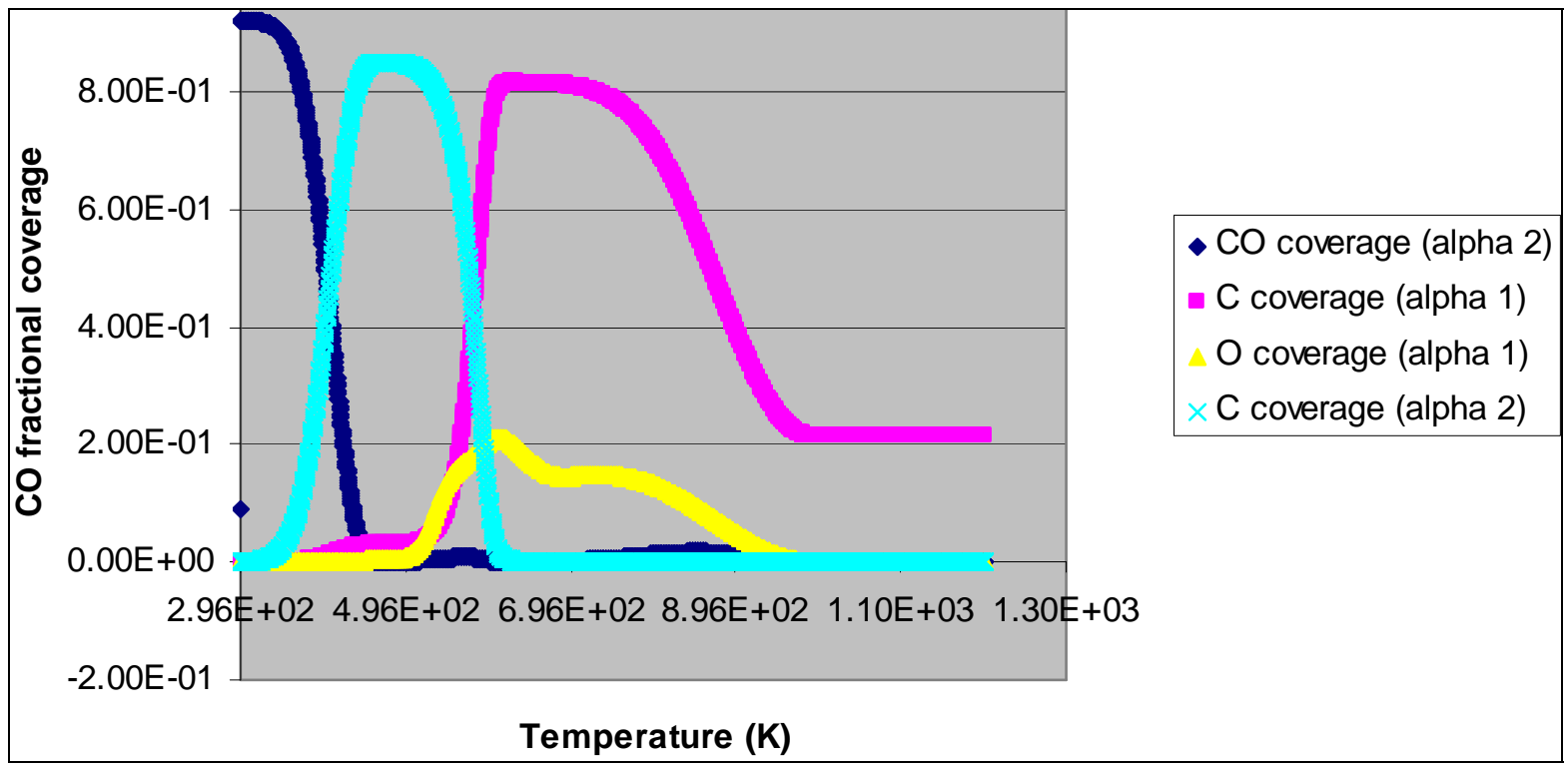

Figure 33 Fractional coverages of $\mathrm{CO}, \mathrm{C}$, and $\mathrm{O}$ as a function of temperature on both $\alpha_{1}$ and $\alpha_{2}$ sites.

The heat of adsorption can be calculated from Equation 19.

$$
\Delta H_{a d s}=E_{r}-E_{f}
$$

Hence for $\alpha_{1}$ site, the heat of adsorption of $\mathrm{CO}\left(\Delta H_{a d s}\right)$ is estimated to be $-50 \mathrm{~kJ} / \mathrm{mol}$ while that for $\alpha_{2}$ site is estimated to be $-36.1 \mathrm{~kJ} / \mathrm{mol}$ The value of heat of adsorption of CO especially on the $\alpha_{1}$ site is comparable to those estimated by TPD on single crystal Fe.

Examination of the mole fraction profiles of $\mathrm{CO}$ and $\mathrm{CO}_{2}$ from the experiment and that predicted by the model indicate a fairly good fit. The undershot of the predicted profiles in the high temperature region is probably due to changes in the structure of the catalyst that are not presently captured by the model. A postmortem examination of the catalyst sample after the TPD experiment did show some physical changes on the structure of the catalyst which may have affected the bed void fraction at these high temperatures.

Some of the strengths of the proposed model are the following:

1. Re-adsorption of desorbed $\mathrm{CO}$ and $\mathrm{CO}_{2}$ were taken into consideration

2. No assumption of quasi-equilibrium 
3. Plug flow model was used in developing the modeling equations instead of a CSTR model. Kanervo et al. showed that it was better to model TPD with a PFR model rather than a CSTR model. [16]

We conclude that the kinetic parameters for the elementary reactions in CO TPD can be successfully estimated from the model presented here. We are presently running CO TPD experiments at various initial CO coverages to see if we will observe a trend that can be used to relate $\mathrm{CO}$ heat of adsorption with coverage.

\section{TPH measurements and model}

Figure 34 shows the isothermal hydrogenation spectra for removal of carbonaceous species from the three $99 \mathrm{FeA}$ series samples. Only one methane formation peak is observed, which reaches a maximum at about 500-800 s, after which methane concentration levels out at a nonzero value after about $3500-4000 \mathrm{~s}$. The observation of only one methane peak is different from results reported for supported iron catalysts in literature.[17] Because of the short exposure to syngas and the mild conditions for removal $\left(50-70^{\circ} \mathrm{C}\right.$ below typical reaction temperatures), the methane is probably associated with hydrogenation of atomic surface carbon. Carbon hydrogenation rate increases in the order Fe, FePt, FeK. 


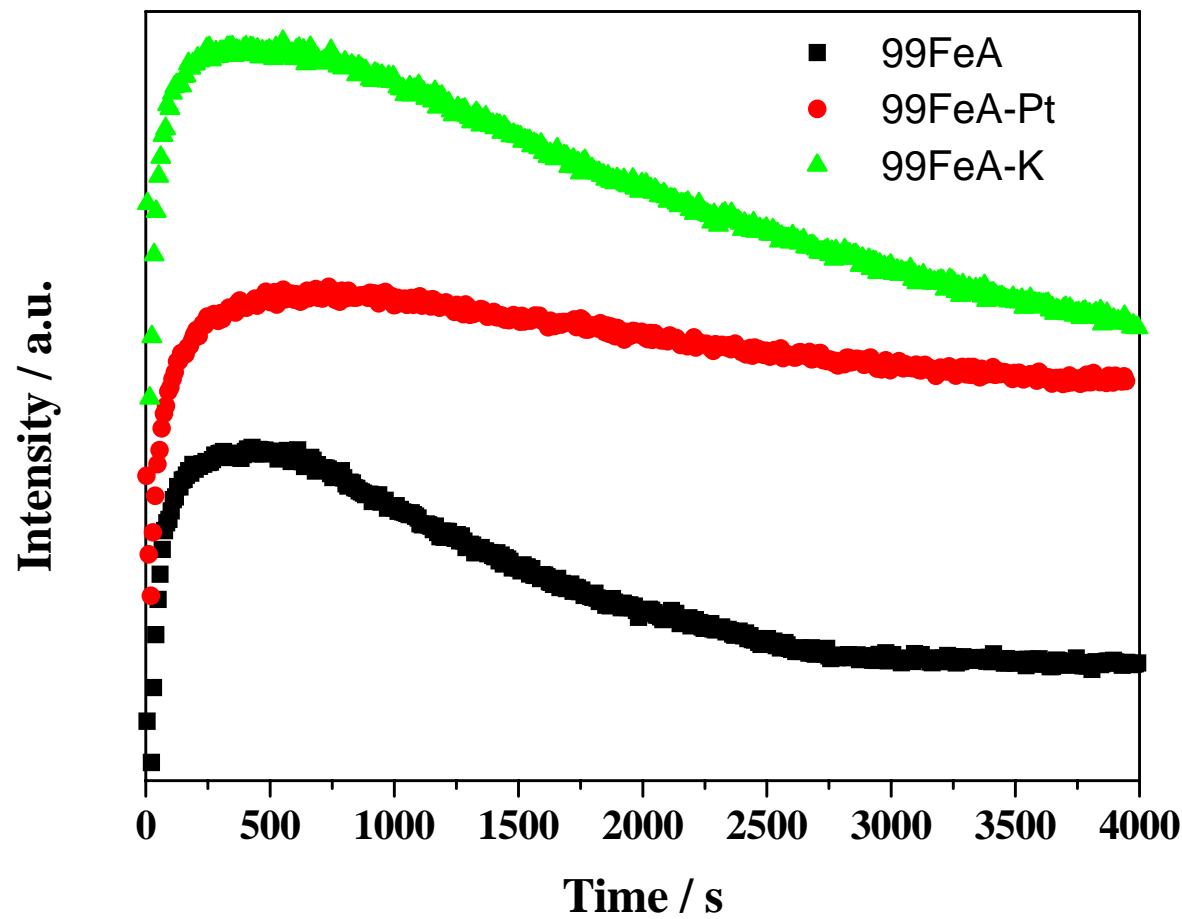

Figure 34 Isothermal hydrogenation spectrum of carbonaceous species of $99 \mathrm{FeA}$ sample at $200^{\circ} \mathrm{C}$.

The results in Figure 34 show that rates of carbon hydrogenation on Fe are readily studied under these mild reaction conditions. Kinetic parameters are obtained by varying the exposure time (and thus carbon coverage from about 0.2 to 0.5 ), hydrogen partial pressure, and reaction temperature and fitting a microkinetic model to the data. Kinetics of $\mathrm{CO}$ dissociation can be obtained by varying the same parameters followed by complete removal of carbon by temperature programmed hydrogenation (TPH). Based on a $\mathrm{H}_{2}$ chemisorption uptake of $97 \mu \mathrm{mol} / \mathrm{g}$, roughly $15 \%$ of a monolayer of $\mathrm{C}$ is removed from the $99 \mathrm{FeA}$ catalyst in this experiment.

Figure 35 contains TPH spectra of 99FeA, 99FeA-Pt, and 99FeA-K samples. The spectra should show methane evolution rate due to reaction of carbon with $\mathrm{H}_{2}$. However, the y-axis is intensity of signal of mass-spectrometer because of lack of calibration data. An enlarged section which includes peaks at low temperatures is shown in Figure 35. The intensity of peaks at high temperature for $99 \mathrm{FeA}$ sample is the highest for $99 \mathrm{FeA}-\mathrm{Pt}$ medium and lowest for $99 \mathrm{FeA}-\mathrm{K}$. A method for quantitative analysis of overlapping TPH peaks for unpromoted and K-promoted Fe FT catalyst was reported by Eliason and Bartholomew [18] Their spectra were fitted with Gaussian curves to yield up to seven peaks, designated as $\alpha_{1}, \alpha_{2}, \beta, \gamma_{1}, \gamma_{2}, \delta_{1}$ and $\delta_{2}$. Figure 36, 
Figure 37 and Figure 38 show deconvoluted TPH spectra for the three unsupported samples of this study. The dashed line is the sum of the individual peaks directly overlaying the measured spectrum in each case. The optimized analysis for the 99FeA and 99FeA-Pt samples yielded seven peaks and the analyses for the 99FeA-K sample yielded eleven peaks. Table 7 lists temperatures associated with each $\mathrm{H}_{2}$-TPSR peak maximum for these three catalysts. $\alpha, \beta, \gamma$, and $\delta$ species are assigned to adsorbed atomic carbon, amorphous surface methylene chains or films, bulk iron carbide, and graphitic carbon. $\alpha_{1}$ and $\alpha_{2}$ refer to atomic carbons on different sites. Four additional individual peaks for the 99FeA-K (compared with 99FeA) suggest that there are unique adsorption sites which may be attributed to Fe-K interfacial sites.

Comparison of the spectral areas in Figure 35 shows that about 4 and 10 times less carbon is deposited on 99FeA-Pt and 99FeA-K compared to 99FeA; thus, $\mathrm{Pt}$ and $\mathrm{K}$ promoters are effective in keeping the surface clean during reaction by facilitating gasification of carbon species. The large high-temperature peaks observed in the spectrum for 99FeA, assigned to iron carbide and $\delta$-carbon, comprise a large fraction of the spectral area, indicating that mostly inactive forms of carbon are deposited on the unpromoted Fe catalyst during a very short period of reaction under very mild conditions (only 10 minutes at $200^{\circ} \mathrm{C}$ ). By contrast, of the relatively small quantity of carbon species deposited during reaction on the surface of $99 \mathrm{FeA}-\mathrm{K}$, about half of are active species, easily gasified with $\mathrm{H}_{2}$ at relatively moderate temperatures. 

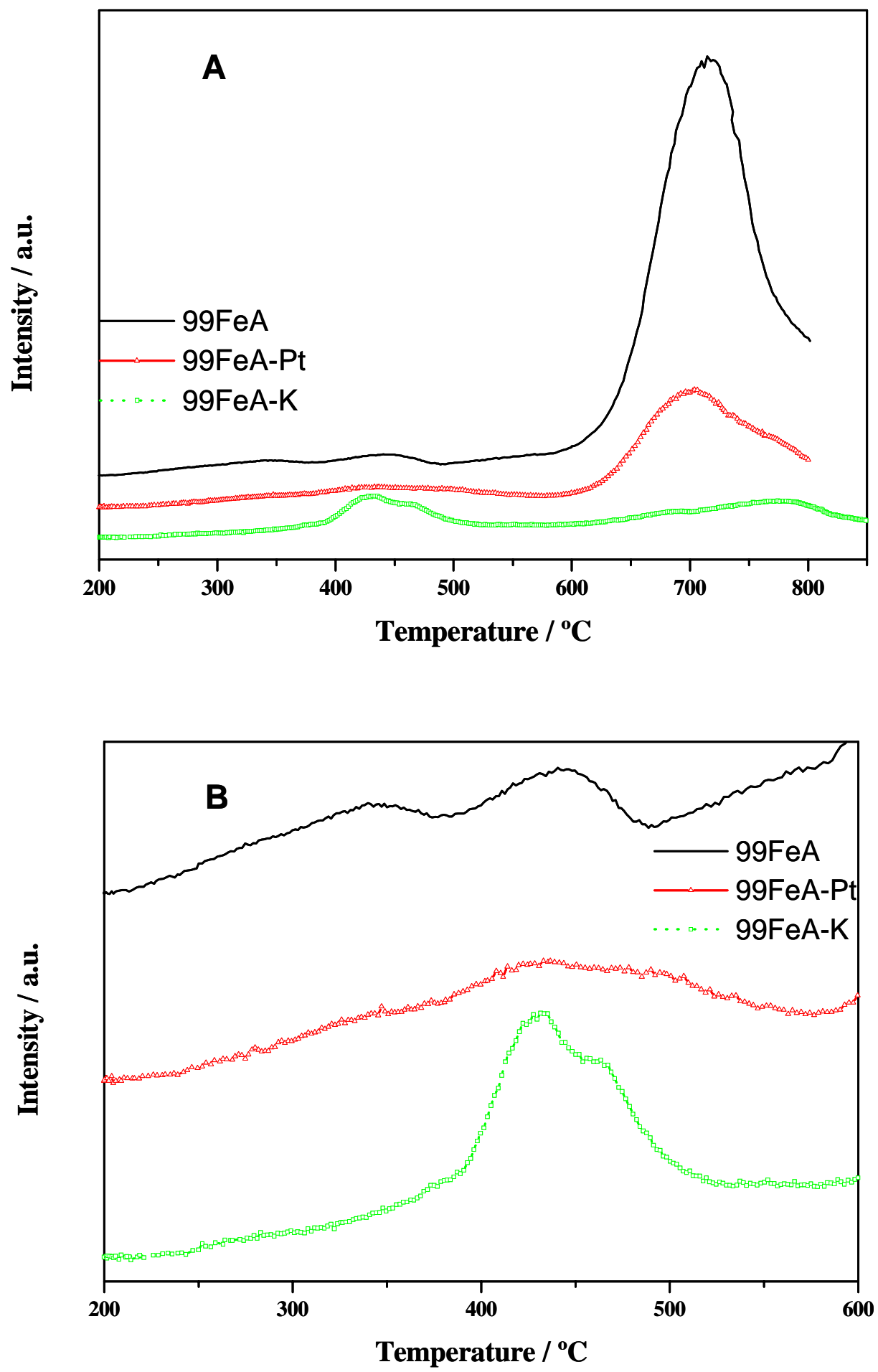

Figure 35 (A) TPH spectra of 99FeA series samples; (B) Enlarged section of temperature period between 200 and $600^{\circ} \mathrm{C}$. 


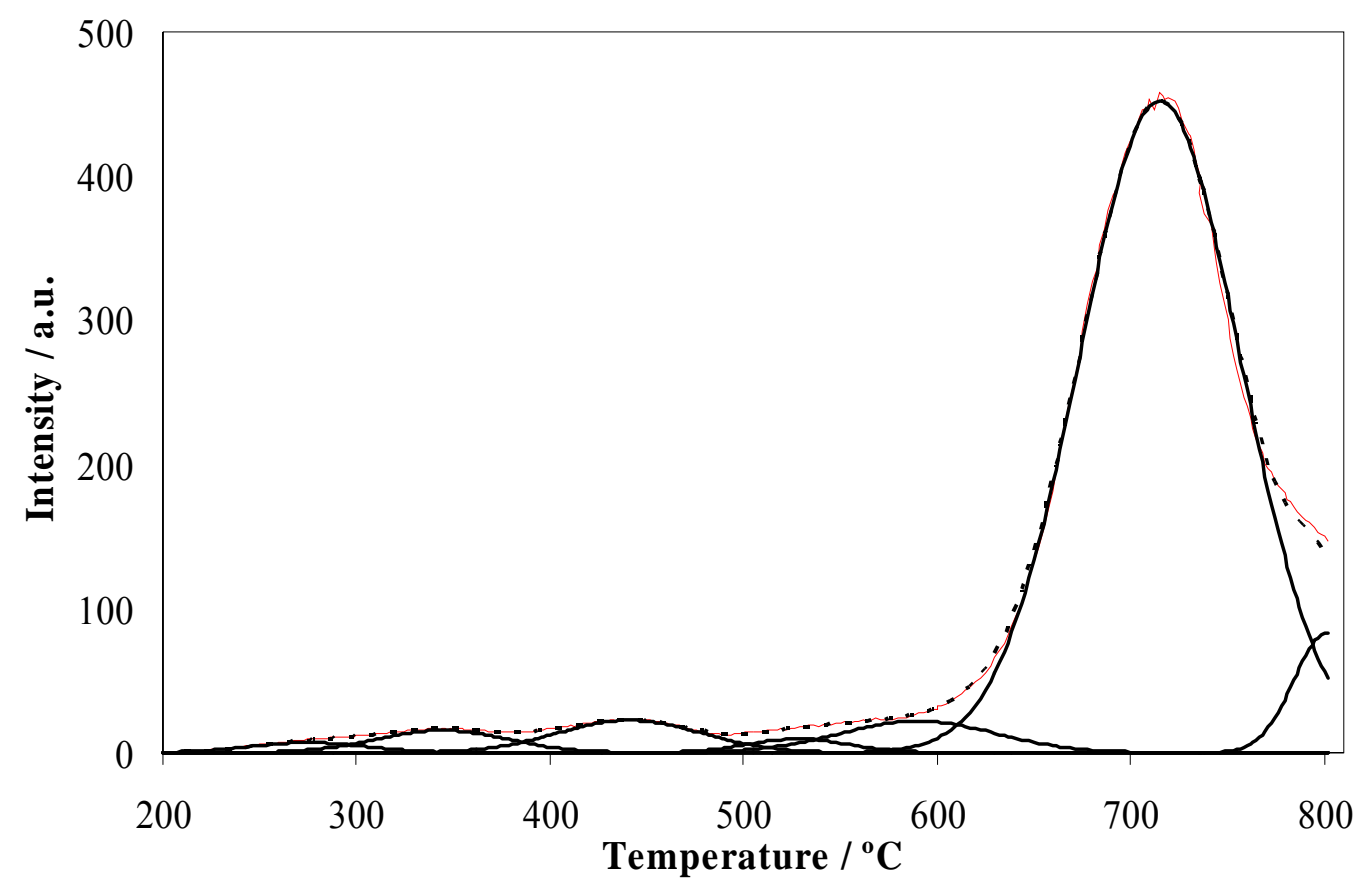

Figure 36 TPH spectra showing individual peak contributions from the carbon species on 99FeA.

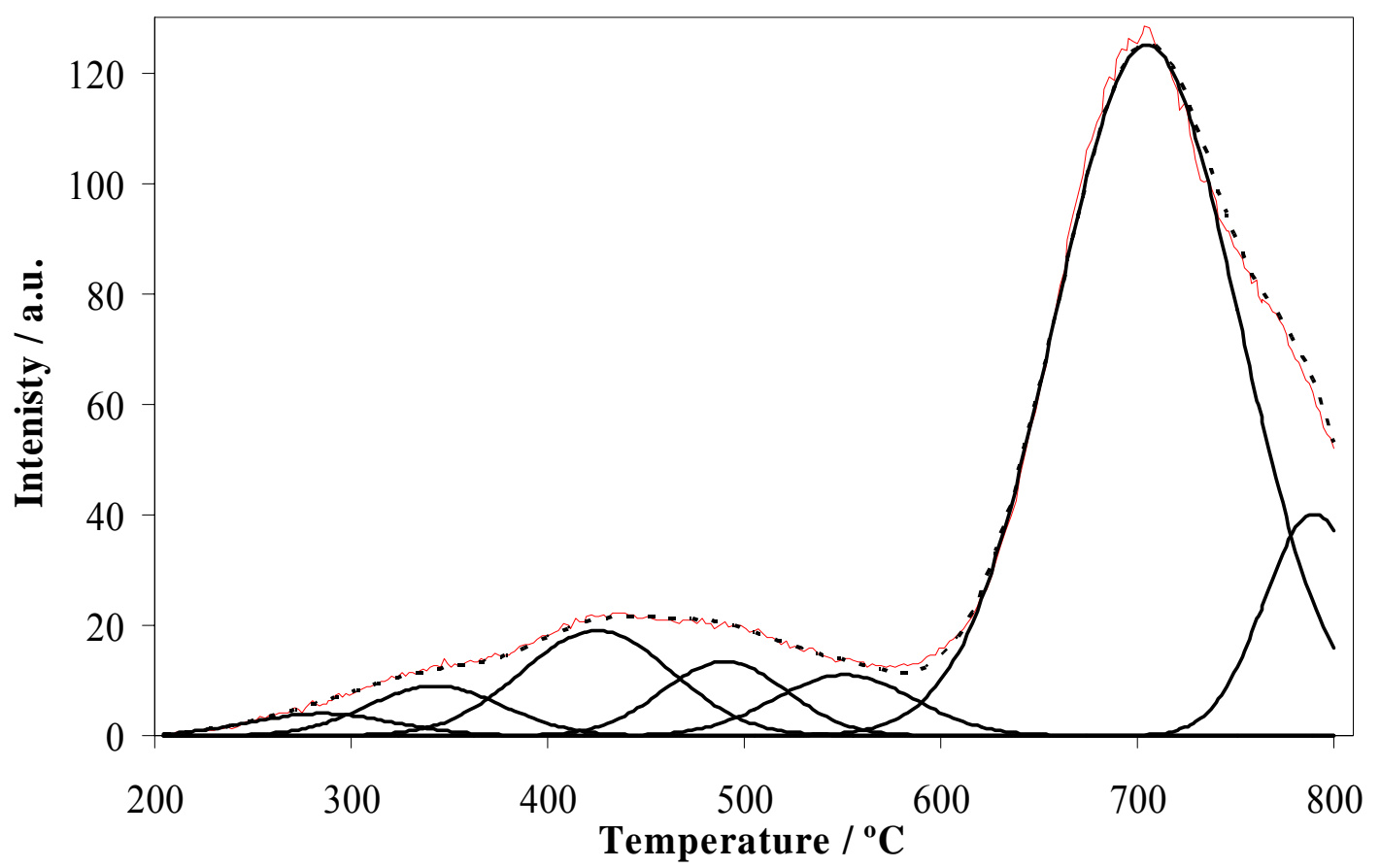

Figure 37 TPH spectra showing individual peak contributions from the carbon species on 99FeA-Pt. 


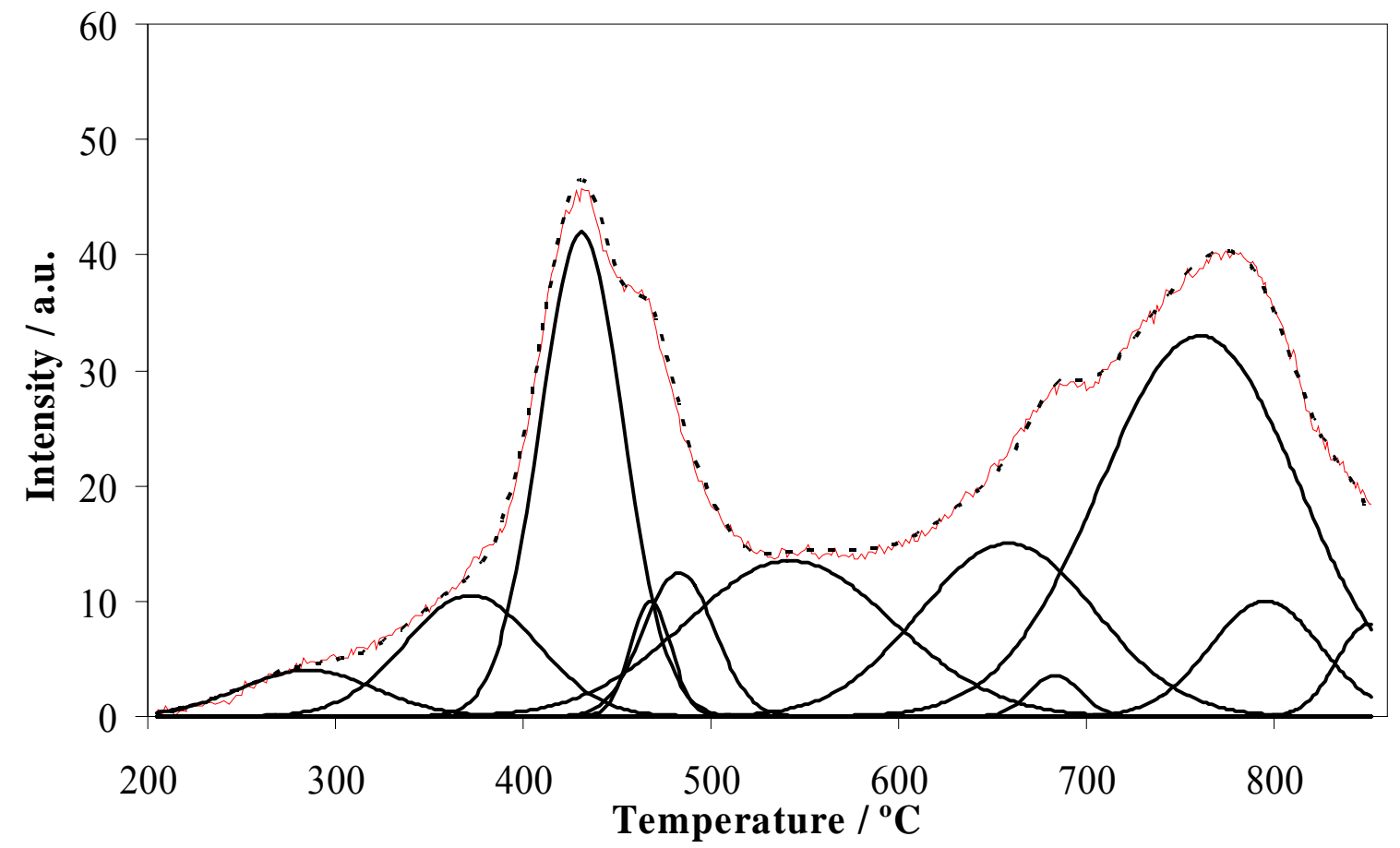

Figure 38 TPH spectra showing individual peak contributions from the carbon species on 99FeA-K.

Table 7 Peak temperature assignments for TPH of carbonaceous species on 99FeA series samples.

\begin{tabular}{lccccccc}
\hline \multirow{2}{*}{ Samples } & \multicolumn{9}{c}{ Carbidic } & Amorphous & \multicolumn{2}{c}{ Carbide } & \multicolumn{2}{c}{ Graphitic } \\
\cline { 2 - 8 } & $\alpha_{1}$ & $\alpha_{2}$ & $\beta$ & $\gamma_{1}$ & $\gamma_{2}$ & $\delta_{1}$ & $\delta_{2}$ \\
\hline $99 \mathrm{FeA}$ & 275 & 344 & 441 & 528 & 590 & 715 & 801 \\
$99 \mathrm{FeA}-\mathrm{Pt}$ & 285 & 343 & 425 & 490 & 551 & 705 & 790 \\
99FeA-K & 285 & 372 & 431 & 483 & 658 & 760 & 795 \\
& & & & & & & \\
\end{tabular}

$*$ The carbon species may be associated with Fe-K sites.

TPH experiments were carried out following FT reaction for the three alumina-supported $10 \%$ and $20 \% \mathrm{Fe}$ catalysts using TGA. Figure 39, Figure 40 and Figure 41 show the weight changes as a function of the temperature and associated TPH spectra. The weight increase (weight change curve) at reaction temperature below $200^{\circ} \mathrm{C}$ for all three samples is probably due to hydrogen adsorption on iron crystallites. Several overlapping derivative peaks are observed above $200^{\circ} \mathrm{C}$. 


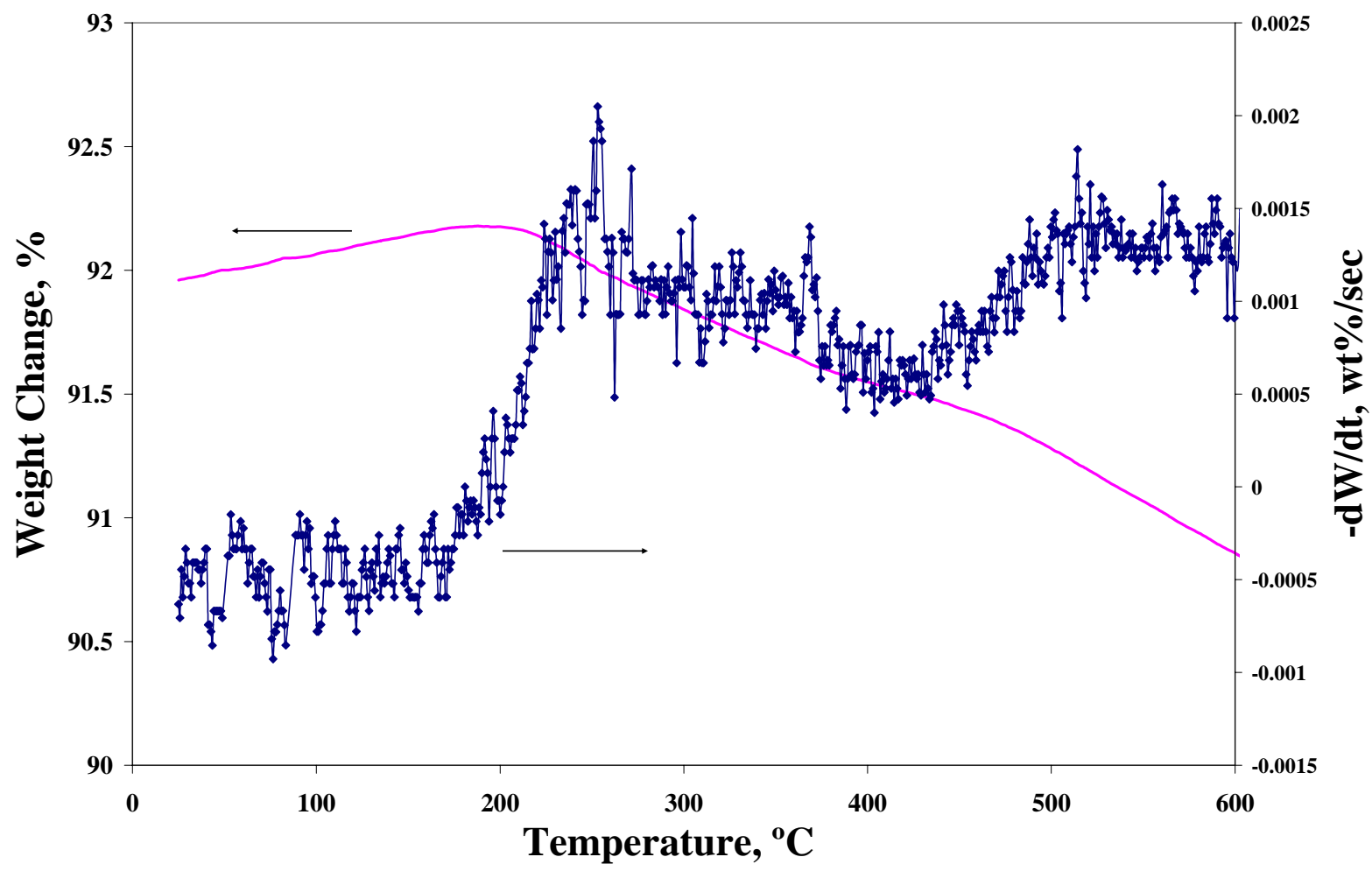

Figure 39 Temperature-programmed hydrogenation of carbonaceous species on $10 \mathrm{FeA}-\mathrm{W}$.

Quantities of carbonaceous species were roughly estimated from weight change curves and used to calculate monolayer carbon equivalents based on hydrogen chemisorption data. Corresponding deconvoluted spectra are shown in Figure 42, Figure 43 and Figure 44; a TPH spectrum obtained by mass spectrometry for the $20 \% \mathrm{Fe} / \mathrm{alumina}$ is shown purposes of comparison in Figure 45. Observed peak temperatures and their assignments are listed in Table 8. Table 9 lists the area under each curve in terms of carbon monolayer equivalents based on iron metal surface area. The corresponding percentage compositions of carbon species are given in Table 10. The carbon mono-layer equivalent of $\alpha$-carbon (reactive atomic carbon) is highest for 10FeA-W. 10FeA-A/E and 20FeA-A/E have the same carbon monolayer equivalents of $\alpha$ carbon. The order of the fractional compositions for various carbon phases for $10 \mathrm{FeA}-\mathrm{W}$ is $\gamma>\beta>\alpha>\delta$; for $10 \mathrm{FeA}-\mathrm{A} / \mathrm{E}$ is $\gamma>\delta>\beta>\alpha$, and for $20 \mathrm{FeA}-\mathrm{A} / \mathrm{E}$ is $\delta>\gamma>\alpha \cong \beta$. The results indicate that $10 \mathrm{FeA}-\mathrm{A} / \mathrm{E}$ and $20 \mathrm{FeA}-\mathrm{A} / \mathrm{E}$ have large fractions of inactive carbon species on the surface after FT reaction. Unfortunately, the TPH experiments had to be terminated at $600^{\circ} \mathrm{C}$ 
because of equipment limitations and hence the fraction of graphitic species should be larger than is shown in Table 9.

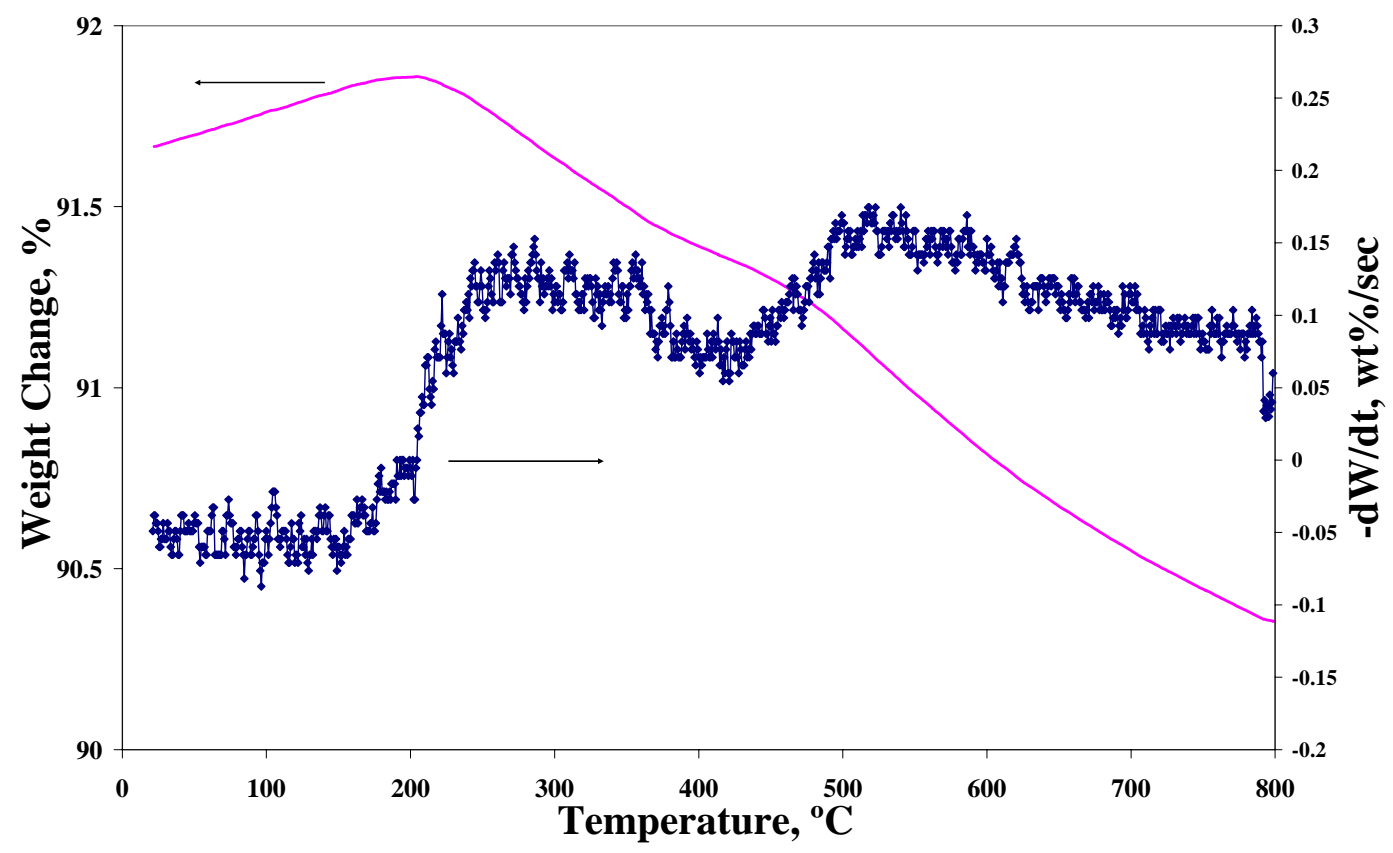

Figure 40 TPH-TGA of carbonaceous species on 10FeA-A/E .

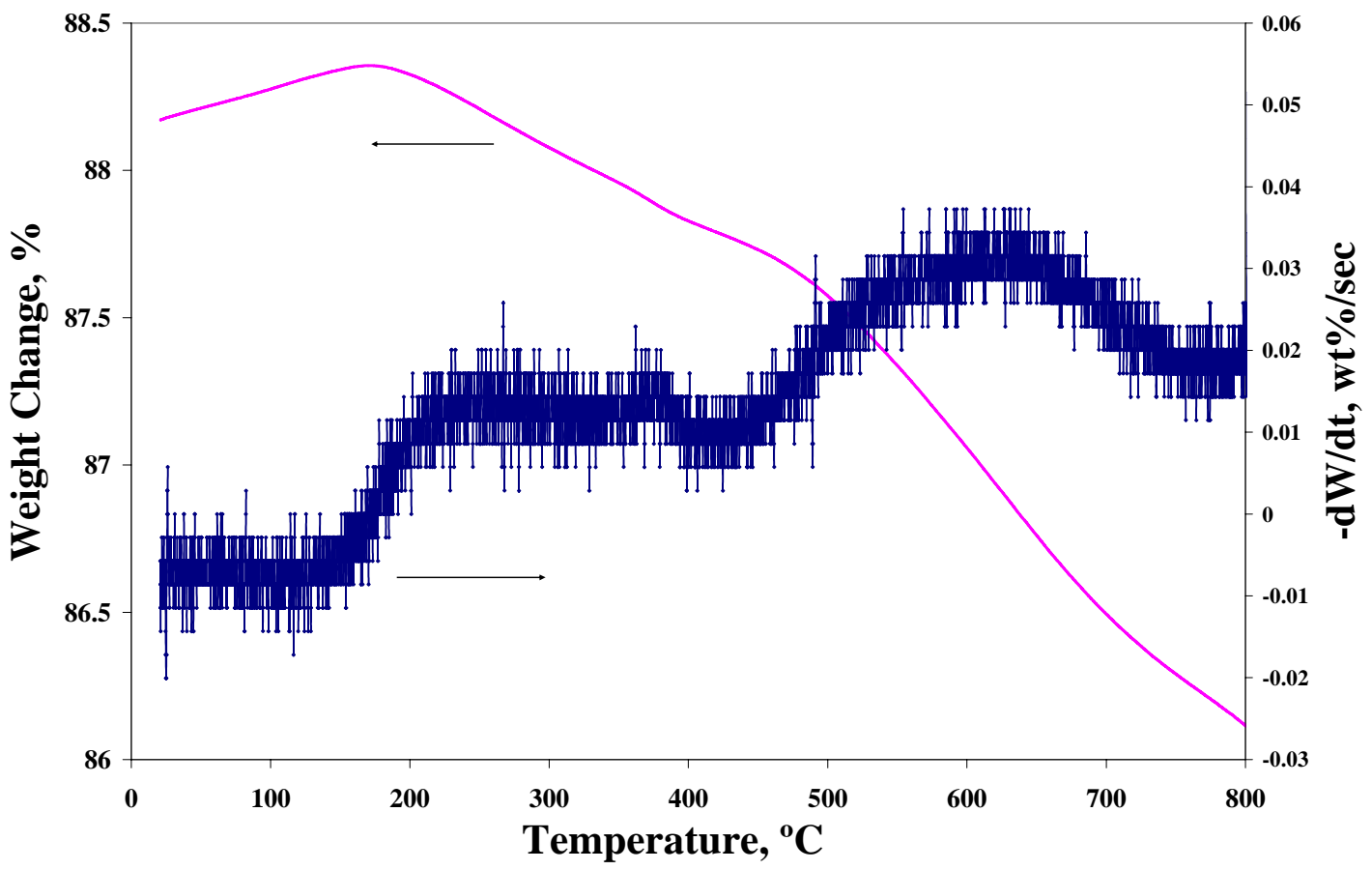

Figure 41 Temperature-programmed hydrogenation of carbonaceous species on 20FeA-A/E . 


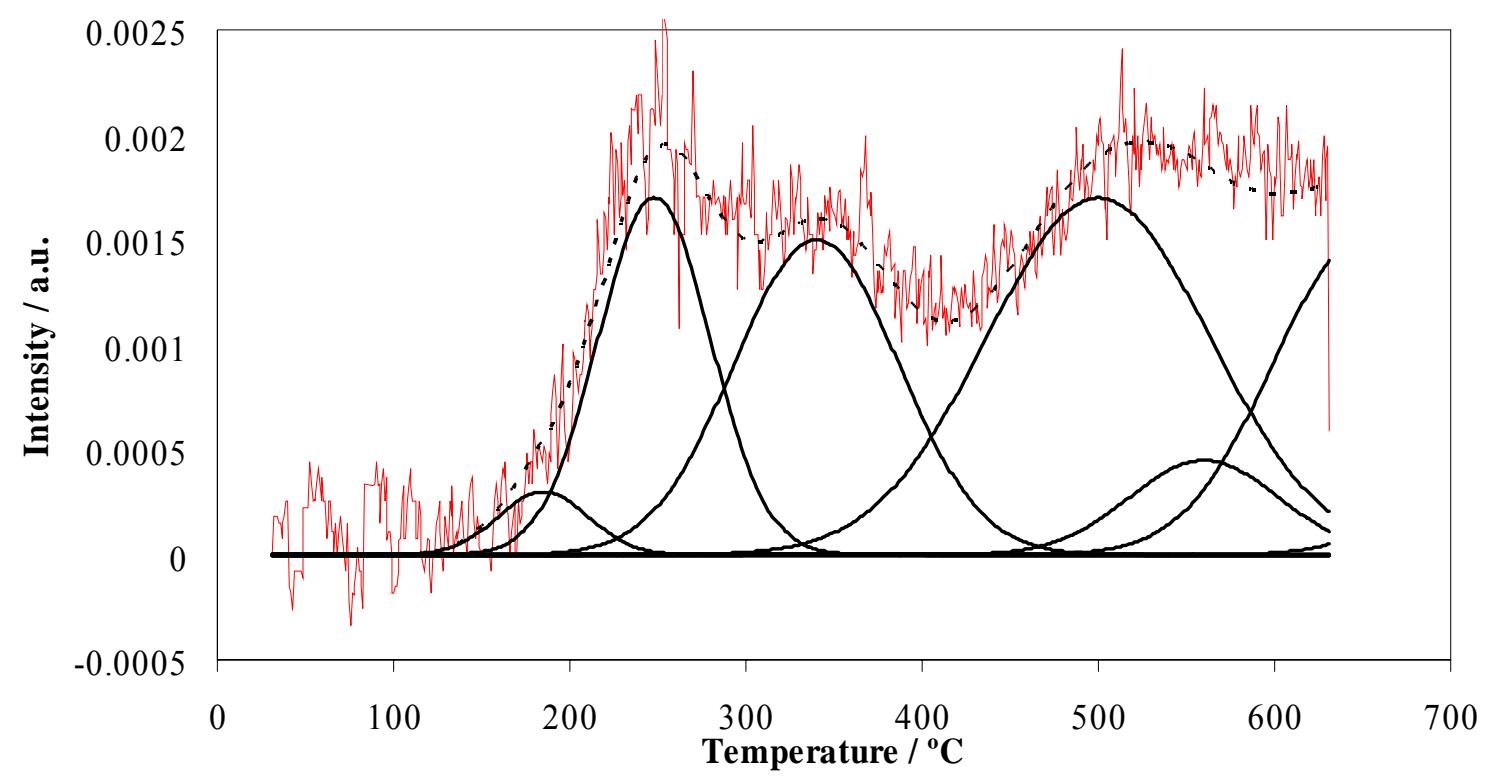

Figure 42 TPH spectra showing individual peak contributions from various carbon species for 10FeA-W.

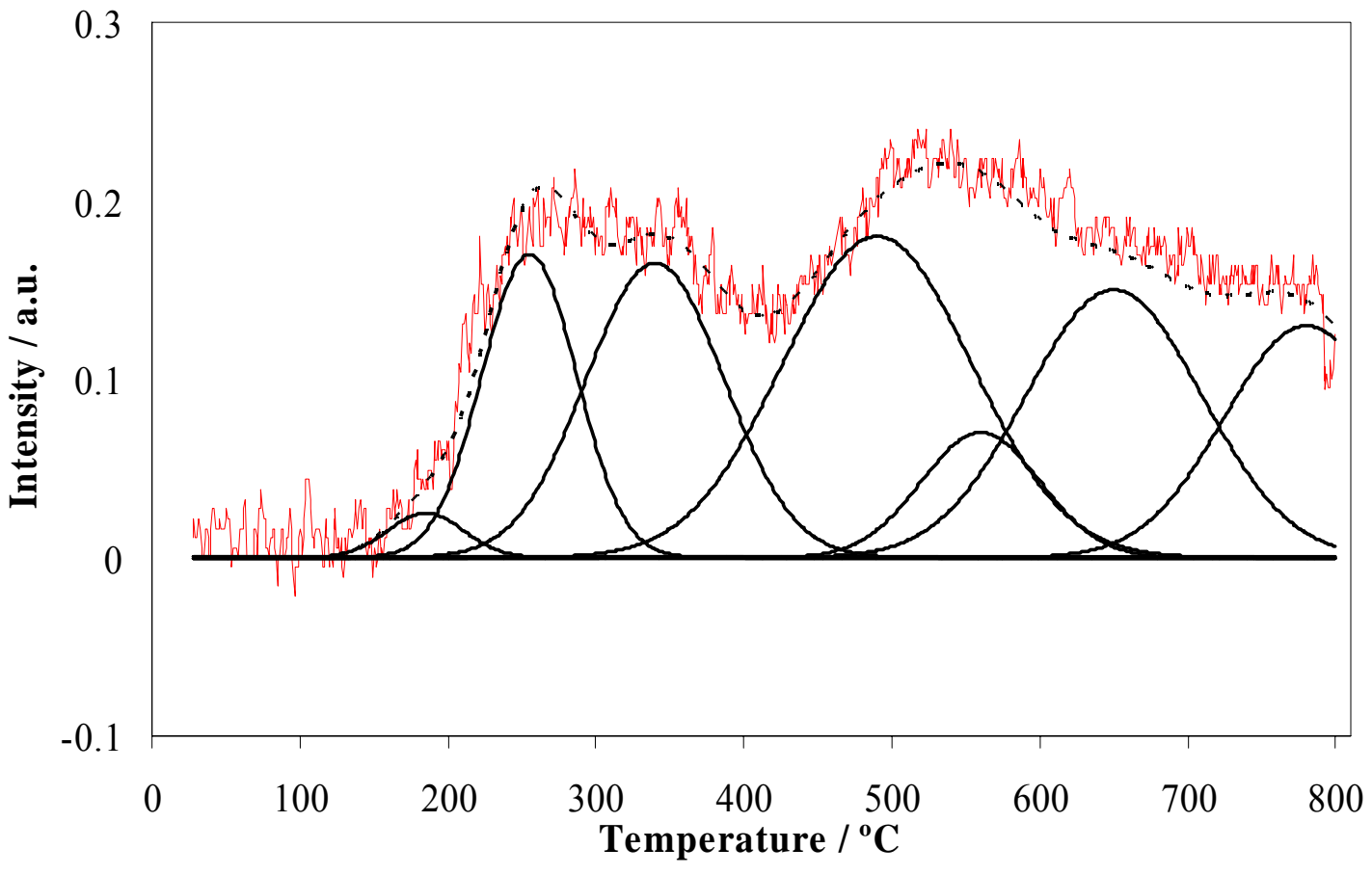

Figure 43 TPH spectra showing individual peak contributions from various carbon species for $10 \mathrm{FeA}-\mathrm{A} / \mathrm{E}$. 


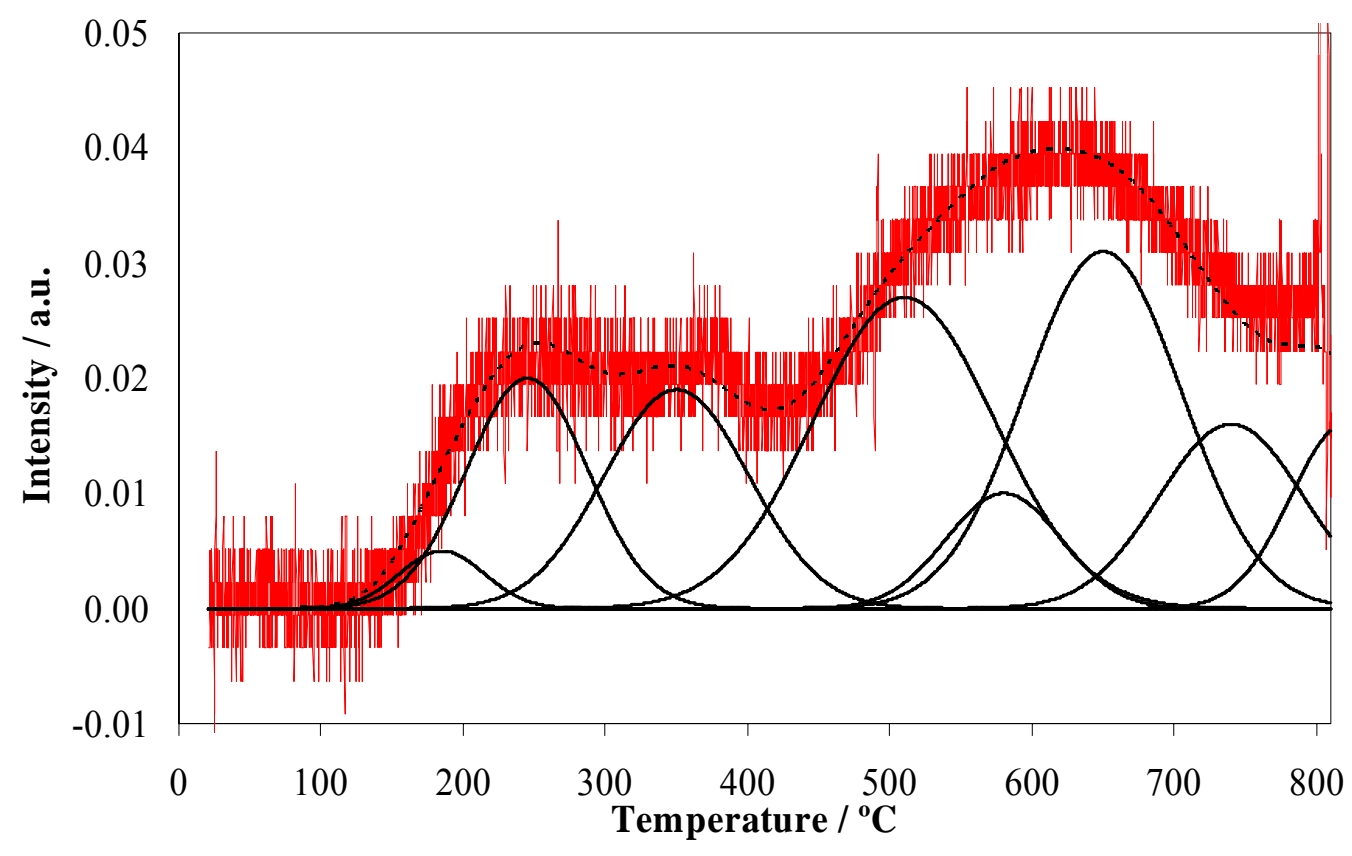

Figure 44 TPH spectrum obtained by TGA showing individual peak contributions from various carbon species for $20 \mathrm{FeA}-\mathrm{A} / \mathrm{E}$.

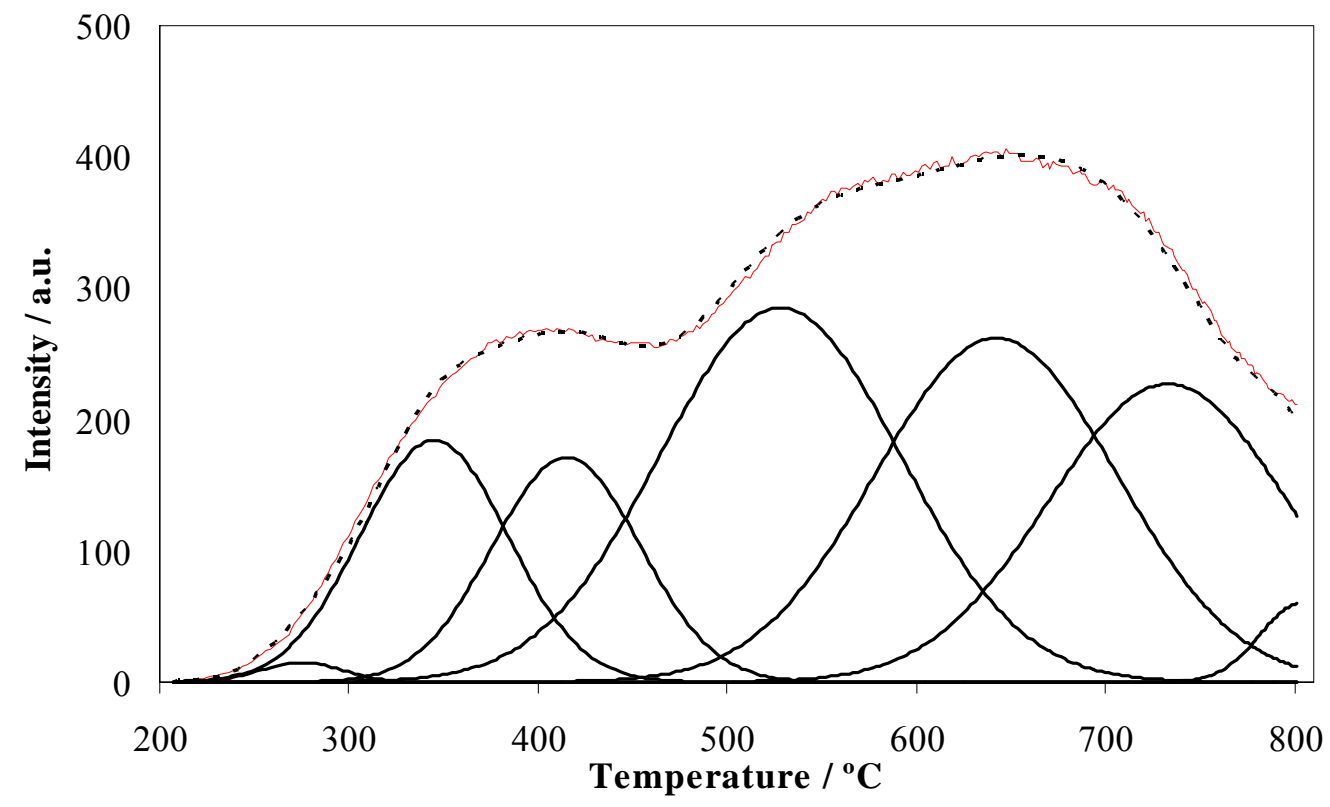

Figure 45 TPH spectrum obtained by TPSR/MS showing individual peak contributions from the various carbon species of $20 \mathrm{FeA}-\mathrm{A} / \mathrm{E}$ sample. 
Table 8 Results of Temperature-Programmed Surface Reaction (TPH) of $\mathbf{H}_{2}$ with carbonaceous species on supported catalysts

\begin{tabular}{|c|c|c|c|c|c|c|c|}
\hline \multirow{3}{*}{ Samples } & \multicolumn{7}{|c|}{ Peak Temperature $\left({ }^{\circ} \mathrm{C}\right)$} \\
\hline & \multicolumn{2}{|c|}{ Carbidic } & \multirow{2}{*}{$\begin{array}{c}\text { Amorphous } \\
\beta\end{array}$} & \multicolumn{2}{|c|}{ Carbide } & \multicolumn{2}{|c|}{ Graphitic } \\
\hline & $\alpha_{1}$ & $\alpha_{2}$ & & $\gamma_{1}$ & $\gamma_{2}$ & $\delta_{1}$ & $\delta_{2}$ \\
\hline $10 \mathrm{FeA}-\mathrm{W}$ & 185 & 248 & 340 & 500 & 560 & 650 & 780 \\
\hline $10 \mathrm{FeA}-\mathrm{A} / \mathrm{E}$ & 185 & 255 & 340 & 490 & 560 & 650 & 780 \\
\hline $20 \mathrm{FeA}-\mathrm{A} / \mathrm{E}$ & 185 & 245 & 350 & 510 & 580 & 650 & 740 \\
\hline
\end{tabular}

Table 9 Fractional compositions for various carbon phases on supported catalysts

\begin{tabular}{cccccccc}
\hline \multirow{2}{*}{ Samples } & \multicolumn{2}{c}{ Carbidic } & Amorphous & \multicolumn{2}{c}{ Carbide } & \multicolumn{2}{c}{ Graphitic } \\
& $\alpha_{1}$ & $\alpha_{2}$ & $\beta$ & $\gamma_{1}$ & $\gamma_{2}$ & $\delta_{1}$ & $\delta_{2}$ \\
\hline $10 \mathrm{FeA}-\mathrm{W}$ & 0.03 & 0.19 & 0.25 & 0.38 & 0.06 & 0.10 & 0.00 \\
$10 \mathrm{FeA}-\mathrm{A} / \mathrm{E}$ & 0.02 & 0.13 & 0.19 & 0.28 & 0.07 & 0.21 & 0.11 \\
$20 \mathrm{FeA}-\mathrm{A} / \mathrm{E}$ & 0.02 & 0.13 & 0.15 & 0.25 & 0.06 & 0.25 & 0.11 \\
\hline
\end{tabular}

Table 10 Monolayer carbon equivalents of peak areas on supported catalysts

\begin{tabular}{cccccccc}
\hline \multirow{2}{*}{ Samples } & \multicolumn{2}{c}{ Carbidic } & Amorphous & \multicolumn{2}{c}{ Carbide } & \multicolumn{2}{c}{ Graphitic } \\
& $\alpha_{1}$ & $\alpha_{2}$ & $\beta$ & $\gamma_{1}$ & $\gamma_{2}$ & $\delta_{1}$ & $\delta_{2}$ \\
\hline $10 \mathrm{FeA}-\mathrm{W}$ & 0.327 & 2.071 & 2.725 & 4.142 & 0.654 & 1.09 & 0 \\
$10 \mathrm{FeA}-\mathrm{A} / \mathrm{E}$ & 0.0424 & 0.2756 & 0.4028 & 0.5936 & 0.1484 & 0.4452 & 0.2332 \\
$20 \mathrm{FeA}-\mathrm{A} / \mathrm{E}$ & 0.0352 & 0.2288 & 0.264 & 0.44 & 0.1056 & 0.44 & 0.1936 \\
\hline
\end{tabular}

By comparison, TPH was run on 20FeA-A/E sample using the TPD/mass-spectrometry system. The TPH spectrum and the corresponding deconvoluted spectra are shown in Figure 45. The distribution of carbonaceous species is very similar to the result obtained by TGA; however, larger amounts of the carbide species were determined from the TPD/MS results.

Figure 46 shows the results of the isothermal hydrogenation experiments over 99FeA sample at different temperatures. As the syngas treatment and isothermal hydrogenation were carried out at $285^{\circ} \mathrm{C}$, three obvious peaks can be seen on the spectrum. Thus, the carbonaceous species may include several carbonaceous species including two kind active surface carbon $\alpha$ and $\beta$, and at least one bulk carbide. At $200^{\circ} \mathrm{C}$, the intensity of isothermal hydrogenation peaks significantly decrease, while carbonaceous species are similar with the sample treated at $285^{\circ} \mathrm{C}$. However, at the two lowest temperatures, $150^{\circ} \mathrm{C}$ and $175^{\circ} \mathrm{C}$, only active surface carbons were formed on surface after syngas treatment. The carbon coverage is less than $1 \mathrm{ML}$ based on the hydrogen chemisorption uptake. Further hydrogenation studies will be conducted at $150^{\circ} \mathrm{C}$. 
The differences in the TPH spectra obtained by TGA and by mass spectrometry (above) for alumina-supported $\mathrm{Fe}$ are very striking. Further study is needed to understand the reasons for these differences. They may relate to (1) differences in the catalyst support and catalyst preparation, (2) fundamental differences in the method of measurement, e.g. the TGA method based on weight loss of the sample may include desorption of water and $\mathrm{CO}_{2}$ while the MS method would not include either effect.

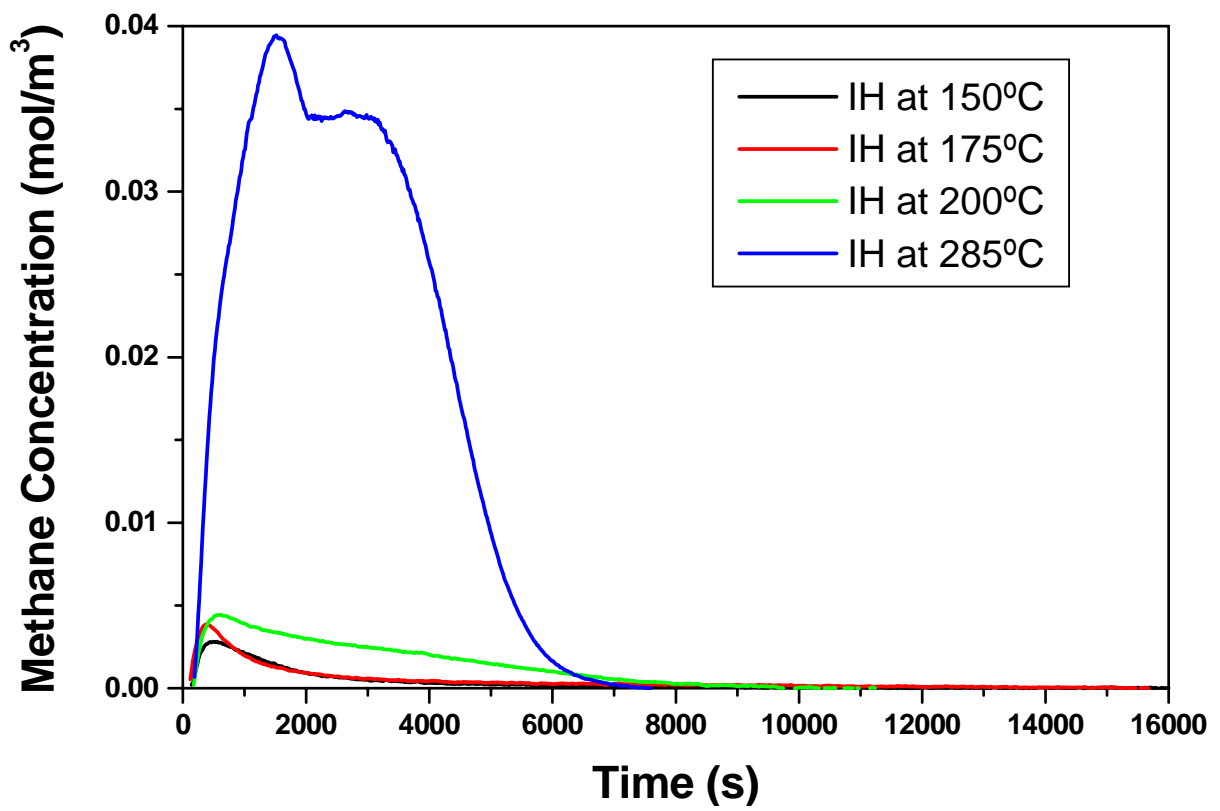

Figure 46 Isothermal hydrogenation spectra of $99 \mathrm{FeA}$ samples after pretreatment in syngas.

The mechanism of methanation of carbonaceous adsorbed species in Fischer Tropsch reaction was hypothesized. Three models based on the types of carbonaceous species involved were proposed: (1) a single site carbon species model (Model 1), a two-site carbon species model (Model 2), and carbene blended with CO insertion model (Model 3). The related elementary steps for each model are listed below in the discussion which follows. A single elementary step is modeled with 2 rate parameters, a frequency factor and activation energy. The reactor model is represented by partial differential equations in time and space for the components. The equation for each gaseous component $i$ is:

$$
\frac{\partial C_{i}}{\partial t}+\frac{1}{\tau} \frac{\partial C_{i}}{\partial x}=\frac{\rho_{b}}{\varepsilon_{b}} R_{w, i}
$$


and the equation for surface component $\mathrm{j}$ is represented by:

$$
\frac{d L_{j}}{d t}=R_{w, j}
$$

where $\rho_{b}$ is the bed density in $\mathrm{kg}_{\text {cat }} \cdot \mathrm{m}_{\text {bed }}{ }^{-3}$; and $\tau$ is the residence time in $\mathrm{s}$, i.e. $\tau=\varepsilon_{b} V_{R} / F_{v} ; \varepsilon_{b}$ is the bed void fraction.

The above partial differential equation was discretized in space into a uniform grid while an ordinary differential equation solver routine DVODE developed by Livermore National Labs was used to integrate the resulting system of ODE's. Rate constants for each elementary step were estimated using an orthogonal distance regression package ODRPACK. Both DVODE and ODRPACK were integrated into a local Fortran routine that was used to regressed the rate constants from experimental data.

The following sets of elementary steps were used to model isothermal hydrogenation at $175^{\circ} \mathrm{C}$. The equations and parameters for fitting Model 2 are attached by way of example in Appendix 1.

\section{$\underline{\text { Single site carbon species model (Model 1) }}$}

The elementary steps of hydrogenation of carbonaceous adsorbed species in Fischer Tropsch reaction to methane in this model are:

$$
\begin{aligned}
& H_{2}+2 s \leftrightarrow 2 H-s \\
& H-s+C-s \leftrightarrow C H-s+s \\
& H-s+C H-s \leftrightarrow C H_{2}-s+s \\
& H-s+C_{2}-s \leftrightarrow C H_{3}-s+s \\
& H-s+\mathrm{CH}_{3}-s \leftrightarrow C \mathrm{CH}_{4}+2 s
\end{aligned}
$$

Figure 47 shows the plot of simulated and experimental methane concentration versus reaction time. The agreement between experiment and prediction is only fair. 


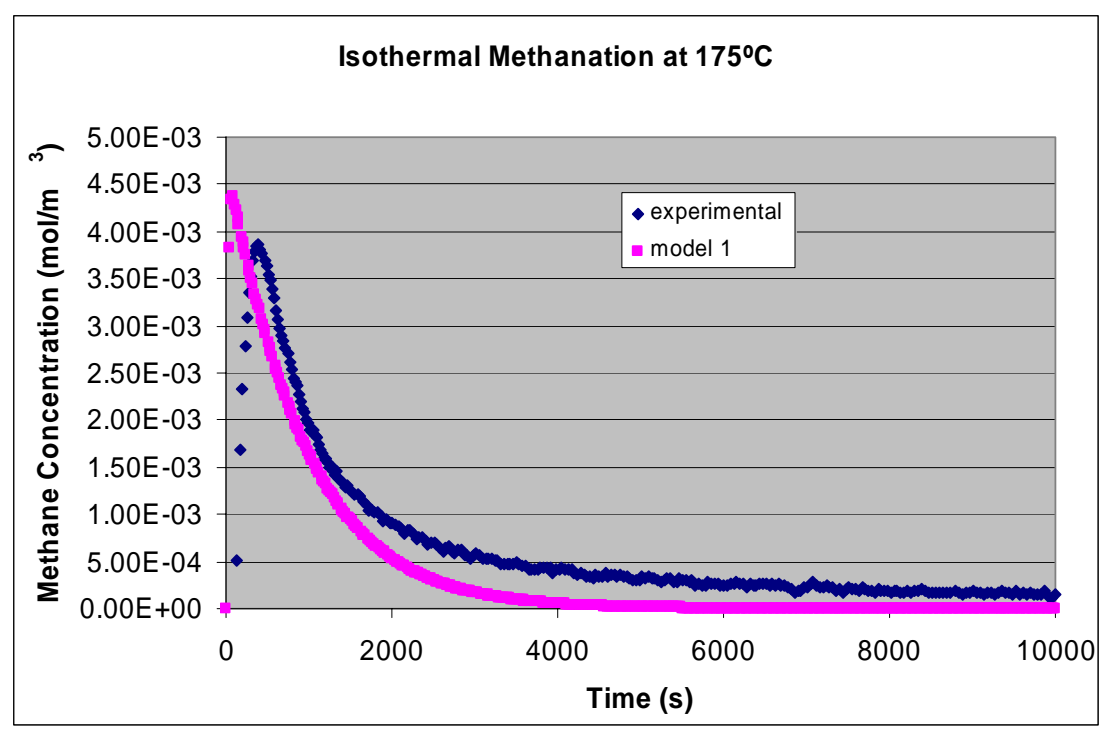

Figure 47 Simulated (model 1) and experimental methane concentration vs. reaction time for the isothermal hydrogenation of carbonaceous species on $99 \mathrm{FeA}$ samples after pretreatment in syngas at $175^{\circ} \mathrm{C}$. 


\section{Two site carbon species model (Model 2)}

Given the broad peak for the experimental data in Figure 47, it is likely that adsorbed carbon atoms are bound to sites of differing coordination (hence surface energy) on the irregular surfaces of small iron crystallites. We have chosen to approximately model this phenomenon by postulating that two different carbon species, $\alpha_{1}$ and $\alpha_{2}$, having different binding energies, are formed on the surface during FT reaction; it is expected that both undergo reaction to methane in the hydrogenation process. The simple kinetic model based on these two carbon species can be written as:

$$
\begin{aligned}
& \mathrm{H}_{2}+2 s \leftrightarrow 2 \mathrm{H}-\mathrm{s} \\
& \mathrm{H}-\mathrm{s}+\mathrm{C}_{\alpha 1}-\mathrm{s} \leftrightarrow \mathrm{CH}-\mathrm{s}+\mathrm{s} \\
& \mathrm{H}-\mathrm{s}+\mathrm{C}_{\alpha 2}-s \leftrightarrow \mathrm{CH}-\mathrm{s}+\mathrm{s} \\
& \mathrm{H}-\mathrm{s}+\mathrm{CH}-\mathrm{s} \leftrightarrow \mathrm{CH}_{2}-s+s \\
& \mathrm{H}-\mathrm{s}+\mathrm{CH}_{2}-\mathrm{s} \leftrightarrow \mathrm{CH}_{3}-\mathrm{s}+\mathrm{s} \\
& \mathrm{H}-\mathrm{s}+\mathrm{CH}_{3}-s \leftrightarrow \mathrm{CH}_{4}+2 \mathrm{~s}
\end{aligned}
$$

While the simulated curve for Model 2 (Figure 48) fits the experimental data better than for Model 1 (Figure 47) it is still not adequate; this result suggests that in addition to surface carbonaceous species other species such as $\mathrm{CH}, \mathrm{CHO}$, etc, also coexist on the surface.

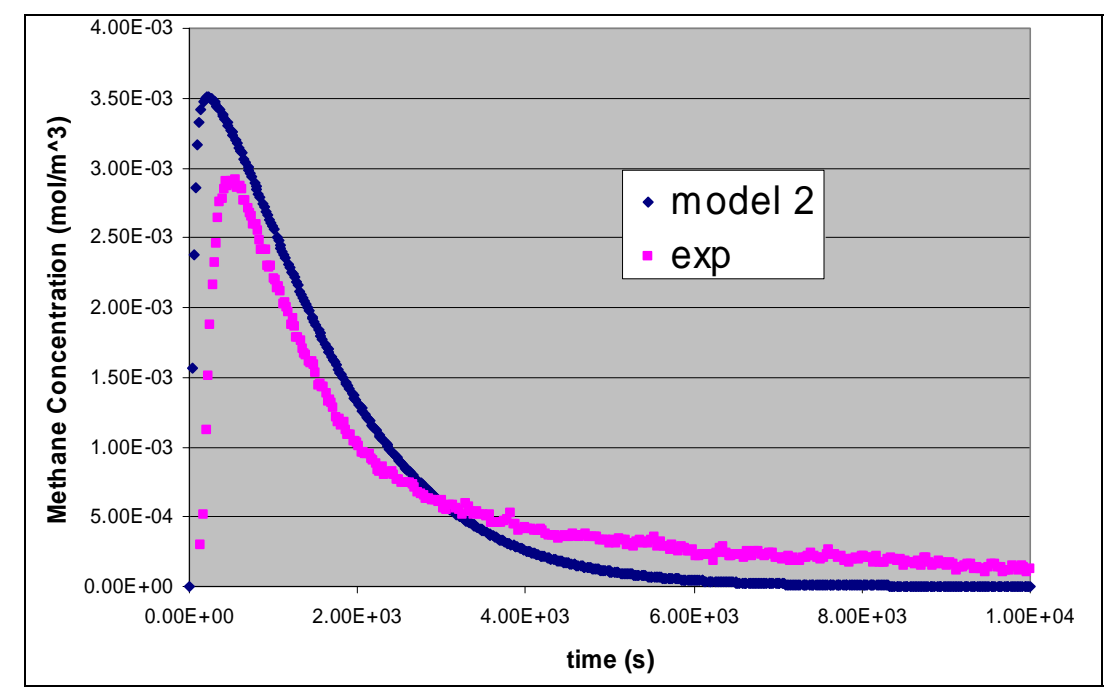

Figure 48 Simulated (model 2) and experimental methane concentration vs. reaction time for the isothermal hydrogenation of carbonaceous species on 99FeA samples after pretreatment in syngas at $175^{\circ} \mathrm{C}$. 
Carbene blended with CO insertion model (model 3)

Considering the complexity of the surface species after pretreatment in syngas, we proposed Model 3 involving 13 elementary steps and 10 surface species, i.e., $\mathrm{H}, \mathrm{CH}, \mathrm{CH}_{2}, \mathrm{CH}_{3}, \mathrm{CHO}$, $\mathrm{CH}_{2} \mathrm{O}, \mathrm{CH}_{3} \mathrm{O}, \mathrm{OH}, \mathrm{O}, \mathrm{CO}$. It involves hydrogenation via both $\mathrm{CH}_{\mathrm{x}}$ and $\mathrm{CHO}$ species. Figure 49 shows the plot of simulated (Model 3) and experimental methane concentration versus reaction time. While Model 3 fits the experimental data better than Models 1 and 2, there is still room for improvement. We have recently found that broadening of the experimental curve occurs as a result of axial and radial dispersion. We tried to minimize this effect through redesign of the reactor (to a smaller diameter); however, we found that it is difficult to design a quartz reactor for smaller diameter with a quartz frit, since the reactor was prone to thermal failure.

$$
\begin{aligned}
& \mathrm{H}_{2}+2 \mathrm{~s} \leftrightarrow 2 \mathrm{H}-\mathrm{s} \\
& \mathrm{CHO}-\mathrm{s}+\mathrm{H}-\mathrm{s} \leftrightarrow \mathrm{CH}_{2} \mathrm{O}-\mathrm{s}+\mathrm{s} \\
& H-s+C-s \leftrightarrow C H-s+s \\
& \mathrm{H}-\mathrm{s}+\mathrm{CH}-\mathrm{s} \leftrightarrow \mathrm{CH}_{2}-\mathrm{s}+\mathrm{s} \\
& \mathrm{H}-\mathrm{s}+\mathrm{CH}_{2}-\mathrm{s} \leftrightarrow \mathrm{CH}_{3}-\mathrm{s}+\mathrm{s} \\
& \mathrm{H}-\mathrm{s}+\mathrm{CH}_{3}-\mathrm{s} \leftrightarrow \mathrm{CH}_{4}(\mathrm{~g})+2 \mathrm{~s} \\
& \mathrm{CHO}-\mathrm{s}+\mathrm{CH}_{3}-\mathrm{s} \leftrightarrow \mathrm{CH}_{3} \mathrm{CHO}(\mathrm{g})+2 \mathrm{~s} \\
& \mathrm{HO}-\mathrm{s}+\mathrm{H}-\mathrm{s} \leftrightarrow \mathrm{H}_{2} \mathrm{O}(\mathrm{g})+2 \mathrm{~s} \\
& \mathrm{O}-\mathrm{s}+\mathrm{H}-\mathrm{s} \leftrightarrow \mathrm{OH}-\mathrm{s}+\mathrm{s} \\
& \mathrm{CH}_{2} \mathrm{O}-\mathrm{s}+\mathrm{H}-\mathrm{s} \leftrightarrow \mathrm{CH}_{3} \mathrm{O}-\mathrm{s}+\mathrm{s} \\
& \mathrm{CH}_{3} \mathrm{O}-\mathrm{s}+\mathrm{H}-\mathrm{s} \leftrightarrow \mathrm{CH}_{3} \mathrm{O}-\mathrm{s}+\mathrm{OH}-\mathrm{s} \\
& \mathrm{CO}-\mathrm{s}+\mathrm{s} \leftrightarrow \mathrm{C}-\mathrm{s}+\mathrm{O}-\mathrm{s} \\
& \mathrm{CO}-\mathrm{s}+\mathrm{OH}-\mathrm{s} \leftrightarrow \mathrm{CO}_{2}(g)-s+\mathrm{H}-\mathrm{s}+\mathrm{s}
\end{aligned}
$$




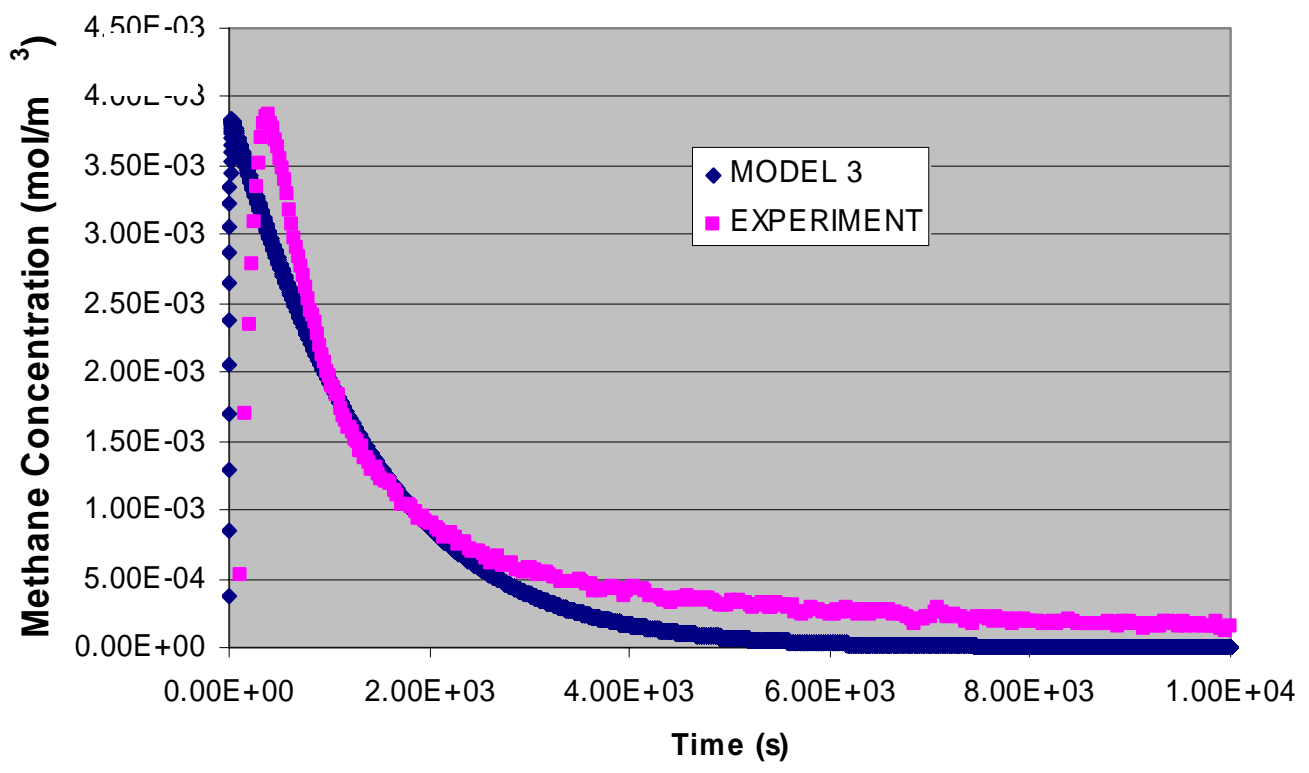

Figure 49 Simulated (Model 3) and experimental methane concentration vs. reaction time for isothermal hydrogenation of carbonaceous species on $99 \mathrm{FeA}$ samples after pretreatment in syngas at $175^{\circ} \mathrm{C}$.

\section{G. Activity tests}

FTS activity of alumina-supported iron catalysts were carried out in a fixed-bed FTS reactor. $\mathrm{CO}$ conversion versus time on stream for $10 \mathrm{FeA}-\mathrm{W}, 10 \mathrm{FeA}-\mathrm{A} / \mathrm{E}$, and $20 \mathrm{FeA}-\mathrm{A} / \mathrm{E}$ catalysts is plotted in Figure 50. CO conversion is higher for the $20 \mathrm{FeA}-\mathrm{A} / \mathrm{E}$ catalyst than for $10 \mathrm{FeA}$ catalysts. The selectivity of $\mathrm{C}_{2+}$, shown in Figure 51 , is up to $86 \%$ for $10 \mathrm{FeA}-\mathrm{A} / \mathrm{E}$ and $20 \mathrm{FeA}-$ $\mathrm{A} / \mathrm{E}$ samples, higher than that for $10 \mathrm{FeA}-\mathrm{W}$ catalyst of $72 \%$. The conversion of CO mostly relies on the iron loadings on alumina supports. Highly iron dispersion of $10 \mathrm{Fe} A-\mathrm{A} / \mathrm{E}$ and $20 \mathrm{Fe} \mathrm{A}-\mathrm{A} / \mathrm{E}$ helps increase $\mathrm{C}_{2+}$ selectivity. However, TOF for $10 \mathrm{FeA}-\mathrm{A} / \mathrm{E}$ and $20 \mathrm{FeA}-\mathrm{A} / \mathrm{E}$ is much lower than $10 \mathrm{FeA}-\mathrm{W}$. All three samples exhibit highly stability over one week. 


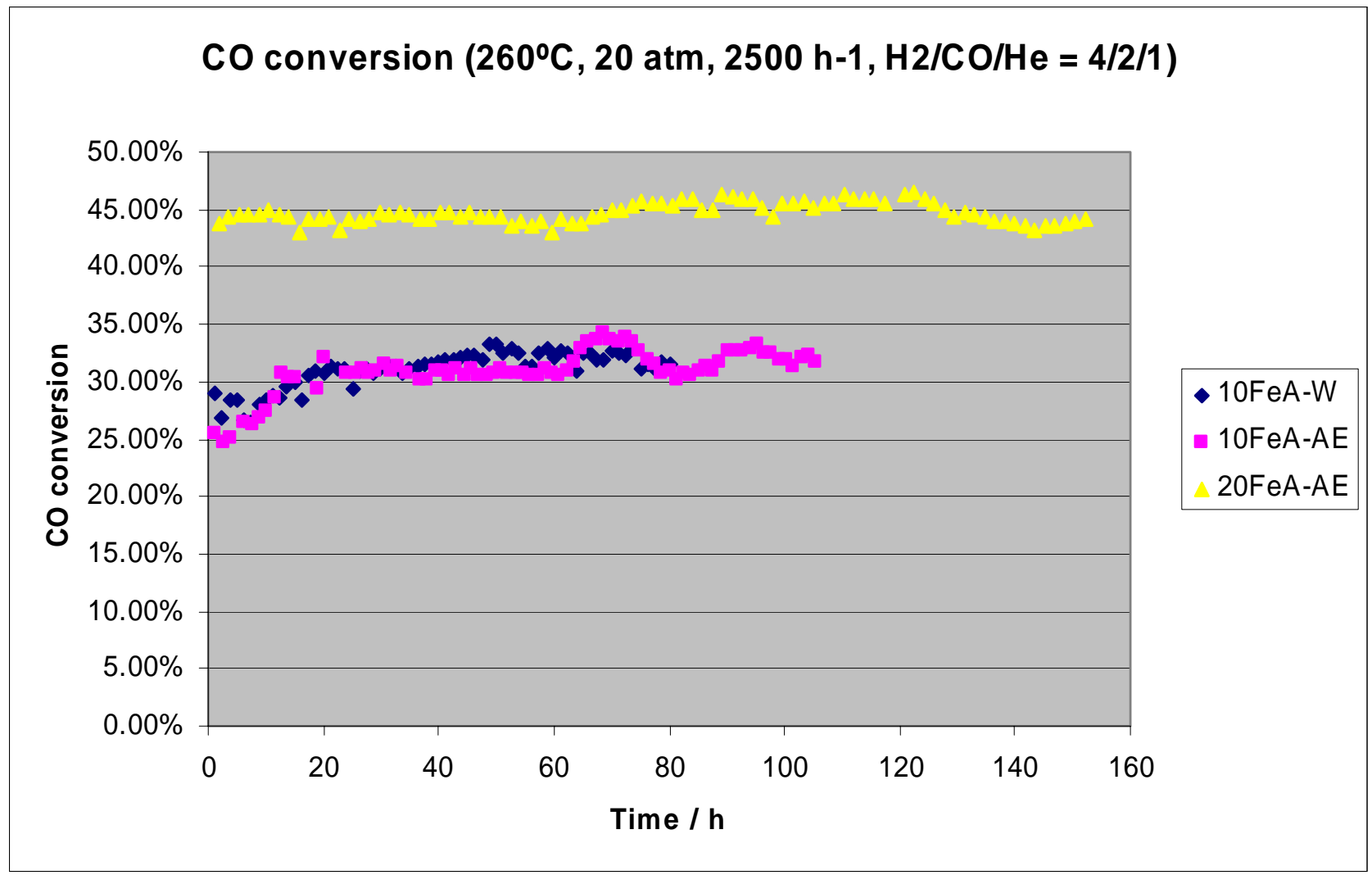

Figure 50 CO conversion plotted as time on stream.

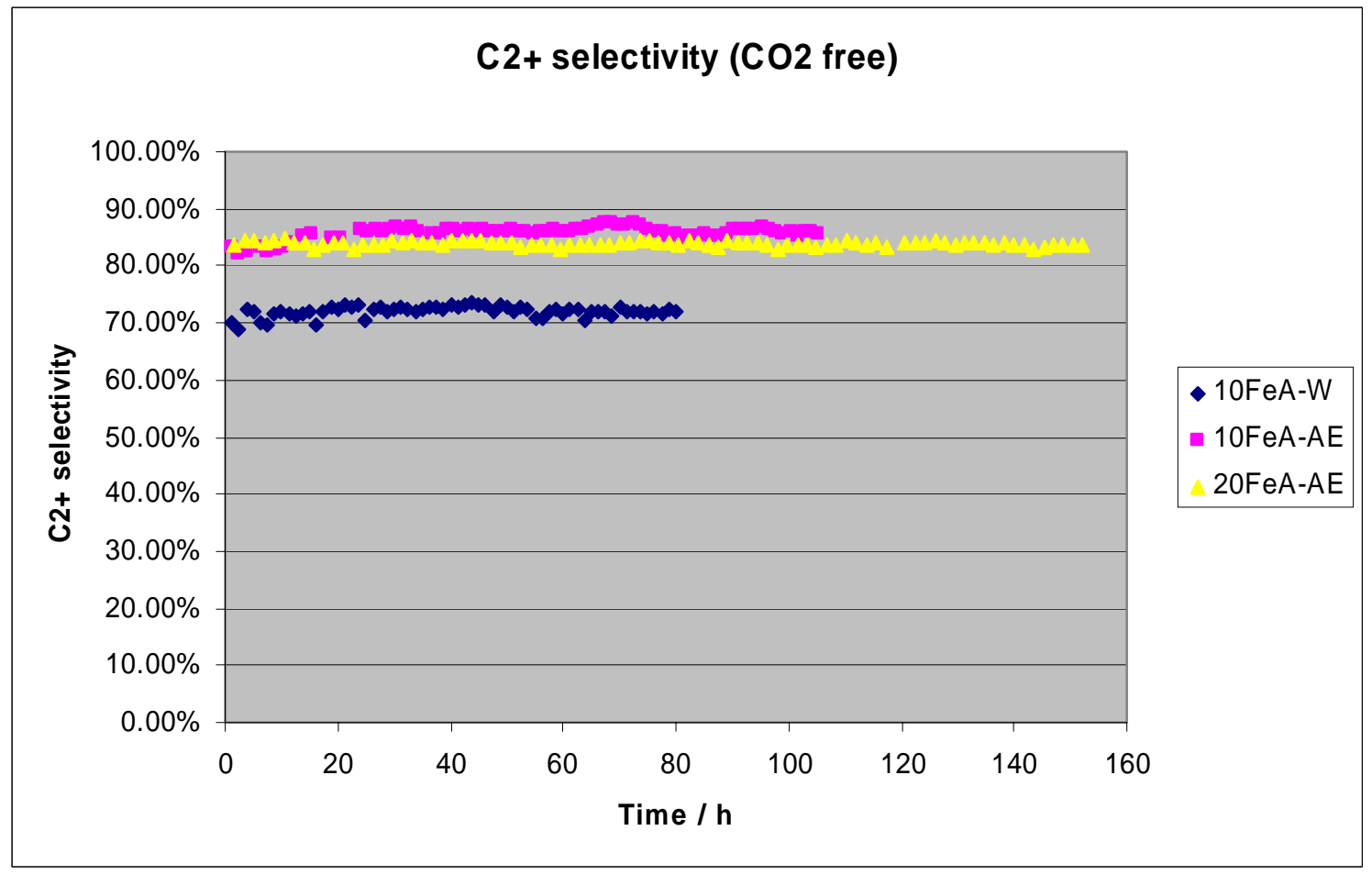

Figure $51 \mathrm{C}_{2+}$ selectivity plotted as time on stream. 


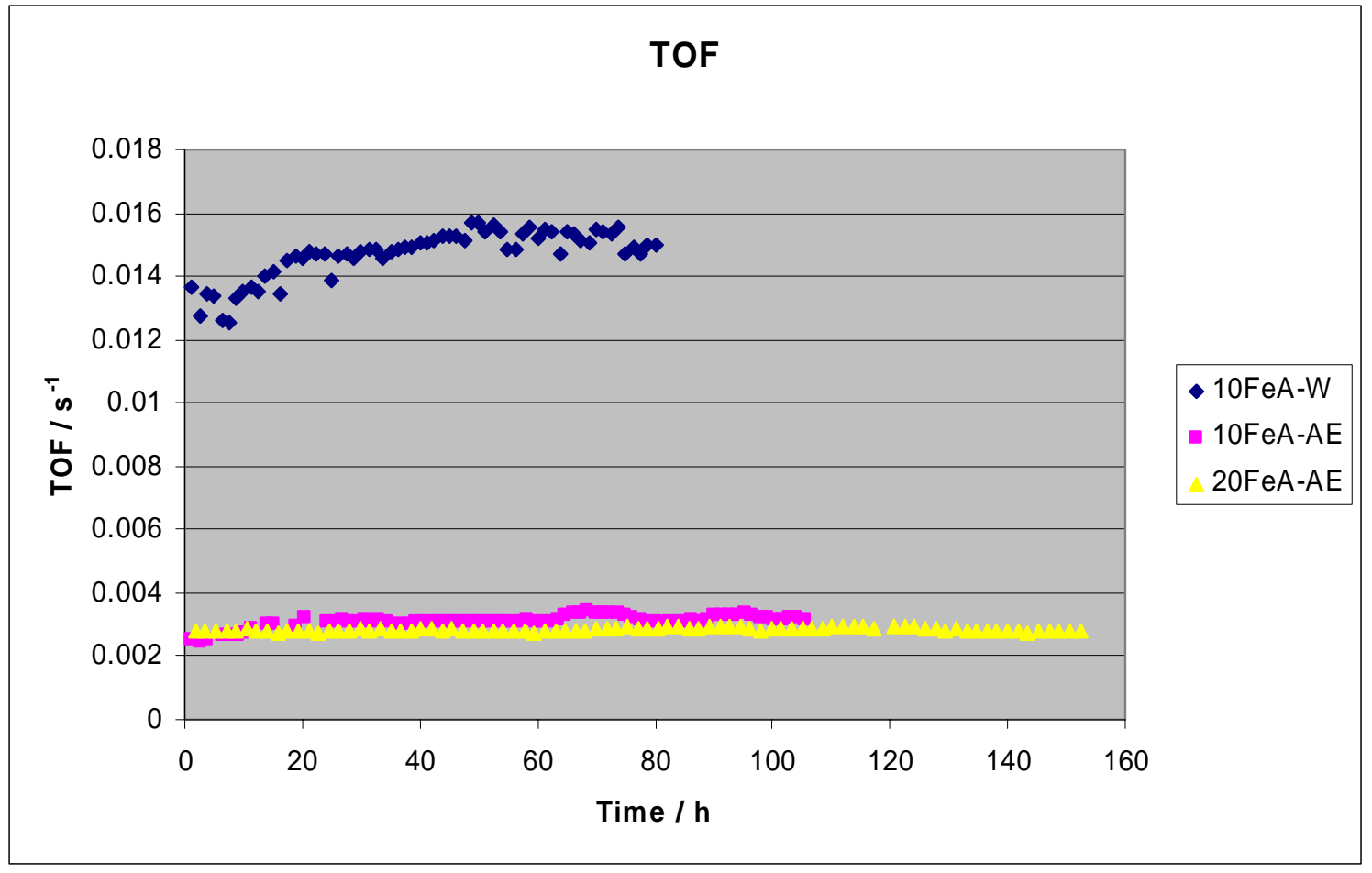

Figure 52 TOF plotted as time on stream.

\section{H. Sequential Design for Determining Kinetic Constants for FT Reaction Rate Model}

Using our Berty Reactor System, we obtained optimized raw kinetic data on unsupported iron catalyst to validate our final mechanistic model. The experimental conditions were obtained using a sequential design approach utilizing a response surface design. The optimality criteria chosen was D-optimality while the rate expression used was a Langmuir-Hinshelwood (LH) type rate expression

$$
r_{\mathrm{C}_{2+}}=\frac{\mathrm{A} P_{\mathrm{CO}}^{0.67} P_{\mathrm{H}_{2}}^{0.83}}{\left(1+\mathrm{D} P_{\mathrm{CO}}^{0.67} P_{\mathrm{H}_{2}}^{0.33}\right)^{2}}
$$

obtained from the mechanistic sequence:

$$
\begin{array}{llll}
\mathrm{CO}+\mathbf{S} & \leftrightarrow & \mathrm{CO}-\mathbf{S} & \\
\mathrm{H}_{2}+2 \mathbf{S} & \leftrightarrow & 2 \mathrm{H}-\mathbf{S} & \\
\mathrm{CO}-\mathbf{S}+\mathbf{S} & \leftrightarrow & \mathrm{C}-\mathbf{S}+\mathrm{O}-\mathbf{S} & \mathrm{RDS} \\
\mathrm{C}-\mathbf{S}+\mathrm{H}-\mathbf{S} & \rightarrow & \mathrm{CH}-\mathbf{S}+\mathbf{S} & \mathrm{RDS} \\
\mathrm{CH}-\mathbf{S}+\mathrm{H}-\mathbf{S} & \rightarrow & \mathrm{CH}_{2}-\mathbf{S}+\mathbf{S} & \\
\mathrm{O}-\mathbf{S}+\mathrm{H}-\mathbf{S} & \leftrightarrow & \mathrm{OH}-\mathbf{S}+\mathbf{S} &
\end{array}
$$




$$
\begin{array}{llll}
2 \mathrm{OH}-\mathbf{S} & \rightarrow & \mathrm{H}_{2} \mathrm{O}+\mathrm{H}-\mathbf{S}+\mathbf{S} & \text { RDS } \\
\text { or } \mathrm{OH}-\mathbf{S}+\mathrm{H}-\mathbf{S} & \rightarrow & \mathrm{H}_{2} \mathrm{O}+2 \mathbf{S} & \text { RDS }
\end{array}
$$

D-optimal design (DOD) method is a proven tool for maximizing the quantity of useful data that can be obtained in the least number of experiments. DOD enables selection of conditions that minimize the variances of the fitted parameters; it does this by "spreading out" the design variables over the available variable space. Sequential DOD is an especially powerful method for greatly reducing uncertainty of the fitted constants with each block or small set of (e.g. 1-4) experiments, the results of which are analyzed and form the basis for choosing the next set of conditions. DOD is also very flexible in allowing incorporation of data from experiments that were not part of the original experimental design.

DOD uses calculus and matrix algebra to maximize the following determinant:

$$
\boldsymbol{D}=\left|\boldsymbol{F}^{\mathrm{T}}(\boldsymbol{X}, \boldsymbol{\theta}) \boldsymbol{F}(\boldsymbol{X}, \theta)\right|
$$

where the function $\boldsymbol{F}$ (or Jacobian) is the matrix of the partial derivatives of the model with respect to the parameters to be regressed. The matrix $\boldsymbol{F}^{\mathrm{T}}$ is the transpose of $\boldsymbol{F} ;\left|\boldsymbol{F}^{\mathrm{T}} \boldsymbol{F}\right|$ is the determinant of the product of $\boldsymbol{F}^{\mathrm{T}}$ and $\boldsymbol{F} . \boldsymbol{X}$ and $\boldsymbol{\theta}$ are matrices of the independent variables and fitted constants, respectively.

The important steps in D-optimal design are shown schematically in Figure 53 and described briefly below.

\section{Specify a preliminary rate function}

$Y_{i}=f\left(x_{\mathrm{i}}, \theta\right)$ in terms of the design parameter inputs, $x_{\mathrm{i}}$, and the kinetic coefficients, $\theta$. Begin with the best available rate equation using the best guesses for the rate coefficients $\theta$. Where there is more than one rate expression, decouple the expressions and fit the rate coefficients independent of each other. Set up a matrix $\boldsymbol{X}$ of the known values (previous experiments) and unknown values (new experiments) of the independent variables and the Jacobian $\boldsymbol{F}\left(\boldsymbol{X}_{\mathrm{i}}, \boldsymbol{\theta}\right)$ : 


$$
\begin{aligned}
\boldsymbol{X} & =\left(\begin{array}{l}
\text { old_experiments } \\
f_{1}\left(P_{\mathrm{C}}, H_{2} / C O, \mathrm{v}, \theta\right) \\
\vdots \\
n e w_{-} \text {experiments } \\
f_{\mathrm{n}}\left(P_{\mathrm{co}}, H_{2} / C O, \mathrm{v}, \theta\right) \\
\vdots
\end{array}\right) \text { where } \theta=A, B, C, D, \ldots \\
\boldsymbol{F} & =\left(\frac{\partial f(x, \theta)}{\partial A}, \frac{\partial f(x, \theta)}{\partial B}, \frac{\partial f(x, \theta)}{\partial C}\right)
\end{aligned}
$$

\section{Use D-optimal criteria and design}

Set up, solve, and maximize the determinant in Equation 9 by optimizing values of the unknown independent variables (see Appendices A and B for details).

a) determine if there are singularities or colinearities of the data, i.e., zero or near zero values of the determinant $\boldsymbol{D}$. A singularity means that at least two of the independent variables are probably collinear, i.e., can't be determined independently. In the case of zero or near-zero values of $\boldsymbol{D}$, design variables can be reset to find a nonzero determinant or alternatively a factorial design (rather than D-optimal design) is used, since it will give the best possible results.

b) determine if the response surface is linear or nonlinear (the response surface is generated by plotting $D$ versus two of the control (independent) variables, e.g. $D$ vs $\mathrm{P}_{\mathrm{CO}}$ and $\mathrm{H}_{2} / \mathrm{CO}$ ratio). If the response surface is linear, fractional factorial design can be used; if nonlinear, DOD should be used.

\section{Collect data.}

Data are collected in blocks with one independent variable held constant, e.g. temperature is held constant within a block but varied from block to block. Blocking has the advantages of (a) allowing treatment of one less independent variable in each block and (b) enabling the experimental design to become more focused and efficient with each succeeding block. Repeat Steps 2 and 3 until the kinetic coefficients have been determined within an acceptable range of uncertainty. 


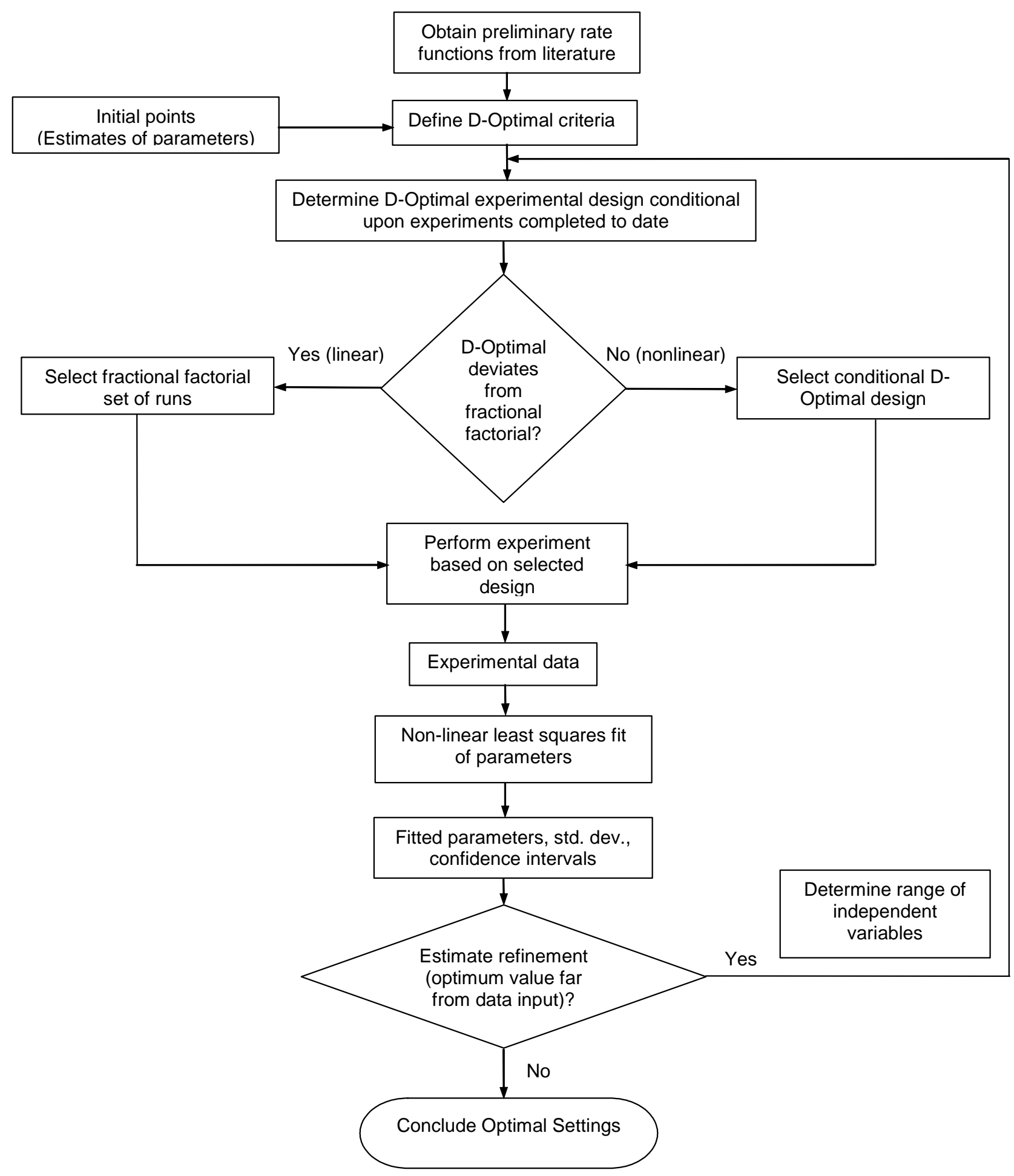

Figure 53 General Approach to D-Optimal Experimental Design. 


\section{Determine kinetic coefficients.}

Once the determinant $\mathrm{D}$ has been maximized and collection of data is finished, the values of the kinetic coefficients, standard deviations and $95 \%$ confidence intervals are determined by nonlinear least squares regression of all data.

\section{Evaluate variability of kinetic coefficients.}

Use standard deviations and $95 \%$ confidence intervals to evaluate the variability of the kinetic coefficients; if variability is too high, repeat Steps 2-4 to obtain additional data in regions of the independent variable space to minimize variability.

Rate data were fitted using a nonlinear least squares routine which involved minimizing the regression squared sum (RSS) defined by Equation 72

$$
R S S(A, B, E)=\sum_{i=1}^{n}\left(Y_{i}-f\left(T_{i}, P_{C O_{i}}, P_{H 2_{i}} ; A, B, E\right)\right)^{2}
$$

where $Y=f\left(T, P_{C O}, P_{\mathrm{H}_{2}} ; A, B, E\right)$ or by maximizing the nonlinear least squares coefficient $r^{2}$ defined by Equation 73

$$
r^{2}=1-\frac{\sum\left(x_{\mathrm{i}}-\hat{x}_{\mathrm{i}}\right)^{2} /(n-\mathrm{v})}{\sum\left(x_{\mathrm{i}}-x_{\mathrm{ave}}\right)^{2} /(n-1)}
$$

where $x_{\mathrm{i}}$ is the set of observations: $\mathrm{i}=1, \ldots . \mathrm{n}, x_{\text {ave }}=(1 / \mathrm{n}) \Sigma x_{\mathrm{i}}$, and $\hat{x}_{\mathrm{i}}$ is predicted by model. If we define $R_{\mathrm{i}}=$ residual squared $=\left(x_{\mathrm{i}}-\hat{x}_{\mathrm{i}}\right)^{2}$, then RSS is the weighted sum of residuals squared, i.e. $R S S=\Sigma R_{\mathrm{i}} /(n-\mathrm{v})=\Sigma\left(x_{\mathrm{i}}-\hat{x}_{\mathrm{i}}\right)^{2} /(n-\mathrm{v})$ where $\mathrm{v}$ is the number of variables; accordingly, RSS is the numerator in the second term of Eqn. 73. The denominator of the second term in Eqn. 73 is the overall maximum error, $O M E=\Sigma y_{\mathrm{i}} /(n-1)=\left(x_{\mathrm{i}}-x_{\mathrm{av}}\right)^{2} /(n-1)$. Note that if the ratio of RSS/OME is close to unity, RSS approaches the maximum error (this is as bad as it gets). However, if this ratio is small, the sum of errors squared is relatively small and the probability of a good fit is high (as good as it gets). Thus $r^{2}$ is the probability of a good fit of the model predictions to the observed data; it is, in fact, a much better discriminator of the goodness of fit than is RSS or the chi-squared probability which is based on RSS. Indeed it will be shown in Section III that $r^{2}$ can be used to discriminate among fits of different models to the same set of data or alternatively among fits of the same model to data sets having the same basis set but to 
which new data have been added in incrementally, while the chi-squared probability is essentially unity for most of these fits.

Rate data were fitted to the various models using the Excel solver, since this tool is relatively easy to use, grounded on sound methods for solving equations, and widely available; in addition, Excel makes many useful statistical functions readily available to users. Moreover, Excel's plotting tools are also easy to use and yield reasonably high quality plots. The results of fitting data using Excel's solver were essentially the same as those obtained using a nonlinear regression tool available in Mathcad.

Initial set of five experimental points in terms of outlet partial pressures of carbon monoxide (CO) and hydrogen $\left(\mathrm{H}_{2}\right)$ as shown in the Table 11 below were chosen based on factorial experimental design. Then the kinetic constants were regressed based on results observed from these experimental points. D-optimality criterion was then applied resulting in another experimental condition. The experiment was then performed at this new experimental point with the data obtained added to the previous data and then regressing the kinetic constants. The process was continued until the values of the regressed constants and that of the D-optimality criterion asymptotes to a constant value. This process was carried out at two different temperature blocks $\left(220^{\circ} \mathrm{C}\right.$ and $\left.239^{\circ} \mathrm{C}\right)$ respectively 
Table 11 Experimental Run Number and Reactor Outlet Conditions at $220^{\circ} \mathrm{C}$.

\begin{tabular}{ccc}
\hline $\begin{array}{c}\text { Run } \\
\#\end{array}$ & $\begin{array}{c}\mathrm{P}_{\mathrm{H} 2} \\
(\mathrm{~atm})\end{array}$ & $\begin{array}{c}\mathrm{P}_{\mathrm{CO}} \\
(\mathrm{atm})\end{array}$ \\
\hline 1 & 9.4 & 3.9 \\
2 & 9.5 & 3.9 \\
3 & 3.8 & 4.0 \\
4 & 3.8 & 0.9 \\
5 & 10.1 & 0.7 \\
6 & 9.8 & 4.0 \\
7 & 10.0 & 0.7 \\
8 & 3.9 & 0.9 \\
9 & 9.9 & 4.0 \\
10 & 9.6 & 4.0 \\
11 & 10.1 & 0.8 \\
12 & 3.8 & 0.9 \\
13 & 10.1 & 0.7 \\
14 & 3.8 & 0.9 \\
15 & 9.9 & 4.0 \\
16 & 3.8 & 0.9 \\
17 & 6.9 & 2.4 \\
18 & 3.7 & 4.1 \\
19 & 9.7 & 3.9 \\
20 & 9.8 & 3.8 \\
\hline
\end{tabular}

Figure 54 and Figure 55 show the plots of the D-optimal criteria and the regressed kinetic constants as a function of run number obtained at $220^{\circ} \mathrm{C}$. 


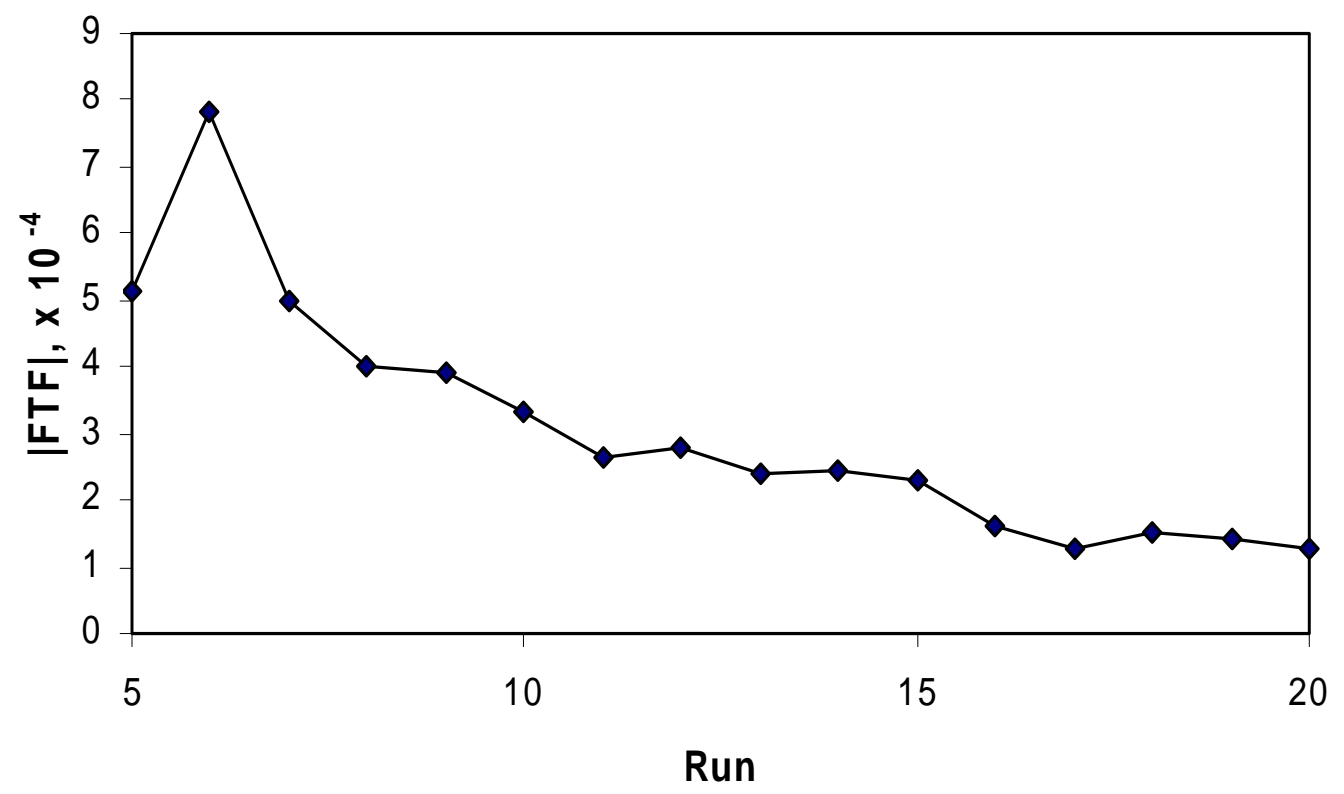

Figure 54 D-Optimal criteria as a function of run number at $220^{\circ} \mathrm{C}$.

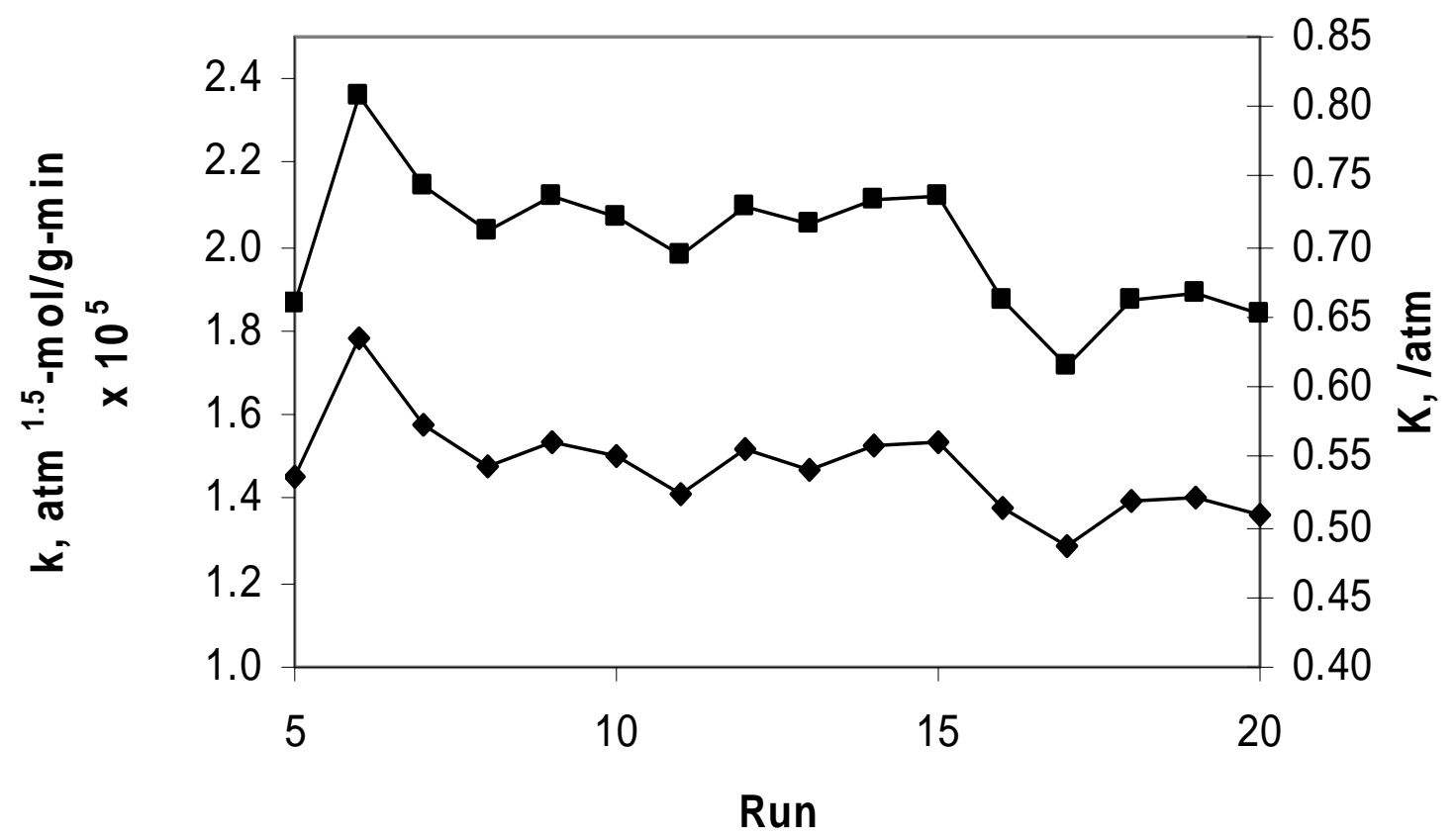

Figure 55 Regressed kinetic constants as a function of run number at $220^{\circ} \mathrm{C}$.

Figure 56 shows the joint confidence interval plots as a function of experimental run while Figure 57 is a parity plot showing the experimentally observed reaction rate against predicted reaction rate at $220^{\circ} \mathrm{C}$. 


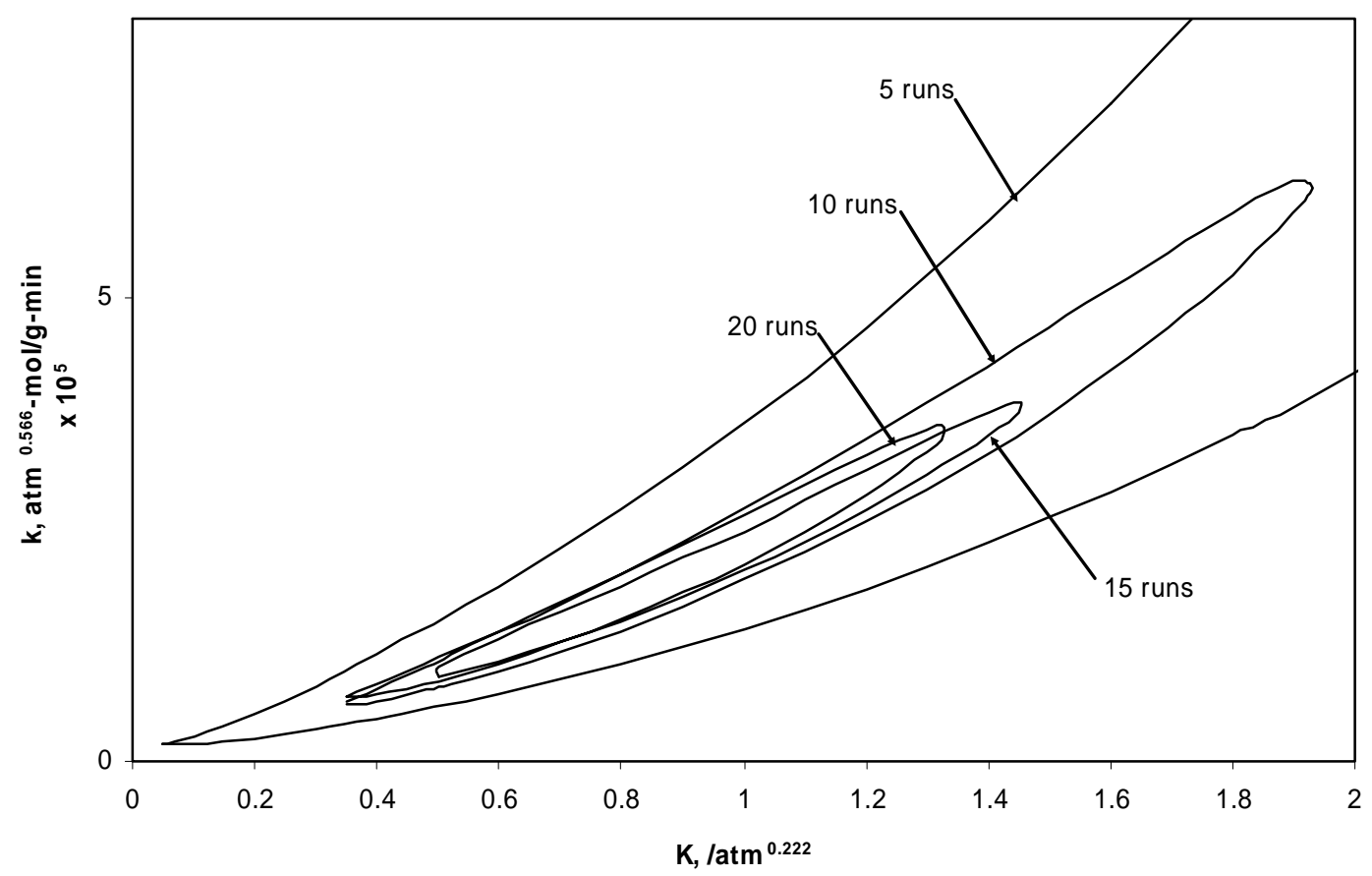

Figure 56 Joint $95 \%$ likelihood confidence regions for $\mathrm{k}$, and $\mathrm{K}$ at $220^{\circ} \mathrm{C}$ at different run lengths.

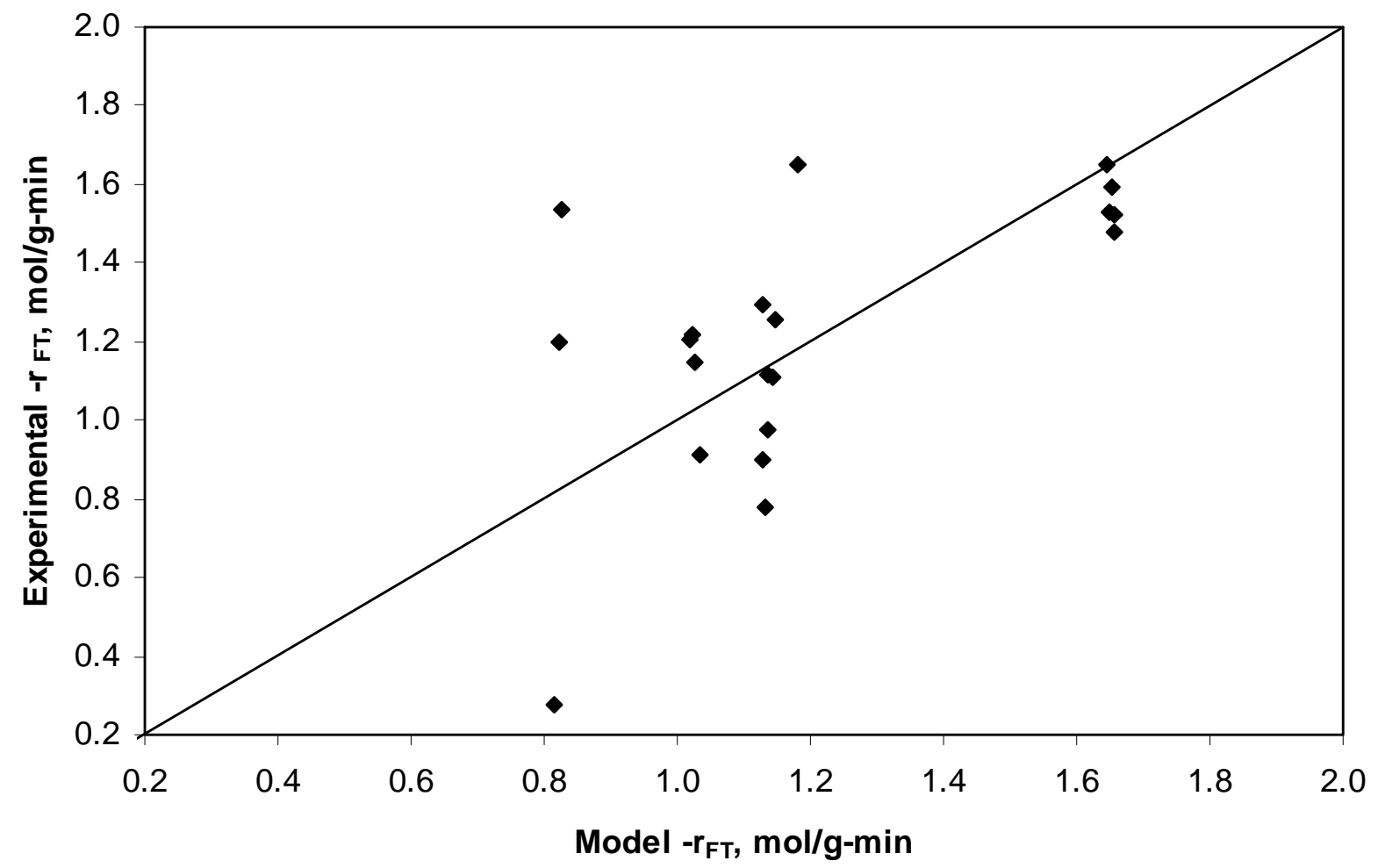

Figure 57 Experimental rates versus model predicted rates for sequentially designed experiments at $220^{\circ} \mathrm{C}$. 
Similar results were obtained at $239^{\circ} \mathrm{C}$. Also, Table 12 shows the regressed values of the activation energy, heat of adsorption and pre-exponential factors.

Table 12 Regressed values of pre-exponential factors, activation energy and heat of adsorption.

\begin{tabular}{|c|c|c|c|c|}
\hline & $\begin{array}{c}\mathrm{A}_{1} \\
\left(\mathrm{~atm}^{1.5}-\mathrm{mol} / \mathrm{g}-\mathrm{min}\right)\end{array}$ & $\begin{array}{c}\mathrm{E} \\
(\mathrm{kJ} / \mathrm{mol})\end{array}$ & $\begin{array}{c}\mathrm{A}_{2} \\
\left(\operatorname{atm} \times 10^{3}\right)\end{array}$ & $\begin{array}{c}\Delta \mathrm{H} \\
(\mathrm{kJ} / \mathrm{mol})\end{array}$ \\
\hline $\begin{array}{l}\text { Parameter } \\
\text { Estimate }\end{array}$ & 1205 & 77.0 & 4.61 & -18.4 \\
\hline $\begin{array}{l}\text { Lower 95\% } \\
\text { Confidence } \\
\text { Level }\end{array}$ & 1137 & 76.8 & 4.36 & -18.6 \\
\hline $\begin{array}{l}\text { Upper 95\% } \\
\text { Confidence } \\
\text { Level }\end{array}$ & 1272 & 77.3 & 4.89 & -18.2 \\
\hline
\end{tabular}

Collection of statistically reliable raw data for the validation of micro-kinetic model is very essential. Such experimental data should be void of mass transfer effects; also, the parameter space should adequately cover conditions that reflect probable industrial operating conditions.

We chose to use Equation 1A to obtain optimized experimental data not just because it was derived by a mechanism that makes sense; but also it predicted rate of hydrocarbon production $\left(\mathrm{C}_{2+}\right)$ better than other analogs that we tried out.

Each experimental condition was preformed in replicates, to gain more statistical information. This is indicated in the parity plot shown in Figure 57. In this figure, the observed high variance in observed rate values at each replicate point is probably due to our inability to effectively control the reactor temperature due to its large thermo-mass. Nevertheless, it is obvious that the 45 degrees parity line passes through the means at each experimental point.

Perhaps, we could have stopped the collection of data after 15-runs as the value of both the optimality criteria and the estimated constants have very well approached asymptotic values. However, the collection of extra data points improved the statistics a little bit. 


\section{Preparation of unsupported catalysts.}

Preparation of the unsupported iron catalysts on a monolith support was conducted by impregnation from the iron nitrate melt of an acid-treated monolith surface. Two 400 mesh, 2 inch diameter and 1 inch length monoliths and two 300 mesh, 2 inch diameter, 0.5 inch length monoliths were cleaned in a 20 volume \% nitric acid 80 volume \% HPLC grade water solution overnight at $60^{\circ} \mathrm{C}$ and rinsed with HPLC grade water. A typical impregnation procedure was as follows. $\mathrm{Fe}\left(\mathrm{NO}_{3}\right)_{3} \cdot 9 \mathrm{H}_{2} \mathrm{O}(147 \mathrm{~g})$ and $\mathrm{Al}\left(\mathrm{NO}_{3}\right)_{3} \cdot 9 \mathrm{H}_{2} \mathrm{O}(1.5 \mathrm{~g})$ were melted in a beaker heated in a water bath at $70^{\circ} \mathrm{C}$. Monoliths were dipped in the melt for approximately 1 minute, then shaken and blown out with ultra high purity helium. The samples were dried overnight at $60^{\circ} \mathrm{C}$ and calcined at $300^{\circ} \mathrm{C}$ for approximately $6 \mathrm{~h}$, initially heating at a rate of $1{ }^{\circ} \mathrm{C} / \mathrm{min}$. This procedure was repeated once. The $\mathrm{wt}^{\%} \%$ of elemental Fe on the monolith is summarized in Table 13 .

Table 13 Summary of weight percentage.

\begin{tabular}{ccc}
\hline Sample & $\mathbf{F e}_{\mathbf{2}} \mathbf{O}_{\mathbf{3}}$ wt \% & Fe wt \% \\
\hline 1 & 22.59 & 15.81 \\
2 & 22.89 & 16.02 \\
3 & 21.73 & 15.21 \\
4 & 21.91 & 15.34 \\
\hline
\end{tabular}

TPR was conducted in the TGA system by flowing $180 \mathrm{~mL} / \mathrm{min}$ of $\mathrm{N}_{2}$ and $20 \mathrm{~mL} / \mathrm{min}$ of $\mathrm{H}_{2}$ over the sample. The temperature was linearly increased from $25^{\circ} \mathrm{C}$ to $800^{\circ} \mathrm{C}$ at $5^{\circ} \mathrm{C} / \mathrm{min}$. The TPR spectrum is shown in Figure 58. Peaks having maxima at $340^{\circ} \mathrm{C}$ and $475^{\circ} \mathrm{C}$ are assigned to the reduction of $\mathrm{Fe}_{2} \mathrm{O}_{3}$ to $\mathrm{Fe}_{3} \mathrm{O}_{4}$ and the reduction of $\mathrm{Fe}_{3} \mathrm{O}_{4}$ to $\mathrm{Fe}$ metal, respectively. These two peaks are similar to those observed previously for a $99 \mathrm{FeAl}$ powder catalyst, indicating that these two catalysts are comparable. The 99FeAl-monolith catalysts were used in a steady-state kinetic study. 


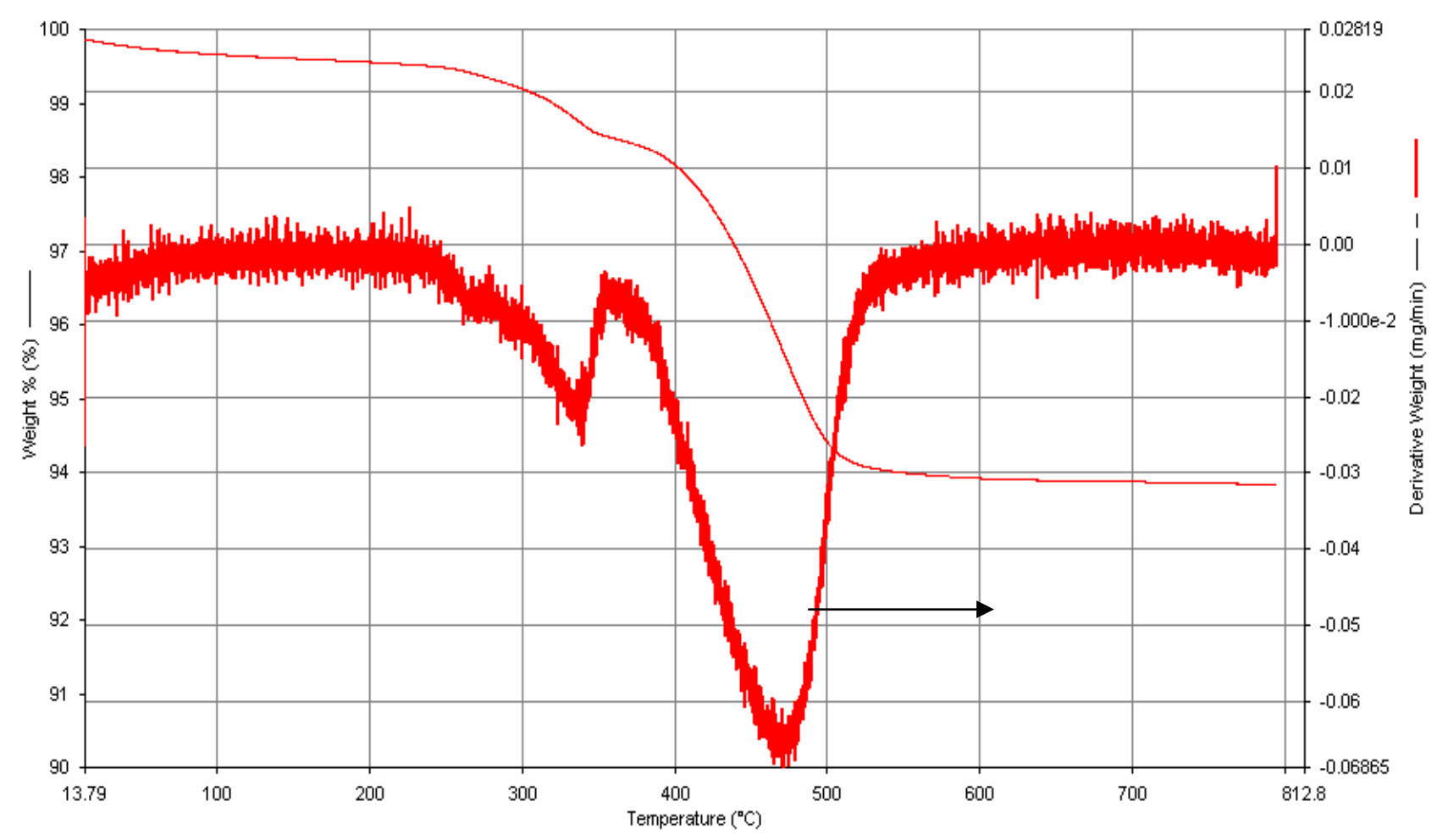

Figure 58 Temperature-programmed reduction spectrum for 99FeAl-monolith catalyst.

\section{Kinetic study of unsupported catalysts.}

A kinetic study of the unsupported catalysts was carried out our Berty CSTR-gas, fixed-bed catalysts reactor. Experimental conditions were chosen using sequential design of experiments based on a D-optimal criterion in order to generate increasingly greater statistical confidence on the regressed kinetic parameters with each step in the sequence. An L-M non-linear regression algorithm in polymath software was used to obtain values of the kinetic constants, calculation of confidence intervals and correlation coefficients.

The catalyst was reduced in $20 \% \mathrm{H}_{2}$ and $80 \% \mathrm{He}$ (total gas flow rate of $200 \mathrm{~mL} / \mathrm{min}$ ) using the following reduction profile: 1) heat from room temperature to $400^{\circ} \mathrm{C}$ at $0.5^{\circ} \mathrm{C} / \mathrm{min}$; 2) hold at $400^{\circ} \mathrm{C}$ for $36 \mathrm{~h} ; 3$ ) cool to $380^{\circ} \mathrm{C}$ at $\left.0.5^{\circ} \mathrm{C} / \mathrm{min} ; 4\right)$ hold at $380^{\circ} \mathrm{C}$ and purge with $\mathrm{H}_{2}$ in He for 24 $\mathrm{h} ; 5)$ after reducing the catalyst, the reactor was cooled to $220^{\circ} \mathrm{C}$.

Scoping runs were done at $220^{\circ} \mathrm{C}$ and a total pressure of 20 atm using a $2^{\mathrm{n}}$ factorial experimental design with center point design based on two parameters - outlet partial pressures of $\mathrm{CO}\left(P_{\mathrm{CO}}\right)$ and $\mathrm{H}_{2}\left(P_{\mathrm{H} 2}\right)$ while blocking temperature. These 5 points provided the starting data for the sequential design of experiment using the rate expression 


$$
-r_{C 2+}=\frac{A P_{C O}^{2 / 3} P_{H 2}^{5 / 6}}{\left(1+B P_{C O}^{2 / 3} P_{H 2}^{1 / 3}\right)^{2}}
$$

Reactor pressure was held constant at 20 atm while partial pressures of $\mathrm{CO}$ and $\mathrm{H}_{2}$ were varied stepwise according to the results of the previous step in the sequential design. The first run was conducted at a standard condition that was repeated after a few runs to check for catalyst deactivation.

Figure 59 and Figure 60 show typical plots of rate and conversion of $\mathrm{CO}$ as a function of time for Run \#3 (see the Table 14 for the run conditions). Table 14 is a summary of run conditions and results for 9 runs; Table 15 lists the values of the regressed constants and their confidence intervals as a function of run number; and Figure 61 is a graph of the regressed kinetic parameters at $220^{\circ} \mathrm{C}$ as a function of run. Figure 62 is a parity plot of calculated rate of $\mathrm{C}_{2+}$ versus observed rate of $\mathrm{C}_{2+}$.

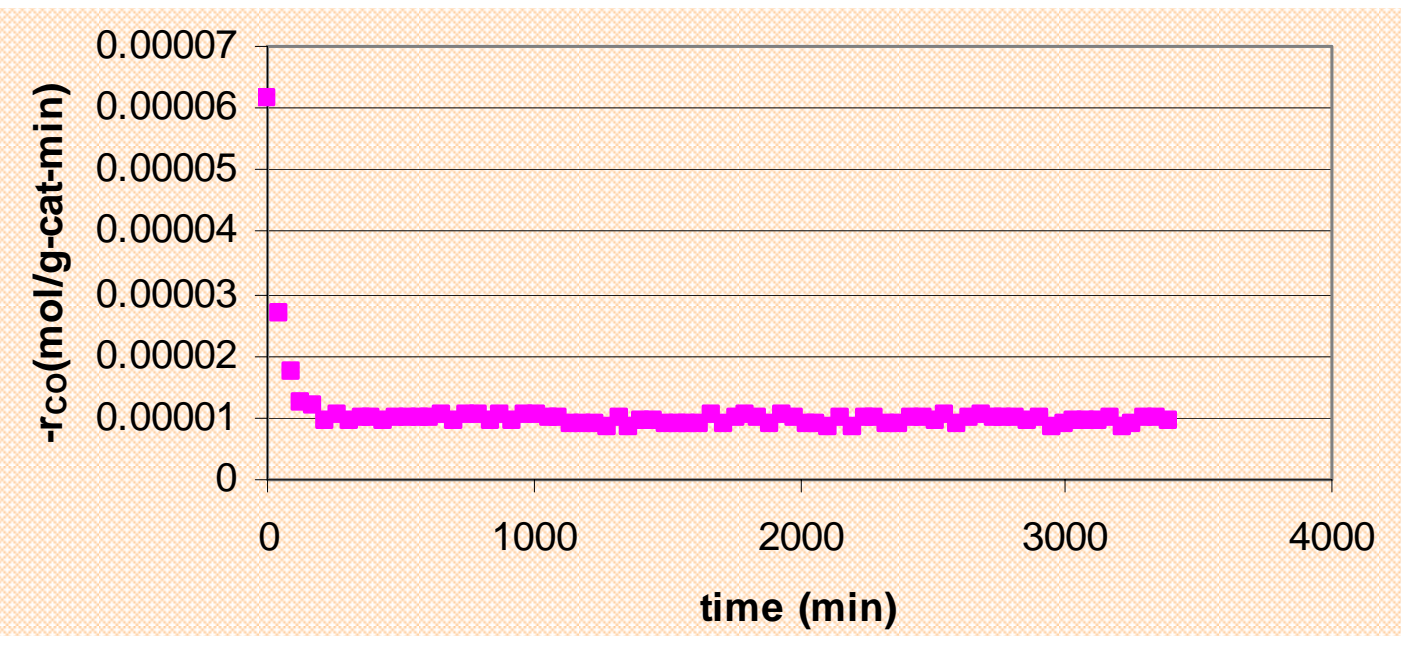

Figure 59 Rate of CO versus time for Run \#3 ( $P_{C O}=3.263$ atm and $\left.P_{H 2}=2.351 \mathrm{~atm}\right)$. 


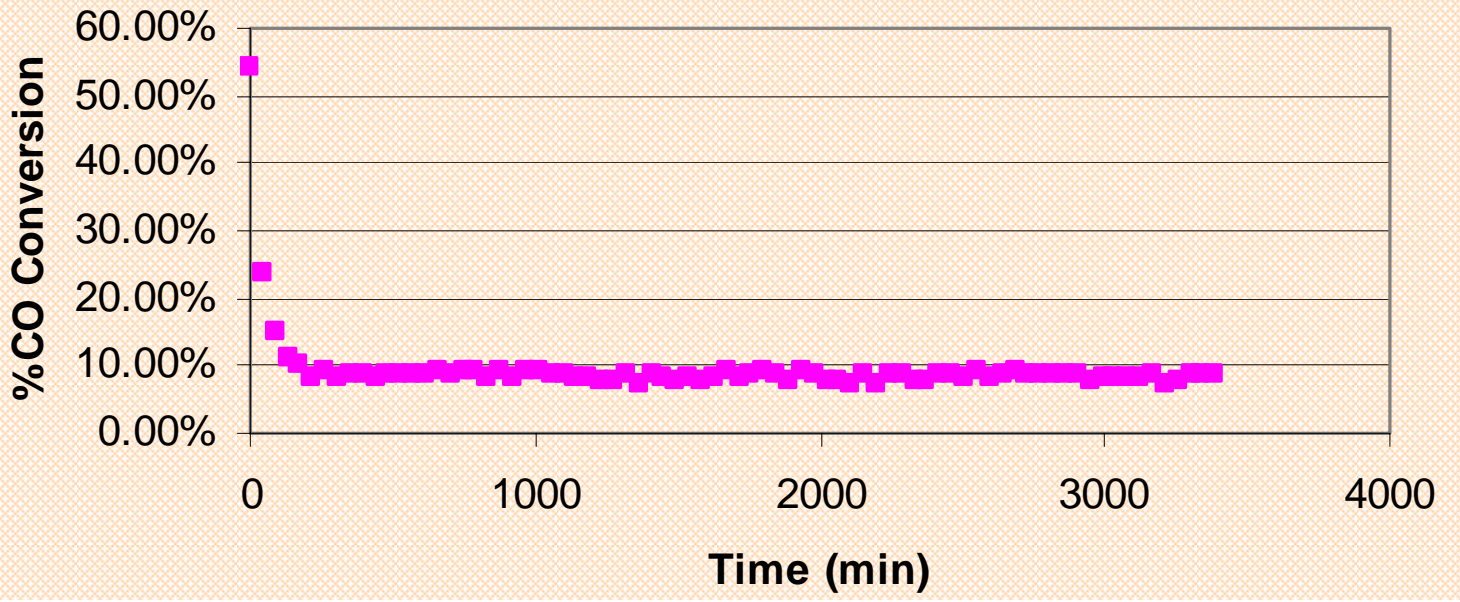

Figure 60 Conversion of CO versus time for run \#3 ( $P_{C O}=3.263 \mathrm{~atm}$ and $\left.P_{\mathrm{H} 2}=2.351 \mathrm{~atm}\right)$ 
Table 14 Summary of run conditions and results

\begin{tabular}{|c|c|c|c|c|c|c|c|c|c|c|}
\hline $\begin{array}{c}\text { Run } \\
\#\end{array}$ & $\begin{array}{c}\text { Inlet vol. } \\
\text { flow rate } \\
\text { of He + } \\
\text { Ar @ } \\
\text { STP } \\
\text { (mL/min) }\end{array}$ & $\begin{array}{c}\text { Inlet vol. } \\
\text { flow rate } \\
\text { of } \mathbf{H}_{2} @ \\
\text { STP } \\
\text { (mL/min) }\end{array}$ & $\begin{array}{c}\text { Inlet vol. } \\
\text { flow rate } \\
\text { of CO @ } \\
\text { STP } \\
\text { (mL/min) }\end{array}$ & $\begin{array}{c}\% \\
\text { Conv. } \\
\text { of CO }\end{array}$ & $\begin{array}{c}\text { Outlet } \\
\text { Partial } \\
\text { Pressure of } \\
\mathbf{H}_{2} \\
(\mathbf{a t m})\end{array}$ & $\begin{array}{c}\text { Outlet } \\
\text { Partial } \\
\text { Pressure of } \\
\text { CO } \\
\text { (atm) }\end{array}$ & $\begin{array}{c}\text { Rate of } \\
\text { CO } \\
\text { (mol/g- } \\
\text { cat } \\
\text { min) } \\
\text { x 10 }\end{array}$ & $\begin{array}{c}\text { Rate of } \\
\mathrm{C}_{2+} \\
(\mathrm{mol} / \mathrm{g}- \\
\text { cat } \mathrm{min}) \\
\times \mathbf{1 0}^{6}\end{array}$ & $\begin{array}{l}\text { \% CH} \\
\text { Selec. }\end{array}$ & $\begin{array}{l}\% \mathrm{CO}_{2} \\
\text { Selec. }\end{array}$ \\
\hline 1 & 60.231 & 130.2 & 59.828 & 17.44 & 6.426 & 3.037 & 93.1421 & 57.01 & 15.057 & 23.72 \\
\hline 2 & 108.202 & 130.2 & 11.157 & 83.39 & 6.194 & 0.115 & 78.7125 & 36.43 & 39.0 & 14.72 \\
\hline 3 & 138.189 & 52.4 & 59.820 & 8.36 & 2.351 & 3.263 & 42.5035 & 18.60 & 9.64 & 46.61 \\
\hline 4 & 186.484 & 52.6 & 11.511 & 48.92 & 2.045 & 0.351 & 47.522 & 26.72 & 20.38 & 23.39 \\
\hline 5 & 124.738 & 90.2 & 35.662 & 22.12 & 3.964 & 1.69 & 66.9659 & 40.26 & 16.33 & 23.55 \\
\hline 6 & \multicolumn{10}{|c|}{ Standard Condition (Same as run $\# 1$ ) to check for catalyst deactivation } \\
\hline 7 & 22.703 & 44.352 & 25.886 & 26.76 & 5.365 & 3.407 & 58.1041 & 38.2 & 10.96 & 23.3 \\
\hline 8 & 35.845 & 57.579 & 27.843 & 26.04 & 5.382 & 2.747 & 60.9819 & 39.52 & 13.19 & 22.01 \\
\hline 9 & 43.462 & 71.13 & 29.278 & 25.59 & 5.739 & 2.409 & 62.7296 & 39.65 & 15.85 & 20.94 \\
\hline
\end{tabular}


Table 15 Values of regressed constants and confidence intervals as a function of run number.

\begin{tabular}{|c|c|c|c|c|c|}
\hline \multirow{2}{*}{$\begin{array}{c}\text { Regression } \\
\#\end{array}$} & \multicolumn{2}{|c|}{ A } & \multicolumn{2}{c|}{$\begin{array}{c}\text { B } \\
\left.\text { mol/(g-cat } x \text { atm }^{\wedge} 1.5\right)\end{array}$} & \multicolumn{2}{c|}{$\begin{array}{c}\text { Number } \\
\text { of }\end{array}$} \\
\cline { 2 - 5 } & $\begin{array}{c}\text { Regressed } \\
\text { Value }\end{array}$ & $\begin{array}{c}\text { Confidence } \\
\text { Interval }\end{array}$ & $\begin{array}{c}\text { Regressed } \\
\text { Value }\end{array}$ & $\begin{array}{c}\text { Confidence } \\
\text { Interval }\end{array}$ & \\
\hline 1 & $5.13 \mathrm{E}-05$ & $5.50 \mathrm{E}-05$ & 0.5799117 & 0.5566209 & 5 \\
\hline 2 & $5.32 \mathrm{E}-05$ & $4.37 \mathrm{E}-05$ & 0.6127011 & 0.4217881 & 6 \\
\hline 3 & $5.41 \mathrm{E}-05$ & $3.45 \mathrm{E}-09$ & 0.6318204 & $3.27 \mathrm{E}-05$ & 7 \\
\hline 4 & $5.48 \mathrm{E}-05$ & $2.94 \mathrm{E}-07$ & 0.6502908 & $2.78 \mathrm{E}-03$ & 8 \\
\hline
\end{tabular}

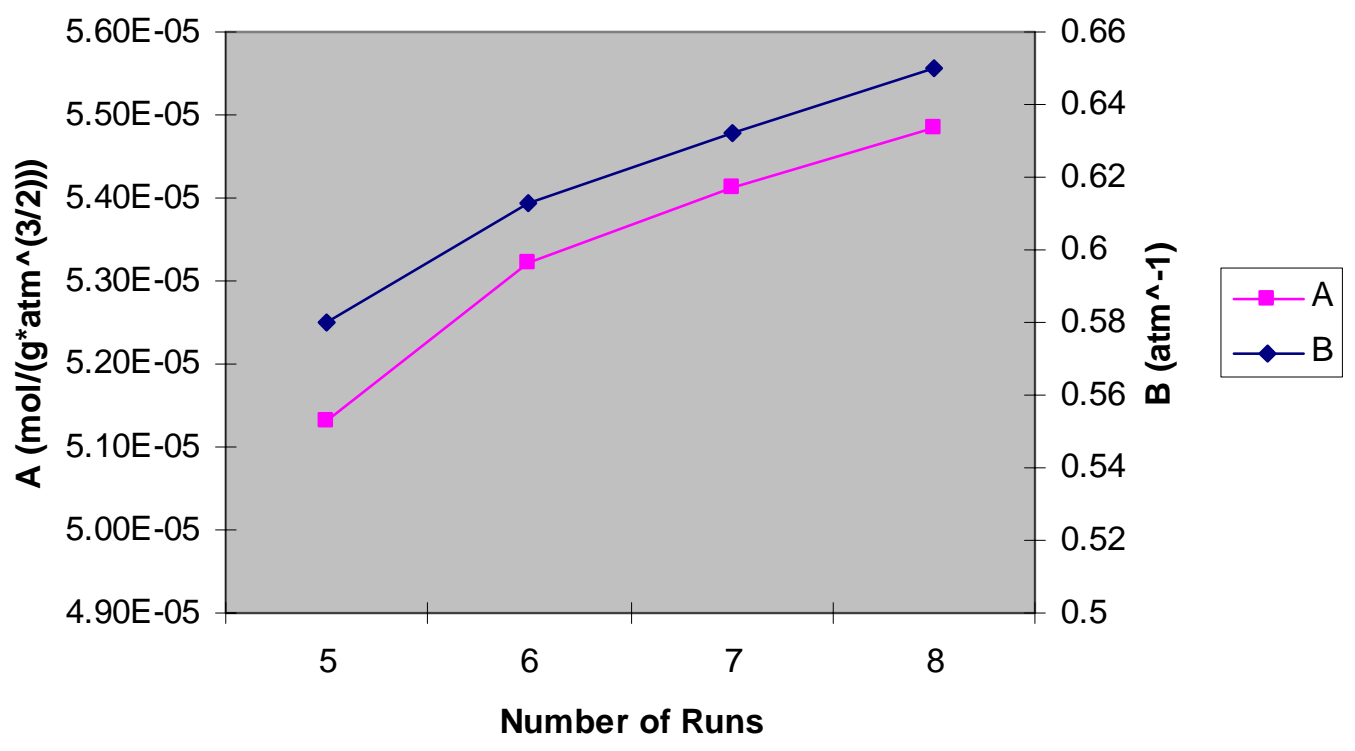

Figure 61 Graph of regressed kinetic constants as a function of number of experimental runs. 


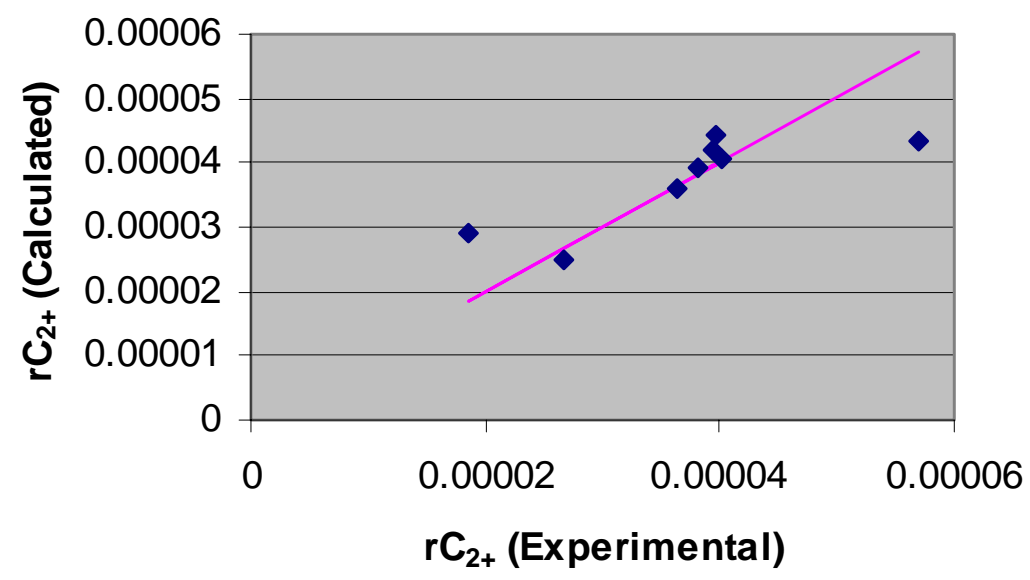

Figure 62 Parity plot of calculated rate of $\mathrm{C}_{2+}$ vs observed rate of $\mathrm{C}_{2+}$.

It is evident from Figure 59 and Figure 60 that steady state values of rate and conversion are reached within about 300 minutes (5 hours) after reaction conditions were changed; moreover, rate and conversion were steady over the next 45 hours. Generally, data were collected for much more than 5 hours after each change of conditions to ensure steady-state had been reached and as a check on catalyst stability. A repeat run (Run \#6) at standard condition also served as a check on catalyst deactivation. Based on these tests, it appears that the catalyst was stable and did not deactivate during the 9 runs.

Based on previous work on a similar type of catalyst that was run under similar conditions on our Berty reactor system, we are confident that the data were free of mass transfer/pore diffusion limitations.

Examination of the parity plot in Figure 61 shows that Equation 60 fits the experimental data well. Nevertheless, the values of the regressed kinetic constants were still changing in Runs 7 and 8 (see Figure 61), although the values improved as the number of runs increased as indicated by the decrease in the confidence interval with succeeding runs (see Table 15).

Runs 1-9 provide useful kinetic data at one temperature; however, these data are not adequate for establishing a complete set of kinetic parameters or for validating microkinetic models. Similar data sets needed to be obtained at two additional temperatures (at least) for modeling the effects of temperature.

A trial model of the form shown in Equation 61 was used first to fit the results. The parity plot obtained from the predicted rate verses the observed rate for this model is shown in Figure 63. It can be seen that this model fits the experiments well and that the orders of $\mathrm{CO}$ and $\mathrm{H}_{2}$ are 
about unity. This is better than an order of about 7 for $\mathrm{H}_{2}$ reported previously. However, it is difficult to attach a physical meaning to the above since the model was not based on a sequence of elementary steps. Below is a summary of the kinetic parameters for this model

$$
r_{C_{2+}}=\frac{A_{1} \cdot \exp \left(\frac{-E_{a}}{R \cdot T}\right) \cdot P_{C O}^{a} \cdot P_{H_{2}}^{b}}{\left(1+A_{2} \cdot \exp \left(\frac{-\Delta H}{R \cdot T}\right) \cdot P_{C O}^{x} \cdot P_{H_{2}}^{y}\right)^{2}}
$$

Table 16 Model 1 parameter values for $99 \% \mathrm{Fe}$

\begin{tabular}{|l|l|}
\hline Parameter & Value \\
\hline $\begin{array}{l}\mathrm{A}_{1} \\
\left(\mathrm{~mol} / \mathrm{kg}_{-} \mathrm{s} \mathrm{atm}^{(\mathrm{a}+\mathrm{b})}\right)\end{array}$ & $2.892 \mathrm{E} 4$ \\
\hline $\mathrm{Ea}(\mathrm{J} / \mathrm{mol})$ & $8.298 \mathrm{E} 3$ \\
\hline $\mathrm{A}_{2}\left(\mathrm{~atm}^{-(\mathrm{x}+\mathrm{y})}\right)$ & 3.716 \\
\hline$\Delta \mathrm{H}(\mathrm{J} / \mathrm{mol})$ & $-3.118 \mathrm{E} 4$ \\
\hline $\mathrm{a}$ & 1.051 \\
\hline $\mathrm{b}$ & 0.993 \\
\hline $\mathrm{x}$ & 0.475 \\
\hline $\mathrm{y}$ & 0.143 \\
\hline
\end{tabular}

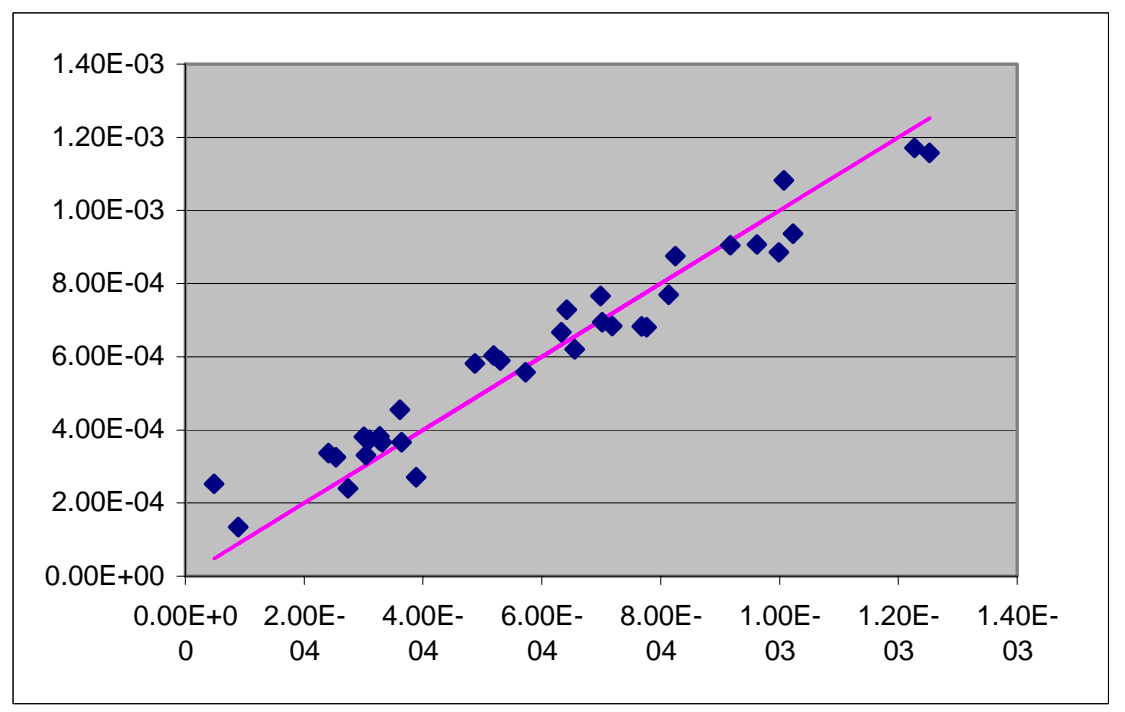

Figure 63 Parity plot for Model 1 for $99 \%$ Fe. 
Another model used to fit the data was based on a rate expression developed by assuming that the rate determining steps were carbon hydrogenation and $\mathrm{OH}$ removal as gas-phase water by adsorbed hydrogen (see Eqn. 62).

$$
r_{C_{2+}}=\frac{A_{1} \cdot \exp \left(\frac{-E_{a}}{R \cdot T}\right) \cdot P_{C O}^{\frac{2}{3}} \cdot P_{H_{2}}^{\frac{5}{6}}}{\left(1+A_{2} \cdot \exp \left(\frac{-\Delta H}{R \cdot T}\right) \cdot P_{C O}^{\frac{2}{3}} \cdot P_{H_{2}}^{\frac{1}{3}}\right)^{2}}
$$

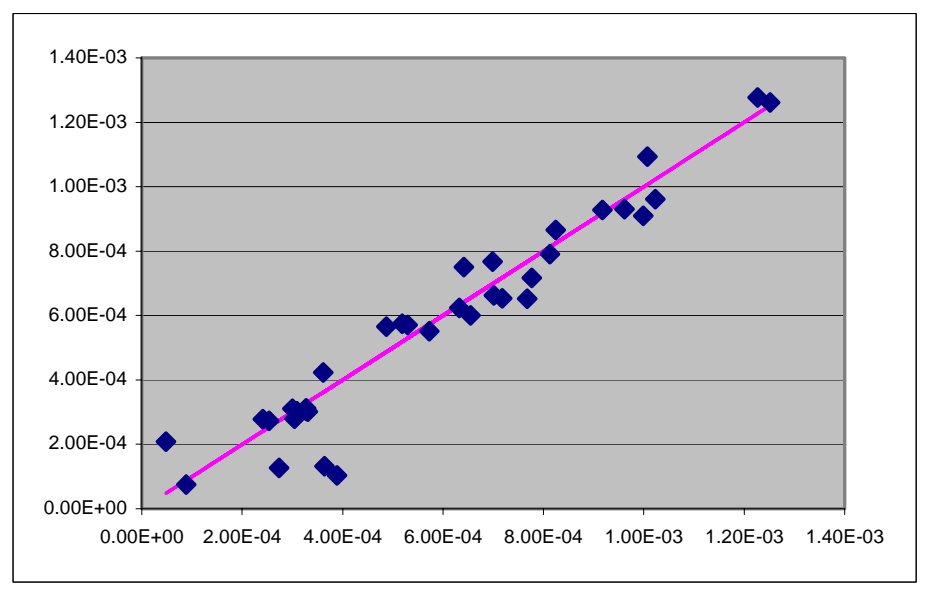

Figure 64 Parity plot for Model 2 for $99 \%$ Fe

Figure 64 is the parity plot obtained when the predicted rates by this model are plotted against the observed rates, while below are the model parameters.

Table 17 Model 2 parameter values for $99 \% \mathrm{Fe}$

\begin{tabular}{|l|l|}
\hline Parameter & Value \\
\hline $\mathrm{A}_{1}\left(\mathrm{~mol} / \mathrm{kg}-\mathrm{s} \mathrm{atm}^{1.5}\right)$ & $2.095 \mathrm{E} 4$ \\
\hline $\mathrm{Ea}(\mathrm{J} / \mathrm{mol})$ & $8.184 \mathrm{E} 4$ \\
\hline $\mathrm{A}_{2}\left(\mathrm{~atm}^{-1}\right)$ & 0.03 \\
\hline$\Delta \mathrm{H}$ & $-5.039 \mathrm{E} 3$ \\
\hline
\end{tabular}

Another model used to fit the data was a rate expression developed by assuming that the rate determining step was $\mathrm{CO}$ dissociation. The model obtained from the above assumptions is shown in Equation 63. 


$$
r_{C_{2+}}=\frac{A_{1} \cdot \exp \left(\frac{-E_{a}}{R \cdot T}\right) \cdot P_{C O}}{\left(1+A_{2}^{\frac{1}{2}} \cdot \exp \left(\frac{-\Delta H_{2}}{R \cdot T}\right) \cdot P_{H_{2}}^{\frac{1}{2}}+A_{3} \cdot \exp \left(\frac{-\Delta H_{3}}{R \cdot T}\right) \cdot P_{C O} \cdot P_{H_{2}}^{-\frac{1}{2}}+A_{4} \cdot \exp \left(\frac{-\Delta H_{4}}{R \cdot T}\right) \cdot P_{C O}\right)^{2}}
$$

Figure 65 is the parity plot obtained when the predicted rates by this model are plotted against the observed rates, while below are the model parameters.

Table 18 Model 3 parameters for $99 \% \mathrm{Fe}$

\begin{tabular}{|l|l|}
\hline Parameter & Value \\
\hline $\mathrm{A}_{1}(\mathrm{~mol} / \mathrm{kg}-\mathrm{s}$ atm $)$ & $1.338 \mathrm{E} 4$ \\
\hline $\mathrm{Ea}(\mathrm{J} / \mathrm{mol})$ & $1.276 \mathrm{E} 4$ \\
\hline $\mathrm{A}_{2}\left(\mathrm{~atm}^{-1}\right)$ & 0.434 \\
\hline$\Delta \mathrm{H}_{2}(\mathrm{~J} / \mathrm{mol})$ & $-3.045 \mathrm{E} 4$ \\
\hline $\mathrm{A}_{3}\left(\mathrm{~atm}^{-0.5}\right)$ & 2.848 \\
\hline$\Delta \mathrm{H}_{3}(\mathrm{~J} / \mathrm{mol})$ & $-4.885 \mathrm{E} 4$ \\
\hline $\mathrm{A} 4\left(\mathrm{~atm}{ }^{-1}\right)$ & 4.077 \\
\hline$\Delta \mathrm{H}_{4}(\mathrm{~J} / \mathrm{mol})$ & $2.663 \mathrm{E} 4$ \\
\hline
\end{tabular}

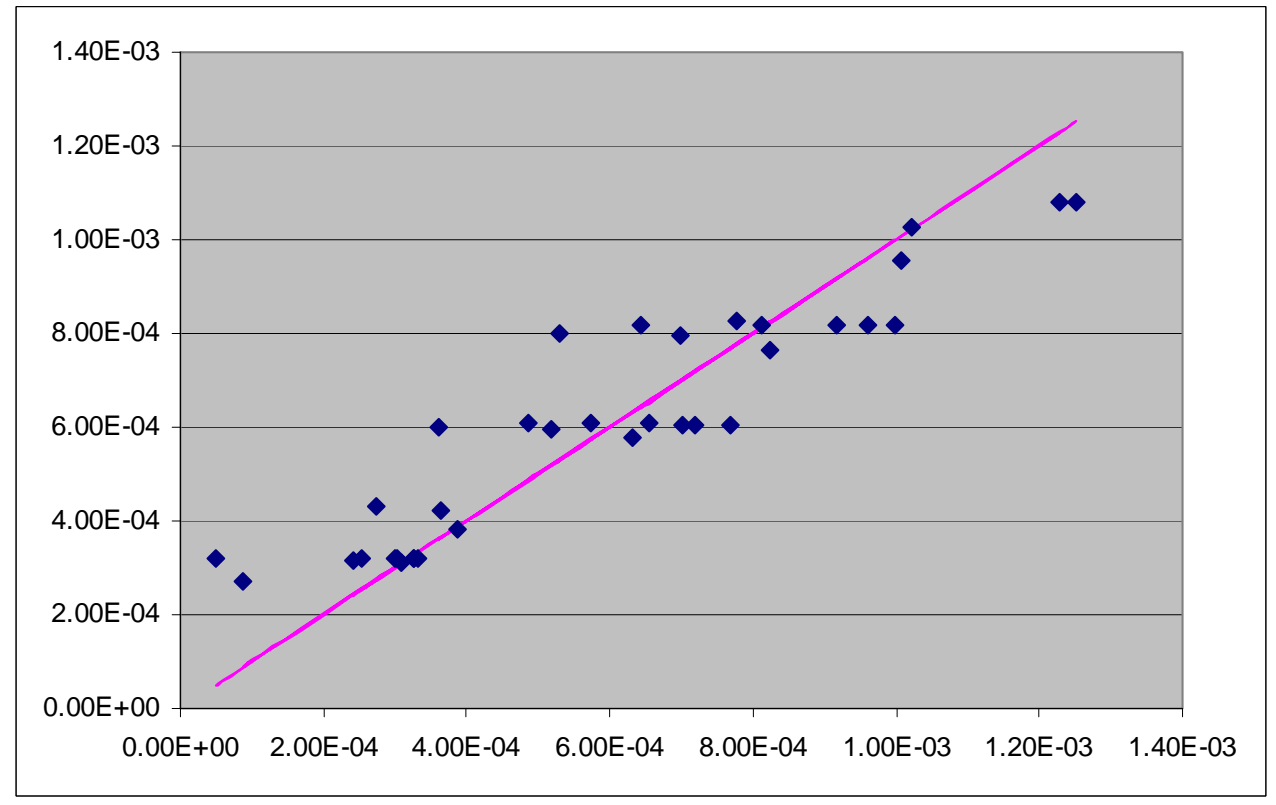

Figure 65 Parity plot for model 3 for $99 \%$ Fe 


\section{Results and Discussion based on First Principles Calculations}

\section{A. Overview and model description.}

The underlying goal of our calculations throughout the duration of this project has been to obtain a detailed mechanistic understanding of FTS on Fe catalysts. This involves performing calculations to evaluate the thermochemistry and kinetics of FTS relevant elementary steps on various models of FTS catalysts. Industrial FTS catalysts frequently incorporate promoters like Pt and furthermore the nature of the catalyst facet where these elementary steps are catalyzed is not entirely clear. A starting point for our calculations was the $\mathrm{Fe}(110)$ facet (Figure 66) which was the first to be analyzed in the very early stages of our calculations. The choice of this particular facet was motivated simply because of the fact that for a typical Fe nanoparticle the (110) facet would be the thermodynamically most stable facet (as for other bcc metal crystal lattices) and hence we would expect facets of this type to predominate in the Fe nanoparticles. Detailed calculations for thermochemistry and kinetics were completed on this facet at the very outset and these were regarded as the "base-case" for all other analysis that followed in the later years of the project. In this report we try to cumulatively sum up our achievements over the duration of the project and try to highlight our key conclusions. This includes work in the first three years of the project (which has already been covered in previous reports in some detail) and the work in this last and final year of the project. Due to limitations of space it is not possible to go into the level of detail that was included in the successive annual reports.

Having said that the $\mathrm{Fe}(110)$ facet is the basic system we analyze we now proceed to list the nature and motivation behind the selection of the other systems analyzed during the project duration. The industrial activity of FTS Catalysts has frequently been correlated with the formation of a carbide phase on the catalyst. Our calculations indicated that it was indeed facile to get $\mathrm{C}$ into the subsurface of a $\mathrm{Fe}(110)$ crystal as a sequel to $\mathrm{CO}$ dissociation on the catalyst surface. This then prompted us to employ a $\mathrm{Fe}(110)$ crystal with subsurface $\mathrm{C}$ at a $1 / 4 \mathrm{ML}$ equivalent coverage as our second model system. This system is henceforth referred to as $\mathrm{Fe}_{\mathrm{C}}$ for brevity with the subscript $\mathrm{C}$ being evocative of the relative position of the $\mathrm{C}$ atom in the model (Figure 66). Thus the choice of the $\mathrm{Fe}(110)$ and the $\mathrm{Fe}_{\mathrm{C}}$ systems was so designed to allow us to probe the FTS reactions on a native, unpromoted industrial FTS catalyst. The next model system we were interested in would be one that allowed us to probe the effects of Pt promotion of Fe catalysts. Herein several options were available for the specific geometries that might be 
constructed from the combinations of $\mathrm{Fe}$ and $\mathrm{Pt}$ atoms in the catalyst surface. For example some models that were considered included the following: a Pt adatom, a Pt atom incorporated in the surface layer or even an entire adlayer of Pt could be envisioned based on considerations of preparative methods and relative energetic stability of these diverse configurations. Our probe calculations identified the Pt adatom model as the most stable energetic alternative and hence we finalized this as our next model system. This system is henceforth designated as $\mathrm{Fe}^{\mathrm{Pt}}$ for brevity with the Pt in the superscript again being evocative of the relative position of $\mathrm{Pt}$ in the model (Figure 66). This particular $\mathrm{Fe}^{\mathrm{Pt}}$ model system was specifically designed to probe Pt promotion effects in Fe based FTS catalysts and includes a 1/4 ML of Pt adatom coverage on the Fe(110) surface. Both the $\mathrm{Fe}_{\mathrm{C}}$ and $\mathrm{Fe}^{\mathrm{Pt}}$ systems were analyzed in considerable detail in the second year of the project.

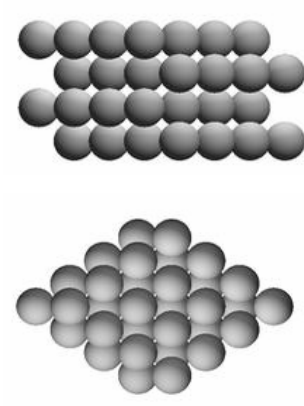

(a)

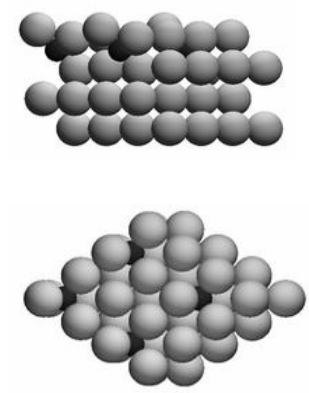

(b)

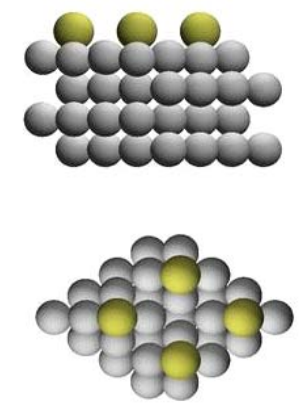

(c)

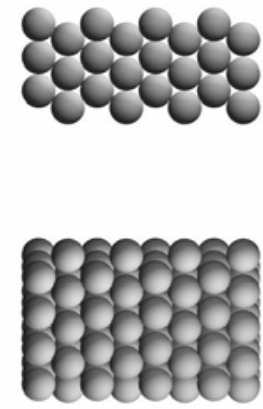

(d)

Figure 66 Model systems for FTS mechanistic studies on Fe catalysts.

(a) $\mathrm{Fe}(110)$, (b) $\mathrm{Fe}_{\mathrm{C}}$ : $\mathrm{Fe}(110)$ slab with a $1 / 4 \mathrm{ML}$ of $\mathrm{C}$ atoms in the first sub-surface layer.

(c) $\mathrm{Fe}^{\mathrm{Pt}}: \mathrm{Fe}(110)$ slab with a $1 / 4 \mathrm{ML}$ of Pt adatoms on the surface. (d) Fe(211). The top panel gives the cross-section view whereas the bottom panel gives the top-view of the corresponding slabs. Color Code for atoms: Pt: yellow, Fe: grey, C: black.

In several catalytic systems in the past stepped surfaces have been implicated as being the dominant sites for one or more elementary reactions of interest. With the view of testing a similar proposition for Fe based FTS catalysts we decided to investigate the effects of a "defected" Fe surface on the elementary steps of interest. Again the choice of a model was not straightforward. Initially we focused on a "stepped Fe(110)" system designed by eliminating a row of atoms from the surface of an defect-free Fe crystal. This might be regarded akin to an extended geometry line defect on the crystal surface. Calculations for the Binding Energies for all relevant species were performed on this model surface but it was found the in most cases the 
species bind with a BE substantially similar to that of the native Fe(110) surface. Although a fair amount of time was spent on calculations on this model of a defected surface this data is not analyzed in this report since it was not found to be very relevant. We then (in the third year of the project) expanded our search for a defected surface to include candidates that are specific facets derived from the bulk bcc crystal structure for Fe and exhibit pronounced steps and terraces in their relief. In particular the $\mathrm{Fe}(321)$ and $\mathrm{Fe}(211)$ facets were given more attention but we eventually settled on Fe(211) model system (Figure 66). This was motivated by the fact that this facet was only slightly higher than the $\mathrm{Fe}(110)$ facet in terms of energy and hence relatively stable. The fact that we were able to simulate the $\mathrm{Fe}(211)$ facet with a reasonable unit cell size also was an important consideration especially in the light of the relatively high computational expense of these spin-polarized calculations. The larger size of the unit cell (the unit cell contained 24 atoms; more details provided later under the Methods section) necessary for simulating Fe(211) and the more open nature of this surface made these calculations additionally challenging. The final part of the project was devoted to a systematic analysis of FTS relevant steps on this $\mathrm{Fe}(211)$ facet. The evolution over time of our calculations is depicted schematically in Figure 77 below.

We now describe the model of FTS reactions that we considered over the course of this project. The reaction products of an industrial FTS reactor cover a wide product distribution ranging from methane, ethane and going as high as the $\mathrm{C}_{20}$ species. Of course, the calculation framework we employ severely restricts the number of $\mathrm{C}$ atoms that we can consider in our Carbon backbone explicitly. Our approach was to explicitly run calculations for all pathways up to the $\mathrm{C}_{2}$ species and then employ heuristics to extend these values (enthalpies and activation energies) for the larger species. Therefore, early on we decided upon a series of elementary steps that would allow us to capture the mechanistic essence of FTS in sufficient detail and then parameterized this consistent set of elementary steps on all of our chosen facets. Recourse was made to the fairly large existing literature on FTS to guide us in prudently selecting the important steps without overwhelming us with an inordinately large model. As our understanding of FTS mechanisms improved with each additional calculation some additional steps were added to make the model more robust. The elementary steps that were included in our final model are tabulated in Figure 67. Additionally these steps are functionally classified into a series of key classes based on the specific reactive transformation involved in each elementary step therein. 


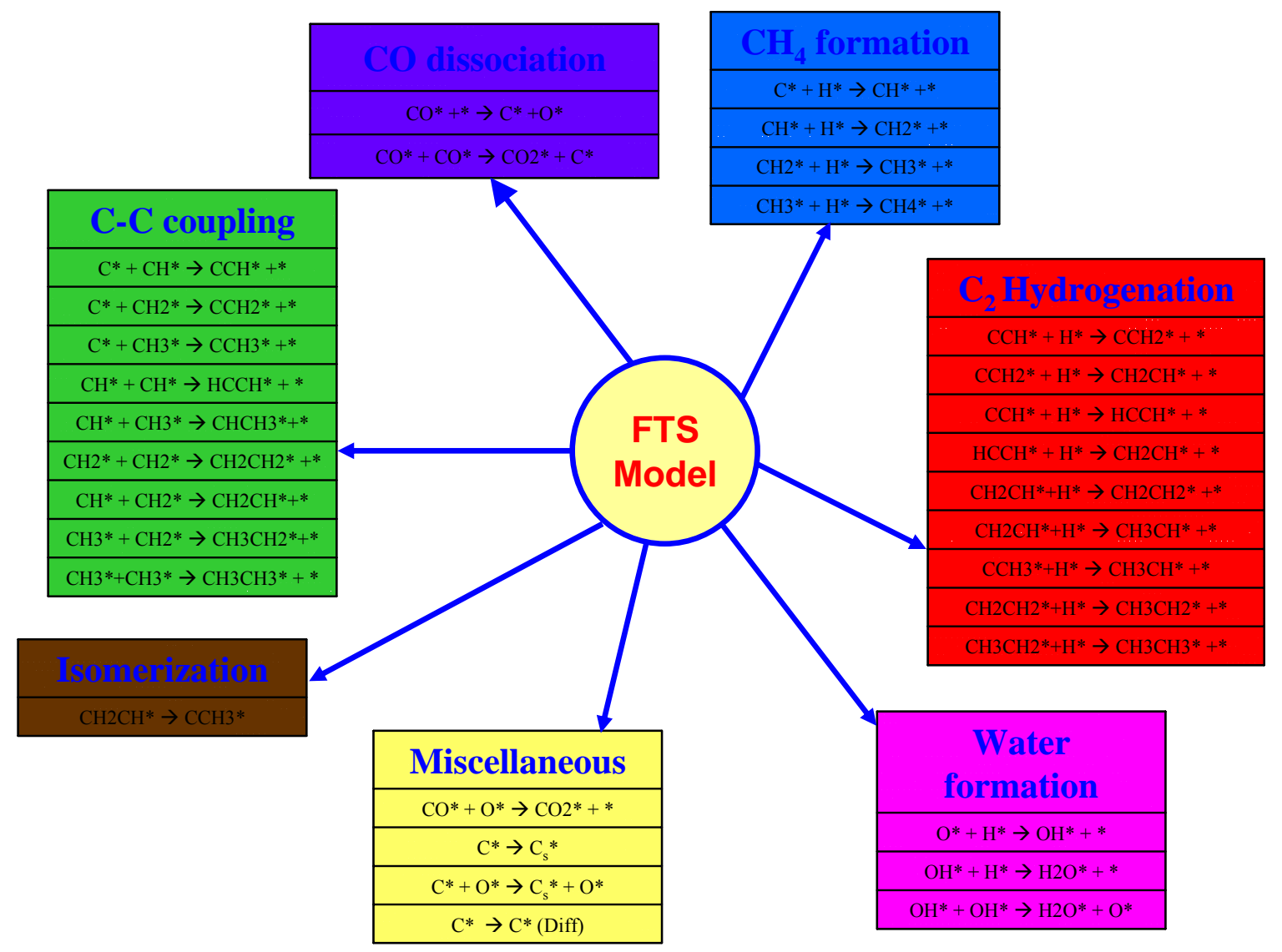

Figure 67 Functional Classification of elementary steps included in the mechanistic model for FTS on Fe catalysts.

A total of 32 elementary steps were studied as a part of our proposed model for FTS Reactions. The classes of steps considered were:

1. CO dissociation via the direct mode as well as by disproportionation. (Boudard Reaction)

2. Successive $\mathrm{H}$ additions to $\mathrm{CHx}$ fragments leading to $\mathrm{CH} 4$ formation

3. C-C coupling steps leading to formation of the larger $\mathrm{C} 2$ species from the smaller CHx fragments.

4. C2 hydrogenation steps

5. Oxygen removal from the surface via. water formation

6. Other miscellaneous steps including isomerization of fragments and internal hydrogen transfer. 


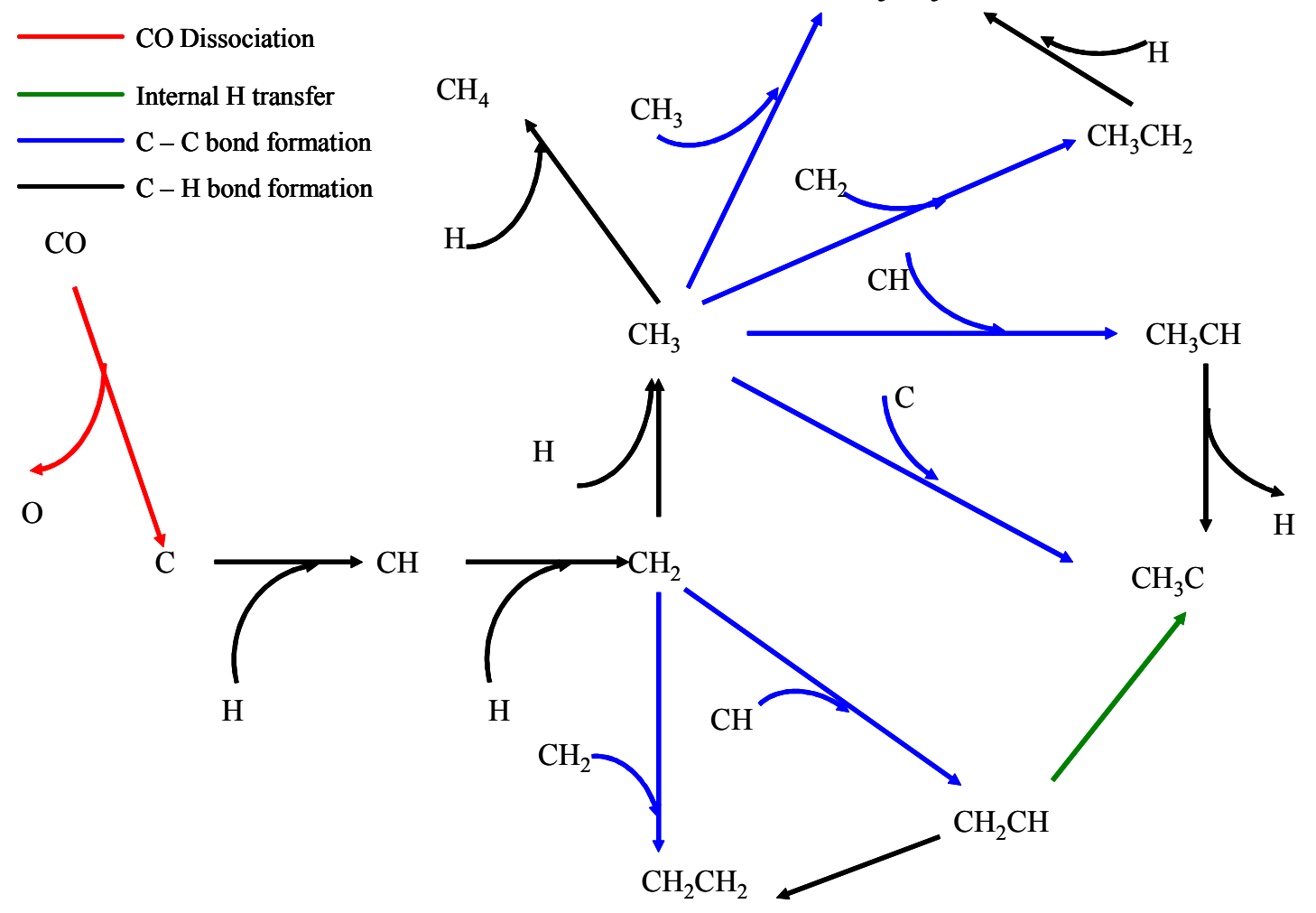

Figure 68 Reaction Network for the major elementary steps included in our models for FTS on $\mathrm{Fe}(110), \mathrm{Fe}(211), \mathrm{Fe}^{\mathrm{Pt}}$ and $\mathrm{Fe}_{\mathrm{C}}$.

\section{B. Thermodynamic Studies}

We note that these steps that go into the FTS model do not for a sequential series of transformations but are highly interconnected leading to a somewhat-nonlinear reaction network. Figure 68 represents a simplified view of this reaction network color coded to further clarify the relative interplay between the various classes of steps. In some sense the first five classes outlined above are sequential with the exception of the steps in class six. However, within each class of steps no such strong ordering is seen. Of course, prior to evaluating the thermochemistry and kinetics of each of these elementary steps one has to obtain the Binding Energies (BE's) of each of the stable molecular species and intermediates involved in our model. These steps required the evaluation of the BEs of a total of 20 species on each of the facets indicated. We have several types of species that enter our BE calculations:

- The single carbon atom containing species: $\mathrm{C}, \mathrm{CH}, \mathrm{CH} 2, \mathrm{CH} 3$ and $\mathrm{CH} 4$

- Larger $\mathrm{C} 2$ intermediates including the species: $\mathrm{C}-\mathrm{CH} 3, \mathrm{CH} 3-\mathrm{CH}, \mathrm{CH} 2-\mathrm{CH}, \mathrm{CH} 3-$ $\mathrm{CH} 2, \mathrm{C} 2 \mathrm{H} 2, \mathrm{C} 2 \mathrm{H} 4$ and $\mathrm{C} 2 \mathrm{H} 6$ 
- Other associated species and intermediates including: $\mathrm{CO}, \mathrm{CO} 2, \mathrm{O}, \mathrm{H}, \mathrm{OH}, \mathrm{H} 2 \mathrm{O}$.

On each of the facets considered the preferred adsorption sites, binding geometries, and BEs were evaluated. Figure 69 and Figure 70 try to represent the key details of this thermodynamic data that was collected over the duration of the project. All the high symmetry sites on the surface were considered and this also gave more detailed information about the heterogeneity / homogeneity in the strength of binding across the non-uniform sites on the metal surface. For the adsorbate $\mathrm{CO}$ additional calculations were run on $\mathrm{Fe}(110)$ to evaluate the saturation coverage of $\mathrm{CO}$. In each case the negative sign of the BE represents the exothermic nature of the adsorption process. Figure 69 and Figure 70 both allow us to extract significant insights into the trends in adsorbate binding; this exercise can be conducted across two dimensions: firstly, we can observe the trends in the binding strength of various adsorbates all adsorbed on the same facet; on the other hand the relative stabilization / destabilization of a particular adsorbate as the modifier / facet is changed provides the second dimension for a comparative analysis. Without going into extensive detail we now present the key findings of this thermochemical part of our calculations:

- On all facets considered the $\mathrm{C}$ atom by itself bound the strongest; poisoning by deposited coke as well as formation of carbide phases could be related to this fact.

- The molecular species including methane $\left(\mathrm{CH}_{4}\right)$, ethane $\left(\mathrm{C}_{2} \mathrm{H}_{6}\right)$, water $\left(\mathrm{H}_{2} \mathrm{O}\right)$ and carbon dioxide $\left(\mathrm{CO}_{2}\right)$ bind very weakly to the surface.

- Amongst the three $\mathrm{C}_{2}$ hydrocarbon species the strength of binding increases as the degree of unsaturation increases (i.e. the paraffins bind weaker than the olefins and the alkynes bind the strongest). Acetylene $\left(\mathrm{C}_{2} \mathrm{H}_{2} / \mathrm{HCCH}\right)$ binds stronger than ethylene $\left(\mathrm{C}_{2} \mathrm{H}_{4}\right)$ which binds stronger than ethane $\left(\mathrm{C}_{2} \mathrm{H}_{6}\right)$.

- CO binds fairly strongly, in spite of being a molecular adsorbate. This might partially explain the relatively high $\mathrm{CO}$ coverages seen experimentally on industrial FTS catalysts in situ.

- In the $\mathrm{CH}_{\mathrm{x}}$ series of species $\mathrm{BEs}$ become weaker as the number of $\mathrm{H}$ atoms increases.

- Subsurface $\mathrm{C}$ tends to stabilize the reactive intermediates whereas the Pt adatoms tend to destabilize them. 
- The Fe(211) facet exhibits a BE strength substantially similar to the Fe(110) facet. Thus the binding of FTS relevant adsorbates seems to a large part structure insensitive on these two facets considered.

- $\mathrm{CCH}_{3}$ which is known to poison catalyst surfaces is much more stable on $\mathrm{Fe}(110)$ and $\mathrm{Fe}_{\mathrm{C}}$ surfaces than on $\mathrm{Fe}(211)$ and $\mathrm{Fe}^{\mathrm{Pt}}$.

The conclusions above were valid for most of the specific values calculated and represented in Figure 69and Figure 70 but of course there were a few exceptions to the general rules outlined above.

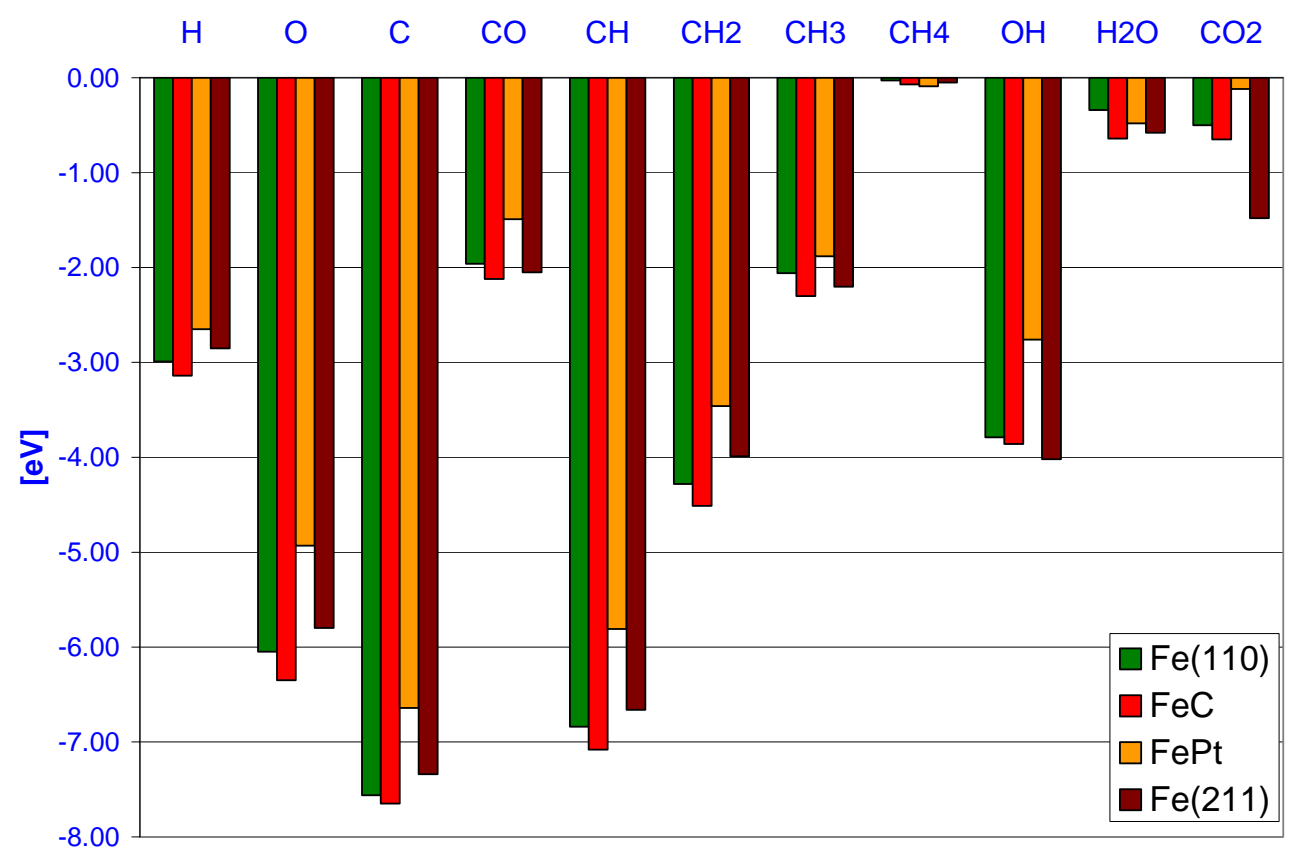

Figure 69 Binding Energies of $C_{1}$ intermediates and some miscellaneous small molecules on $\mathrm{Fe}(110), \mathrm{Fe}(211), \mathrm{Fe}^{\mathrm{Pt}}$ and $\mathrm{Fe}_{\mathrm{C}}$.

Negative signs signify the exothermic nature of adsorption. 


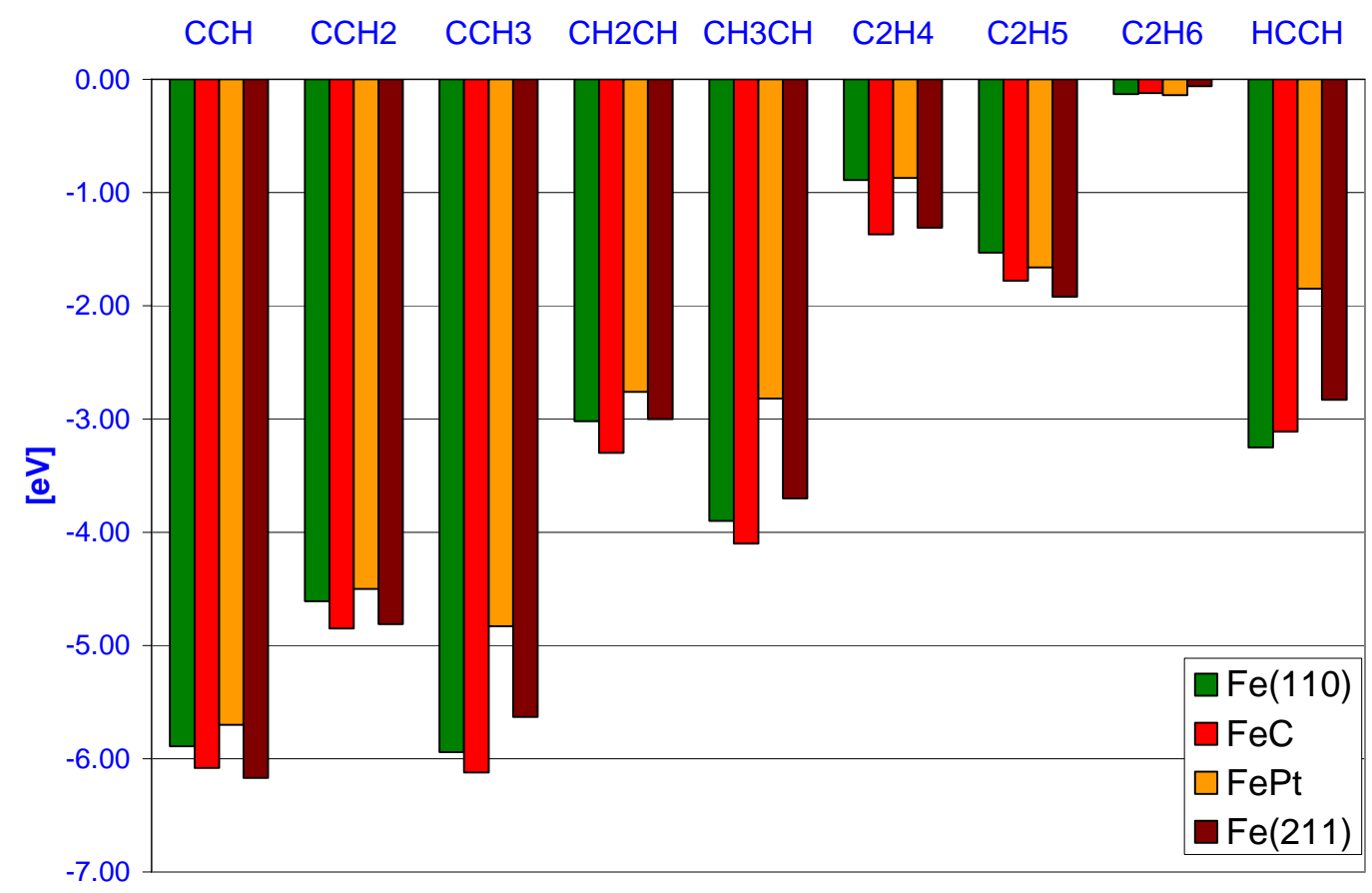

Figure 70 Binding Energies of $\mathrm{C}_{2}$ intermediates on $\mathrm{Fe}(110), \mathrm{Fe}(211), \mathrm{Fe}^{\mathrm{Pt}}$ and $\mathrm{Fe} \mathrm{C}_{\text {. }}$

Negative signs signify the exothermic nature of adsorption. 


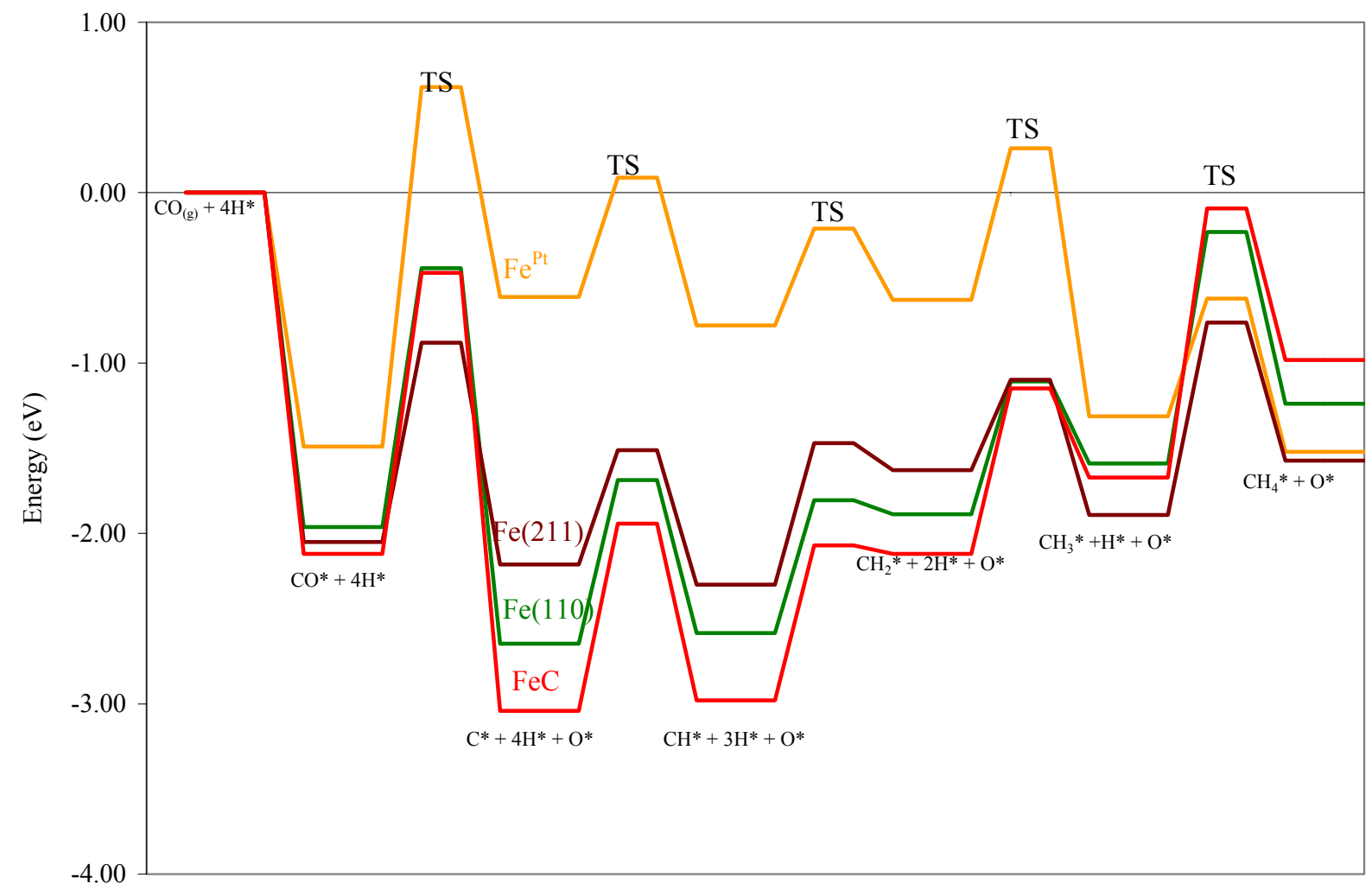

Figure 71 Potential Energy Surface (PES) for early FTS steps on Fe(110), Fe(211), Fe ${ }^{\mathrm{Pt}}$ and $\mathbf{F e}_{\mathrm{C}}$.

Both thermochemistry and kinetics are indicated and all barriers are with respect to the individual species adsorbed at their best sites and at infinite separation from each other. Color Code: Fe(110):green; Fe(211):brown; Fe ${ }_{C}$ : red; Fe ${ }^{\mathrm{Pt}}$ : yellow.

\section{Kinetic Calculations}

Having analyzed the thermodynamics of the elementary steps we were now ready to calculate the kinetics of each step and eventually construct the Potential Energy Surface (PES) for the series of steps involved. This involves calculating the Minimum Energy Pathway (MEP) for each step which then yields the magnitudes of the forward and reverse reaction barriers (activation energies). Additionally more detailed information about the nature of the reaction coordinate, geometric and electronic structure of the Transition State (TS) and the indicated vibrational frequencies was also extracted. This in itself creates a significant body of data and the remaining sections of this report try to present a coherent picture of the insights obtained. Figure 72, Figure 73 and Figure 74 represent schematically the relative magnitudes of the forward activation barriers $\left(E_{f}\right)$ for various important classes of elementary steps on each of the four facets considered. Of course, the reverse barrier $\left(E_{r}\right)$ is an equally important parameter but for 
the sake of conciseness this data is not presented here. As mentioned earlier for the most part it is difficult to represent the steps in the FTS network as linear PES's, nevertheless for certain subclasses such a PES can be constructed. Figure 71 is one such PES constructed for the early FTS steps and CO dissociation whereas Figure 76 is a similar PES for water formation routes. We note that the $E_{f}, E_{r}$ and $\Delta E$ values in each of the plots and figures are in eV units and are calculated with respect to the individual species adsorbed at their most preferred sites and at infinite separation from each other.

Finally, from a equilibrium standpoint it is relevant to evaluate the energetics of each individual reactive step as quantified by $\Delta E$. We present this data only for the class of steps that lead to C-C coupling in Figure 75 but the omission of the other classes of steps (as identified in the scheme given in Figure 67) does in no way decrease their relative importance in those steps in our mechanistic model of the FTS reaction mechanism. We now try to outline the salient observations that were made on the basis of this set of energetic and kinetic data:

- On all the catalysts considered CO dissociation remains one of the most activated (high reaction barrier) steps (Figure 71 and Figure 72).

- $\mathrm{CO}$ desorption and $\mathrm{CO}$ activation would be competitive processes in most cases. $\mathrm{CO}$ dissociation itself is more facile on the stepped $\mathrm{Fe}(211)$ facet than on native $\mathrm{Fe}(110)$.

- Once $\mathrm{CO}$ dissociation is achieved $\mathrm{CH}_{4}$ formation proceeds via successive sequential hydrogenation of $\mathrm{CH}_{\mathrm{x}}$ fragments $\left(\mathrm{CO} \rightarrow \mathrm{C}+\mathrm{O} ; \mathrm{C}+\mathrm{H} \rightarrow \mathrm{CH} \rightarrow \mathrm{CH}_{2} \rightarrow \mathrm{CH}_{3} \rightarrow \mathrm{CH}_{4}\right)$. The PES on the $\mathrm{Fe}^{\mathrm{Pt}}$ catalyst is substantially different from the PES on native $\mathrm{Fe}(110), \mathrm{Fe}_{\mathrm{C}}$ and $\mathrm{Fe}(211)$ facets (Figure 71).

- The steps subsequent to $\mathrm{CO}$ dissociation that will lead to $\mathrm{CH}_{4}$ formation are relatively facile. Amongst these hydrogenation steps the final formation of $\mathrm{CH}_{4}\left(\mathrm{CH}_{3}+\mathrm{H} \rightarrow\right.$ $\mathrm{CH}_{4}$ ) is relatively difficult but yet more facile than $\mathrm{CO}$ activation.

- The Boudard Reaction $\left(\mathrm{CO}+\mathrm{CO} \rightarrow \mathrm{CO}_{2}+\mathrm{C}\right)$ is more difficult than direct $\mathrm{CO}$ dissociation for all catalysts considered.

- On $\mathrm{Fe}(110)$ and $\mathrm{Fe}_{\mathrm{C}}$ surfaces almost all the $\mathrm{C}-\mathrm{C}$ bond formation steps are endothermic. 
- $\mathrm{On} \mathrm{Fe}{ }^{\mathrm{Pt}}$ catalysts many of the $\mathrm{C}-\mathrm{C}$ bond formation steps are exothermic. This might lead to the $\mathrm{C}_{2}$ species becoming more stable on this surface as compared to the $\mathrm{C}_{1}$ species. Pt modifies Fe surface so that $\mathrm{C}-\mathrm{C}$ bond formation is thermodynamically favored (Pt promotion effects).

- $\mathrm{On} \mathrm{Fe}(110)$ and $\mathrm{Fe}_{\mathrm{C}}$ propagation of the $\mathrm{C}$ chains could take place due to the formation of any of the $\mathrm{C}_{2}$ species and per se and at this stage we could not identify any specific kinetically favored route.

- Oxygen removal reactions are necessary to keep the catalyst surface free of the deposited $\mathrm{O}$ atoms. $\mathrm{O}$ removal is possible via water formation or $\mathrm{CO}_{2}$ evolution.

- We find that each one of the three steps implicated in $\mathrm{H}_{2} \mathrm{O}$ formation $\left(\mathrm{OH}_{(\mathrm{a})}+\mathrm{H}_{(\mathrm{a})} \rightarrow\right.$ $\mathrm{H}_{2} \mathrm{O}_{(\mathrm{a})} ; \mathrm{OH}_{(\mathrm{a})}+\mathrm{OH}_{(\mathrm{a})} \rightarrow \mathrm{H}_{2} \mathrm{O}_{(\mathrm{a})}+\mathrm{O}_{(\mathrm{a})} ; \mathrm{O}_{(\text {a) }}+\mathrm{H}_{(\mathrm{a})} \rightarrow \mathrm{OH}_{(\mathrm{a})}$ ) are more facile on $\mathrm{Fe}(211)$ as opposed to native $\mathrm{Fe}(110)$ leading us to expect that the stepped facet could play a significant role in oxygen removal reactions.

- On both $\mathrm{Fe}(110)$ and $\mathrm{Fe}(211)$ facets the $\mathrm{OH}$ disproportionation route is more facile than direct $\mathrm{H}_{2} \mathrm{O}$ formation but in the absence of high $\mathrm{OH}$ coverages on the surface disproportionation is unlikely.

- $\mathrm{CO}_{2}$ formation $\left(\mathrm{CO}_{(\mathrm{a})}+\mathrm{O}_{(\mathrm{a})} \rightarrow \mathrm{CO}_{2(\mathrm{a})}\right)$ itself might present an alternative route for $\mathrm{O}$ removal but the barrier here is again almost comparable to those seen on the $\mathrm{H}_{2} \mathrm{O}$ formation pathways. 


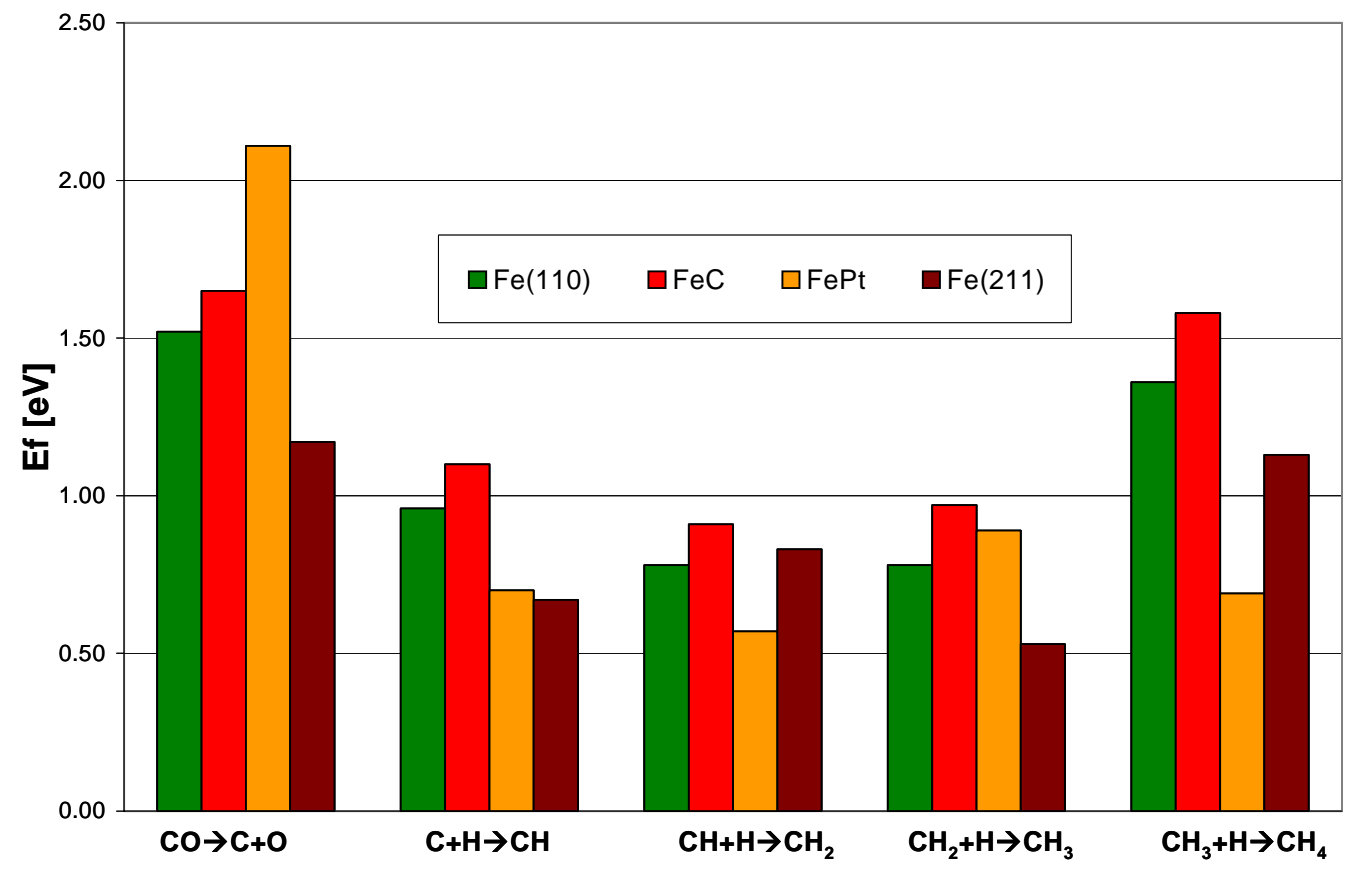

Figure 72 Activation energies for early FTS steps (including CO dissociation) on Fe(110), $\mathrm{Fe}(211), \mathrm{Fe}^{\mathrm{Pt}}$ and $\mathrm{Fe}_{\mathrm{C}}$.

Barriers are in $\mathrm{eV}$ units and with respect to the species adsorbed at infinite separation from each other.

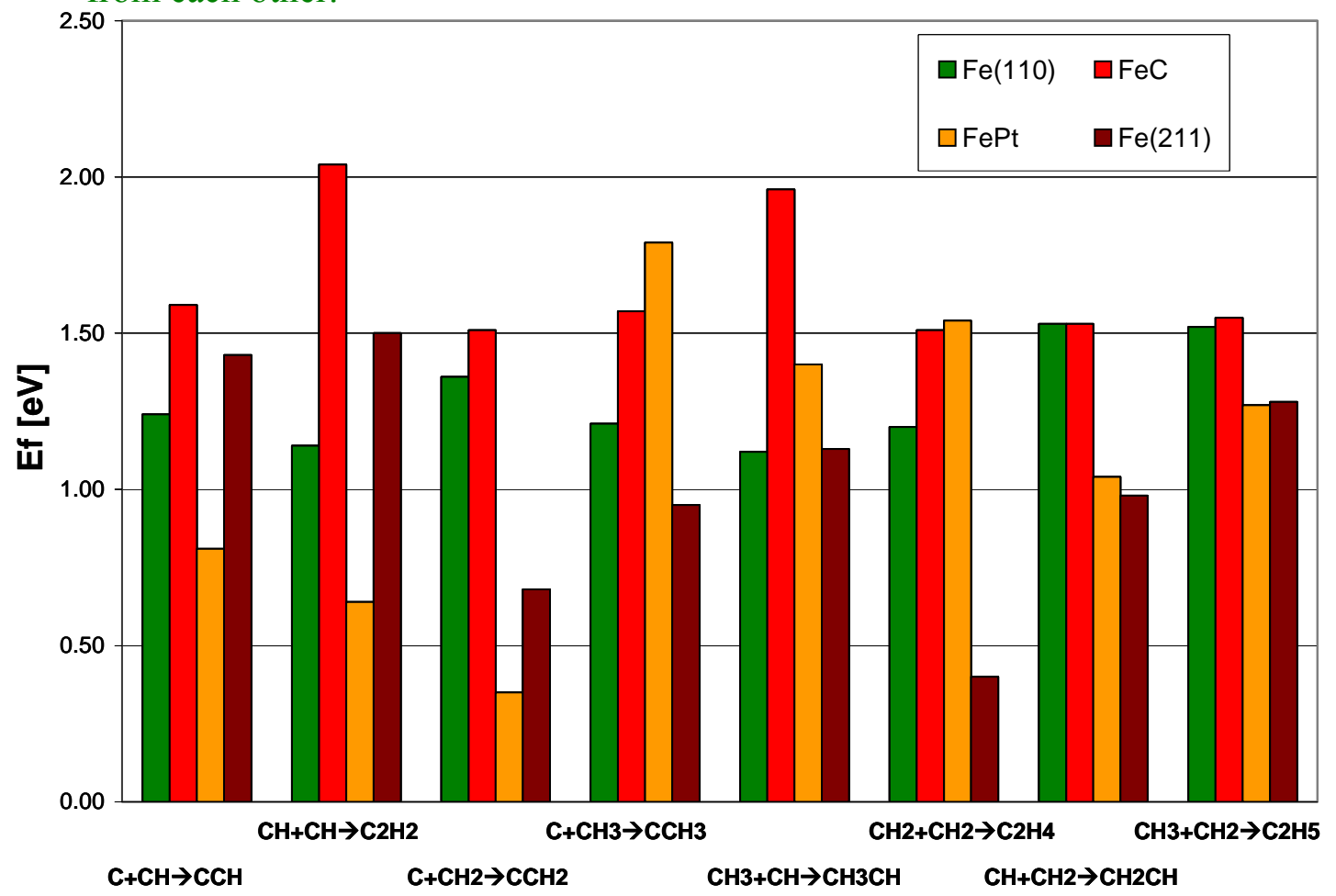

Figure 73Activation Energies for the C-C Coupling Steps on $\mathrm{Fe}(110), \mathrm{Fe}(211), \mathrm{Fe}^{\mathrm{Pt}}$ and $\mathrm{Fe}_{\mathrm{C}}$.

Barriers are in $\mathrm{eV}$ units and with respect to the species adsorbed at infinite separation from each other. 


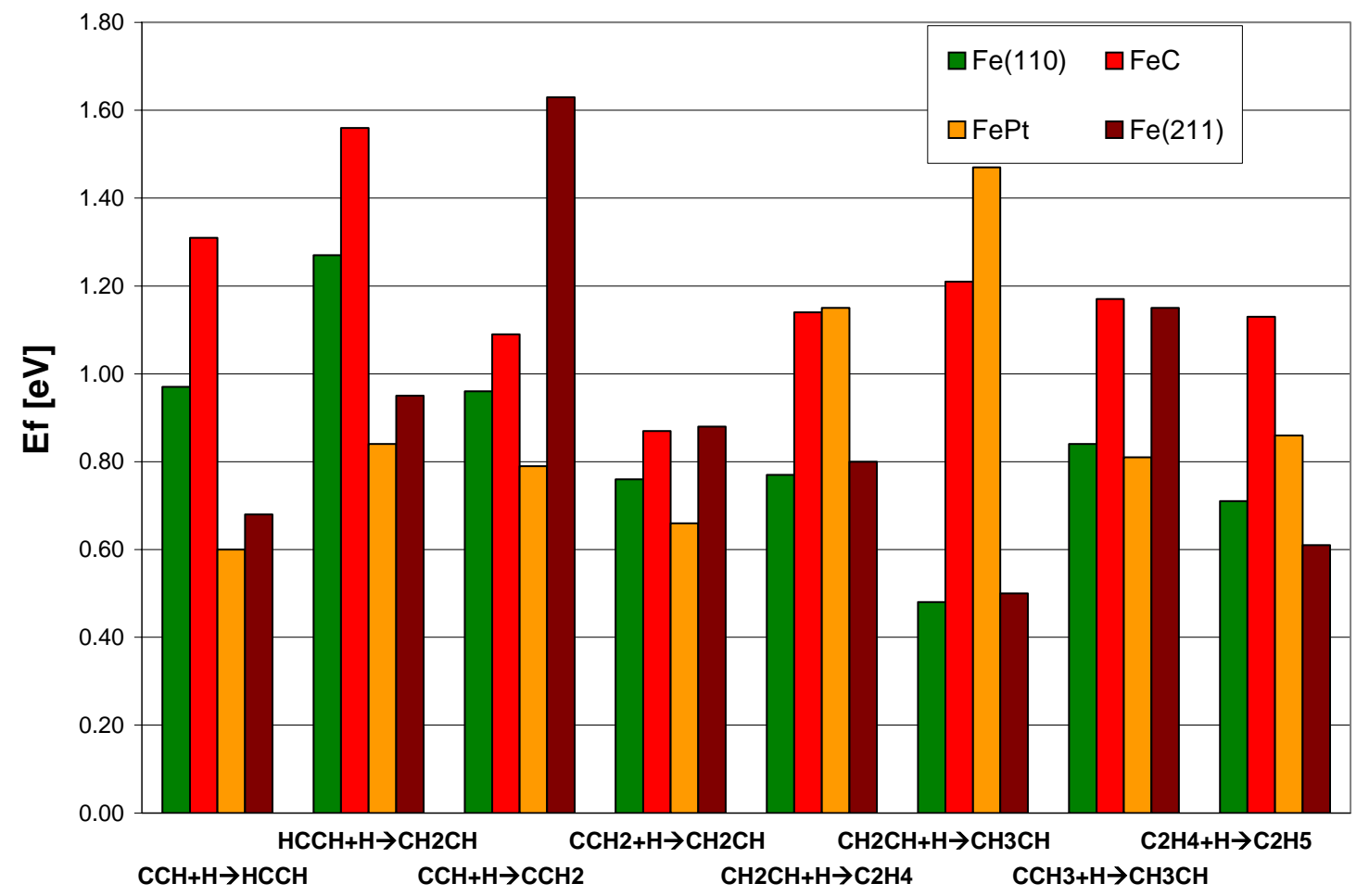

Figure 74 Activation energies for the $\mathrm{C}_{2}$ hydrogenation steps on $\mathrm{Fe}(110), \mathrm{Fe}(211), \mathrm{Fe}^{\mathrm{Pt}}$ and $\mathrm{Fe}_{\mathrm{C}}$.

Barriers are in $\mathrm{eV}$ units and with respect to the species adsorbed at infinite separation from each other. 


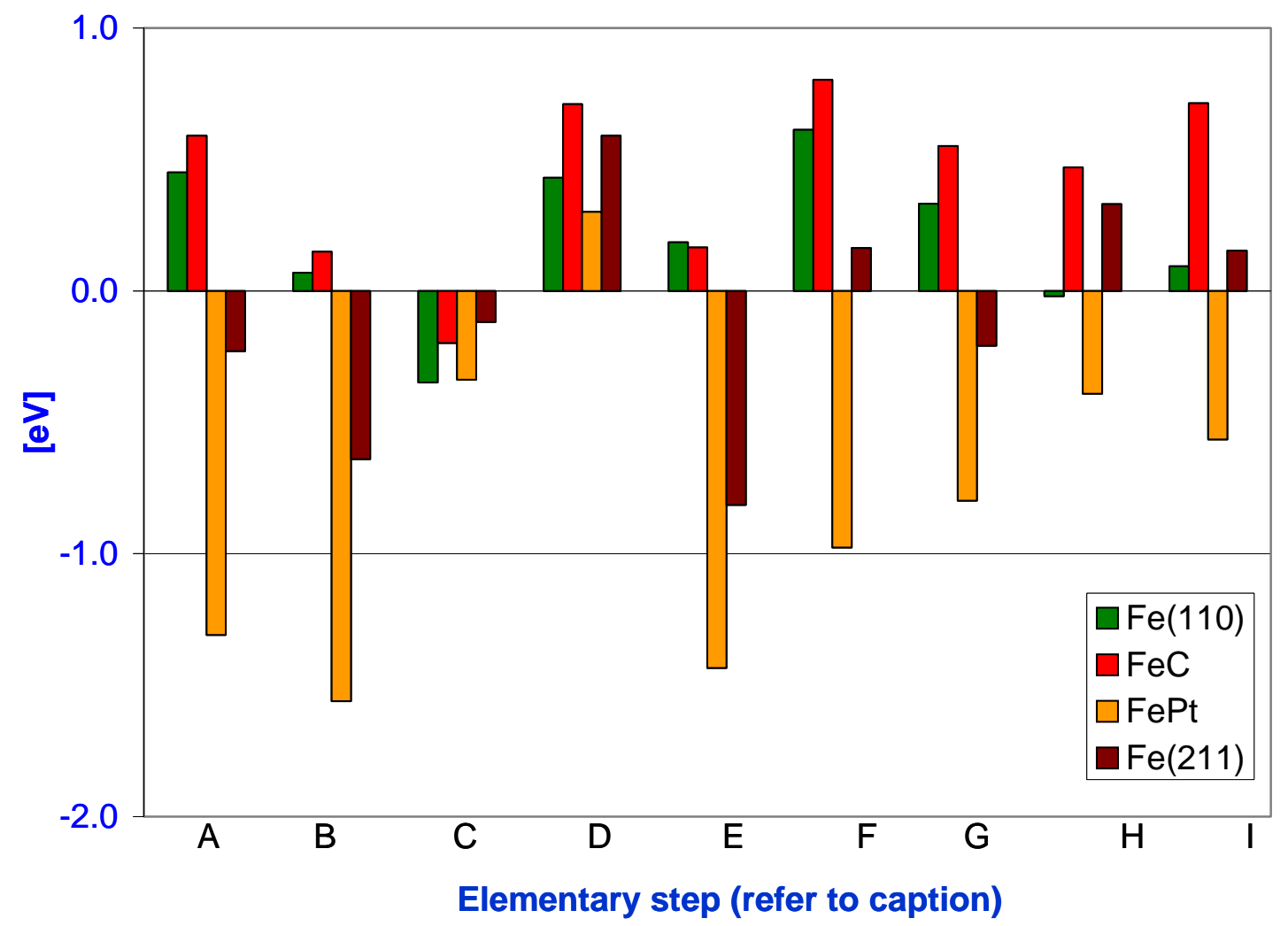

Figure 75 Comparative analysis of the thermodynamics of $\mathrm{C}-\mathrm{C}$ coupling reactions on $\mathrm{Fe}(110), \mathrm{Fe}_{\mathrm{C}}, \mathrm{Fe}^{\mathrm{Pt}}$ and $\mathrm{Fe}(211)$ facets.

All $\Delta E$ values are in $\mathrm{eV}$ units. Key: (A) $\mathrm{C}+\mathrm{CH} \rightarrow \mathrm{CCH},(\mathrm{B}) \mathrm{C}+\mathrm{CH}_{2} \rightarrow \mathrm{CCH}_{2},(\mathrm{C}) \mathrm{C}+$ $\mathrm{CH}_{3} \rightarrow \mathrm{CCH}_{3}$, (D) $\mathrm{CH}+\mathrm{CH}_{3} \rightarrow \mathrm{CHCH}_{3}$, (E) $\mathrm{CH}_{2}+\mathrm{CH}_{2} \rightarrow \mathrm{C}_{2} \mathrm{H}_{4}$ (F) $\mathrm{CH}+\mathrm{CH}_{2} \rightarrow$ $\mathrm{CH}_{2} \mathrm{CH}(\mathrm{G}) \mathrm{CH}_{3}+\mathrm{CH}_{2} \rightarrow \mathrm{C}_{2} \mathrm{H}_{5}(\mathrm{H}) \mathrm{CH}_{3}+\mathrm{CH}_{3} \rightarrow \mathrm{C}_{2} \mathrm{H}_{6}(\mathrm{I}) \mathrm{CH}+\mathrm{CH} \rightarrow \mathrm{C}_{2} \mathrm{H}_{2}$ 


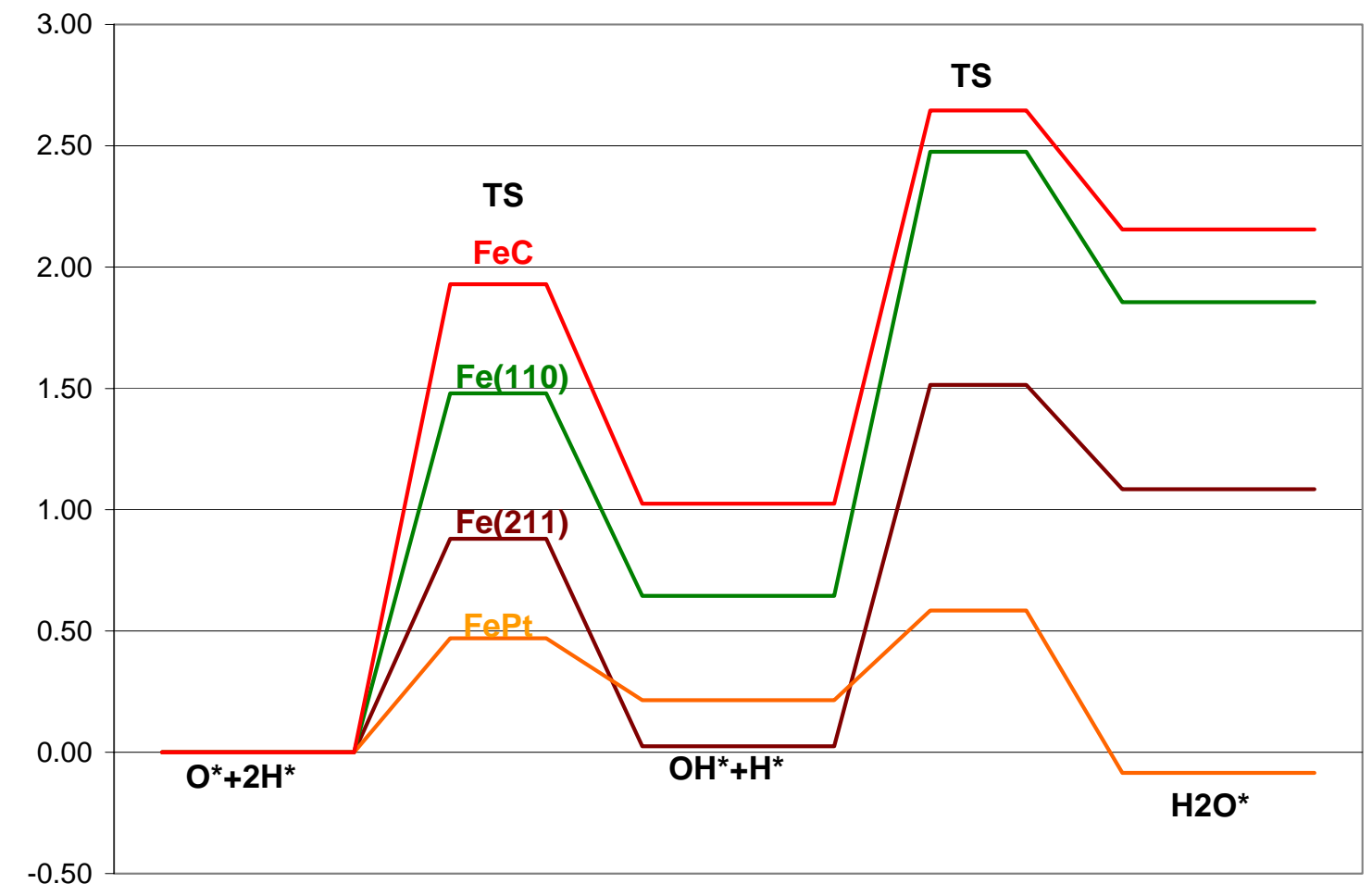

Figure 76 Potential Energy Surface(PES) for direct water formation on Fe(110), Fe(211), $\mathrm{Fe}_{\mathrm{C}}$ and $\mathrm{Fe}^{\mathrm{Pt}}$.

Both thermochemistry and kinetics are indicated and all barriers are with respect to the individual species adsorbed at infinite separation from each other. Color Code:

$\mathrm{Fe}(110)$ :green; $\mathrm{Fe}(211)$ :brown; $\mathrm{Fe}_{\mathrm{C}}$ : red; $\mathrm{Fe}^{\mathrm{Pt}}$ : yellow.

In the final months of this project we ran several sets of calculations that were relevant to the central goals of the project but not completed so far in the light of limited time and resources earlier. In this project $\mathrm{Fe}(211)$ has been the dominant model system that was considered to investigate the effects of surface defects on Fe based FTS catalysts but in earlier years we had considered other possibilities. The main candidates had been (a) Fe(321) and (b) an artificially defected Fe(110) surface obtained by removing a surface row of atoms. Some preliminary calculations on the model surface (b) had been completed in the earlier years (but not covered in any detail in the reports). For the sake of completeness in the final months of this project we completed these calculations so that we had the BEs for all our FTS relevant intermediates on this surface as well. We find that most intermediates bind with a strength that is similar to their binding on Fe (110). Binding geometries also mirror the trends presented on $\mathrm{Fe}(110)$ in the earliest years of this project. These findings are not surprising and further validate our focusing 
on the $\mathrm{Fe}(211)$ facet as the more relevant (and interesting) manifestation of defects on $\mathrm{Fe}$ catalysts.

Another direction that we investigated was the effect of the higher $\mathrm{CO}$ coverages on the mechanistic details of FTS on the Fe catalysts. Industrial Fe catalysts often operate at conditions where $\mathrm{CO}$ is likely to be a major species on the surface of the catalyst. All the calculations so far presented in this report have been on the clean surface of the catalyst with no spectator CO molecules. The relevant question was how the thermochemistry of the FTS-relevant reactions would be affected if there were a higher coverage of $\mathrm{CO}$ present on the surface. We evaluated the BEs of a representative fraction of our FTS intermediates on the Fe(110) surface and found that in most cases the species are substantially destabilized by the presence of $\mathrm{CO}$ on the surface. This destabilization can be attributed to through the substrate and space repulsive interaction between the adspecies and spectator $\mathrm{CO}$ molecules. Calculations for $\mathrm{CO}$ binding itself were also performed at several higher coverages and thus the coverage dependence of BECO on $\mathrm{Fe}(110)$ was also established. The results indicate that higher coverages of CO (ca. $0.75-1.0 \mathrm{ML} \mathrm{CO}$ ) might very well be realistic. Throughout the course of this project we have made significant progress into obtaining a comparative picture of FTS on various native and modified Fe catalysts and in the final months of the project we devoted a part of our time in preparing a manuscript of the results obtained during this project.

Thus at the end of this last year of the project we have succeeded in presenting a reasonably complete description of the thermochemistry and kinetics of FTS relevant steps on four distinct model surfaces: $\mathrm{Fe}(110), \mathrm{Fe}(211), \mathrm{Fe}_{\mathrm{C}}$, and $\mathrm{Fe}^{\mathrm{Pt}}$ (Figure 77). For each component species and reactive intermediates the best adsorption geometry and site preferences were evaluated and the Binding Energies (BEs) calculated. These BEs allowed us to present the detailed thermochemistry of our reaction network and this work was then extended by obtaining the kinetics for each elementary step. Minimum Energy Pathways (MEPs) were obtained and insights gained into the nature of the Transition States (TSs) involved in each reactive pathway. Additionally vibrational calculations were completed on each stable species and TS involved. The evaluation of these frequencies then enabled calculation of the entropies of the various species adsorbed on the surface and the pre-exponential factors for the reactive steps. The aforementioned calculations allowed us to make qualitative comparisons between the various steps on the several models that we considered especially highlighting the role of steps, carbide 
formation and Pt promotion. Significantly, we found that CO dissociation was made more facile on the stepped $\mathrm{Fe}(211)$ facet and so also many of the steps responsible for the formation of the $\mathrm{C}_{2}$ species via the $\mathrm{C}-\mathrm{C}$ coupling steps. Recall that $\mathrm{CO}$ dissociation is in most cases a high-barrier step and is frequently invoked as a Rate Determining Step (RDS) in FTS models. Oxygen removal via water formation was another area where the $\mathrm{Fe}(211)$ facet might have a competitive advantage over the $\mathrm{Fe}(110)$ facet. Pt promotion seems to favor higher hydrocarbon formation by making C-C coupling reactions more facile. On the other hand the complex nature of the FTS reaction network (Figure 68 and Figure 67) make it evident that a quantitative description of the reactive fluxes and coverages must await a detailed microkinetic model. The construction and optimization of such a model is by no means a trivial task yet the foregoing calculations did evaluate most of the parameters that are required as inputs to such a model. In summary, our work has highlighted the varied roles of defects, carbides and Pt promotion in FTS mechanisms by performing a comparative analysis of the thermochemistry and kinetics. At the same time our calculations over the course of this project have allowed us to obtain the requisite data to serve as input for detailed microkinetic models for FTS on $\mathrm{Fe}(110), \mathrm{Fe}(211)$ and their various modifications.

\begin{tabular}{|l|r|r|r|r|}
\hline \multicolumn{1}{|c|}{ Task } & Year 1 & Year 2 & Year 3 & Year 4 \\
\hline $\mathrm{Fe}(110)$ & & & & \\
\hline $\mathrm{Fe}_{\mathrm{C}}$ & & & & \\
\hline $\mathrm{Fe}^{\mathrm{Pt}}$ & & & & \\
\hline $\mathrm{Fe}(211)$ & & & & \\
\hline Comparative Analysis & & & & \\
\hline Annual Reports & $\boldsymbol{\Delta}$ & $\mathbf{\Delta}$ & $\mathbf{\Delta}$ & $\mathbf{\Delta}$ \\
\hline & & & & \\
\hline
\end{tabular}

Figure 77 Timeline of first-principles calculations completed over the course of the project. 


\section{Methods}

All calculations were performed using the first-principles total energy calculation code DACAPO. Adsorption is allowed on only one of the two surfaces of the slab and the electrostatic potential is adjusted accordingly. Calculations are all spin-polarized. The $\mathrm{Fe}(110)$ surface is modeled by a $(2 \times 2)$ unit cell, corresponding to a $1 / 4 \mathrm{ML}$ coverage for all individual adsorbates. $\mathrm{Fe}(211)$, on the other hand, is a more open stepped surface and requires a larger $(2 \times 4)$ unit cell with a total of 3 equivalent layers(24 atoms). Since the $\mathrm{Fe}(110)$ and $\mathrm{Fe}(211)$ surfaces considered are rather open, surface-perturbation could have a significant effect on the adsorption properties of the various species; hence $\mathrm{Fe}(110)$ is modeled using a four layer slab with the top two layers fully relaxed [details differ slightly for Fe(211)]. Kohn-Sham one-electron valence states are expanded in a basis of plane waves with kinetic energy below $25 \mathrm{Ry}$. The exchange-correlation energy and potential are described by the generalized gradient approximation (GGA-PW91); the ionic cores are described by ultrasoft pseudopotentials. The surface Brillouin zone is sampled with a $4 \times 4 \times 1 k$ point set. The calculated equilibrium PW91 lattice constant for bulk Fe is: $\mathrm{a}=$ $2.85 \AA$, in good agreement with the experimental value of $2.87 \AA$. The minimum energy reaction paths of various elementary steps are studied using the Climbing-Image Nudged Elastic Band (CI-NEB) method, a state-of-the-art iterative method. The existence of saddle points is further verified by the existence of a single imaginary vibrational frequency for the optimized transition state. 


\section{Conclusions}

1. In reviewing the mechanism and kinetics on FTS reaction on iron catalysts we found several plausible mechanisms capable of fitting our steady-state rate data. This emphasizes the importance of developing more precise mechanistic models based on microkinetic modeling.

2. Three iron catalysts prepared by precipitation using $1 \%$ alumina as a textural promoter; two contained either $1 \% \mathrm{~K}$ or $1 \% \mathrm{Pt}$ as chemical promoters. The extent of reduction of the $\mathrm{Fe} /$ alumina of $90.6 \%$ is indicative of a relatively high extent of reduction. In $\mathrm{H}_{2}$ and $\mathrm{CO}$ atmosphere, these iron catalysts exhibit very different reduction properties. Addition of $\mathrm{K}$ decreases while Pt increases reducibility.

3. Two $10 \% \mathrm{Fe} /$ alumina catalysts prepared by evaporative deposition in acetone/ethanol and by aqueous impregnation and then reduced at $300^{\circ} \mathrm{C}$ were found to have dispersions of 48 and $9.8 \%$. The $48 \%$ dispersion is unusually high for a $10 \%$ $\mathrm{Fe} /$ alumina catalyst.

4. A $20 \% \mathrm{Fe} / a$ lumina was prepared by two-step evaporative deposition steps in acetone/ethanol solution. The extent of reduction of the catalyst was $45 \%$, which is slightly lower than for the two $10 \% \mathrm{Fe} /$ alumina catalysts due to its higher iron loading. The catalyst reduced at $500^{\circ} \mathrm{C}$ has an iron dispersion of $37 \%$ which is also unusually high for a $20 \% \mathrm{Fe} /$ alumina catalyst.

5. Two impacts on improvement of extent of reduction and iron dispersion of aluminasupported iron catalysts in preparation process are pre-calcination of alumina support for dehydrating the support and the utility of acetone/ethanol mixture as impregnation solution.

6. The crystallite diameters of supported iron catalysts were estimated by XRD, $\mathrm{H}_{2}$ chemisorption, and TEM methods. The order of crystallite size for these three iron catalysts is $10 \mathrm{FeA}-\mathrm{W}>20 \mathrm{FeA}-\mathrm{A} / \mathrm{E}>10 \mathrm{FeA}-\mathrm{A} / \mathrm{E}$. When iron loading is increased from $10 \%$ to $20 \%$, the crystallite diameter does not increase very much.

7. $\mathrm{CO}$ adsorbs molecularly and dissociatively at relatively low temperatures $\left(25-200^{\circ} \mathrm{C}\right)$ on polycrystalline iron. $\mathrm{K}$ increases the amount of $\mathrm{CO}$ adsorbed and its binding 
energy. Since CO adsorbs dissociatively on polycrystalline Fe at RT, CO dissociation is probably facile under reaction conditions at $250^{\circ} \mathrm{C}$, thus, it would not be the RDS.

8. After FT reaction at $200^{\circ} \mathrm{C}$ for only 10 minutes, the $\mathrm{Fe}$ surface of $99 \mathrm{FeA}$ series samples contains many monolayer equivalents of carbidic, amorphous, and graphitic carbon species. Amounts deposited are roughly 10: 2: 1 for Fe: Fe/Pt: Fe/K. Thus, Pt and $\mathrm{K}$ facilitate $\mathrm{C}$ removal during reaction. The fraction of active carbons on the surface decreases in the order $\mathrm{Fe} / \mathrm{K}, \mathrm{Fe} / \mathrm{Pt}, \mathrm{Fe}$. About half of the carbon on the $\mathrm{Fe} / \mathrm{K}$ catalyst is active.

9. After FT reaction and during isothermal $\mathrm{TPH}$ at $200^{\circ} \mathrm{C}$, only $0.15 \mathrm{ML}$ is removed after $2 \mathrm{~h}$ for $99 \mathrm{FeA}$ sample; rates of $\alpha-\mathrm{C}$ removal decrease in the order $\mathrm{Fe} / \mathrm{K}>\mathrm{Fe} / \mathrm{Pt}>$ Fe.

10. The alumina support affects the amount of $\mathrm{CO}$ adsorbed and its binding energy; the removal temperature of dissociatively-adsorbed $\mathrm{CO}$ is relatively low at $280^{\circ} \mathrm{C}$ for the 20FeA-A/E sample.

11. After FT reaction at $200^{\circ} \mathrm{C}$ for only 5 minutes, the order of monolayer carbon equivalents is $10 \mathrm{FeA}-\mathrm{W}>10 \mathrm{FeA}-\mathrm{A} / \mathrm{E}>20 \mathrm{FeA}-\mathrm{A} / \mathrm{E}$.

12. The sequential design procedure using DOD resulted in the most precise parameter estimates in a minimal number of experiments. However, precise parameter estimates might not be the only object of the experiments, thus other experimental approaches might be needed.

13. $\mathrm{CO}$ dissociation occurs readily on polycrystalline $\mathrm{Fe}$ at $25-100^{\circ} \mathrm{C}$ and is completely dissociated above about $150^{\circ} \mathrm{C}$. Accordingly $\mathrm{CO}$ dissociation is probably not the rate determining step in FT reaction.

14. The heat of $\mathrm{CO}$ adsorption on polycrystalline $\mathrm{Fe}$ is around $100 \mathrm{~kJ} / \mathrm{mol}$.

15. After FT reaction at temperatures above about $200^{\circ} \mathrm{C}$, the Fe surface of $99 \% \mathrm{Fe}$ contains a complex distribution of carbonaceous species. After reaction at $150-175^{\circ} \mathrm{C}$ the predominant surface species are active carbons, $\mathrm{CH}_{\mathrm{x}}$, and $\mathrm{CHO}_{\mathrm{x}}$ species.

16. Hydrogenation of the surface species following reaction is best modeled by as many as a dozen (or more) elementary steps and 10 different surface species. 
17. First principles calculations indicated that direct $\mathrm{CO}$ dissociation was a comparatively difficult (high activation energy) step on the catalyst models studied. In most cases CO desorption would be competitive with $\mathrm{CO}$ activation. The stepped Fe(211) surface offers a marginally easier (more facile) route to $\mathrm{CO}$ dissociation than the close-packed Fe(110) facet.

18. Subsequent to $\mathrm{CO}$-dissociation it was reasonably facile to get the $\mathrm{C}$ atom into the sub-surface forming a Fe-carbide thus motivating a closer study of the $\mathrm{Fe}_{\mathrm{C}}(110)$ system. $\mathrm{On} \mathrm{Fe}(110)$ as well as $\mathrm{Fe}_{\mathrm{C}}$ surfaces almost all $\mathrm{C}-\mathrm{C}$ bond formation steps were endothermic ( in contrast to $\mathrm{Fe}^{\mathrm{Pt}}(110)$; see next point )

19. Pt promotion was best modeled by a Pt-adatom on a Fe(110) slab due to its superior stability. Many of the $\mathrm{C}-\mathrm{C}$ bond formation steps become exothermic in the presence of the Pt promoter (in contrast with $\mathrm{Fe}(110)$ and $\mathrm{Fe}_{\mathrm{C}}$ ). The resultant higher stability of the $\mathrm{C}_{2}$ species as compared to the $\mathrm{C}_{1}$ species leads to the conclusion that $\mathrm{C}-\mathrm{C}$ bond formation is thermodynamically favored by Pt. (Pt-promotion effects)

20. On most facets $\mathrm{C}$ is the strongest binding adsorbate. Poisoning by coking or carbide formation might be related to this observation. Most molecular species $\left(\mathrm{CO}_{2}, \mathrm{H}_{2} \mathrm{O}\right.$, $\mathrm{CH}_{4}, \mathrm{C}_{2} \mathrm{H}_{6}$ etc.) bind fairly weakly. $\mathrm{CO}$, though, has a fairly strong binding preference and might explain the high $\mathrm{CO}$ coverages observed experimentally on industrial catalysts.

21. Subsurface $\mathrm{C}$ tends to stabilize the reactive intermediates whereas Pt adatoms tend to destabilize them.

22. The stepped $\mathrm{Fe}(211)$ exhibits a BE substantially similar to $\mathrm{Fe}(110)$ and the binding of FTS relevant adsorbates seems to a large degree structure insensitive on these facets.

23. Among the various models of defected Fe catalyst the Fe(211) facet seems the most relevant candidate for study.

24. The binding of the $\mathrm{CH}_{\mathrm{x}}$ species becomes weaker as the number of $\mathrm{H}$ atoms increases. Amongst the $\mathrm{C}_{2}$ hydrocarbon products of FTS the strength of binding seems proportional to the degree of unsaturation i.e. the paraffins bind weaker than the olefins and the alkynes bind the strongest. 
25. The Boudard Reaction $\left(\mathrm{CO}+\mathrm{CO} \rightarrow \mathrm{CO}_{2}+\mathrm{C}\right)$ is more difficult than direct $\mathrm{CO}$ dissociation and therefore unlikely to be a viable alternative. Oxygen removal reactions via. water formation are more facile on the $\mathrm{Fe}(211)$ facet than $\mathrm{Fe}(110)$

26. It is likely that $\mathrm{CO}$ coverages on actual $\mathrm{Fe}$ catalysts are high and in the $0.75-1.0 \mathrm{ML}$ range. The effect of these higher $\mathrm{CO}$ coverages is a substantial destabilization of the FTS-relevant species on the $\mathrm{Fe}(110)$ surface. 


\section{References}

1. G. P. Van der Laan, A. A. C. M. Beenackers "Kinetics and selectivity of the Fischer-Tropsch synthesis: A literature review" Catal. Rev. -Sci. Eng. 41 (1999) 255-318.

2. C.H. Bartholomew and R. J. Farrauto, "Fundamentals of Industrial Catalytic Processes" Wiley, 2006.

3. N. Koga, S. Takemoto, S. Okada, and H. Tanaka, "A kinetic study of the thermal decomposition of iron(III) hydroxide oxides. Part 1. $\alpha-\mathrm{FeO}(\mathrm{OH})$ in banded iron formations" Thermochimica Acta 254 (1995) 193-207.

4. G. Neri, A. M. Visco, S. Galvagno, A. Donato, and M. Panzalorto, "Au/iron oxide catalysts: temperature programmed reduction and X-ray diffraction characterization" Thermochimica Acta 329 (1999) 39-46.

5. H. Y. Lin, Y. W. Chen, and C. P. Li, "The mechanism of reduction of iron oxide by hydrogen" Thermochimica Acta 400 (2003) 61-67.

6. A. Basinska, W. K. Jozwiak, J. Goralski, and F. Domka, "The behaviour of $\mathrm{Ru} / \mathrm{Fe}_{2} \mathrm{O}_{3}$ catalysts and $\mathrm{Fe}_{2} \mathrm{O}_{3}$ supports in the TPR and TPO conditions" Appl. Catal. A 190 (2000) 107-115.

7. K. Yoshida, Japanese Journal of Applied Physics, 20 (1981) 823.

8. K. Ueda, M. Enatsu, Surface Science, 159 (1985) L421.

9. U. Seip, M. C. Tsai, K. Christmann, J. Kuppers, and G. Ertl, Surface Science, 139 (1984) 29.

10. C. E. Bartosch, L. J. Shitman, and W. Ho, J. Chem. Phys. 85 (1986) 1052.

11. K. Ueda, and T. Mega, Japanese Journal of Applied Physics 27 (1988) 2227.

12. T.C. Bromfield, D. C. Ferre, and J.W. Niemantsverdriet, ChemPhysChem, 6, 254 (2005).

13. T.J. Vink, O.L. Gijzeman, J.W. Geus, Surf.Sci.,150,14 (1985).

14. Brown Peter N., H.A.C., Byrne George B.,. 2005 .

15. 15. Boggs, P.T., R. H. Byrd, R. B. Schnabel. A Stable and Efficient Algorithm for nonlinear orthogonal distance regression.

16. Kanervo J. M., K.T.J., Slioor R. I., Krause A. O. I., Temperature-programmed desorption as a tool to extract quantitative kinetic or energetic information for porous catalysts. Journal of Catalysis, 2006. 238: p. 382-393.

17. D. Bianchi, and J. L. Gass, J. Catal. 123 (1990) 298.

18. Eliason, S. A.; Bartholomew, C. H. In Catalyst Deactivation 1997.

19. M. Claeys, "Effect of Metal Crystallite Size in Supported Iron Based Fischer-Tropsch Catalysts", $19^{\text {th }}$ North American Catalysis Society Meeting, May 22-27, 2005, Philadelphia, Pennsylvania USA. 